\title{
By accident : pain catastrophizing and fear of movement in patients with neck pain after a motor vehicle accident
}

Citation for published version (APA):

Vangronsveld, K. L. H. (2007). By accident : pain catastrophizing and fear of movement in patients with neck pain after a motor vehicle accident. [Doctoral Thesis, Maastricht University]. Datawyse / Universitaire Pers Maastricht. https://doi.org/10.26481/dis.20070914kv

Document status and date:

Published: 01/01/2007

DOI:

10.26481/dis.20070914kv

Document Version:

Publisher's PDF, also known as Version of record

Please check the document version of this publication:

- A submitted manuscript is the version of the article upon submission and before peer-review. There can be important differences between the submitted version and the official published version of record.

People interested in the research are advised to contact the author for the final version of the publication, or visit the DOI to the publisher's website.

- The final author version and the galley proof are versions of the publication after peer review.

- The final published version features the final layout of the paper including the volume, issue and page numbers.

Link to publication

\footnotetext{
General rights rights.

- You may freely distribute the URL identifying the publication in the public portal. please follow below link for the End User Agreement:

www.umlib.nl/taverne-license

Take down policy

If you believe that this document breaches copyright please contact us at:

repository@maastrichtuniversity.nl

providing details and we will investigate your claim.
}

Copyright and moral rights for the publications made accessible in the public portal are retained by the authors and/or other copyright owners and it is a condition of accessing publications that users recognise and abide by the legal requirements associated with these

- Users may download and print one copy of any publication from the public portal for the purpose of private study or research.

- You may not further distribute the material or use it for any profit-making activity or commercial gain

If the publication is distributed under the terms of Article $25 \mathrm{fa}$ of the Dutch Copyright Act, indicated by the "Taverne" license above, 


\section{BY ACCIDENT}

Pain Catastrophizing and Fear of Movement in patients with neck pain after a motor vehicle accident 
Cover design: Wendy Peters

Printed by Datawyse Maastricht

ISBN 9789052786452

Universitaire Pers Maastricht

C) Copyright KLH Vangronsveld, Bilzen 2007 


\title{
BY ACCIDENT \\ Pain Catastrophizing and Fear of Movement in patients with neck pain after a motor vehicle accident
}

\author{
PROEFSCHRIFT
}

ter verkrijging van de graad van doctor

aan de Universiteit Maastricht, op gezag van de Rector Magnificus,

Prof. mr. G.P.M.F. Mols,

volgens het besluit van het College van Decanen,

in het openbaar te verdedigen

op vrijdag 14 september 2007 om 14.00 uur

door

Karoline Lisette Helena Vangronsveld

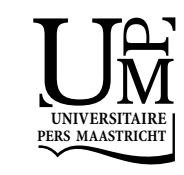




\section{PROMOTORES}

Prof. dr. J.W.S. Vlaeyen

Prof. dr. M.L. Peters

\section{COPROMOTOR}

Dr. M.E.J.B. Goossens

\section{BEOORDELINGSCOMMISSIE}

Prof. dr. O. Van Schayck (voorzitter)

Prof. dr. M. Van Kleef

Prof. dr. F. Kraamaat (UCM Radbout, Nijmegen)

Prof. dr. J. van Lankveld

Prof. dr. M. Sullivan (McGill University, Montreal, Canada) 


\section{Contents}

Chapter 1 Introduction

7

Chapter 2 Applying the Fear Avoidance Model to the Chronic Whiplash Syndrome

Chapter 3 Active and passive range of motion in acute whiplash injury

Chapter 4 The influence of fear of movement and pain catastrophizing on daily pain and disability in individuals with acute whiplash complaints: a daily diary study.

Chapter 5 Fear of movement, pain catastrophizing and anger as possible predictors for developing persistent physical and psychological complaints after an acute whiplash injury

Chapter 6 An experimental investigation on attentional interference by threatening fixations of the neck in patients with chronic whiplash syndrome

Chapter 7 The relationship of self-discrepancies, mood, and fear of movement in patients with acute whiplash injury

Chapter 8 Reduction of pain-related fear and disability in posttraumatic neck pain: a replicated single case experimental study of exposure in vivo

Chapter 9 General Discussion

Summary

Samenvatting 

Chapter 1

\section{Introduction}

Karoline Vangronsveld 
"It happened about 5 years ago. My husband and I were on our way to visit our daughter in a nearby town. We did not see the car coming. We were waiting at an intersection but, the other driver did not notice us in time. Result: a rear-end collision and the car totally wrecked. My husband and I got out of the car to speak to the other drive who was shocked about what happened. After about 15 minutes my neck started to hurt. Badly. It got so bad that my husband decided to drive me to the Emergency Care Department of the local hospital. After an examination the doctor told me that my neck symptoms were self-limiting and the neck pain would become less over the next couple of days. But the pain did not go away. In fact it got worse; my neck became so painful that I could hardly move. I had headaches and I could not do anything in the house, let alone go back to work. In fact, I was not able to do anything accept lay down and rest.

After five years, I'm still in pain. It has not been easy. I had to quit my job and I'm still not capable of running my own household. I'm very lucky that my husband understands what I'm going trough. But it's been tough on him too. I'm not the same woman anymore. I used to be joyful and outgoing, but now I'm just a scared woman trapped in a broken body. I'm afraid of what may come, that my body will finally let me down and that I'll end up in a wheelchair. I've tried so many treatments, hoping that they would give me tools to relieve my pain. But no treatment has managed to do that. I try to find comfort and joy in little things, a sunny day, being able to watch a movie with my husband or a visit from a friend.

I know that the person who caused this accident did not do this on purpose. But people should think twice when driving carelessly. They should know what the consequences can be for other people, all the pain, all the insurance hassles. It makes me really angry sometimes, knowing that in those few seconds, my life completely changed......

Derived from several personal stories of patients from the

Dutch Whiplash Patients Association 


\section{INTRODUCTION}

Chronic neck pain is a common complaint in western society. In more than $90 \%$ of the cases, the condition is called non-specific because medical investigations fail to reveal a somatic origin. Neck pain complaints frequently follow motor vehicle accidents, and rear-end collisions in particular. In 20 to $30 \%$ of patients with neck complaints after a motor vehicle accident, functioning is limited and quality of life is affected in terms of social participation. This dissertation is a compilation of studies investigating psychological mechanisms involved in the transition from acute to chronic neck pain after a motor vehicle accident. In this general introductory chapter of this dissertation, the theoretical models on which the research is based will be described, and the investigated concepts defined. Finally, a brief overview of the content of each of the chapters is presented.

\section{ACUTE WHIPLASH INJURY AND CHRONIC WHIPLASH SYNDROME}

When a person is being hit by a car in a rear-end collision, the head makes a movement that can be described by the term "whiplash". The movement of the head can be compared to the movement of a cracking whip. The head is being subjected to a brusque backward movement (extension) and subsequently to a brusque movement forward (flexion). However, the term whiplash is also being used not only to describe the movement of the head, but also to describe the injury itself, or the symptoms, or the syndrome as a whole.

A striking pattern of complaints often occurs after the accident. Patients mostly complain about neck pain, headache, visual disturbances, dizziness, muscle weakness, parasthesias, concentration difficulties, amnesia, fear, anxiety, and mood disorders. This set of complaints has been named in different ways in the literature. In 1995 the Quebec Task Force developed guidelines for patients with these complaints based on the clinical manifestation of the complaints and named them Whiplash Associated Disorders (WAD) (Spitzer et al., 1995). In this dissertation we will utilize its definitions and terms. Whiplash is defined as an acceleration-deceleration mechanism of energy transfer on the cervical spine, usually the result of a caraccident (rear-end collision or side collision). This impact can lead to soft tissue or bone injuries (whiplash-injuries) which consequently can lead to a variation of clinical symptoms (Whiplash Associated Disorders, WAD) (Spitzer et al., 1995). These WADs can be classified into five different grades based on the complaints reported by the patient in combination with additional medical examinations (see table 1). 
Table 1: The Quebec Classification of Whiplash-Associated Disorders (Spitzer et al., 1995)

\begin{tabular}{|c|c|}
\hline Grade & Clinical Presentation \\
\hline \multirow[t]{2}{*}{0} & No complaint about the neck \\
\hline & No Physical sign(s) \\
\hline \multirow[t]{2}{*}{1} & Neck complaint of pain, stiffness or tenderness only \\
\hline & No physical sign(s) \\
\hline 2 & Neck complaint AND Musculoskeletal sign(s) (†) \\
\hline 3 & 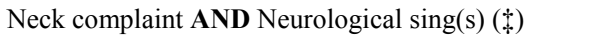 \\
\hline 4 & Neck complaint AND Fracture or dislocation \\
\hline
\end{tabular}

$(\dagger) \quad$ Musculoskeletal signs include decreased range of motion and point tenderness

(\$) Neurological signs include decreased or absent deep tendon reflexes, weakness and sensory deficits

Symptoms and disorders that can be manifest in all grades include deafness, dizziness, tinnitus, headache, memory loss, dysphasia, and temporomandibular joint pain.

There is no precise dividing line between the acute symptoms and the development of possible chronic complaints. It is estimated that $65 \%$ of the patients recovers after two months. In about $30 \%$ of acute neck patients the pain has developed towards chronic neck pain 6 months after the acute pain episode. After one year, ca. $20 \%$ of patients with an acute neck pain episode has developed a chronic neck pain (Radanov et al., 1995). When this chronic neck pain persists for over six months it is also being referred to as "Late Whiplash Syndrome" or "Chronic Whiplash Syndrome". In this dissertation we will use the terms "acute whiplash injury" and "chronic whiplash syndrome" as labels for the acute and chronic group of patients. The question rises why this last group of patients still has complaints and becomes disabled.

\section{PREDICTORS OF CHRONIC WHIPLASH SYNDROME}

\section{Somatic predictors}

So far, studies focussing on medical predictors for chronic whiplash syndrome have not found conclusive evidence that biomedical factors contribute to the development and persistence of complaints. Reviews on the literature reveal that serious physical injuries in whiplash associated disorders are rare (for a review: see Rodriquez et al., 2004). Some investigated the hypothesis that the complaints after a motor vehicle accident might be a result of injury to the neck musculature or cerebral injury. However, these studies have yielded inconsistent results (Ronnen et al., 1996; Radanov et al., 1999; Patijn et al., 2001; Wilmink and Patijn, 2001; Rodriquez et al., 
2004; Centeno et al., 2005; Nederhand et al., 2006). The hypothesis of injury to neck musculature (muscles or ligaments) in WAD less than grade 4 was asserted by various studies. For instance, Ronnen et al (1996) evaluated the plain radiographs and MRI findings of 100 patients without neurological injury who were studied within 3 weeks after acute whiplash injury. They could not relate pain complaints to ligamentous, muscular or other soft-tissue injuries. Also, the involvement of the alar ligament as a source of injury seems to be untenable. Both MRI findings and rotatory computerized tomography scans did not reveal injury to the alar ligament (Patijn et al., 2001; Wilmink and Patijn, 2001). Various studies have addressed whether brain injury may account for complaints such as poor attention and memory. However causal factors for these complaints are unclear. Radanov and colleagues (1999) examined emotional functioning, cognitive performance and results of functional brain imaging. They found no relationship between neuroimaging and attention and memory tests.

It seems that the hypothesized lesions or injuries are not supported by objective (f)MRI findings or other imaging techniques (Ronnen et al., 1996; Karlsborg et al., 1997; Wilmink and Patijn, 2001). Moreover, there appears to be no relationship between the extent of objectively assessed lesions or injuries and the degree of pain, disability or other symptoms reported by patients (Rodriquez et al. 2004). Finally, studies investigating pathophysiology are mainly performed in patients with chronic complaints, and therefore conclusions regarding the predictive value of the observed injuries should be made with great caution (Stovner, 1996). Furthermore, several researchers base their assumptions on pathophysiology on favourable outcomes of treatments, but cannot provide evidence for this pathofysiology in the development of complaints.

In an attempt to develop an assessment tool that is based on somatic symptoms in the acute phase, but that is also predictive for the persistence of complaints, the Quebec Task Force introduced the WAD classification system. It was assumed that classifying people on the basis of the severity of somatic symptoms in the acute phase would be predictive of the persistence of complaints. Some studies indeed found that the WAD classification predicts time to recovery (Hartling et al., 2001; Suissa et al., 2001). However, this classification is mostly based on the subjective complaints of patients and not on objective examination. Therefore the predictive value can be summarized as having high initial complaints being the best predictor for bad outcome, which gives us no information on the mechanisms involved.

Because of the lack of predictive value of somatic variables, researchers have begun to examine the role of cognitive, affective and behavioural factors in the transition from acute whiplash injury to chronic whiplash syndrome. It is well established that psychological factors are related to the transition from acute to chronic pain and disability in patients with chronic back pain (Linton 1990; 1995; 2000). 


\section{Psychological predictors}

A recent systematic review on predictive psychological variables for developing chronic whiplash syndrome revealed only partial evidence for the predictive value of psychosocial factors. However, this may be largely due to the heterogeneity of the predictor variables in the studies reviewed, precluding firm conclusions about specific psychological factors (Scholten-Peeters et al., 2003). This is in contrast with similar reviews in chronic low back pain showing that cognitive, affective and behavioural factors are related to pain and disability (Linton 1990; 1995; 2000). We will review the evidence for the role of psychological variables in the transition from acute whiplash injury to chronic whiplash syndrome based on a number of recent studies.

\section{Neuroticism or Negative Affect}

Neuroticism reflects emotional distress, the tendency to worry, hypervigilance and proneness to psychopathology. Neuroticism has long been considered as one of the personality traits most relevant to psychopathology, especially for anxiety and depression. Because of its significant associations with many forms of negative affect, the terms Negative Affectivity, Anxiety Sensitivity and Trait Anxiety have also occasionally been used as a synonym of neuroticism (Johnson, 2003; Goubert et al., 2004; Ormel et al., 2004). However, there still is some debate as to whether these concepts measure the same proposed underlying trait vulnerability (Lilienfeld et al., 1993).

Although neuroticism has strong prospective associations with psychopathology and associated outcomes, and also with pain, it does not give useful information on the aetiology and pathogenesis of psychopathology. Moreover its specificity is extremely low (Claridge and Davis, 2001; Ormel et al., 2004). Two theories try to explain the influence of neuroticism and/or negative affectivity on health. Watson and Pennebaker (1989) argued that persons scoring high on neuroticism are more likely to notice and attend to internal physical sensations and minor aches because their attentional scanning of both the external and internal environment is fraught with anxiety and uncertainty. This model is also known as the symptom perception model, suggesting that there is a direct influence on psychopathology. However, with regards to pain, Goubert et al. (2004) found results in favour of a "diathesisstress model" in which neuroticism is conceptualized as a vulnerability factor. This states that neuroticism will mainly have an effect on specific health problems when it is combined with stressors that are specifically related to the outcome variables of interest (Claridge and Davis, 2001). In the study by Goubert et al. (2004) the effect of neuroticism was largely mediated by pain catastrophizing and pain-related fear. It was suggested that neuroticism may lower the threshold at which pain is perceived 
as threatening, and at which pain elicits catastrophic thoughts. However, these conclusions were based on cross-sectional research. With regards to patients with whiplash injury, studies by Radanov et al. $(1995,1996)$ showed that neuroticism was associated with poor recovery from acute whiplash injury, although later studies by this research group showed that psychological factors are more likely to be a symptom than a cause of chronic whiplash syndrome (Radanov et al., 1996). So far, the causal relationship between neuroticism and the persistence of complaints after acute whiplash injury could not be established and its possible interactions with specific stressors has not yet been investigated.

\section{Trauma-related complaints}

For some patients with chronic whiplash syndrome it is possible to link their psychological complaints to the trauma of the accident. In this case, the complaints are similar to those reported by patients with a Post Traumatic Stress Disorder (PTSD). The prevalence of acute PTSD after a severe car accident is 34\% after one month and then half of this 34\% still has PTSD after 6 months. (Ursano et al., 1999) Other studies report a prevalence of PTSD after a Motor Vehicle Accident (MVA) ranging from 11\% to 50\%. (Jaspers, 1998; Sharp and Harvey, 2001).

Because of the lack of research on this subject, nothing can be said with any certainty about the causal relationship between acute whiplash injury and PTSD. Spijkerman et al. (1995) explained the chronic pain complaints in whiplash patients in terms of learning theory. The pain resulting from the characteristic hypertonia of the neck muscles, which occurs in the acute phase and the chronic phase, can be seen as a form of respondent pain that becomes chronic under the influence of operant processes. It is conceivable that post-traumatic stress affects this process, by preserving both the hypertonia and the operant process. Sharp and Harvey (2001) state that the cognitive, affective, and behavioural components of chronic pain may exacerbate and maintain PTSD. At the same time, the physiological, affective and avoidance components of PTSD may exacerbate and maintain problems associated with chronic pain. Asmundson et al. (2000) however, hypothesizes that the comorbidity of PTSD in chronic pain patients is associated with the amount of disability that the patient perceives. Results indicate that the dysfunctional patients are particularly vulnerable to respond in a generally helpless fashion to the stressors they encounter. In fact, their global presentation of symptoms seems to suggest that their 'psychological immune system' has collapsed (Asmundson et al., 2000). Sterling et al. (2005) were one of the first to investigate the predictive value of acute traumarelated complaints. The results indicate that elevated scores on the Impact of Event Scale (IES) in patients with acute whiplash injury was indeed a good predictor of a bad outcome at follow-up (Sterling et al., 2005). 


\section{Coping}

Coping has been conceptualized by Folkman and Lazarus (1984) as engaging in cognitive and behavioural efforts to manage external or internal stressors. Pain can be seen as such a stressor and therefore pain coping is referred to a purposeful effort to manage or minimize the negative impact of pain. Folkman and Lazarus (1984) differentiated between two types of coping, being, (1) problem-focused coping (aimed at altering person-environment relationships) and (2) emotion-focused coping (aimed at regulating emotional distress). However, with regards to research on pain, the concept of coping and its subtypes has been conceptualized in different ways, often dependent on the questionnaire or measurement used. In the literature one can find subtypes, such as passive and active coping (Buitenhuis et al., 2003; Caroll et al., 2006) or avoidant and non-avoidant coping (Endler et al., 2003). However, when looking at specific types of coping strategies in relation to patients with whiplash injury, catastrophizing seems to be an important coping style, related to worse outcome (Endler et al., 2003). However, catastrophizing can not easily be fitted to the definition by Lazarus and Folkman, since although it is an emotionfocused coping strategy it is not likely to regulate emotional distress in an adaptive manner. Moreover, one could argue whether catastrophizing is an intentional coping style requiring effort or an automatic predisposed reaction to stress. Results regarding catastrophizing as maladaptive coping have yielded mixed results in the field of whiplash research. Kivioja et al. (2005) did not find evidence for the influence of early coping strategies such as catastrophizing (within one week after the collision) on the prognosis after an acute whiplash injury. However, recently Caroll et al. (2006) demonstrated that catastrophizing (being defined as a passive coping style) is associated with slowed recovery after whiplash.

One of the obstacles to make progress in the area of psychological variables as predictors for chronic whiplash syndrome is that many of the psychological variables implicated as causative of whiplash pain and disability have not been standardized. Moreover, it seems difficult to measure these variables in a reliable manner because they are often couched within theoretical frameworks that have minimal value for either conceptualising or treating whiplash injuries. To enhance knowledge in this area, it is necessary to introduce a more evidence based theoretical model to identify psychological risk factors for the pain and disability associated with whiplash. 


\section{THE FEAR-AVOIDANCE MODEL}

The lack of consistent findings underscores the need for a new approach to evaluating research on prognostic factors for chronic whiplash syndrome. The FearAvoidance model is a promising model since it incorporates several risk factors known to be associated with pain and based on experimental evidence.

Lethem et al. (1983) were one of the first to propose a theoretical multidisciplinary approach for exaggerated pain perception. Central to the model is the concept of 'fear of pain'. The two most extreme responses to this fear of pain are 'confrontation' and 'avoidance'. Confrontation will lead to maintaining synchrony between the actual level of nociception and pain behaviour since the individual is likely to resume his or her activities even when experiencing pain. Avoidance however, leads to exaggerated pain responses since it does not lead to disconfirmation of expectations of pain and the reality of sensory stimuli. Philips (1987) took a more cognitive view on avoidance behaviour, and proposed that avoidance of pain was not only the result of negative reinforcement, but also of the expectation that certain activities or situations will produce pain(increase).

Based upon this previous work, Vlaeyen et al. (1995a; 1995b; 2000) proposed the cognitive-oriented "fear-avoidance model". The main difference with the early fearavoidance model is that not the pain itself, but the meaning attached to the pain is assumed to initiate a downward spiral of increasing avoidance, disability and pain (Vlaeyen et al., 1995a). Catastrophic (mis)interpretations of pain lead to pain-related fear and thereafter spirals into a vicious and self-perpetuating cycle of fearhypervigilance-avoidance-disability-pain cycle (figure 1). This contemporary fearavoidance model has served as a useful heuristic model upon which an accumulating number of empirical studies and clinical applications have been based. Studies have shown that pain catastrophizing is associated with pain disability in patients with chronic low back pain and chronic whiplash syndrome (Sullivan et al., 1998; Sullivan et al., 2002; Peters et al., 2005). Patients with catastrophizing cognitions about pain become fearful (Vlaeyen et al., 1995a). Fear of pain is associated with impaired physical performance and increased self-reported disability (Waddell et al., 1993; Crombez et al., 1999). Furthermore, fearful patients will also attend more to bodily symptoms and they will be less able to shift attention away from painful stimuli. When pain is interpreted as a physical threat, it demands attention and interrupts ongoing activities (Eccleston and Crombez, 1999). Hypervigilance emerges when patients experience intense pain, have catastrophic thoughts about pain, and become fearful of pain (Goubert et al., 2004; Crombez et al., 2005). All these factors initiate avoidance behaviour that, over a longer period of time, contributes to decondition- 


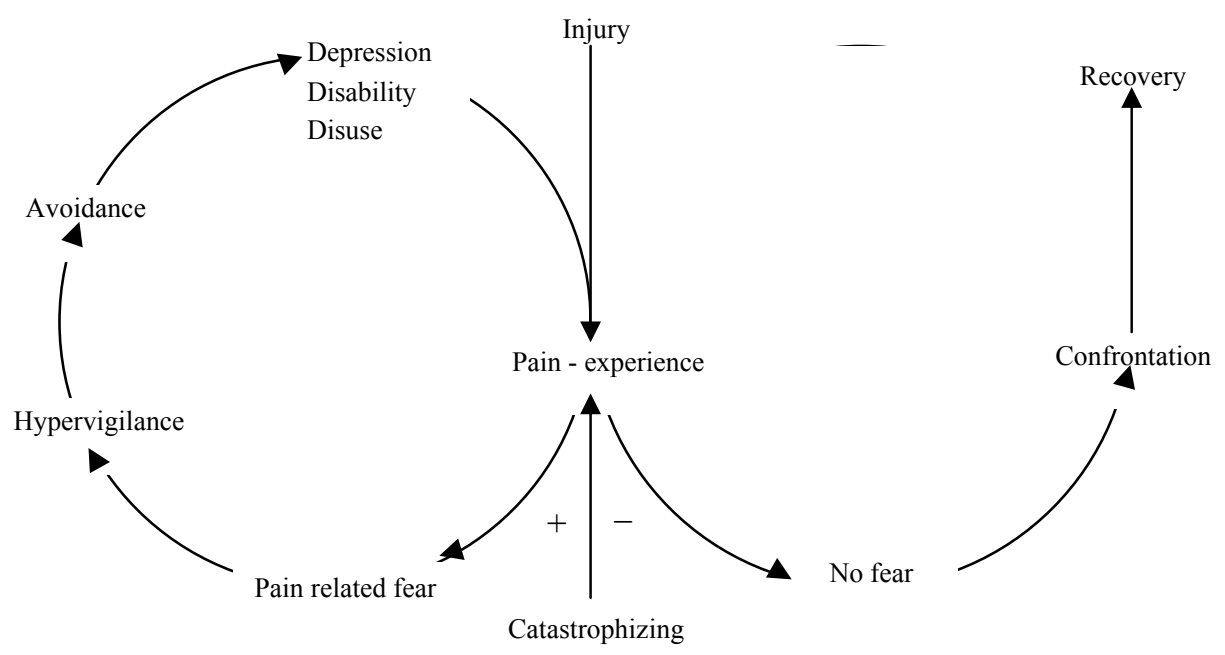

Figure 1: the Fear - Avoidance Model (Adapted from Vlaeyen and Linton 2000)

ing, and in turn, reinforces further pain experiences, negative expectancies and avoidance.

This model has proven to be successful in predicting persistence of chronic pain and disability in patients after an acute back pain episode (Buer and Linton, 2002; Boersma and Linton, 2006), and in predicting the inception of a new pain episode in the general population (Linton, 2005; Severeijns et al., 2005). In the open population, pain-related fear predicts future disability and health due to back pain (Picavet et al., 2002). Furthermore, the FA-model has already been generalized to other chronic pain populations such as osteoarthritis (Heuts et al., 2004), burn pain (Willebrand et al., 2006), knee pain (Kvist et al., 2005), and fibromyalgia (de Gier et al., 2003). Results from treatment studies are also in favour of the FA-model, although we can not use those as evidence for the hypothesized causal relationships between the various variables. Educational interventions aimed at reducing negative attitudes and beliefs that mediate avoidance behavior, have shown to reduce absence from work (Moore et al., 2000). Moreover, when targeting specific pain-related beliefs by means of cognitive behavioral treatments, including exposure in vivo, patients will show improvement in functional abilities and increased activity tolerance (Vlaeyen et al., 2001; 2002a; Vlaeyen et al., 2002b).

The available literature on patients with chronic low back pain and other chronic pain populations suggests that the FA-model may provide a sound framework to explain the transition from acute whiplash injury to chronic whiplash syndrome. The 
group of patients with chronic whiplash patients seems extremely suitable for prospective research regarding this model, because there is a clearly marked point in time for the onset of complaints. In chapter two, the evidence so far and the benefits for applying the fear avoidance model to patients with chronic whiplash syndrome will be discussed.

\section{SELF-DISCREPANCIES AND SELF-PAIN ENMESHMENT}

When people have developed chronic pain, they may experience a variety of consequences in their daily life. According to the fear-avoidance theory, possible consequences from the experience of continuous pain may be deconditioning, disability and depression. However, it is possible that pain has a larger impact on patients then assumed so far. Due to pain-related fear, the emerging avoidance behaviour and disability may in fact increase the discrepancy between the major life goals of the individual and the actual situation. These kinds of discrepancies are known to affect a person's experience of self and identity. The self-discrepancy theory and self-pain enmeshment theory both elaborate on the effects of discrepancies.

\section{Self-discrepancy theory}

The Self-Discrepancy Theory (Higgins, 1987) assumes that people have several distinct types of self-guides. These self-guides are values against which people compare their self-concept or actual self. The actual self or self-concept represent the attribution a person actually possesses. Two self-guides are of particular importance, being the ideal self and ought self. An ideal self contains the attributions one would ideally like to possess. The ought self represents the attributions one feels he or she should possess. People are motivated to achieve the state of concordance between the actual self and their self-guides.

However, people may experience a discrepancy between their actual self and their self-guides. An ideal self-discrepancy means that a person has no concordance between who he/she would ideally like to be (the ideal self), and the person he/she is at this moment (the actual self). An ought self-discrepancy means that a person has no concordance with the actual self and the person he or she should be. Having a discrepancy between the actual self and a self-guide, may lead to having feelings of discomfort. In several studies Higgins et al. (1987) found that the actual-ideal discrepancy is related to feelings of depression and dejection whereas the actualought discrepancy is more associated with feelings of anxiety and agitation (Higgins, 1987; Higgins et al., 1986). These feelings of discomfort will urge the individual to take actions in order to reduce the discrepancies felt. 
Carver et al. (1999) elaborated on the discrepancy theory by adding a third selfguide derived from the possible-self model by Markus and Nurius (1986). In addition to the discrepancy between the ideal and actual self and ought self, people can encounter a discrepancy between their actual and their feared self. This means that they are more distant or proximate to the person they do not want to be and who they are afraid of becoming in the future. The larger the discrepancy between the actual self and the feared self, the better. The feared self-discrepancy is associated with both dejection-related as with agitation-related emotions and therefore has some overlap with the other two self-guides. However, associations between dejectionrelated emotions and the actual-ideal discrepancy are independent of levels of actual feared self, whereas the relation between agitation-related emotions and the actualought self is influenced by levels of the actual feared self (Carver et al., 1999). This suggests that being near to a feared self is dominant over achieving a concordance between the actual and ought self. When a person is too near the feared value, what matters is getting away from it.

The evidence so far on self-discrepancies in patients with acute or chronic pain is scarce, but some studies found evidence for the association between dejectionrelated emotions and agitation-related emotions and different types of discrepancies (Waters et al., 2004; Morley et al., 2005a). People will undertake actions or set goals to either approach an ideal or ought self or avoid a feared self. These approach and avoidance behaviours could be linked to or guided by specific fears, such as fear of movement and pain catastrophizing, both factors included in the fear-avoidance model.

Up until now, it is unknown when self-discrepancies are activated or changed in patients experiencing pain and which factors are of influence. Given the observation that pain interrupts and interferes with daily activities, pain is likely to interfere with major life goals as well. Self-discrepancies could be of influence on the transition from acute to chronic pain. They may also be of influence on the development of negative mood and avoidance behaviour and on persistence behaviour by means of a constant drive of relieving the discrepancy.

When pain becomes chronic and it interferes repeatedly with major goals in life it will have an impact on the self-schemata and, thereby on the person's identity. Eventually cognitive self-representations will become more and more enmeshed with cognitive representations about pain. The identity of the person is being taken over by pain and important aspects of the self are trapped by pain (Pincus and Morley, 2001; Waters et al., 2004; Morley et al., 2005b). 


\section{Self-pain enmeshment}

One of the consequences of experiencing chronic pain in combination with selfdiscrepancies is self-pain-enmeshment. The self-pain-enmeshment model builds on the principle of the three I's: Interruption, Interference, and Identity (Morley and Eccleston, 2004). Pain demands attention and interrupts ongoing activities. Not only the immediate pain experience has the ability to interrupt, but this is also true for cognitions related to the pain experience. Interference refers to the detrimental effects of repeated interruptions on daily life functioning. Repeated interference then, will lead to an impact on self-schemata and thereby on identity. Important life goals become out of reach because of long lasting pain. Eventually, cognitive representation about the self will become more and more enmeshed with the cognitive representation about pain. The identity is taken over by pain and important aspects of the self are captured by pain (see figure 3). A first study by Morley et al. (2005) has shown that after accounting for the influence of demographics, pain characteristics and the degree of pain interference, the amount of self-pain enmeshment predicted the magnitude of depression and acceptance.

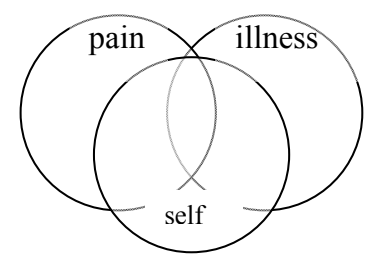

Figure 3: schematic representation of normal self-pain schemata (left) and enmeshed self-pain schemata (right) (Morley et al., 2005a).

\section{OUTLINE OF THIS DISSERTATION}

The aforementioned concepts and theoretical models form the base of several studies regarding the predictive value of pain-related fear in the transition from acute neck pain after a motor vehicle accident to chronic whiplash syndrome. Chapter 2 reviews the existing evidence in favour of the FA-model in patients with Chronic Whiplash Syndrome. 
Chapter 3 presents a cross-sectional study in which pain, pain catastrophizing and pain-related fear are measured in the acute phase of whiplash injury. In addition, this study also includes a measure of restricted range of motion, a very specific complaint of patients with pain after a motor vehicle accident. We hypothesize that this restricted range of motion in some patients may be a feature of fear of movement, meaning that patients may show submaximal performance on a range of motion test because of fear of experiencing pain.

If the fear-avoidance model is indeed an important model in explaining the transition from acute whiplash injury to chronic whiplash syndrome, it is likely that these processes will already take place within the first six weeks after the injury, not only within groups, but more importantly on an individual level. Therefore, a diary study was performed in a subgroup of patients with acute whiplash injury (Chapter 4). The hypothesized relationship between the variables of the fear-avoidance model are now tested using both a within and between subjects experimental design.

If we assume that the hypothesized relationships investigated in chapter 3 and 4 are already present in acute whiplash injury, it is necessary to investigate whether the factors included in the fear-avoidance model are predictors for the transition to chronic whiplash syndrome. Chapter 5 addresses this issue and describes the analyses for the follow-up measurement of the prospective cohort study. By means of multiple regression analyses, the predictive value of various concepts of the FAmodel (pain catastrophizing and pain related fear) are investigated together with more explorative analyses on anger. It is also investigated whether these variables are not only predictive for the development of chronic disability and pain but also for the development of depression, post-traumatic stress disorder and quality of life. We hypothesize that the same factors responsible for predicting pain and disability are predictive for depression, post-traumatic stress and quality of life.

In chapter 6 we address one particular feature of patients with chronic whiplash syndrome that was not included in the previous studies. By means of a laboratory experiment we investigate whether hypervigilance is an important factor in the maintenance of chronic whiplash syndrome. Forty patients with chronic whiplash syndrome are requested to perform a primary task paradigm while being distracted by a threatening neck movement. It is hypothesized that this distraction will lead to increased reaction times, compared to baseline levels and healthy controls. It is also hypothesized that these increased reaction times are more prominent in patients with high levels of pain catastrophizing and pain related fear.

As an extension of the FA model, chapter 7 focuses on the relationship among painrelated fear, self-discrepancies and self-pain enmeshment. A secondary analysis is performed on the data of the diary study to examine whether other processes take place in addition to those that are suggested by the fear-avoidance model in acute whiplash injury. It is hypothesized that the continuous experience of pain and 
disability not only leads to the initiation of chronic disability and pain, but also to the development of other problems such as an impact on the patients' identity. In chapter 8 , indirect evidence for the role of pain-related fear in predicting avoidance behaviour and disability is sought by offering an exposure in vivo treatment for patients identified as having high levels of pain catastrophizing and pain related fear. From the literature on chronic low back pain we know that an exposure in vivo treatment can be effective to break through the downward cycle of the fearavoidance model. It is hypothesized that this treatment is equally effective for the population of patients with chronic whiplash syndrome.

Finally, in chapter 9, the results of the different studies will be critically appraised. The chapter includes a general discussion on whether the fear-avoidance model is indeed a valuable model to predict the transition from acute whiplash injury to chronic whiplash syndrome. Furthermore, some theoretical and methodological considerations are made, and lastly, the suggestions for further research and clinical implications are discussed. 


\section{REFERENCES}

Asmundson GJG, Bonin M, Frombach I, Norton GR. Evidence of a disposition toward fearfulness and vulnerability to posttraumatic stress in dysfunctional pain patients. Behaviour Research and Therapy 2000;38:801-812.

Boersma K, Linton SJ. Expectancy, fear and pain, in the prediction of chronic pain and disability: A prospective analysis. European Journal of Pain 2006;10(6):551-557.

Buer N, Linton SJ. Fear-Avoidance beliefs and catastrophizing: occurence and risk factor in back pain and ADL in the general population. Pain 2002;99(3):485-491.

Buitenhuis J, Spanjer J, Fidler V. Recovery from acute whiplash. Spine 2003;28(9):896-901.

Caroll LJ, Cassidy JD, Côté P. The role of pain coping strategies in prognosis after whiplash injury: Passive coping predicts slowed recovery. Pain 2006;124:18-26.

Carver CS, Lawrence JW, Scheier MF. Self-Discrepancies and Affect: Incorporating the Role of Feared Selves. Personality and social psychology bulletin 1999;25(7):783-792.

Centeno CJ, Freeman MD, Elkins WL. A review of the literature refuting the concept of minor impact on soft tissue injury. Pain research and management 2005;10(2):71-74.

Claridge G, Davis C. What's the use of neuroticism? Personality and individual differences 2001;31:383400.

Crombez G, Van Damme S, Eccleston C. Hypervigilance to pain: an experimental and clinical analysis. Pain 2005;116:4-7.

Crombez G, Vlaeyen JW, Heuts PH, Lysens R. Pain-related fear is more disabling than pain itself: evidence on the role of pain-related fear in chronic back pain disability. Pain 1999;80(1-2):329-339.

de Gier M, Peters ML, Vlaeyen JWS. Fear of pain, physical performance, and attentional processes in patients with fybromyalgia. Pain 2003;104:121-130.

Eccleston C, Crombez G. Pain demands attention: a cognitive-affective model of the interruptive function of pain. Psychological Bulletin 1999;125(3):356-366.

Endler NS, Corace KM, Summerfeldt LJ, Johnson JM, Rothbath P. Coping with chronic pain. Personality and individual differences 2003;34:323-346.

Goubert L, Crombez G, Van Damme S. The role of neuroticism, pain catastrophizing and pain-related fear in vigilance to pain: a structural equations approach. Pain 2004;107:234-241.

Hartling L, Brison RJ, Ardern C, Pickett W. Prognostic value of the Quebec Classification of WhiplashAssociated Disorders. Spine 2001;26(1):36-41.

Heidrich SM, Powwattana A. Self-discrepancy and mental health in older women with chronic illnesses. Journal of adult development 2004;11(4):251-259.

Heuts PHTG, Vlaeyen JWS, Roelofs J, De Bie RA, Aretz K, van Weel C, van Schayck OCP. Pain-related fear and daily functioning in patients with osteoarthritis. Pain 2004;110:228-235.

Higgins ET. Self-discrepancy: a theory relating self and affect. Psychological review 1987;94(3):319-340.

Higgins ET, Bond RN, Klein R, Strauman T. Self-discrepancies and emotional vulnerability: how magnitude, accessibility and type of discrepancy influence affect. Journal of Personality and Social Psychology 1986;51(1):5-15.

Jaspers JPC. Whiplash and post-traumatic stress disorder. Disability and Rehabilitation 1998;20(11):397404.

Johnson M. The vulnerability status of neuroticism: over-reporting or genuine complaints. Personality and individual differences 2003;35:877-887.

Karlsborg M, Smed A, Jespersen H, Stephensen S, Cortsen M, Jennum P, Herning M, Korfitsen E, Werdelin L. A prospective study of 39 patients with whiplash injury. Acta Neurologica Scandinavica 1997;95:65-72. 
Kivioja J, Jensen I, Lindgren U. Early coping strategies do not influence the prognosis after whiplash injuries. Injury 2005;36:935-940.

Kvist J, Ek A, Sporrstedt K, Good L. Fear of re-injury: a hindrance for returning to sports after anterior cruciate ligament construction. Knee Surgery, Sports Traumatology, Arthroscopy 2005;13:393-397.

Lazarus RS, Folkman S. Stress, appraisal, and coping. New York: Springer Publishing Company, 1984.

Lethem J, Slade PD, Troup JDG, Bentley G. Outline of a fear-avoidance model of exaggerated pain perception-I. Behaviour research and therapy 1983;21(4):401-408.

Lilienfeld SO, Turner SM, Jacob RG. Anxiety sensitivity: an examination of theoretical and methodological issues. Advances in Behaviour Research and Therapy 1993;15:147-183.

Linton SJ. Risk factors for neck and back pain in a working population in Sweden. Work \& Stress 1990;4(1):41-49.

Linton SJ. An overview of psychosocial and behavioral factors in neck- and shoulder pain. Scandinavian Journal of Rehabilitation Medicin 1995;suppl 32:67-78.

Linton SJ. A review of Psychological Risk Factors in Back and Neck pain. Spine 2000;25(9):1148-1156.

Linton SJ. Do psychological factors increase the risk for back pain in the general population in both a cross-sectional and prospective analysis? European Journal of Pain 2005;9(4):355-361.

Markus H, Nurius P. Possible Selves. American Psychologist 1986;41(9):954-969.

Moore JE, Von Korff M, Cherkin D, Saunders K, Lorig K. A randomized trial of a cognitive-behavioral program for enhancing back pain self care in a primary care setting. Pain 2000;88(2):145-153.

Morley S, Davies C, Barton S. "Future Possible Selves". Enmeshment and adjustment to chronic pain. $2005 \mathrm{a}$

Morley S, Davies C, Barton S. Possible selves in chronic pain: self-pain enmeshment, adjustment and acceptance. Pain 2005b;115:84-94.

Morley S, Eccleston C. The object of fear in pain. In: GJG Asmundson, JWS Vlaeyen, G Crombez, editors|. Understanding and treating fear of pain.. Oxford: Oxford University Press, 2004. 163-188.

Nederhand MJ, Hermens HJ, Ijzerman MJ, Groothuis KGM, Turk DC. The Effect of Fear of MOvement on Muscle Activation in Posttraumatic Neck Pain Disability. Clinical Journal of Pain 2006;22(6):519-525.

Ormel J, Rosmalen J, Farmer A. Neuroticism: a non-informative marker of vulnerability to psychopathology. Social Psychiatry and Psychiatric Epidemiology 2004;39:906-912.

Patijn J, Wilmink J, ter Linden FHJ, Kingma H. CT study of craniovertebral rotation in whiplash injury. European Spine Journal 2001;10:38-43.

Peters ML, Vlaeyen JWS, Weber WEJ. The joint contribution of physical pathology, pain-related fear and catastrophizing to chronic back pain disability. Pain 2005;113:45-50.

Philips HC. Avoidance behaviour and its role in sustaining chronic pain. Behaviour Research and Therapy 1987;25:273-279.

Picavet HS, Vlaeyen JW, Schouten JS. Pain Catastrophizing and Kinesiophobia: Predictors of Chronic Low Back Pain. Am J Epidemiol 2002;156(11):1028-1034.

Pincus T, Morley S. Cgonitive-Pocessing Bias in Chronic Pain: A Review and Integration. Psychological Bulletin 2001;127(5):599-617.

Radanov BP, Bergé S, Sturzenegger M, Augustiny KF. Course of psychological variables in whiplash injury - a 2-year follow-up with age, gender and education pair-matched patients. Pain 1996;64:429434.

Radanov BP, Bicik I, Dvorak J, Antinnes J, von Schulthess GK, Buck A. Relation between neuropsychological and neuroimaging findings in patients with late whiplash syndrome. Journal of Neurology, Neurosurgery and Psychiatry 1999;66:485-489.

Radanov BP, Sturzenegger M, Di Stefano G. A 2-year follow-up considering features of injury mechanism and somatic, radiologic and psychological findings. Medicine 1995;74(5):281-297. 


\section{CHAPTER 1}

Rodriquez AA, Barr KP, Burns SP. Whiplash: pathophysiology, diagnosis, treatment, and prognosis. Muscle \& Nerve 2004;29:768-781.

Ronnen HR, de Korte PJ, Brink PRG, van der Bijl HJ, Tonino AJ, Franke CL. Acute whiplash injury: is there a role for MR Imaging? A prospective study of 100 patients. Radiology 1996;201:93-96.

Scholten-Peeters GGM, Verhagen AP, Bekkering GE, van der Wint DAWM, Barnsley L, Oostendorp RAB, Hendriks EJM. Prognostic factors of whiplash-associated disorders: a systematic review of prospective cohort studies. Pain 2003;104:303-322.

Severeijns R, Vlaeyen JWS, Van den Hout MA, Picavet HSJ. Pain Catastrophizing and consequences of musculoskeletal pain: A prospective study in the Dutch community. The Journal of Pain 2005;6(2):125-132.

Sharp TJ, Harvey AG. Chronic pain and posttraumatic stress disorder: mutual maintenance? Clinical Psychology Review 2001;21(6):857-877.

Spijkerman AMW, van Akkerveeken PF, Rozeman A, Groenman NH. Whiplash en chronische pijn: de invloed van hypertonie en operante conditionering. Nederlands Tijdschrift voor Pijn en Pijnbestrijding 1995;15(3):25-31.

Spitzer WO, Skovron ML, Salmi LR, Cassidy JD, Duranceau J, Suissa S, Zeiss E. Scientific Monograph of the Quebec Task Force on Whiplash-Associated Disorders: Redefining "Whiplash" and its management. Spine 1995;20(8 suppl.):1S-73S.

Sterling M, Jull G, Vicenzino B, Kenardy J, Darnell R. Physical and psychological factors predict outcome following whiplash injury. Pain 2005;114:141-148.

Stovner LJ. The nosologic status of the Whiplash Syndrome: A critical review based on a methodological approach. Spine 1996;21(23):2735-2746.

Suissa S, Harder S, Veilleux M. The relation between initial symptoms and signs and the prognosis of whiplash. European Spine Journal 2001;10:44-49.

Sullivan MJL, Stanish W, Sullivan ME, Tripp D. Differential predictors of pain and disability in patients with whiplash injuries. Pain Research Management 2002;7(2):68-74.

Sullivan MJL, Stanish W, Waite H, Sullivan M, Tripp DA. Catastrophizing, pain and disability in patients with soft-tissue injuries. Pain 1998;77:253-260.

Ursano RJ, Fullerton CS, Epstein RS, Crowley B, Kao T-C, Vance K, Craig KJ, Dougall AL, Baum A. Acute and chronic posttraumatic stress disorder in Motor Vehicle Accident Victims. The American Journal of Psychiatry 1999;156:589-595.

Vlaeyen JW, de Jong J, Geilen M, Heuts PH, van Breukelen G. Graded exposure in vivo in the treatment of pain-related fear: a replicated single-case experimental design in four patients with chronic low back pain. Behav Res Ther 2001;39(2):151-166.

Vlaeyen JW, De Jong J, Geilen M, Heuts PH, Van Breukelen G. The Treatment of Fear of Movement/(Re)injury in Chronic Low Back Pain: Further Evidence on the Effectiveness of Exposure In Vivo. Clin J Pain 2002a;18(4):251-261.

Vlaeyen JW, De Jong JR, Onghena P, Kerckhoffs-Hanssen M, Kole-Snijders AM. Can pain-related fear be reduced? The application of cognitive- behavioural exposure in vivo. Pain Res Manag 2002b;7(3):144-153.

Vlaeyen JW, Kole-Snijders AM, Boeren RG, van Eek H. Fear of movement/(re)injury in chronic low back pain and its relation to behavioral performance. Pain 1995a;62(3):363-372.

Vlaeyen JWS, Kole-Snijders AMJ, Rotteveel AM, Ruesink R, Heuts PHTG. The role of fear of movement/(re)injury in pain disability. Journal of Occupational Rehabilitation 1995b;5(4):235-252.

Vlaeyen JWS, Linton SJ. Fear-avoidance and its consequences in chronic musculoskeletal pain: a state of the art. Pain 2000;85:317-332. 
Waddell G, Newton M, Henderson I, Somerville D, Main CJ. A Fear-Avoidance Beliefs Questionnaire (FABQ) and the role of fear-avoidance beliefs in chronic low back pain and disability. Pain 1993;52(2):157-168.

Waters SJ, Keefe FJ, Strauman TJ. Self-discrepancy in chronic low back pain: relation to pain, depression and psychological distress. Journal of Pain and Symptom Management 2004;27(3):251-259.

Watson D, Pennebaker JW. Health Complaints, Stress and Distress: Exploring the Central Role of Negative Affectivity. Psychological review 1989;96(2):234-254.

Willebrand MA, G., Kildal M, Gerdin B, Ekselius L. Injury-related fear-avoidane, neuroticism and burnspecific health. Burns 2006;32:408-415.

Wilmink JT, Patijn J. MR imaging of alar ligament in whiplash-associated disorders: an observer study. Neuroradiology 2001;43:859-863. 

Chapter 2

\title{
Applying the Fear Avoidance Model to the Chronic Whiplash Syndrome
}

\author{
Karoline Vangronsveld, Madelon Peters, \\ Mariëlle Goossens, Steven Linton, Johan Vlaeyen,
}


CHAPTER 2

28 


\section{WHIPLASH: THE DEBATE}

During a rear-end collision, the impact on the driver results in a backward and forward head movement that is similar to the crack of a whip and thus this often painful problem has been termed "whiplash". A striking pattern of complaints often occurs after the accident, characterized by neck pain, headache, visual disturbances, dizziness, muscle weakness, parasthesia, concentration difficulties, amnesia, and negative mood. The proportion of persons who develop chronic complaints after an acute whiplash injury varies considerably across studies, with figures ranging from $0 \%$ to $50 \%$ (Berglund et al., 2000; Olsson et al., 2002; Sterner et al., 2003).

So far, the available studies have not found conclusive evidence that biomedical factors contribute to the persistence of complaints after acute whiplash injury. Some researchers investigated the hypothesis that the complaints after a motor vehicle accident might be a result of injury to the neck musculature or cerebral injury. However, these studies have yielded inconsistent results (Ronnen et al., 1996; Wilmink and Patijn, 2001; Rodriquez et al., 2004; Nederhand et al., 2006). Often the hypothesized lesions or injuries are not supported by objective (f)MRI findings or other imaging techniques (Ronnen et al., 1996; Wilmink and Patijn, 2001). Moreover, there appears to be no relationship between the extent of objectively assessed lesions or injuries and the degree of pain, disability or other symptoms reported by patients (Rodriquez et al., 2004). Finally, studies investigating pathophysiology have mainly been performed in patients with chronic complaints, and therefore conclusions regarding the predictive value of the observed injuries should be made with great caution.

Based on the clinical manifestations of the complaints the Quebec Task Force introduced the WAD classification (Spitzer et al., 1995). It was assumed that classifying people on the basis of the severity of somatic symptoms in the acute phase would be predictive of the persistence of complaints. Some studies indeed found that the WAD classification predicts time to recovery (Hartling et al., 2001; Suissa et al., 2001). However, this classification is based on the subjective complaints of patients and not on objective examination. At best, these studies show that initial elevated levels of complaints are the best predictor for bad outcome, but lack information on putative mechanisms involved.

Because of the lack of predictive value of somatic variables, researchers have begun to examine the role of cognitive, affective and behavioural factors in the transition from acute whiplash injury to chronic whiplash syndrome. It is well established that psychological factors are related to the transition from acute to chronic pain and disability in patients with chronic back pain (Linton, 2005). Two systematic reviews have evaluated the evidence that psychological factors may be involved in the transition from acute to chronic WAD (Côté et al., 2001; Scholten-Peeters et al., 
2003). Both reviews concluded that there is only limited evidence for the prognostic role of psychological variables. However, this may be largely due to the heterogeneity of the predictor variables in the studies reviewed, precluding firm conclusions about specific psychological factors. Clearly there is a need for more standardization in research and a common theoretical framework.

\section{A THEORETICAL FRAMEWORK}

The lack of consistent findings underscores the need for a new approach for evaluating research on prognostic factors for chronic whiplash syndrome. We argue that the fear-avoidance model (FA-model) may be a promising model for understanding the development of persistent complaints after an acute whiplash injury. The FA-model presents possible pathways by which injured patients might be "trapped" in a downward spiral of increasing avoidance, disability and pain. In essence, individuals with extreme negative thoughts about the harmfulness of pain (pain catastrophizing), are likely to develop fear of pain for events and situations that they associate with pain. This fear initiates avoidance behaviour and hypervigilance that can have short term pain reducing effects, but paradoxically, contributes to physical deconditioning and increased disability over a longer period of time. Increased disability may in turn reinforce further pain experiences, negative thoughts and avoidance behaviour. This model has proven to be successful in predicting persistence of chronic pain and disability in patients after an acute back pain episode (Boersma and Linton, 2006), and in predicting the inception of a new back pain episode in the general population (Linton, 2005; Severeijns et al., 2005). Similarly, catastrophizing and pain-related fear may be predictive of the persistence of neck pain after acute whiplash injury.

From a research standpoint, studying the recovery from acute whiplash injury is a very suitable paradigm to establish the prognostic value of the FA-model, since there is a clearly marked point in time for the onset of complaints, allowing for truly prospective designs. Moreover, it may be speculated that fear-avoidance beliefs are especially salient in patients with an acute and traumatic origin of complaints, because this may strengthen the belief that pain arises from physical injury and signifies harm to the body. Indeed, in a study including back pain and neck pain patients with either acute or gradual onset pain George et al. (2001) found that patients with acute onset pain showed elevated levels of fear-avoidance beliefs compared to patients with gradual onset pain. 


\section{REVIEW OF RELEVANT STUDIES}

Only a limited number of studies have examined whether the FA-model can be applied to the chronic whiplash syndrome. Nederhand et al. (2004) used the Tampa Scale of Kinesiophobia (TSK) to measure pain-related fear and found this to be predictive for the development of chronic whiplash syndrome. The combination of high acute pain and high pain-related fear one week after the accident predicted disability at 6-months follow-up.

However, recently Buitenhuis et al. (2006) found mixed results for the role of painrelated fear in the development of chronic whiplash syndrome. Cross-sectional analyses showed that pain-related fear measured with the TSK was significantly related to pain intensity, concentration problems and difficulties in falling asleep at baseline. Moreover, survival analyses indicated that pain-related fear at baseline was a significant predictor of duration of complaints. However, when analyses were repeated with the inclusion of several somatic variables, the predictive value of TSK was no longer significant.

Another prospective cohort study by Sterling et al. could neither establish the predictive value of pain-related fear for the persistence of acute complaints. Although a first analyses of their data suggested that TSK measured at baseline was elevated for those individuals who were not recovered at 6 months, their more definite analyses of the same data showed that TSK was not predictive (Sterling et al., 2003; 2005).

Other studies investigated the role of pain catastrophizing in relation to pain and disability following motor vehicle accidents. In one cross-sectional study pain catastrophizing was associated with higher levels of perceived pain intensity and perceived disability in patients with chronic whiplash syndrome, independent of levels of depression and anxiety (Sullivan et al., 1998). So far, no study has yet considered pain catastrophizing as a predictor for the transition from acute whiplash injury to chronic whiplash syndrome. There is, however a recent study providing indirect evidence for a role of pain catastrophizing in the development of chronic whiplash syndrome. Caroll et al. (2006) investigated the relationship between active and passive coping and recovery in patients with acute whiplash injury. The results showed that a passive coping style was associated with less recovery at 12 months follow-up. Looking at the specific items that constituted the measure of passive coping, it is notable that these show considerable overlap with items assessing pain catastrophizing (Caroll et al., 2006). 
Indirect evidence for the validity of the FA model also comes from clinical studies. Cognitive-behavioural interventions that promote physical activity have been quite effective in decreasing pain and disability in patients with chronic whiplash syndrome and were found to lead to faster return to work in patients with acute whiplash complaints (Vendrig et al., 2000; Söderlund and Lindberg, 2001). Moreover, we recently demonstrated that in patients with chronic whiplash syndrome who were selected on the basis of the presence of high levels of pain-related fear, an exposure in vivo treatment led to major improvements in disability and pain (De Jong et al, submitted). In an exposure in vivo treatment the patient is gradually exposed to feared movements or activities. The patient learns that after performing the feared activity, the negative consequences such as increases in pain or re-injury fail to occur or will be less than expected. Exposure in vivo treatment was found to be very effective in reducing pain and disability in chronic back pain patients with high levels of pain-related fear (Vlaeyen et al., 2002) and our first small-scale study in patients with chronic whiplash syndrome revealed that this treatment is equally effective for these patients. Thus, the clinical evidence, though quite preliminary, suggests that reducing pain-related fear and pain catastrophizing results in improvements. This indirectly supports the idea that fear of pain is an important mechanism maintaining pain and disability.

\section{CONCLUSION AND IMPLICATIONS}

Although the evidence for the prognostic role of pain catastrophizing and painrelated fear is limited and not always consistent, we conclude that the FA-model is an interesting model that may bear fruit in future research initiatives. To substantiate whether indeed fear-avoidance beliefs are predictive of the prognosis of complaints after acute whiplash injury, additional longitudinal research is needed. This research should make multiple assessments in time of relevant predictor, outcome and mediating variables as this will provide information about the temporal precedence of changes in predictor and outcome variables and on the potential mediators of the association between predictor and outcome. For instance, it could be examined whether high levels of catastrophizing shortly after sustaining a whiplash trauma would lead to more complaints at final follow-up through an increase (or lack of decrease) of pain-related fear during the intermediate assessment period. In addition, the inclusion of a comprehensive set of predictor variables from both the fearavoidance model as well as from competing models would create the possibility to compare the predictive utility of the variables from these alternative models. An example of a competing model would be the post-traumatic stress model. High comorbidity of chronic whiplash syndrome and complaints of Post-traumatic Stress 
Disorder (PTSD) have been reported. Although PTSD symptoms tend to be elevated in patients with various chronic pain conditions, this seems to be especially the case in patients with chronic pain after a motor vehicle accident (Mayou, 1992; Ursano et al., 1999). Asmundson et al. (2002) have argued that the high comorbidity of chronic pain and PTSD can be traced back to a shared vulnerability, namely a high level of anxiety sensitivity (i.e. the fear of anxiety related sensations). Furthermore, because of high symptom overlap between chronic pain and PTSD and the traumatic origin of complaints in this specific population initial levels of post-traumatic stress may have additional or better predictive power in comparison to fear-avoidance variables. Indeed, Sterling et al. (2005) found that elevated scores on the Impact of Event Scale (IES) in patients with acute whiplash injury was a better predictor of complaints at follow-up than pain-related fear. Thus, the inclusion of other potential predictors such as anxiety sensitivity and acute traumatic stress symptoms in future research is warranted.

Finally, future research should include multiple outcome measures. Patients after an acute whiplash injury are not only more prone to develop high levels of pain and disability, but they are also at risk to develop mood disorders (Sullivan et al., 2002), cognitive complaints (Bosma and Kessels, 2002), and as discussed above, posttraumatic stress disorder. Different predictors may emerge for these different outcome variables.

We conclude that the FA-model may offer a novel framework to explain the transition from acute whiplash injury to chronic whiplash syndrome. The FA-model may give direction for future research. This research should focus on comprehensive assessment of the various concepts in the FA-model as well as of concepts related to alternative models, and multiple outcome measures should be included. More information on the factors of influence on the transition form acute to chronic neck pain after a motor vehicle accident may provide tools for screening for patients at risk in the acute stage and enhance the development of treatment strategies for patients with both acute and chronic pain. Finally, the model is flexible in the sense that additional factors, specific for this patient population may be added and be tested for their shared vulnerability and mutual maintenance. 


\section{REFERENCES}

Asmundson GJG, Coons MJ, Taylor S, Katz J. PTSD and the Experience of Pain: Research and Clinical Implicatinos of Shared Vulnerability and Mutual Maintenance Models. Canadian Journal of Psychiatry 2002;47(10):930-937.

Berglund A, Alfredsson L, Cassidy JD, Jensen I, Nygren Å. The association between exposure to a rearend collision and future neck or shoulder pain: a cohort study. Journal of Clinical Epidemiology 2000;53:1089-1094.

Boersma K, Linton SJ. Expectancy, fear and pain, in the prediction of chronic pain and disability: A prospective analysis. European Journal of Pain 2006;10(6):551-557.

Bosma FK, Kessels RPC. Cognitive impairments, Psychological Dysfunction and Coping Styles in Patients with Chronic Whiplash Syndrome. Neuropsychiatry, Neuropsychology and Behavioural Neurology 2002;15(1):56-65.

Buitenhuis J, Jaspers JPC, Vaclav F. Can Kinesiophobia Predict the Duration of Neck Symptoms in Acute whiplash? The Clinical Journal of Pain 2006;22(3):272-277.

Caroll LJ, Cassidy JD, Côté P. The role of pain coping strategies in prognosis after whiplash injury: Passive coping predicts slowed recovery. Pain 2006;124:18-26.

Côté P, Cassidy JD, Carroll L, Frank JW, Bombardier C. A systematic review of the prognosis of acute whiplash and a new conceptual framework to synthesize the literature. Spine 2001;26(19):E445E458.

George SZ, Fritz JM, Erhard RE. A comparison of fear-avoidance beliefs in patients with lumbar spine pain and cervical spine pain. Spine 2001;26(19):2139-2145.

Hartling L, Brison RJ, Ardern C, Pickett W. Prognostic value of the Quebec Classification of WhiplashAssociated Disorders. Spine 2001;26(1):36-41.

Linton SJ. Do psychological factors increase the risk for back pain in the general population in both a cross-sectional and prospective analysis? European Journal of Pain 2005;9(4):355-361.

Mayou R. Psychiatric aspects of road traffic accidents. International review of Psychiatry 1992;4:45-54.

Nederhand MJ, Hermens HJ, Ijzerman MJ, Groothuis KGM, Turk DC. The effect of fear of movement on muscle activation in posttraumatic neck pain disability. The Clinical Journal of Pain 2006;22(6):519525 .

Nederhand MJ, Ijzerman MJ, Hermens H, Zilvold G. Predictive value of fear avoidance in developing chronic neck pain disability: consequences for clinical decision making. Archives of Physical Medicine and Rehabilitation 2004;85(3):496-501.

Olsson I, Bunketorp O, Carlsson SG, STyf J. Prediction of Outcome in Whiplash-Associated Disorders Using West Haven-Yale Multidimensional Pain Inventory. The Clinical Journal of Pain 2002;18:238244.

Rodriquez AA, Barr KP, Burns SP. Whiplash: pathophysiology, diagnosis, treatment, and prognosis. Muscle \& Nerve 2004;29:768-781.

Ronnen HR, de Korte PJ, Brink PRG, van der Bijl HJ, Tonino AJ, Franke CL. Acute whiplash injury: is there a role for MR Imaging? A prospective study of 100 patients. Radiology 1996;201:93-96.

Scholten-Peeters GGM, Verhagen AP, Bekkering GE, van der Wint DAWM, Barnsley L, Oostendorp RAB, Hendriks EJM. Prognostic factors of whiplash-associated disorders: a systematic review of prospective cohort studies. Pain 2003;104:303-322.

Severeijns R, Vlaeyen JWS, Van den Hout MA, Picavet HSJ. Pain Catastrophizing and consequences of musculoskeletal pain: A prospective study in the Dutch community. The Journal of Pain 2005;6(2):125-132. 
Söderlund A, Lindberg P. An integrated pyhsiotherapy/cognitive behavioral approach to the analysis and treatment of chronic Whiplash Associated Disorders, WAD. Disability and rehabilitation 2001;23(10):436-447.

Spitzer WO, Skovron ML, Salmi LR, Cassidy JD, Duranceau J, Suissa S, Zeiss E. Scientific Monograph of the Quebec Task Force on Whiplash-Associated Disorders: Redefining "Whiplash" and its management. Spine 1995;20(8 suppl.):1S-73S.

Sterling M, Jull G, Vicenzino B, Kenardy J, Darnell R. Physical and psychological factors predict outcome following whiplash injury. Pain 2005;114:141-148.

Sterling M, Kenardy J, Jull G, Vicenzino B. The development of psychological changes following whiplash injury. Pain 2003;106:481-489.

Sterner Y, Toolanen G, Gerdle B, Hildingson C. The Incidence of Whiplash Trauma and the Effects of Different Factors on Recovery. Journal of Spinal Disorders \& Techniques 2003;16(2):195-199.

Suissa S, Harder S, Veilleux M. The relation between initial symptoms and signs and the prognosis of whiplash. European Spine Journal 2001;10:44-49.

Sullivan MJL, Stanish W, Sullivan ME, Tripp D. Differential predictors of pain and disability in patients with whiplash injuries. Pain Research Management 2002;7(2):68-74.

Sullivan MJL, Stanish W, Waite H, Sullivan M, Tripp DA. Catastrophizing, pain and disability in patients with soft-tissue injuries. Pain 1998;77:253-260.

Ursano RJ, Fullerton CS, Epstein RS, Crowley B, Kao T-C, Vance K, Craig KJ, Dougall AL, Baum A. Acute and chronic posttraumatic stress disorder in Motor Vehicle Accident Victims. The American Journal of Psychiatry 1999;156:589-595.

Vendrig AA, van Akkerveeken PF, McWhorter KR. Results of a multimodal treatment program for patients with chronic symptoms after a whiplash injury of the neck. Spine 2000;25(2):238-244.

Vlaeyen JWS, de Jong J, Geilen M, Heuts PHTG, van Breukelen G. The treatment of fear of movement/(re)injury in chronic low back pain - Further evidence on the effectiveness of exposure in vivo. The Clinical Journal of Pain 2002;18(4):251-261.

Wilmink JT, Patijn J. MR imaging of alar ligament in whiplash-associated disorders: an observer study. Neuroradiology 2001;43:859-863. 

Chapter 3

\section{Active and Passive Range of Motion in Acute Whiplash Injury}

Karoline Vangronsveld, Ivan Huijnen, Madelon Peters, Johan Vlaeyen, Mariëlle Goossens, Jaap Patijn 


\begin{abstract}
Previous studies found that patients with acute neck pain after a motor vehicle accident (MVA) have a restricted range of motion (ROM). It is unknown whether this restricted ROM in patients with acute whiplash injury is a symptom of somatic origin or a symptom of submaximal performance caused by pain or fear for a new pain experience. In this study we assessed Active and Passive ROM in 100 MVA victims selected from Emergency Care Units and the Traffic Police and 46 healthy controls. Passive ROM may be considered as a reflection of a possible underlying somatic injury, while Active ROM may be influenced by both underlying injury and avoidance of movement induced by pain or pain-related fear. Moreover, pain-related fear and avoidance could lead to larger differences between Active and Passive ROM. We hypothesized that MVA victims would differ from controls on both Active and Passive ROM and that especially the difference between Active and Passive ROM would correlate with fear of movement and pain catastrophizing. The results showed that symptomatic MVA victims differed from asymptomatic MVA victims and from controls both on Active and Passive ROM. Moreover, not only Active but also Passive ROM correlated with pain, fear of movement and pain catastrophizing. The difference between Active and Passive ROM was not related to pain, fear of movement or pain catastrophizing except for forward flexion. It is concluded that restricted ROM in symptomatic MVA victims may be due to the interplay of somatic and psychological variables.
\end{abstract}




\section{INTRODUCTION}

Research has shown that patients with acute neck pain after a motor vehicle accident (MVA) show a restricted range of motion (ROM) compared to controls with no neck pain (Kasch et al., 2001b). This restricted ROM is related to higher levels of pain and higher levels of perceived disability (Kasch et al., 2001a; Kasch et al., 2001b; Sterling et al., 2003). So far, there is no conclusive evidence for a biomedical explanation for this restricted ROM. Review of the literature reveals that physical serious injuries in patients with whiplash injury are rare and can not be linked to decreased ROM (Rodriquez et al., 2004). Some studies suggested that an isolated lesion in the alar ligament may be responsible for hyper-rotation of the neck, but MRI-findings and rotatory computed tomography could not support this theory (Patijn et al., 2001; Wilmink and Patijn 2001). Klein et al. (2001) suggested that chronic whiplash patients were either unable or unwilling to move the cervical spine into regions that required high muscle activity because they were restricted by pain or fear of pain. Indeed, Sterling et al. found an association between fear of movement and Active ROM but the effect sizes were low (Sterling et al., 2003; Sterling et al., 2004).

In research of the cervical spine, a difference is made between Active and Passive ROM. Active ROM is the measurement of ROM in which the patient performs the movements on his or her own. This gives the patient the opportunity to decide how far he or she is willing to move the neck. Passive ROM is the measurement of ROM in which the movements are guided by pressure by a researcher, physiotherapist or medical doctor. While performing Passive ROM, the examiner will try to assess the actual limits of ROM. A Passive ROM test will result in a larger motion (Dvorak et al., 1992). Both active and passive movements are influenced by age and gender (Dvorak et al., 1992). So far, most studies only assessed Active ROM. By only analyzing Active ROM, one is dependent on the collaboration of the patient who may perform submaximally in order to escape from actual pain or to avoid increases in pain or injury out of fear (Klein et al., 2001). By measuring Passive ROM one can retrieve the actual limits of the spine and assess a more objective ROM. Moreover, the profit margin that can be calculated as the difference between the Passive and the Active ROM could be a measure of avoidance behaviour. We speculated that especially this difference measure would be related to actual pain or pain-related fear or pain catastrophizing.

In the present study, we compared symptomatic and asymptomatic MVA victims and controls with no neck pain on their Active and Passive ROM. It was expected that only symptomatic MVA victims would show a restriction on Active ROM and possibly also on Passive ROM. Moreover we expected that the profit margin from Active to Passive ROM would be related to fear of movement and pain catastrophizing. 


\section{MATERIALS AND METHOD}

\section{Participants and Setting}

We included 100 patients referred to the Emergency Care Units of five different hospitals and the Dutch Traffic Police (Zuid-Limburg) who were contacted by telephone with an invitation to participate in this study. Inclusion criteria for this study were that patients had to be between the age of 18 and 65 and they were involved in a car accident. The exclusion criteria were (1) having a head injury, (2) experiencing unconsciousness after the accident, (3) having fractures or dislocations of a vertebra, diagnosed by the medical doctor at the Emergency Care Department by means of X-ray or CT-scan and (4) being pregnant. Furthermore patients were excluded if they didn't speak Dutch fluently. All selected patients came to the University Hospital Maastricht for a measurement of the ROM of their neck. All patients gave informed consent and were free to terminate the experiment at any time. In addition to the patient sample, 50 healthy control subjects with no current neck or shoulder pain were recruited between the age of 18 and 65 . There were 10 subjects per age group (18-25, 26-35, 36-45, 46-55 and 56-65). The healthy control subjects were recruited through leaflets and personal contact of one of the authors. In order to match the three groups on age and gender we removed the 4 oldest participants ( 2 men, 2 women) in the control group, leaving 46 participants for the present study. Numbers per age group were comparable between the three groups.

\section{Questionnaires}

Disability: The Dutch version of the Neck Disability Index (NDI) consists of 10 items concerning limitations in functional activities and symptoms. The 10 items are scored 0 (no limitations/symptoms) to 5 (major limitations/symptoms) and summed to yield a total score. The NDI is a valid and reliable instrument, sensitive to measure changes within a population of neck pain patients (Vernon, 1997; Helmerson Ackelman and Lindgren, 2002).

Pain: Current pain was assessed using an 11-point Likert Scale anchored with two labels "no pain at all" on the left side and with "worst pain ever" on the right side.

Pain Catastrophizing: Participants completed the Dutch version of the Pain Catastrophizing Scale (PCS: Sullivan et al., 1995). Respondents are asked to reflect on past painful experiences and to indicate the degree to which they experienced each of the 13 thoughts or feelings during pain on a five-point scale from 0 (not at all) to 4 (all the time). The Dutch version of the PCS has been shown to be valid and reliable (Van Damme et al., 2002). 
Fear of movement/(re)injury: The Dutch version of the Tampa Scale for Kinesiophobia (TSK: Miller et al., 1991) was used to measure fear of movement/(re)injury. The 17 items are scored on a four point scale from "I strongly disagree" (1) to "I strongly agree" (4). The scale has a good internal consistency and a good test retest reliability (Swinkels-Meewisse et al., 2003; Roelofs et al., 2004).

\section{Range of Motion}

The Active and Passive ROM was measured by a 3Space InsideTrak HP system (Polhemus Navigational Division, Kaiser Aerospace, Vermont, USA). The measurement of ROM was performed by a qualified physiotherapist. An electromagnetic receiver and transducer measured the range of rotations and translations in respectively the X, Y and Z-axes and the sagittal, frontal and transversal planes.

The subject was seated on a chair, without back support, in a relaxed upright position. The subject was looking straightforward to a marked sign on the wall. The distance between subject and the wall was 2 metres. The distance of the eyes of the subject to the floor was measured and the height of the marked sign on the wall was adapted to this distance. The receiver was placed in a pocket fixed on a rubber swimming-cap on the head. The receiver was located in a frontal plane of the head at a point $\mathrm{X}$ halfway the distance between both external acoustic pores (centre of the movement). The transducer was placed above the patient and received the information about the movement of the receiver with reference to the transducer. A light spot was projected from the transducer perpendicular on point $\mathrm{X}$ halfway the distance between both external acoustic pores. The transversal plane of the head was placed parallel to the horizontal plane of the transducer, by placing a spirit level on the receiver on the subject.

\section{Procedure}

The experiment was approved by the Medical Ethical Committee of the University Hospital Maastricht. MVA victims and controls were contacted by the researcher to inform them about the study and to ask for their participation. If they agreed to participate they were then scheduled for an appointment at the University Hospital for a measurement of their ROM within a month after the accident.

The measurement of ROM was performed by a qualified physiotherapist. At the beginning of the measurement, the physiotherapist informed MVA victims and controls verbally and in writing. After signing the informed consent form, the MVA victims and controls were placed into position for the measurement of both active and passive cervical motion. The motions were restricted to the cervical spine by manual fixation by the physical therapist of the spinal process of Th1. Each study 
movement was preceded by replacing the participant in the correct position, defined by the measurement conditions mentioned above. The sequence of the different movements was fixed. The following movements were performed five times (1) rotation (left and right), (2) cervical forward flexion, and (3) cervical backward flexion. First the subject performed the Active ROM. Then, the physical therapist applied pressure to the head in order to assess Passive ROM. After measuring the ROM MVA victims were seated at a desk and completed the questionnaires. Controls did not fill in the questionnaires.

\section{Statistical analyses}

Analyses were conducted with the Statistical Package for the Social Sciences version 13.0 (SPSS Inc., 444N. Wacker Drive, Chicago, IL, 60606, USA). When possible, missing value analyses were performed by the missing value analyses command in SPSS. We did not perform missing value analyses if patients did not fill in a complete questionnaire or if the missing data in one questionnaire was more than $10 \%$. We computed 4 different range of motion scores in our data set being (1) rotation left, (2) rotation right, (3) forward flexion, (4) backward flexion. All scores were computed for active movements and passive movement, giving a total of 8 range of motion scores. To obtain difference scores Active ROM was subtracted from Passive ROM. We used an ANOVA to compare the three groups on sociodemographic variables, questionnaires and ROM. Partial correlations (corrected for age) were used to investigate relationships between Active ROM and Passive ROM and pain, fear of movement and pain catastrophizing. Multiple regression analyses were used to investigate which variables significantly contributed to Active ROM. It was hypothesized that Active ROM would mainly be a feature of actual limits of ROM (Passive ROM) but pain and fear would have an additional influence. In model 1 we entered the passive measurement of the dependent variable. Next, we entered fear of movement as a predictor variable in the model (model 2). In model 3 current pain was entered as a predictive variable.

\section{RESULTS}

\section{Differences in ROM between symptomatic and asymptomatic MVA victims and controls}

MVA victims were divided into two groups based on their scores on the Neck Disability Index (NDI): a symptomatic (NDI $>4, \mathrm{~N}=83$ ) and an asymptomatic group (NDI 0-4, $\mathrm{N}=17$ ). Students' t-tests and Chi-Squares tests were used to investigate whether the symptomatic MVA victims, the asymptomatic MVA victims 
and controls differed in age and gender. Table 1 presents an overview. Symptomatic and asymptomatic MVA victims and controls were not significantly different with regards to age and gender. MVA victims in the symptomatic group show significantly higher scores on pain, pain-related fear, and pain catastrophizing.

Table 1 presents an overview of the ROM of symptomatic and asymptomatic MVA Victims, and the control group. Asymptomatic MVA victims do not significantly differ in either Active or Passive ROM for any of the movements from the control group. However, symptomatic MVA victims show significantly lower scores for ROM than asymptomatic MVA victims and controls for every active and passive movement. However, the groups do not differ with regards to the difference score (Passive minus Active ROM). Although for the backward flexion movement the symptomatic and asymptomatic are significantly different, both groups do not differ from the control group.

\section{Association between $R O M$ and pain, pain related fear and pain catastrophizing}

Based on the previous work by Dvorak et al., we calculated Partial Correlations, corrected for age, to investigate the relationship between Active and Passive ROM, pain related fear and pain catastrophizing for the total group of MVA victims (see table 2 and 3). Almost all ROM scores showed high intercorrelations. All rotation movements were highly interrelated (table 2). This was also the case for all flexion movements.

Fear of movement, pain catastrophizing and current pain significantly correlated with almost all Active and Passive ROM's, with a few exceptions. Active backward flexion and Passive forward flexion were not significantly correlated with fear of movement or pain catastrophizing. Passive backward flexion was not significantly correlated with fear of movement (see table 3).

It was hypothesized that large discrepancies between Active ROM and Passive ROM reflect fear of moving. Partial correlations between the difference scores of all four movements and fear of movement, pain catastrophizing and current pain for the total group of MVA victims showed that the difference scores for forward flexion was significantly correlated with fear of movement, pain catastrophizing and pain. However, none of the other difference scores were significantly related to fear of movement, pain catastrophizing or pain (see table 3 ). 


\section{CHAPTER 3}

Table 1 :Findings at baseline measurement: Frequencies (percentages) and Means (standard deviations) on the questionnaires and range of motion

\begin{tabular}{|c|c|c|c|c|c|}
\hline & $\begin{array}{c}\text { Symptomatic } \\
\mathrm{N}=83\end{array}$ & $\begin{array}{l}\text { Asymptomatic } \\
\qquad \mathrm{N}=17\end{array}$ & $\begin{array}{l}\text { Control } \\
\mathrm{N}=46\end{array}$ & $\mathrm{~T} / \mathrm{X}^{2} / \mathrm{F}$ & $\mathrm{P}$ (2-tailed) \\
\hline Age & $38.95(13.71)$ & $39.17(14.04)$ & $39.69(13.26)$ & 0.04 & .958 \\
\hline Gender ( $\%$ men $)$ & $30(36)$ & $10(59)$ & $23(50)$ & 4.24 & .120 \\
\hline Pain & $5.42(2.18)$ & $0.88(1.15)$ & - & -12.18 & $<.001$ \\
\hline Disability (NDI) & $19.47(8.31)$ & $2.00(1.37)$ & - & -17.99 & $<.001$ \\
\hline Pain-related fear (TSK) & $37.42(6.52)$ & $29.06(8.21)$ & - & -4.60 & $<.001$ \\
\hline Pain catastrophizing (PCS) & $15.21(11.05)$ & $7.76(8.33)$ & - & -2.62 & .010 \\
\hline Active rotation left & $59.23(14.99)$ & $69.45(6.61)^{\mathrm{a}}$ & $70.65(9.71)^{\mathrm{a}}$ & 13.55 & $<.001$ \\
\hline Active rotation right & $58.12(13.47)$ & $68.17(5.58)^{\mathrm{a}}$ & $70.29(9.31)^{\mathrm{a}}$ & 18.10 & $<.001$ \\
\hline Active forward flexion & $58.15(15.67)$ & $71.01(9.53)^{\mathrm{a}}$ & $68.53(8.60)^{\mathrm{a}}$ & 12.77 & $<.001$ \\
\hline Active backward flexion & $47.47(15.68)$ & $61.44(11.21)^{\mathrm{a}}$ & $62.57(11.98)^{\mathrm{a}}$ & 19.61 & $<.001$ \\
\hline Passive rotation left & $70.25(13.37)$ & $79.62(7.64)^{a}$ & $79.65(11.91)^{\mathrm{a}}$ & 10.28 & $<.001$ \\
\hline Passive rotation right & $72.52(12.14)$ & $81.67(8.00)^{\mathrm{a}}$ & $83.58(9.97)^{a}$ & 16.40 & $<.001$ \\
\hline Passive forward flexion & $65.47(16.10)$ & $76.56(8.31)^{\mathrm{a}}$ & $73.15(8.03)^{\mathrm{a}}$ & 7.91 & .001 \\
\hline Passive backward flexion & $53.02(15.73)$ & $61.53(12.81)^{\mathrm{a}}$ & $65.44(11.81)^{\mathrm{a}}$ & 11.76 & $<.001$ \\
\hline Difference score rotation left & $11.03(12.26)$ & $10.17(3.16)$ & $9.00(8.80)$ & 0.54 & .582 \\
\hline Difference score rotation right & $14.40(8.62)$ & $13.50(4.83)$ & $13.29(6.32)$ & 0.35 & .707 \\
\hline Difference score forward flexion & $7.32(8.42)$ & $5.55(6.78)$ & $4.62(5.97)$ & 1.98 & .141 \\
\hline Difference score backward flexion & $5.02(6.95)^{\mathrm{a}}$ & $0.09(5.96)^{\mathrm{b}}$ & $2.87(6.68)^{\mathrm{ab}}$ & 4.33 & .015 \\
\hline
\end{tabular}

Groups with the same superscript denote homogeneous subsets

Table 2: Partial correlations between active and passive range of motion, corrected for age for the total group of patients and for asymptomatic and symptomatic patients separately

Total Group

\begin{tabular}{lcccc}
\hline & Act-ROT-L & Act- ROT-R & Act-ForwFLEX & Act-BackFLEX \\
\hline Pas-ROT-L & $.672 * *$ & $.678^{* *}$ & $.264 * *$ & $.398 * *$ \\
Pas-ROT-R & $.536^{* *}$ & $.789 * *$ & $.280 * *$ & $.451 * *$ \\
Pas-ForwFLEX & .047 & .148 & $.860 * *$ & $.554 * *$ \\
P-BackFLEX & $.240^{*}$ & $.474 * *$ & $.600 * *$ & $.896 * *$ \\
\hline
\end{tabular}

* significant at the 0.05 level, ** significant at the 0.01 level, Act=Active range of motion, Pas = passive range of motion, $L=$ left, $R=$ right, $R O T=$ rotation, ForwFLEX = forward flexion, BackFLEX $=$ backward flexion 
Table 3: partial correlation matrix for range of motion with pain related fear and pain catastrophizing, corrected for age

\begin{tabular}{lccc}
\hline & \multicolumn{2}{c}{ Total group } & \\
\cline { 2 - 4 } & TSK & PCS & \multicolumn{2}{c}{ PAIN } \\
\hline Active Rotation left & $-.325 * *$ & $-.328 * *$ & $-.399 * *$ \\
Active Rotation right & $-.310 * *$ & $-.388 * *$ & $-.538 * *$ \\
Active Forward Flexion & $-.251 *$ & $-.221 *$ & $-.403 * *$ \\
Active Backward Flexion & -.183 & -.200 & $-.433 * *$ \\
Passive Rotation left & $-.296 * *$ & $-.402 * *$ & $-.432 * *$ \\
Passive Rotation right & $-.259 * *$ & $-.383 * *$ & $-.483 * *$ \\
Passive Forward Flexion & -.068 & -.004 & $-.292 * *$ \\
Passive Backward Flexion & -.176 & $-.210 *$ & $-.347 * *$ \\
Difference Score Rotation left & .122 & .022 & .013 \\
Difference Score Rotation right & .127 & .064 & .162 \\
Difference Score Forward Flexion & $.304 * *$ & $.395 * *$ & $.227 *$ \\
Difference Score Backward flexion & .105 & .076 & .197 \\
\hline$*$
\end{tabular}

* significant at the 0.05 level, ** significant at the 0.01 level, TSK = Tampa Scale of Kinesiophobia, PCS = Pain Catastrophizing Scale

\section{Regression analyses}

Blockwise multiple regression analyses were conducted to identify predictors for Active ROM. Table 4 presents an overview of the final models for each movement. For each active movement, passive movement was the most important predictor. Current pain intensity reached significance for Active rotation right and Active backward flexion. The negative Beta shows that with more pain, participants were less inclined to approach their actual limits of movement.

Table 4: regression analyses with Active Range of Motion as dependent variables and Passive Range of Motion, fear of movement and pain as predictor variables

\begin{tabular}{|c|c|c|c|c|}
\hline Final Model Active Rotation Left & $\mathrm{R}^{2}=.47$ & $\mathrm{p}=<.001$ & $\Delta \mathrm{F}=1.175$ & $\mathrm{p}=.281$ \\
\hline Passive Rotation Left & & $\beta=.595$ & & $<.001$ \\
\hline Fear of Movement & & $\beta=-.112$ & & 183 \\
\hline PAIN & & $\beta=-.097$ & & .281 \\
\hline Final Model Active Rotation Right & $\mathrm{R}^{2}=.67$ & $\mathrm{p}=<.001$ & $\Delta \mathrm{F}=6.227$ & $\mathrm{p}=.014$ \\
\hline Passive Rotation Right & & $\beta=.694$ & & $<.001$ \\
\hline Fear of Movement & & $\beta=-.050$ & & .449 \\
\hline PAIN & & $\beta=-.183$ & & .014 \\
\hline Final Model Active Forward Flexion & $\mathrm{R}^{2}=.79$ & $\mathrm{p}=<.001$ & $\Delta \mathrm{F}=2.907$ & $\mathrm{p}=.091$ \\
\hline Passive Forward Flexion & & $\beta=.824$ & & $<.001$ \\
\hline Fear of Movement & & $\beta=-.151$ & & .005 \\
\hline PAIN & & $\beta=-.095$ & & .091 \\
\hline Final Model Active Backward Flexion & $\mathrm{R}^{2}=.82$ & $\mathrm{p}=<.001$ & $\Delta \mathrm{F}=8.496$ & $\mathrm{p}=.004$ \\
\hline Passive Backward Flexion & & $\beta=.845$ & & $<.001$ \\
\hline Fear of Movement & & $\beta=.002$ & & .972 \\
\hline PAIN & & $\beta=-.149$ & & .004 \\
\hline
\end{tabular}


Fear of movement reached significance as a predictor for forward flexion. Thus more fearful patients are less inclined to fully execute a forward flexion movement than patients with less fear of movement. This coincides with the significant association between fear of movement and the difference score between Passive and Active ROM for forward flexion specifically.

Analyses were repeated with pain catastrophizing as a predictor instead of fear of movement. These analyses yielded similar results. Passive movements were the most important predictors. Pain was a significant predictor for active rotation right $(\beta=-.207, p=.005)$ and active backward flexion $(\beta=-.152, .004)$. Pain catastrophizing only reached significance for active forward flexion $(\beta=-.167, p=.002)$

\section{DISCUSSION}

To the best of our knowledge, this study is the first to establish that symptomatic MVA victims not only show a decreased Active ROM, but also a decreased Passive ROM. Moreover, this symptomatic group is not only significantly different as compared to the asymptomatic MVA victims, but also from controls. The result that symptomatic MVA victims have lower scores on both active and passive movements when compared to asymptomatic MVA victims and controls indicates that there might be somatic factors involved. However, our method of measuring ROM cannot give additional information on possible lesions such as injury to the neck musculature or spine. Still, the significant difference in ROM between the three groups suggests that our method for measuring ROM enables us to discriminate between symptomatic and asymptomatic MVA victims in the acute stage of whiplash injury.

Our hypothesis that there is a group of acute patients performing submaximally on Active ROM because of fear of movement could not be confirmed. First of all, the three groups did not differ in their difference scores between Passive and Active ROM. Second, neither pain catastrophizing, nor fear of movement were related to the difference scores between Passive and Active ROM except for the forward flexion movement. The regression analysis confirms that for forward flexion there was a significant contribution of fear of movement. Although not consistent with the results from other movements, the forward flexion results show that for some specific movements, submaximal performance guided by fear may be the case. However, based on our clinical observations, we would have expected to find this for the backward flexion movement since participants reported this to be the most painful and threatening movement, rather than forward flexion. 
Finally, in this study we identified significant associations between fear of movement, pain catastrophizing and restricted ROM. Fear of movement and pain catastrophizing were related to both Active ROM and Passive ROM. This was also the case for current pain intensity. Despite the cross-sectional nature of our study, we were able to show that pain-related fear and pain catastrophizing were associated with the avoidance of active movements in MVA victims. These results lend support for the fear-avoidance model in the acute stage of whiplash injury. The Fearavoidance model shows two opposite behavioural responses to pain or injury, being confrontation or avoidance. Confronting pain or painful situation will most likely lead to a fast recovery, as the individual experiences that the feared consequences are overestimated, whereas avoiding pain of painful situations because of pain catastrophizing and fear of movement will maintain the fear, which is associated with more pain and disability (Vlaeyen et al., 1995a; Vlaeyen et al., 1995b). Unexpectedly and of interest, we found that this is also true for passive movements. We did not expect to find strong differences with regards to Passive ROM. Nevertheless, there is a relationship between fear and ROM, being that subjects showing the most functional limitations (low Passive ROM) show high levels of fear. It is yet unclear whether fear of movement may contribute to actual functional limitations (e.g. by increasing muscle tension) or whether actual limitations give rise to enhanced levels of fear of movement, i.e. that in the acute stage of pain fear of movement is a reaction upon the experienced difficulties in daily live with regards to restricted ROM. Whether baseline levels of fear of movement, pain catastrophizing, pain or ROM can be predictive for the transition from acute whiplash injury to chronic whiplash syndrome needs to be investigated by means of prospective research. All variables will probably decline over time (Vangronsveld et al., Submitted), but similar to low back pain patients, MVA victims showing an increase or a lack of decrease in fear of movement may be at risk (Sieben et al., 2002). It is yet unknown whether the decreased ROM will resolve over time without being treated. It is likely that most patients will seek treatment in the acute stage of their injury in order to relieve pain and restricted ROM. We cannot say anything with certainty with regards to the natural recovery from decreased ROM.

In this study we measured ROM both actively and passively. Up until now, most studies only used Active ROM. This quality is also one of the limitations of the study. The procedure we used for measuring ROM is a new method. Although this method is very much standardized and is reliable, some movements still lack reliability, most importantly being the forward flexion movement (Huijnen et al., In Preparation). Further research on our method could increase the reliability of the measurement procedure.

To our knowledge, this is the first study that examines the relationship between restricted ROM, fear of movement and pain catastrophizing. Symptomatic MVA 
victims do not only differ from asymptomatic MVA victims and controls on Active ROM, but also on Passive ROM. The relationships between fear of movement, pain catastrophizing and pain and both active and passive range of motion suggest that there may be interplay between fear and somatic factors.

\section{Acknowledgments}

This research was supported by grant 940-31-071 from the Dutch Organisation for Scientific Research. The authors are grateful to the Emergency Care Units of Ziekenhuis Oost Limburg Genk, Salvator Hasselt, Academisch Ziekenhuis Maastricht, Atrium Heerlen and Maaslandziekenhuis Sittard and the Dutch Traffic Police (ZuidLimburg) for referring patients to our study. 


\section{REFERENCES}

Dvorak J, Antinnes JA, Panjabi M, Loutalot D, Bonomo M. Age and Gender related normal motion of the Cervical Spine. Spine 1992;17(10S):393-398.

Helmerson Ackelman B, Lindgren U. Validity and reliability of a modified version of the neck disability index. Journal of Rehabilitation Medicine 2002;34:284-287.

Huijnen I, Vangronsveld K, Kingma H, Patijn J. Passive versus Active Range of Motion: a valid outcome measurement? In Preparation.

Kasch H, Bach FW, Jensen TS. Handicap after acute whiplash injury. A 1-year prospective study of risk factors. Neurology 2001a;56:1637-1643.

Kasch H, Stengaard-Pedersen K, Arendt-Nielsen L, Jensen TS. Headache, neck pain and neck mobility after acute whiplash injury. A prospective study. Spine 2001b;26(11):1246-1251.

Klein GN, Mannion AF, Panjabi MM, Dvorak J. Trapped in the neutral zone: another symptom of whiplash-associated disorder? European Spine Journal 2001;10:141-148.

Miller RP, Kori SH, Todd DD. The Tampa Scale

Patijn J, Wilmink J, ter Linden FHJ, Kingma H. CT study of craniovertebral rotation in whiplash injury. European Spine Journal 2001;10:38-43.

Rodriquez AA, Barr KP, Burns SP. Whiplash: pathophysiology, diagnosis, treatment, and prognosis. Muscle \& Nerve 2004;29:768-781.

Roelofs J, Goubert L, Peters ML, Vlaeyen J, Crombez G. The Tampa Scale for Kinesiophobia: further examination of psychometric properties in patients with chronic low back pain and fibromyalgia. European Journal of Pain 2004;8(5):495-502.

Sieben JM, Vlaeyen JWS, Tuerlinckx S, Portegijs PJM. Pain-related fear in acute low back pain: the first two weeks of a new episode. European Journal of Pain 2002;6:229-237.

Sterling M, Jull G, Vicenzino B, Kenardy J. Characterization of Acute Whiplas-Associated Disorders. Spine 2004;29(2):182-188.

Sterling M, Jull G, Vicenzino B, Kenardy J, Darnell R. Development of motor system dysfunction following whiplash injury. Pain 2003;103:65-73.

Sullivan MJL, Bishop SR, Pivik J. The Pain Catastrophizing Scale: Development and validation. Psychological Assessment 1995;7(4):524-532.

Swinkels-Meewisse EJCM, Swinkels RAHM, Verbeek ALM, Vlaeyen JWS, Oostendorp RAB. Psychometric properties of the Tampa Scale for Kinesiophobia and the fear-avoidance beliefs questionnaire in acute low back pain. Manual Therapy 2003;8(1):29-36.

Van Damme S, Crombez G, Eccleston C. Retarded disengagement from pain cues: the effects of pain catastrophizing and pain expectancy. Pain 2002;100:111-118.

Vangronsveld KL, Peters ML, Goossens M, Vlaeyen J. The influence of fear of movement and pain catastrophizing on daily pain and disability in individuals with acute whiplash complaints: a daily diary study. Submitted.

Vernon H. Correlations among ratings of pain, disability and impairment in chronic whiplash-associated disorders. Pain Research Management 1997;2(4):207-213.

Vlaeyen JWS, Kole-Snijders AMJ, Boeren RGB, van Eek H. Fear of movement/(re)injury in chronic low back pain and its relation to behavioral performance. Pain 1995a;62:363-372.

Vlaeyen JWS, Kole-Snijders AMJ, Rotteveel AM, Ruesink R, Heuts PHTG. The role of fear of movement/(re)injury in pain disability. Journal of Occupational Rehabilitation 1995b;5(4):235-252.

Wilmink JT, Patijn J. MR imaging of alar ligament in whiplash-associated disorders: an observer study. Neuroradiology 2001;43:859-863. 



\section{Chapter 4}

\section{The influence of fear of movement and pain catastrophizing on daily pain and disability in individuals with acute whiplash injury: a daily diary study}

Karoline Vangronsveld, Madelon Peters, Mariëlle Goossens, Johan Vlaeyen, 


\begin{abstract}
Previous research supports the fear-avoidance model in explaining the transition form acute to chronic non-specific musculoskeletal pain. However, there is still little knowledge on when this vicious circle of pain, disability, pain catastrophizing and fear of movement starts. We performed a daily diary study in 60 patients with acute whiplash injury. Pain, disability, pain catastrophizing and fear of movement were measured at a daily basis with paper diaries for 21 consecutive days. Most participants showed a decline in pain and disability from day 1 to day 21 and this was paralleled by a decline in fear of movement and pain catastrophizing. Multilevel analyses showed that both between and within persons, high levels of pain catastrophizing and fear of movement are associated with more pain and disability. Moreover, fear of movement was also predictive of pain and disability on the following day. We also examined the reverse association, i.e. whether changes in pain predict changes in next day's fear of movement and pain catastrophizing. Although for fear of movement the model reached significance, the amount of explained variance was negligible. Thus, this study provides evidence that already in the early stages of whiplash related complaints, significant associations between fear of movement and pain intensity and disability occur, and that this association may be predictive of the persistence of pain.
\end{abstract}




\section{INTRODUCTION}

There is growing evidence for the fear-avoidance model as a predictive model for the transition from acute to chronic non-specific musculoskeletal pain. The fearavoidance model states that patients who have a tendency to catastrophize about their pain and avoid situations that they perceive as harmful, will have an increased risk for developing chronic pain and disability (Vlaeyen et al., 1995; Leeuw et al., 2007). The Fear-avoidance model has proven its validity in predicting chronic pain and disability in patients after an acute back pain episode (Buer and Linton, 2002; Boersma and Linton, 2006), and in predicting the inception of a new back pain episode in the general population (Linton, 2005; Severeijns et al., 2005). It has also successfully been applied to patients with osteoarthritis (Heuts et al., 2004), burn pain (Willebrand et al., 2006), and knee pain after surgery (Kvist et al., 2005). These results are limited in that they are mainly based on prospective cohort studies and cross-sectional studies that only contain one or a few assessments of all predictive and outcome variables by means of self-report measures. First, they are not able to capture the dynamic interrelationships between variables over time within the same individual. Between-persons associations do not necessarily generalize to associations within one individual at different moments in time. Second, they may generate recall bias, because patients may base their estimates on the most salient or most recent experiences (Stone et al., 1998). We therefore performed a diary study in which the variables pain catastrophizing and fear of movement were chosen as variables to predict daily pain and disability. Both variables are derived from the Fear-Avoidance model. We hypothesized that high levels of pain catastrophizing and fear of movement are associated with elevated levels of pain and disability both within and between individuals. Previous studies have already found evidence for the within person associations between pain related fear and catastrophizing on the one hand and pain intensity and disability on the other (Grant et al., 2002; Keefe et al., 2004; Roelofs et al., 2004b; Turner et al., 2004; Sorbi et al., 2006a; b). This means that within an individual patient, at times when he or she experience more fear of movement and has elevated levels of pain catastrophizing, he or she will also experience more pain and more disability. A number of studies have found concurrent associations between these variables, but failed to support any causal relationships. Researchers that have investigated the predictive value of pain catastrophizing or fear of movement for pain and disability at the subsequent time measurement have not found consistent results. Sorbi et al. (2006b) did not find evidence for pain catastrophizing or fear of movement as a predictor of pain on the next assessment time. Roelofs et al. (2004b) found evidence for fear of movement on the previous time measurement as a predictor for pain experience the next time. However, in their analyses pain measured at the previous time measurement was not entered into the 
model as a control variable, and therefore it cannot be ruled out that the predictive effect was due to serial autocorrelation. The only study so far that did correct for serial autocorrelation, did not find evidence for a predictive association between pain catastrophizing and pain intensity (Turner et al., 2004). There was no clear trend for increased pain either to precede or follow increased catastrophizing. The present study examines concurrent as well as time-lagged associations between pain catastrophizing and fear of movement on the one hand and pain intensity and disability on the other, controlling for serial autocorrelation.

Another important feature of the present study is that it focuses on the influence of fear and movement and pain catastrophizing on pain and disability in patients with acute pain complaints. Most diary studies so far have been conducted in patients with chronic pain, when cognitive and affective responses to pain may have become relatively stable and little variation in the variables of interest may be present. When pain complaints are of recent onset changes in pain intensity, disability, catastrophizing and fear of movement are more likely to occur, increasing the possibility of finding causal relationships between these variables. Moreover, research in patients with acute pain will provide more information on the stability of pain catastrophizing and fear of movement in this stage. It is known from studies in chronic pain patients that both concepts are fairly stable (Sullivan et al., 1995; SwinkelsMeewisse et al., 2003; Turner et al., 2004). However, research by Sieben et al. (2002) has shown that changes can occur in levels of fear of movement in the acute stage of low back pain. Therefore, the present study included patients with acute whiplash complaints after a motor vehicle accident. This population is particularly suited to investigate within-person associations between fear-avoidance beliefs, pain and disability, since the onset of pain is truly acute, starting at a clearly marked point in time, and patients often have no prior experience with this particular type of complaints.

The research questions of this study can be summarized as follows:

- Are pain catastrophizing and fear of movement associated with pain and disability on a daily basis in patients with acute whiplash injury?

- Are pain catastrophizing and fear of movement predictive of an increase of pain and disability the following day?

- Are pain catastrophizing and fear of movement stable during a three-week period of diary recording in patients with acute whiplash injury? 


\section{MATERIALS AND METHODS}

\section{Patients}

A total number of 60 acute whiplash patients were recruited for this study. Patients were referred by the emergency care units of five hospitals and by the traffic police of Limburg Zuid (the Netherlands). The patients were contacted by telephone and they were given the opportunity to enter the study after receiving full verbal and written information. Exclusion criteria were (a) age not between 18 and 65 years old, (b) motor vehicle accident longer than four weeks ago, (c) head injury, (d) fracture or dislocation of the neck (WAD IV), (e) being non-fluent in Dutch, and (f) pregnancy.

Due to drop out and missing data, 47 participants were finally included in the statistical analyses. The reasons for drop out were: lack of time, no more complaints, severe aggravation of complaints and no longer willing to participate in the study. Mean age of the participants was 36.5 years $(S D=13.37$, range 18-65). Baseline pain was measured by means of a 10 point Likert Scale at day 1 of the study. Mean score on this measure at the start of the diaries was $4.83(\mathrm{SD}=2.26$, range $0-8)$. Disability was also measured at day 1 by the Neck Disability Index. Mean score on the NDI at baseline was $14.51(\mathrm{SD}=9.40$, range $0-32)$, indicating that subjects on average were mildly disabled.

\section{Diary and baseline questionnaires}

\section{Baseline questionnaires:}

Disability: The Dutch version of the Neck Disability Index (NDI) consists of 10 items concerning limitations in functional activities and symptoms. The 10 items are scored 0 (no limitations/symptoms) to 5 (major limitations/symptoms) and summed to yield a total score. The NDI is a valid and reliable instrument, sensitive to measure changes within a population of neck pain patients (Vernon, 1997; Helmerson Ackelman and Lindgren, 2002).

Pain Catastrophizing: Participants completed the Dutch version of the Pain Catastrophizing Scale (PCS: Sullivan et al., 1995). Respondents are asked to reflect on past painful experiences and to indicate the degree to which they experienced each of the 13 thoughts or feelings during pain on a five point scale from 0 (not at all) to 4 (all the time). The Dutch version of the PCS has been shown to be valid and reliable (Van Damme et al., 2002).

Fear of movement/(re)injury: The Dutch version of the Tampa Scale for Kinesiophobia (TSK: Miller et al., 1991) was used to measure fear of movement/(re)injury. The 17 items are scored on a four-point scale from "I strongly disagree" (1) to "I 
strongly agree" (4). The Dutch version of the scale has a good internal consistency and a good test - retest reliability (Swinkels-Meewisse et al., 2003; Roelofs et al., 2004a).

\section{Diary}

End-of-day paper diaries were used to assess pain, perceived disability, fear of movement and catastrophizing on a daily basis for 21 consecutive days.

Pain: Pain was measured by two items, one item assessing current pain intensity and one item assessing average pain intensity during the day. Both items were scored by means of an 11-point Likert Scale.

Disability: Disability was measured by 9 items based on the Neck Disability Index (NDI). The pain item (item 1) of the NDI was omitted since the diary included a specific item for pain intensity. All items were scored on a 7-point Likert scale. Two items assessing complaints (headache and concentration problems) were anchored with " 0 " meaning 'no complaints at all today' and "6" meaning 'experienced severe complaints today". The other 5 items assessing functional limitation where anchored with " 0 " meaning 'not being able to perform this activity at all' and " 6 " meaning 'being able to perform this activity very well'.

Fear of movement: Two items reflecting fear of movement were formulated that were derived from the Tampa Scale of Kinesiophobia (TSK). The item "Today, moving was harmful for my body" reflected the 'Harm' subscale. The item "Today, I avoided activities that cause me pain" reflected the 'Avoidance' subscale.

Pain Catastrophizing: To measure Pain Catastrophizing, three items were derived from the Pain Catastrophizing Scale (PCS). Every item reflected one subscale. The item "Today, I kept thinking how much it hurts" represents the subscale "Rumination'. The item "Today, I was afraid that the pain would get worse" represented the subscale 'Magnification' and "Today, I felt as if the pain overwhelmed me" represented the subscale 'Helplessness'. All items were rated on a 7-point Likert scale labelled 'not at all' to 'very much'.

The items in the diary formulated for fear of movement and pain catastrophizing have previously been used in another diary study (Roelofs et al., 2004b). Several additional questions were also included in each diary. However, since these data are not considered below, a detailed presentation of these questions is omitted.

\section{Procedure}

Eligible study participants were contacted by telephone to make an appointment with the research assistant for a home visit, within one month after the motor vehicle accident. During this visit, the research assistant explained the diary and gave instructions on how to fill in the diary in a correct manner. Each subject was handed 
a set of 21 diaries and 1 set of baseline questionnaires. Participants were instructed to complete the diary each day at the end of the day, starting with the day at which the home visit took place. Baseline questionnaires also needed to be filled in at day 1. The set of 21 diaries also contained three pre-stamped envelopes. The patients were asked to return a set of 7 diaries each week, and the baseline questionnaires in week one by using the envelopes. All patients were informed about the purpose of the study by written and oral information and all signed an informed consent. Patients received 25 Euro for participation. The Ethics Committee of the Maastricht University Hospital approved the study protocol.

\section{Statistical analyses}

A composite score for disability was computed by summing up the 9 neck disability items in the diary. The five items measuring limitations in functional activities were first recoded so that a high score on this composite measure reflects high disability levels. For fear of movement and pain catastrophizing composite scores were computed by adding up the scores of the two items for fear of movement and three items of pain catastrophizing respectively. For pain we only used the item that measured average pain during the day.

The diary data were analysed with multilevel regression analyses. In multi-level modelling, the repeated observations (daily diaries) are called level 1 units. These observations are organized within level 2 units. In this study level 2 represents the individual. This implies that there is one between subjects level (participant level) and one within subject level (day level). The hypothesized relationships between the variables were first tested within the same day. For the second set of analyses the dataset was time-lagged in order to be able to make predictions for the next day. The independent variables measured at the previous day (day $\mathrm{x}$ ) were used as predictors for the dependent variables at the next day $($ day $x+1)$.

For each model, first the time trend of disability and pain were investigated over the 21 consecutive days. Next, pain catastrophizing and fear of movement were entered into the models as predictors of pain and disability. In the time-lagged model pain and disability at the previous day were also entered in addition to pain catastrophizing and fear of movement of the previous day to control for autocorrelation. All analyses were performed by MLWin version 1.1 and the significance of variances was determined by the likelihood ratio test. Beta values are standardized for presentation. Some participants needed to be removed from the dataset because of missing data in crucial variables. Therefore, the total $\mathrm{N}$ in the multilevel analyses may vary from 42 to 46 . 


\section{RESULTS}

\section{Descriptive analyses}

A total of 13 participants did not return any of the diaries (drop-out). The remaining 47 participants returned a total of 877 diaries (89\%), which amounts to an average of 18.7 diaries per person (range: $3-21$ ). Patients filled in the first diary on average within 17 days after their motor vehicle accident (range 2-50 days). Mean ratings averaged over 21 days and for day 1 and day 21 separately, for the outcome and predictive variables as measured by the diary items are presented in table 1.

Table 1: Mean scores overall of daily pain, disability, fear of movement and pain catastrophizing and for day 1 and day 21. Differences between day 1 and day 21 were tested with paired samples t-test.

\begin{tabular}{lcccrr}
\hline Variable & $\begin{array}{l}\text { Overall } \\
\text { Mean (SD) }\end{array}$ & $\begin{array}{l}\text { Day 1 } \\
\text { Mean (SD) }\end{array}$ & $\begin{array}{l}\text { Day 21 } \\
\text { Mean (SD) }\end{array}$ & T & Sign. \\
\hline Daily Pain & $3.64(2.54)$ & $4.43(2.15)$ & $2.73(2.34)$ & 5.18 & $<.001$ \\
Daily Disability & $15.86(11.49)$ & $19.50(11.46)$ & $13.35(11.11)$ & 3.96 & .004 \\
Daily Fear of Movement & $3.32(3.18)$ & $4.14(3.22)$ & $2.44(3.18)$ & 3.12 & .001 \\
Daily Pain Catastrophizing & $2.76(3.93)$ & $3.97(4.91)$ & $1.49(2.86)$ & 3.90 & $<.001$ \\
\hline
\end{tabular}

We calculated paired samples t-tests for the differences between ratings on day 1 and day 21 for each variable to investigate whether there was a significant change during the study period. Analyses indicated that overall, participants showed a decline in scores on all variables. They became less disabled and had less pain on day 21 , and they also had lower scores on pain catastrophizing and fear of movement on day 21 compared to day 1 . On day 1 up to $91.5 \%$ of patients reported to have pain and $85 \%$ of patients felt at least somewhat disabled (defined as a score of 9 or higher on the daily disability rating, indicating that participants scored on average 1 on each item). On day 21 , still $66.3 \%$ of patients reported to have had pain during the day and $62.5 \%$ still felt at least somewhat disabled.

\section{Multilevel regression analyses}

Concurrent associations between pain catastrophizing, fear of movement, disability and pain

Pain: The model with the intercept only (model 0) showed that most variance in the outcome variable was due to differences between participants $(78 \%)$. Thus, there were larger differences in pain intensity between individuals than there were differences from day to day within one individual. Model 1, in which "day" was entered in the analyses, revealed a time effect. The negative association between day and pain confirms that pain declined during the data collection period. In model 2, fear of movement and pain catastrophizing were entered. The significant effects for both 
independent variables indicate that on days that participants catastrophized more about their pain and had more fear of movement, they also experienced more pain (table 2). The decrease in random variance from the empty model (model 0) to the final model (model 2) demonstrated that the final model could explain $49 \%$ of the variance between participants and $46 \%$ of the variance between days. Comparing the final model with the previous model in which day was the single predictor demonstrated that pain catastrophizing and fear of movement together accounted for $44 \%$ and $34 \%$ of the variance between participants and days respectively.

Disability: The model with the intercept only (model 0) showed that most variance in the outcome variables was again due to differences between participants $(78 \%)$. Model 1, in which "day" was entered in the analyses, again revealed a time effect, indicating that disability declined during the 21 days of the study. In model 2, fear of movement and pain catastrophizing were entered. The significant effects for both independent variables indicated that on days that participants showed higher pain catastrophizing and fear of movement, they experienced more disability (table 2). When comparing model 2 to model 0 , model 2 could explain $43 \%$ of the variance between participants and $30 \%$ of the variance between days. Comparing model 2 to model 1 demonstrated that pain catastrophizing and fear of movement together explained $39 \%$ of the variance between participants and $23 \%$ of the variance between days.

Table 2: Multilevel Analyses of the same day associations between pain, disability, fear of movement and pain catastrophizing

\begin{tabular}{|c|c|c|c|c|c|c|}
\hline \multirow{3}{*}{ Pain } & \multicolumn{3}{|c|}{ Model 1} & \multicolumn{3}{|c|}{ Model 2} \\
\hline & \multicolumn{3}{|c|}{$-2 * \log (\mathrm{lh})=2513.910$} & \multicolumn{3}{|c|}{$-2 * \log (1 \mathrm{~h})=2189.37$} \\
\hline & Estimate & SE & Beta & Estimate & SE & Beta \\
\hline Intercept & 4.644 & 0.329 & & 2.985 & 0.262 & \\
\hline Day & -0.087 & 0.007 & -0.211 & -0.048 & 0.006 & -0.117 \\
\hline Fear of Movement & & & & 0.232 & 0.021 & 0.298 \\
\hline Pain Catastrophizing & & & & 0.125 & 0.015 & 0.194 \\
\hline \multirow{3}{*}{ Disability } & \multicolumn{3}{|c|}{ Model 1} & \multicolumn{3}{|c|}{ Model 2} \\
\hline & \multicolumn{3}{|c|}{$-2 * \log (\mathrm{lh})=5007.730$} & \multicolumn{3}{|c|}{$-2 * \log (\mathrm{lh})=4790.570$} \\
\hline & Estimate & SE & Beta & Estimate & SE & Beta \\
\hline Intercept & 20.450 & 1.595 & & 13.510 & 1.332 & \\
\hline Day & -0.289 & 0.033 & -0.152 & -0.123 & 0.031 & -0.065 \\
\hline Fear of Movement & & & & 0.908 & 0.109 & 0.252 \\
\hline Pain Catastrophizing & & & & 0.582 & 0.082 & 0.196 \\
\hline
\end{tabular}

All Beta's were significant at the 0.05 level 
Pain catastrophizing and fear of movement as predictors of next day's pain and disability

The analyses were repeated with pain catastrophizing and fear of movement as predictors of pain and disability on the subsequent day.

Pain: Day was entered in model 1 to control for the time trend and pain on the previous day was entered in model 2 to adjust for autocorrelation. Pain catastrophizing and fear of movement were entered in model 3. Since pain catastrophizing did not show a significant association with next day's pain this variable was removed from the final model. Fear of movement did significantly predict pain on the next day, even after controlling for previous day pain levels (table 3). It should be noted that the decrease in random variance on the day level (model 3 compared to model 2) was only modest, previous day's fear of movement explained $2 \%$ of additional variance in next day's pain intensity. The explained variance in next day's pain that was accounted for by the previous day's pain was $8 \%$ (model 2 compared to model 1).

Disability: Similar analyses were performed for predicting next day's disability. In model 1 the time effects, and in model 2 previous day's disability were entered. In model 3, fear of movement and pain catastrophizing were entered. Again, pain catastrophizing was not a significant predictor of next day's disability and was removed form the final model. Fear of movement was significantly related to next day's pain (see table 3), but the additional explained variance in next day's experience of disability was only $1 \%$. Previous day experience of disability was the strongest predictor of next day's experience of disability, explaining $10 \%$ of the variance on the day level (model 2 compared to model 1).

\section{Pain as a predictor of next day's pain catastrophizing and fear of movement}

To investigate whether the relationship between pain, pain catastrophizing and fear of movement was a bidirectional association, reversed time-lag analyses were performed. Pain measured at day $\mathrm{x}$ was used as a predictor for pain catastrophizing and fear of movement at day $\mathrm{x}+1$.

Fear of Movement: In the model with the intercept only most variance in the outcome variable was due to differences between participants $(66 \%)$. Thus, participants differed more from each other in fear of movement than that they differed within themselves in day to day levels of fear. Model 1, in which "day" was entered in the analyses showed a significant negative association between day and fear of movement, indicating that fear of movement decreased during the data collection period. 
Table 3: Multilevel Analyses for the prediction of next day's pain and disability

\begin{tabular}{|c|c|c|c|c|c|c|c|c|c|}
\hline \multirow{3}{*}{ Pain } & \multicolumn{3}{|c|}{ Model 1} & \multicolumn{3}{|c|}{ Model 2} & \multicolumn{3}{|c|}{ Model 3} \\
\hline & \multicolumn{3}{|c|}{$-2 * \log (\mathrm{lh})=2338.210$} & \multicolumn{3}{|c|}{$-2 * \log (\mathrm{lh})=2243.83$} & \multicolumn{3}{|c|}{$-2 * \log (\mathrm{lh})=2230.820$} \\
\hline & Estimate & SE & Beta & Estimate & SE & Beta & Estimate & SE & Beta \\
\hline Intercept & 4.345 & 0.347 & & 2.635 & 0.270 & & 2.619 & 0.274 & \\
\hline Day & -0.081 & 0.007 & -0.188 & -0.049 & 0.007 & -0.114 & -0.048 & 0.007 & -0.112 \\
\hline Pain & & & & 0.378 & 0.034 & 0.380 & 0.294 & 0.040 & 0.295 \\
\hline \multirow[t]{2}{*}{ Fear of Movement } & & & & & & & 0.087 & 0.024 & 0.112 \\
\hline & \multicolumn{3}{|c|}{ Model 1} & \multicolumn{3}{|c|}{ Model 2} & \multicolumn{3}{|c|}{ Model 3} \\
\hline \multirow[t]{2}{*}{ Disability } & \multicolumn{3}{|c|}{$-2 * \log (\mathrm{lh})=4728.96$} & \multicolumn{3}{|c|}{$-2 * \log (\mathrm{lh})=4605.01$} & \multicolumn{3}{|c|}{$-2 * \log (\mathrm{lh})=4598.42$} \\
\hline & Estimate & SE & Beta & Estimate & $\mathrm{SE}$ & Beta & Estimate & $\mathrm{SE}$ & Beta \\
\hline Intercept & 19.21 & 1.565 & & 10.66 & 1.137 & & 10.23 & 1.147 & \\
\hline Day & -0.270 & 0.036 & -0.136 & -0.148 & 0.035 & -0.075 & -0.134 & 0.036 & -0.068 \\
\hline Disability & & & & 0.430 & 0.033 & 0.433 & 0.386 & 0.037 & 0.389 \\
\hline Fear of Movement & & & & & & & 0.287 & 0.111 & 0.080 \\
\hline
\end{tabular}

All Beta's were significant at the 0.05 level

In model 2, fear of movement of the previous day was entered into the model as a control variable. This variable was the strongest predictor of next day's fear of movement, explaining $12 \%$ of the variance in daily fear of movement between days. Next, in model 3, pain on the previous day was entered as a predictive variable. Pain on the previous day was a significant predictor of fear of movement the next day (table 4). However, when comparing the final model to model 2 the decrease in random variance $(<1 \%)$ indicated that an almost negligible amount of variance in next day's fear of movement was explained.

Pain Catastrophizing: The same analysis was repeated with pain catastrophizing as the dependent variable. Again most variance was due to differences between participants (59\%). Model 1 showed a significant negative association between "day" and pain catastrophizing, indicating a decreasing trend during the data collection period. In model 2, pain catastrophizing during the previous day was entered as a predictor for pain catastrophizing the next day. This explained $9 \%$ of the variance of next day's pain catastrophizing. In model 3, pain was entered as predictor. There was no significant relationship between pain on the previous day and pain catastrophizing the next day (table 4). 
Table 4: Multilevel Analyses for the prediction of next day's fear of movement and pain catastrophizing

\begin{tabular}{|c|c|c|c|c|c|c|c|c|c|}
\hline \multirow{3}{*}{ Fear of Movement } & \multicolumn{3}{|c|}{ Model 1} & \multicolumn{3}{|c|}{ Model 2} & \multicolumn{3}{|c|}{ Model 3} \\
\hline & \multicolumn{3}{|c|}{$-2 * \log (\mathrm{lh})=3080.11$} & \multicolumn{3}{|c|}{$-2 * \log (\mathrm{lh})=2951.71$} & \multicolumn{3}{|c|}{$-2 * \log (\mathrm{lh})=2942.61$} \\
\hline & Estimate & SE & Beta & Estimate & SE & Beta & Estimate & SE & Beta \\
\hline Intercept & 4.363 & 0.416 & & 2.476 & 0.300 & & 1.869 & 0.337 & \\
\hline Day & -0.087 & 0.012 & -0.157 & -0.049 & 0.012 & -0.089 & -0.037 & 0.012 & -0.067 \\
\hline Fear of Movement & & & & 0.416 & 0.032 & 0.417 & 0.361 & 0.038 & 0.362 \\
\hline Pain & & & & & & & 0.189 & 0.061 & 0.148 \\
\hline \multirow{3}{*}{$\begin{array}{l}\text { Pain Catastrophi- } \\
\text { zing }\end{array}$} & \multicolumn{3}{|c|}{ Model 1} & \multicolumn{3}{|c|}{ Model 2} & \multicolumn{3}{|c|}{ Model 3} \\
\hline & \multicolumn{3}{|c|}{$-2 * \log (\mathrm{lh})=3494.31$} & \multicolumn{3}{|c|}{$-2 * \log (\mathrm{lh})=3383.40$} & \multicolumn{3}{|c|}{$-2 * \log (\mathrm{lh})=3382.21$} \\
\hline & Estimate & SE & Beta & Estimate & SE & Beta & Estimate & SE & Beta \\
\hline Intercept & 4.064 & 0.475 & & 2.314 & 0.336 & & 19.74 & 0.418 & \\
\hline Day & -0.130 & 0.016 & -0.201 & -0.075 & 0.016 & -0.116 & -0.069 & 0.016 & -0.107 \\
\hline $\begin{array}{l}\text { Pain Catastrophi- } \\
\text { zing }\end{array}$ & & & & 0.393 & 0.032 & 0.411 & 0.379 & 0.038 & 0.396 \\
\hline Pain & & & & & & & 0.090 & 0.077 & $0.060 *$ \\
\hline
\end{tabular}

All Beta's were significant at the 0.05 level, except for Beta "pain” predicting Pain Catastrophizing (*)

\section{DISCUSSION}

The purpose of this study was to examine the daily relationships between pain, disability, fear of movement and pain catastrophizing in patients with acute whiplash injury by means of end-of-day diaries. The multilevel analyses revealed that most variance in the predictor and outcome variables was due to differences between individuals, and that the day-to-day variance in fear of movement, catastrophizing, pain intensity and disability within an individual was much smaller. Nevertheless, there was sufficient variability within the individual to conduct meaningful analyses on the within person associations between these variables. The analyses also revealed a significant time trend: during the 21 day assessment period there was overall a significant decrease in pain intensity, disability, fear of movement and pain catastrophizing. The decrease in pain and disability during the acute stage of whiplash injury reflects the fact that this is usually a fairly benign condition characterized by rapid recovery and in which only a small proportion of individuals go on to develop chronic pain and disability. Nevertheless, the number of patients still reporting pain and disability during the three-week study period was more than expected.

Regarding our first research question, the multilevel regression analyses revealed that fear of movement and pain catastrophizing were both significantly associated with pain and disability when measured on the same day. There were significant associations both between persons and within persons. The highest proportions of explained variance were consistently found between persons, indicating that indi- 
vidual differences in average pain catastrophizing and average fear of movement are more strongly related to the level of pain and disability than the day-to-day fluctuations in pain catastrophizing and fear of movement within an individual. This is consistent with the idea that pain catastrophizing and fear of movement may reflect an automatic or habitual way of responding to pain that is characteristic of an individual, and that especially those patients with high levels of catastrophizing and fear may be at risk to go on to develop chronic pain and disability. Nevertheless, also within individuals, there was an association between the constructs of the fearavoidance model and the level of pain and disability. Thus daily changes in fear and catastrophizing concurred with daily changes in pain and disability.

Our second research question concerned the possible causal relationship between changes in fear of movement and pain catastrophizing on the one hand and changes in pain and disability on the other. Therefore, in the next set of analyses we examined whether fear of movement and pain catastrophizing predicted pain and disability on the next day. Only the within person analyses are relevant here. We corrected the time-lagged analyses for prior levels of the outcome variable since a time-lagged association between predictor and outcome may be a reflection of trends in the data, or autocorrelation. These time-lagged analyses showed that there was no significant association between previous day's pain catastrophizing and next day's pain or disability, when the analyses were controlled for serial autocorrelation. This parallels earlier finding by Turner et al. (2004) and Sorbi et al. (2006a) who could neither establish a predictive relationship between pain catastrophizing and pain at the following time measurement. Fear of movement on the other hand did turn out to be a significant predictor for pain and disability on the next day, even when controlled for levels of pain and disability during the previous day. Previously, a predictive relation between fear of movement and next day's pain intensity was reported by Roelofs et al. (2004b). However, their analyses were not controlled for pain intensity during the previous assessment and therefore it cannot be excluded that the predictive association was due to autocorrelations between subsequent pain assessments. Our study shows that also when the analyses are controlled for this autocorrelation the effect of fear of movement on next day's pain remained significant, although the proportion of explained variance in next day's pain intensity was low. We also tested whether the association between fear of movement and pain is bi-directional. The model that tested previous day's pain as a predictor of next day's fear of movement reached significance, but in this analysis the amount of explained variance was close to zero.

An additional research question was related to the stability of pain catastrophizing and fear of movement in patients with acute pain. Both variables decreased over time. With regards to fear of movement, it was already found by Sieben et al. (2002) that changes in fear of movement can occur within the first two weeks of a new 
episode of low back pain. However, to our knowledge, this is the first study that has found changes in levels of pain catastrophizing in the acute stage of pain. This is in contradiction to earlier suggestions that pain catastrophizing is a more trait like concept that remains stable over time (Sullivan et al., 2001). However, data on the stability of this concept has mostly been derived from pain-free individuals or chronic pain patients (Sullivan et al., 1995, Turner et al., 2004). Our data suggest that in patients experiencing acute pain catastrophizing does not have the immutable characteristics normally ascribed to personality traits of trait like concepts. The reduction of pain catastrophizing and fear of movement may reflect the decrease of complaints that participants experience during the three-week assessment period. Sieben et al. (2002) demonstrated that in the first two weeks of a new back pain episode changes occur in levels of fear of movement. In the Sieben et al. study (2002), three subgroups of patients were identified, being (1) one group that remained stable on levels of fear of movement, (2) one group that improved and (3) one group that showed an increase in fear of movement. This latter group also had worse outcome at follow-up. Therefore, Sieben et al. (2002) suggested that patients showing an increase in fear of movement in the acute stage of low back pain are at risk for developing chronic complaints. A similar prognosis could be the case for participants in the present study. Although overall participants show a declining pattern in pain, disability, pain catastrophizing and fear of movement, some patients may still show an increase on all variables over time. However, to prove this hypothesis data collection has to be continued for a longer period of time.

There are several limitations with regard to this study. First, we had a drop out percentage of $23 \%$. This was unexpected, since each participant was visited at home by a research assistant and they all agreed on participating. Participants had also only one diary to complete at the end of the day, which was not very intrusive when compared to other diary studies were patients were asked to fill in diaries at several times throughout the day. Although patients that dropped out did not differ from the patients included with regards to age and gender, we do not know whether these patients still had complaints and if we therefore had selective drop-out. Second, paper diaries give participants a chance to look back on previous completed diaries (Peters et al., 2000) and third, when using paper diaries the researcher has no control on whether participants actually fill in the diaries at the time requested, because of lack of automatic registration of missing values and response time (Sorbi et al., 1996; Stone et al., 2002). Finally, we used evening diaries, and by measuring all variables only once a day, we may have induced recall bias, influenced by current pain intensity, age and mood (Gaertner et al., 2004). Moreover, when using such a small amount of assessments, it is more difficult to find causal relationships because of extended time lags between two measurements and because of lack of knowledge on the time course of the temporal association of the assessed variables. Further 
research could explore different time lags by recording a larger number of assessments per day.

In conclusion, this study shows that fear of movement is predictive of experienced pain. Time lagged analyses of the diary data revealed that fear of movement on the previous day was predictive of pain and disability the next day. This was not the case for pain catastrophizing although this variable was significantly and positively associated with concurrently measured pain and disability at the between and within person level. Future research could be directed towards the predictive value of increases in fear of movement in the acute stage of whiplash injury for the development of chronic whiplash syndrome. Finally, knowledge on the presence and temporal relationships of fear of movement may provide tools for interventions in the acute stage. It may be useful to target the patients' fear of movement in addition to pain control in acute whiplash injury.

\section{Acknowledgements}

This research was supported by grant 940-31-071 from the Dutch Organisation for Scientific Research. The authors are grateful to the Emergency Care Units of Ziekenhuis Oost Limburg Genk, Salvator Hasselt, Academisch Ziekenhuis Maastricht, Atrium Heerlen and Maaslandziekenhuis Sittard and the Dutch Traffic Police (ZuidLimburg) for referring patients to our study. 


\section{REFERENCES}

Boersma K, Linton SJ. Expectancy, fear and pain, in the prediction of chronic pain and disability: A prospective analysis. European Journal of Pain 2006;10(6):551-557.

Buer N, Linton SJ. Fear-Avoidance beliefs and catastrophizing: occurence and risk factor in back pain and ADL in the general population. Pain 2002;99(3):485-491.

Gaertner J, Elsner F, Pollmann-Dahmen K, Radbruch L, Sabatowski R. Electronic Pain Diary: A Randomized Crossover Study. Journal of Pain and Symptom Management 2004;28(3):259-267.

Grant LD, Long BC, Willms JD. Women's adaptation to chronic back pain: daily appraisals and coping strategies, personal characteristics and perceived spousal responses. Journal of Health Psychology 2002;7(5):545-563.

Helmerson Ackelman B, Lindgren U. Validity and reliability of a modified version of the neck disability index. Journal of Rehabilitation Medicine 2002;34:284-287.

Heuts PHTG, Vlaeyen JWS, Roelofs J, De Bie RA, Aretz K, van Weel C, van Schayck OCP. Pain-related fear and daily functioning in patients with osteoarthritis. Pain 2004;110:228-235.

Keefe FJ, Affleck G, France CR, Emery CF, Waters S, Caldwell DS, Stainbrook D, Hackshaw K, Fox LC, Wilson K. Gender differences in pain, coping, and mood in individuals having osteoaarthritic knee pain: a within-day analysis. Pain 2004;110:57--577.

Kvist J, Ek A, Sporrstedt K, Good L. Fear of re-injury: a hindrance for returning to sports after anterior cruciate ligament construction. Knee Surgery, Sports Traumatology, Arthroscopy 2005;13:393-397.

Leeuw M, Goossens MEJB, Linton SJ, Crombez G, Boersma K, Vlaeyen JWS. The Fear-Avoidance Model of Musculoskeletal Pain: Current State of Scientific Evidence. journal of Behavioral Medicine In Press.

Linton SJ. Do psychological factors increase the risk for back pain in the general population in both a cross-sectional and prospective analysis? European Journal of Pain 2005;9(4):355-361.

Miller RP, Kori SH, Todd DD. The Tampa Scale

Peters ML, Sorbi MJ, Kruise DA, Kerssens JJ, Verhaak PFM, Bensing JM. Electronic diary assessment of pain, disability and psychological adaptation in patients differing in duration of pain. Pain 2000;84:181-192.

Roelofs J, Goubert L, Peters ML, Vlaeyen J, Crombez G. The Tampa Scale for Kinesiophobia: further examination of psychometric properties in patients with chronic low back pain and fibromyalgia. European Journal of Pain 2004a;8(5):495-502.

Roelofs J, Peters ML, Patijn J, Schouten EGW, Vlaeyen JWS. Electronic diary assessment of pain-related fear, attention to pain, and pain intensity in chronic low back pain patients. Pain 2004b;112:335-342.

Severeijns R, Vlaeyen JWS, Van den Hout MA, Picavet HSJ. Pain Catastrophizing and consequences of musculoskeletal pain: A prospective study in the Dutch community. The Journal of Pain 2005;6(2):125-132.

Sieben JM, Vlaeyen JWS, Tuerlinckx S, Portegijs PJM. Pain-related fear in acute low back pain: the first two weeks of a new episode. European Journal of Pain 2002;6:229-237.

Sorbi MJ, Maassen GH, Spierings ELH. A time series analyses of daily hassles and mood changes in the 3 days before the migraine attack. Behavioral Medicine 1996;22:103-113.

Sorbi MJ, Peters ML, Kruise DA, Maas CJM, Kerssens JJ, Verhaak PFM, Bensing JM. Electronic Momentary Assessment in Chronic Pain I: Psychological Pain Responses as Predictors of Pain Intensity. Clinical Journal of Pain 2006a;22(1):55-66.

Sorbi MJ, Peters ML, Kruise DA, Maas CJM, Kerssens JJ, Verhaak PFM, Bensing JM. Electronic Momentary Assessment in Chronic Pain II: Pain and Psychological pain responses as predictors of pain disability. Clinical Journal of Pain 2006b;22(1):67-81. 
Stone AA, Schwartz JE, Shiffman S, Marco CA, Hickcox M, Paty J, Porter LS, Cruise LJ. A comparison of coping assessed by ecological momentary assessment and retrospective recall. Journal of Personality and Social Psychology 1998;74(6):1670-1680.

Stone AA, Shiffman S, Schwartz JE, Broderick J, Hufford MR. Patient non-compliance with paper diaries. Britisch Medical Journal 2002;324:1193-1194.

Sullivan MJL, Bishop SR, Pivik J. The Pain Catastrophizing Scale: Development and validation. Psychological Assessment 1995;7(4):524-532.

Sullivan MJL, Thorn B, Haythornthwaite JA, Keefe F, Martin M, Bradley LA, Lefebvre JC. Theoretical perspectives on the relation between catastrophizing and pain. The Clinical Journal of Pain 2001;17:52-64.

Swinkels-Meewisse EJCM, Swinkels RAHM, Verbeek ALM, Vlaeyen JWS, Oostendorp RAB. Psychometric properties of the Tampa Scale for Kinesiophobia and the fear-avoidance beliefs questionnaire in acute low back pain. Manual Therapy 2003;8(1):29-36.

Turner JA, Mancl L, Aaron LA. Pain-related catastrophizing: a daily process study. Pain 2004;110(12):103-111.

Van Damme S, Crombez G, Eccleston C. Retarded disengagement from pain cues: the effects of pain catastrophizing and pain expectancy. Pain 2002;100:111-118.

Vernon H. Correlations among ratings of pain, disability and impairment in chronic whiplash-associated disorders. Pain Research Management 1997;2(4):207-213.

Vlaeyen JWS, Kole-Snijders AMJ, Boeren RGB, van Eek H. Fear of movement/(re)injury in chronic low back pain and its relation to behavioral performance. Pain 1995;62:363-372.

Willebrand MA, G., Kildal M, Gerdin B, Ekselius L. Injury-related fear-avoidane, neuroticism and burnspecific health. Burns 2006;32:408-415. 

Chapter 5

\title{
Fear of Movement, Pain Catastrophizing and Anger as predictors for developing persistent physical and psychological complaints after an Acute Whiplash Injury
}

\author{
Karoline Vangronsveld, Madelon Peters, \\ Mariëlle Goossens, Johan Vlaeyen,
}




\section{ABSTRACT}

So far, studies focussing on medical predictors for chronic complaints after acute whiplash injury have not found conclusive evidence that biomedical factors contribute to the development and persistence of complaints. This study investigated the influence of fear of movement, pain catastrophizing, anger, and range of motion on the persistence of both physical and psychological complaints.

In this study, 300 victims of a Motor Vehicle Accident (MVA) were recruited at Emergence Care Units and by the Traffic Police. Assessments of range of motion and baseline questionnaires were assessed within one month after the MVA. Questionnaires were again filled in at 6-months follow-up. Up to $72 \%$ of patients still reported being somewhat disabled at follow-up. Baseline levels of dependent variables were found to be the strongest predictors for persistent complaints. Pain catastrophizing was a significant predictor for disability, depression and quality of life. However, with regards to disability and mental health, the significant effect of pain catastrophizing was diminished when anger was entered into the model. Anger was a significant predictor for all outcome variables.

This study shows that pain catastrophizing and anger are predictors of physical and psychological complaints, six months after a motor vehicle accident. Both variables may provide us targets for intervention strategies. However, more research is warranted to investigate the mechanisms by which anger has an influence on prolonged physical and psychological complaints. 


\section{INTRODUCTION}

One of the current challenges for clinicians is to predict the prognosis of functional recovery of patients with an acute whiplash injury. Whiplash refers to the head making a brusque backward movement (extension) and subsequently a brusque forward movement (flexion). The pattern of complaints that can occur after the accident is characterized by neck pain, headache, visual disturbances, dizziness, muscle weakness, parasthesia, concentration difficulties, amnesia, and increased negative mood. A significant proportion of persons with an acute whiplash injury develop chronic complaints, also called late or chronic whiplash syndrome with figures varying from study to study from $0 \%$ to $50 \%$ (Karlsborg et al., 1997; Berglund et al., 2000; Olsson et al., 2002; Sterner et al., 2003).

So far, studies focussing on medical predictors for chronic complaints after acute whiplash injury have not found conclusive evidence that biomedical factors contribute to the development and persistence of complaints (for a review see: Rodriquez et al., 2004). Two recent systematic reviews investigated the evidence for the contribution of psychological factors to the transition from acute whiplash injury to chronic whiplash syndrome (Côté et al., 2001; Scholten-Peeters et al., 2003). Both studies only found limited evidence for the predictive power of psychological variables. According to Scholten-Peeters et al. (2003) this lack of evidence is mainly a consequence of the heterogeneity of the variables included in the studies and the lack of valid and standardized measurements for measuring these variables. Therefore, our primary goal in the present study was to investigate the predictive value of different psychological variables based on a theoretical model or variables that have proven their predictive value in other research populations or other research areas. A promising variable, derived from the "fear-avoidance model" is fear of movement (Vlaeyen et al., 1995). Fear of movement represents the excessive, irrational, and debilitating fear of physical movement and activity resulting from a feeling of vulnerability to painful (re)injury (Kori et al., 1990) and has been shown to predict the transition from acute to chronic low back pain (Buer and Linton, 2002; Boersma and Linton, 2006) and the onset of new back pain episodes in the general population (Linton, 2005; Severeijns et al., 2005). However, studies that investigated the predictive value of fear of movement in patients with whiplash injury have provided mixed results. (Sterling et al., 2003a; Sterling et al., 2003b; Nederhand et al., 2004; Sterling et al., 2005; Buitenhuis et al., 2006; Nederhand et al., 2006). One explanation for these mixed results could lie in the fact that the instrument to measure fear of movement (TSK: Tampa Scale for Kinesiophobia) was developed for research in patients with chronic low back pain and therefore may not reflect possible different dimensions or targets of fear in patients with neck pain. Therefore, in this study we included a second important component derived from the FA-model, being pain 
catastrophizing. Although pain catastrophizing is associated with higher levels of perceived pain intensity and perceived disability in patients with chronic whiplash syndrome in cross-sectional studies (Sullivan et al., 1998), no study has yet considered pain catastrophizing as a predictor for the transition from acute whiplash injury to chronic whiplash syndrome. Both pain catastrophizing and fear of movement may be highly related to neuroticism. Neuroticism is the trait-like tendency to experience a broad range of negative feelings, such as distress, worry and anxiety. It is hypothesized by Goubert et al. (2004) that neuroticism is a vulnerability factor that lowers the threshold for perceiving pain as threatening and at which pain catastrophizing emerges. We therefore included neuroticism in our analyses.

In addition to fear of movement, pain catastrophizing and neuroticism, we included one explorative variable, being anger. Several studies have provided evidence for the association between anger and pain intensity, the affective components of pain and emotional distress in patients with chronic pain and their family (Okifuyi et al., 1999). Although there is evidence that anger is associated with chronic pain, anger has not been considered so far as a prognostic factor for the persistence of acute pain.

Finally we included range of motion as a possible somatic predictor for prolonged disability and pain. Research has shown that patients with neck pain after a motor vehicle accident (MVA) have a restricted range of motion compared to controls with no neck pain (Kasch et al., 2001b). Restricted range of motion is related to higher levels of pain and perceived disability (Kasch et al., 2001a; Kasch et al., 2001b; Sterling et al., 2003a). More recently, the research of Sterling et al. (2005) revealed that restricted range of motion in the acute stage of whiplash injury was a significant predictor for the development of chronic disability.

In sum, the present study assessed neuroticism, fear of movement, pain catastrophizing, anger and range of motion, assessed within the acute stage of whiplash injury and at 6-months follow-up to investigate their predictive value for the persistence of physical and psychological complaints.

\section{MATERIALS AND METHODS}

\section{Participants}

We included 300 patients selected by the Emergency Care Units of five different hospitals and the Dutch Traffic Police (Zuid-Limburg) who were contacted by telephone in order to ask them for participation in this study. Inclusion criteria for this study were that patients had to be between the age of 18 and 65 and they were involved in a car accident. The exclusion criteria were (1) having a head injury, (2) 
experiencing any unconsciousness after the accident, (3) having fractures or dislocations of a vertebra, diagnosed by the medical doctor at the Emergency Care Department by means of X-ray or CT-scan, and (4) being pregnant. Furthermore patients were excluded if they didn't speak Dutch fluently. Of the original 300 patients, 100 patients came to the University Hospital Maastricht for a measurement of the Range of Motion of their neck. All patients gave informed consent and were free to terminate the experiment at any time.

\section{Procedure}

The experiment was approved by the Medical Ethical Committee of the University Hospital Maastricht. Patients were contacted by the researcher to inform them about the experiment and to ask for their participation. If patients agreed to participate and if it was possible for them to travel to the University Hospital (because of work and transportation), they were then scheduled for an appointment at the University Hospital for a measurement of their range of motion within one month after the accident. The other patients received all questionnaires at home, including a prestamped return envelope. In the group of patients only filling in questionnaires we lost 71 patients already at baseline measurement because of them not returning the questionnaires (see figure 1). Patients that dropped out, where contacted by telephone to retrieve the reason for drop out. If patients could not be contacted by telephone they received a letter with a prestamped return envelope and a form on which they could fill in their reason for drop out and if they still had complaints as a result from their motor vehicle accident. Patients dropped out for various reasons (see table 1).

All patients received follow-up measurements at home after six months, including a prestamped return envelope. The questionnaires in the follow-up measurement were identical to the questionnaires at baseline. At follow-up an additional number of 88 patients did not return the questionnaires (see figure 1). Again drop-outs were contacted to obtain additional information. Table 1 presents an overview of the various reasons for drop-out at follow-up (see table 1).

\section{Questionnaires}

\section{Predictor variables}

Demographic variables: Participants had to answer questions about their gender and age. Education was assessed on an ordinal scale with 9 categories ranging from "no education" to "university degree". 


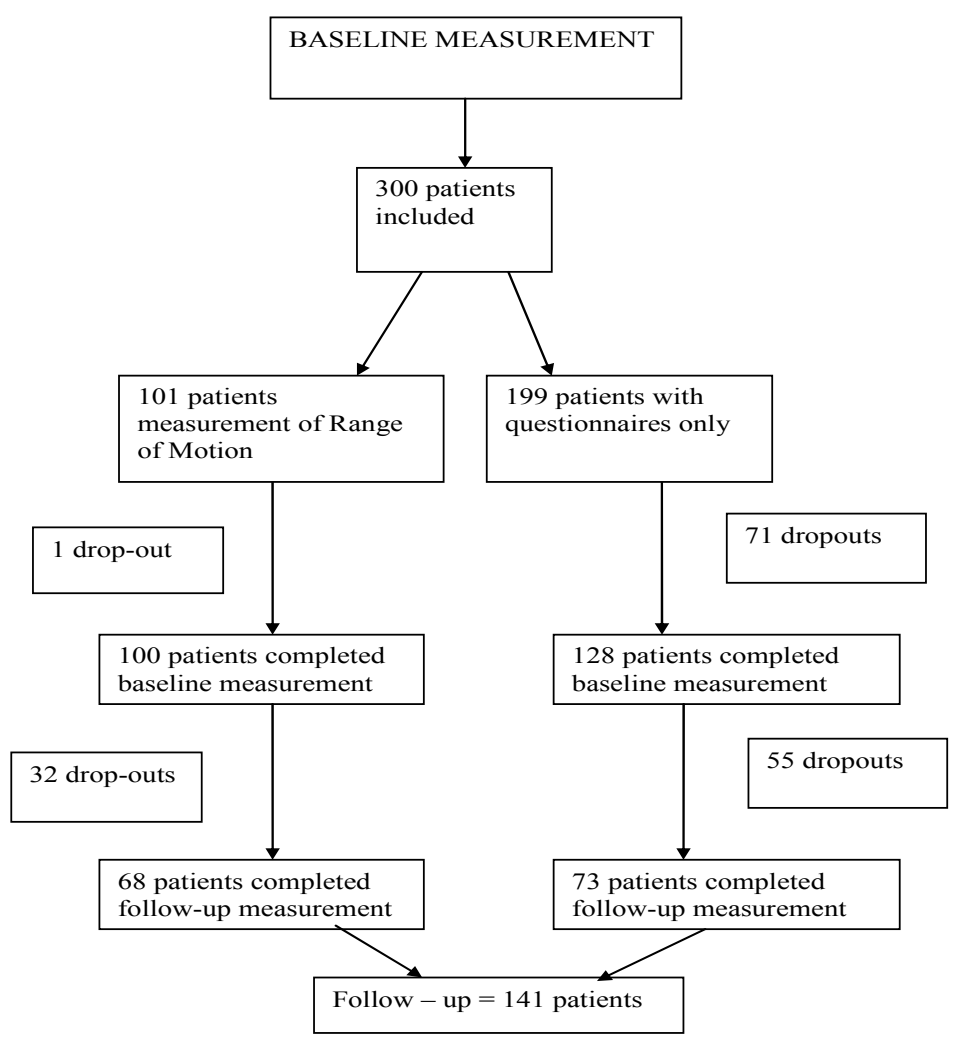

Fig.1 Flow chart of drop out baseline measurement and follow-up

Event Factors: Patients had to answer with yes or no whether they were to blame for the accident, whether they received financial compensation for their car, the type of collision (rear-end or other), whether they were the driver or passenger of the car and whether they were prepared for the crash (saw the other car coming).

Pre-Motor Vehicle Accident (MVA) Complaints: Participants had to endorse 20 preMVA complaints with yes or no. Based on the prevalence of pre-MVA complaints, participants were classified (score 0 or 1), indicating whether they belonged to 1 to 3 groups, being (1) pre-MVA neck complaints, (2) pre-MVA musculoskeletal complaints (e.g. previous episode of low back pain), and (3) pre-MVA other complaints (e.g. heart disease, diabetes, incontinence).

Neuroticism: The Neuroticism subscale of the Eysenck Personality Questionnaire (EPQ) was used to measure neuroticism. The subscale Neuroticism of the EPQ consists of 12 items with dichotomous answers (YES/NO). The minimum score is 0 
and the maximum score is 12 . The EPQ is considered to be a valid and reliable instrument (Sanderman et al.).

Table 1: Overview of drop-outs on baseline and follow-up measurement.

\begin{tabular}{lcc}
\hline Reason given & Baseline & Follow-up \\
\hline Other healt complaints & 2 & 1 \\
Complaints resolved, so no use in filling in questionnaires & 3 & 4 \\
Not had time to fill in questionnaires & 12 & 14 \\
Forgot to fill in questionnaires & 7 & 13 \\
Did no longer feel like filling in questionnaires & 4 & 8 \\
Patient or researcher did not receive questionnaires & 16 & 15 \\
Patient could not be contacted again & 12 & 15 \\
Private or family circumstances & 4 & 2 \\
Moved to different address & 1 & 9 \\
Complaints got worse / questionnaires too difficult & 1 & 2 \\
Other & 10 & 4 \\
\hline Total drop out & 72 & 87 \\
Patients in drop-out still having complaints & 19 & 32 \\
Patients in drop-out who recovered & 41 & 38 \\
Patients in drop-out with no information of recovery & 12 & 17 \\
\hline
\end{tabular}

Pain Catastrophizing: Participants completed the Dutch version of the Pain Catastrophizing Scale (PCS; Sullivan et al., 1995). Respondents are asked to reflect on past painful experiences and to indicate the degree to which they experienced each of the 13 thoughts or feelings during pain on a five point scale from 0 (not at all) to 4 (all the time). The Dutch version of the PCS has been shown to be valid and reliable (Van Damme et al., 2002).

Fear of movement/(re)injury: The Dutch version of the Tampa Scale for Kinesiophobia (TSK: Miller et al., 1991) was used to measure fear of movement/(re)injury. The 17 items are scored on a four point scale from "I strongly disagree" (1) to "I strongly agree" (4). The scale has a good internal consistency and a good test retest reliability (Swinkels-Meewisse et al., 2003; Roelofs et al., 2004).

Anger: The short version of the Targets of Anger Scale (TAS) consists of 10 items to measure the presence of anger in 9 specific areas for chronic pain patients. One item asks for the presence of anger in general. The specific areas are (1) the whole world, (2) the self, (3) God or destiny, (4) significant others, (5) the employer, (6) the insurance company, (7) attorney or legal system (8) health care providers, and (9) the person responsible for the accident. Patients are asked to score the level of anger on a 10-point scale from 0 (not angry at all) to 10 (extremely angry) (Okifuyi et al., 1999). In deviation from the original list we asked patients to only fill in those areas, which apply to their personal situation. Items that are endorsed by the partici- 
pant are summed up to yield a total score and divided by the number of items endorsed, resulting in a mean item score.

\section{Outcome variables}

Disability: The Dutch version of the Neck Disability Index (NDI) consists of 10 items concerning limitations in functional activities and symptoms. The 10 items are scored 0 (no limitations/symptoms) to 5 (major limitations/symptoms) and summed to yield a total score. The NDI is a valid and reliable instrument, sensitive to measure changes within a population of neck pain patients (Vernon, 1997; Helmerson Ackelman and Lindgren, 2002).

Pain: Pain was assessed on an 11-point Likert Scale anchored with two labels "no pain at all" on the left side and with "worst pain ever" on the right side. Patients rated their pain on four levels, being (1) current pain, (2) worst pain since the accident, (3) least pain since the accident and (4) average pain.

Depression: The Center for Epidemiological Studies Depression Scale (CES-D; Radloff, 1977) consists of 20 items to measure different dimensions of depression. Questions are rated on a four point scale (0-3). A score of more than 16 is to be considered as an indication for clinical depression. The Dutch version of the CES-D has a good internal consistency and a very good sensitivity and specificity (Beekman et al., 1994).

Post-traumatic Stress: The Post-Traumatic Stress Scale - Self Report (PSS-SR) consists of 17 items that can diagnose Post Traumatic Stress Disorder according to the DSM-IV criteria. The items can be clustered into three factors, being (1) avoidance, (2) re-experiencing, and (3) arousal. For all items, symptom frequency over the preceding two weeks is reported on a four-point scale $(0=$ never, $1=\mathrm{a}$ few times a month, $2=\mathrm{a}$ few times a week, $3=\mathrm{a}$ few times a day or continuously). A total score is obtained by summing each symptom rating. Based on this questionnaire a diagnosis of PTSD can be made when at least one re-experiencing, 3 avoidance and 2 arousal symptoms are endorsed (item score 1 or greater). The PSS-SR has a good internal consistency, high test-retest reliability and good concurrent validity (Foa et al., 1993).

Quality of Life : The Rand-36 is a questionnaire for measuring health-related quality of life. It consists of 36 items and contains 9 subscales, being (1) physical functioning, (2), social functioning, (3) limitations in physical functioning, (4) limitations in emotional functioning, (5) mental health, (6) pain, (7) vitality, (8) general health perception and (9) health changes. Eight of these subscales (all except health changes) can be merged into two major factors, being physical health and mental health. The Rand-36 is a reliable and valid instrument, internationally used to make comparisons between general populations, syndromes and interventions (van der Zee and Sanderman, 1993). 


\section{Range of Motion}

At baseline, patients that came to the University Hospital underwent an assessment of range of motion of their neck. A qualified physiotherapist performed the assessment of range of motion. At the beginning of the assessment, the physiotherapist informed patients verbally and in writing. Patients then gave informed consent and were placed into position for the measurement. To quantify the different cervical motions a 3Space Inside Track HP system Polhemus Navigational Division, Kaiser Aerospace, Vermont, USA), was used. An electromagnetic receiver and transducer measured the range of rotations and translations in respectively the $\mathrm{X}, \mathrm{Y}$ and $\mathrm{Z}$-axes and the sagittal, frontal and transversal planes. The receiver was placed on the centre of the moving part and the transducer was receiving the signal. The subject was seated on a chair, without back support, in a relaxed upright position. The subject was looking straightforward to a marked sign on the wall. The distance between subject and the wall was 2 meters. The distance of the eyes of the subject to the floor was measured and the height of the marked sign on the wall was adapted to this distance. The receiver is placed in a pocket fixed on a rubber swimming-cap on the head. The receiver was located in a frontal plane of the subject at a point $\mathrm{X}$ halfway the distance between both external acoustic pores (centre of the movement). The transducer was placed above the patient and received the information about the movement of the receiver with reference to the transducer. A light spot was projected from the transducer perpendicular on point $\mathrm{X}$ halfway the distance between both external acoustic pores. The transversal plane of the head had to be placed parallel to the horizontal plane of the transducer, by placing a spirit level on the receiver on the subject.

Both active and passive cervical motion was performed (see Vangronsveld et al, Submitted). The motions were restricted to the cervical spine by manual fixation by the physical therapist of the spinal process of Th1. Subjects were placed into the right position defined by the measurement conditions mentioned above before each movement. The sequence of the different movements was fixed. The following movements were performed five times (1) rotation (left and right), (2) cervical forward flexion, and (3) cervical backward flexion. First the subject performed Active ROM. Then, the physical therapist would perform the same movement with pressure (Passive ROM). After measuring the Range of Motion patients were seated at a desk and completed all questionnaires. For the present study only Passive ROM will be used in analyses, since this is the most objective measurement of ROM (Dvorak, 1988). 


\section{Statistical analyses}

Analyses were conducted with the Statistical Package for the Social Sciences version 13.0 (SPSS Inc., 444N. Wacker Drive, Chicago, IL, 60606, USA). When possible, missing value analyses were performed by the missing value analyses command in SPSS. We did not perform missing value analyses if patients did not fill in a complete questionnaire or if the missing data in one questionnaire was more than $10 \%$. Because several patients had complete questionnaires missing at followup, the total $\mathrm{N}$ in the analyses may vary from 123 to 141 . Results were regarded as being significant from a p-value less than .05 .

The main analyses for describing the sociodemographic variables, event factors and questionnaires were analysis of variances (ANOVA) and $\mathrm{X}^{2}$ test. Based on the results by the ANOVA and theoretical considerations we decided to include the socio-demographic variables and pre-MVA complaints as control variables in the regression analyses.

We used regression with blockwise entry of variables with a forced entry method for predicting outcome at 6-months follow up for all dependent variables (disability, average pain, post-traumatic stress disorder, depression, and quality of life). Model 1 contained the socio-demographic control variables, being age, gender $(0=$ female, 1 $=$ male) and education. Education was coded into a dichotomous variable with no education to pre-high-school as low education and high-school to university as high education. In model 2 we entered neuroticism as the most global theoretical variable, together with the baseline measurement of the outcome variable as a control variable. In the next step (model 3) we entered pre-MVA complaints. In model 4 the variables from the FA-model, being pain catastrophizing and fear of movement were entered. Finally, the explorative variable anger was entered in model 5 . The control variables in model 1 and 2 were never removed from the model, whereas in the latter models the non-significant predictors were removed.

We performed additional analyses on disability for the subgroup of 68 patients that had a baseline measurement of Range of Motion (ROM) of the neck. Passive range of motion was entered as a variable in model 4 before adding the psychological predictor variables from the FA-model. Regression analyses were repeated for all four passive movements.

\section{RESULTS}

There were 141 patients (57 men and 84 woman) included in the analyses. Patients on average returned their baseline questionnaires within 23 days after their MVA $(\mathrm{SD}=10.62$, range $4-58)$. The mean age of the patients was 37 years old $(\mathrm{SD}=$ 
12.30). Mean scores for outcome variables and predictive variables at baseline and follow-up are presented in table 2. The paired sample t-test comparing the baseline and follow-up scores showed that patients showed significantly decreased scores on follow-up for pain, disability, depression, post traumatic stress symptoms and increased scores on quality of life. Patients also showed decreased scores on fear of movement, but remained stable on pain catastrophizing, and anger. Finally, patients showed elevated scores at follow-up for neuroticism.

Table 2: Mean scores for baseline measurement and follow up. Paired samples t-test for predictive and outcome variables

\begin{tabular}{lcccc}
\hline Variable & $\begin{array}{c}\text { Baseline } \\
\text { Mean (SD) }\end{array}$ & $\begin{array}{c}\text { Follow up } \\
\text { Mean (SD) }\end{array}$ & t & $\begin{array}{c}\text { Sign. } \\
\text { (2-tailed) }\end{array}$ \\
\hline Pain & $4.07(2.72)$ & $3.36(2.80)$ & 4.12 & $<.001$ \\
Disability & $15.11(10.14)$ & $12.57(10.32)$ & 4.69 & $<.001$ \\
Depression & $15.17(11.34)$ & $13.51(12.16)$ & 2.45 & .016 \\
Post Traumatic Stress & $13.23(10.77)$ & $11.13(10.65)$ & 3.71 & $<.001$ \\
Quality of Life - physical health & $54.90(19.58)$ & $58.74(23.02)$ & 2.35 & .020 \\
Quality of Life - mental health & $61.84(23.49)$ & $67.12(24.29)$ & 2.97 & .004 \\
Neuroticism & $5.03(3.16)$ & $5.53(3.45)$ & -2.64 & .009 \\
Pain Catastrophizing & $12.69(9.81)$ & $12.82(11.10)$ & -.18 & .858 \\
Fear of movement & $35.42(6.52)$ & $34.20(8.12)$ & 2.09 & .038 \\
Anger & $1.20(1.37)$ & $1.30(1.62)$ & -1.03 & .304 \\
\hline
\end{tabular}

We divided patients into subgroups based on their score at follow-up on the Neck Disability Index (NDI) (Vernon, 1996), being (1) no disability (NDI 0-4), (2) mild disability (NDI 5-14), (3) moderate disability (NDI 15-24), (4) severe disability (NDI 25-34), and (5) complete disability (NDI 35-50). The complete disability group contained only 4 patients and we therefore merged them into the severe disability group. Approximately $72 \%$ of patients at follow-up still reported to be somewhat disabled as a result from their Motor Vehicle Accident, measured by the Neck Disability Index. However, the largest proportion of these patients still having complaints (49\%) could be classified as being mildly disabled (see table 3 and 4). An ANOVA was performed to see whether the patients differed on sociodemographic variables, event factors and pre-MVA complaints

Patients did not differ on age or gender, but significantly differed on education, with the two groups with highest levels of disability having more patients with a low level of education. With regards to the Event Factors there were no differences in the amount of people to be blaimed for the crash or having received financial compensation for their car, the number of patients being the driver, or the number of patients that were prepared for the crash. Patients only differed on collision type, with the higher disability groups reporting more rear-end collisions (see table 3). Patients did not report significantly different frequencies concerning pre-MVA neck complaints. 


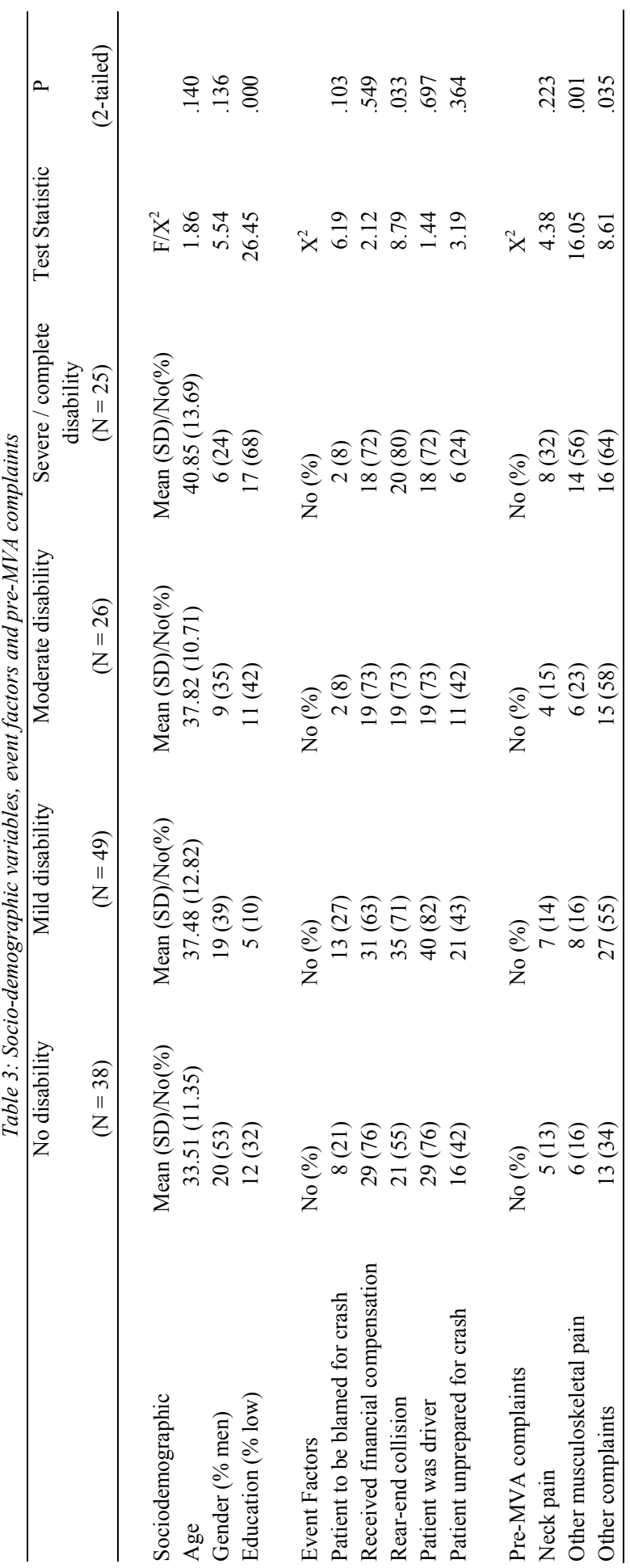




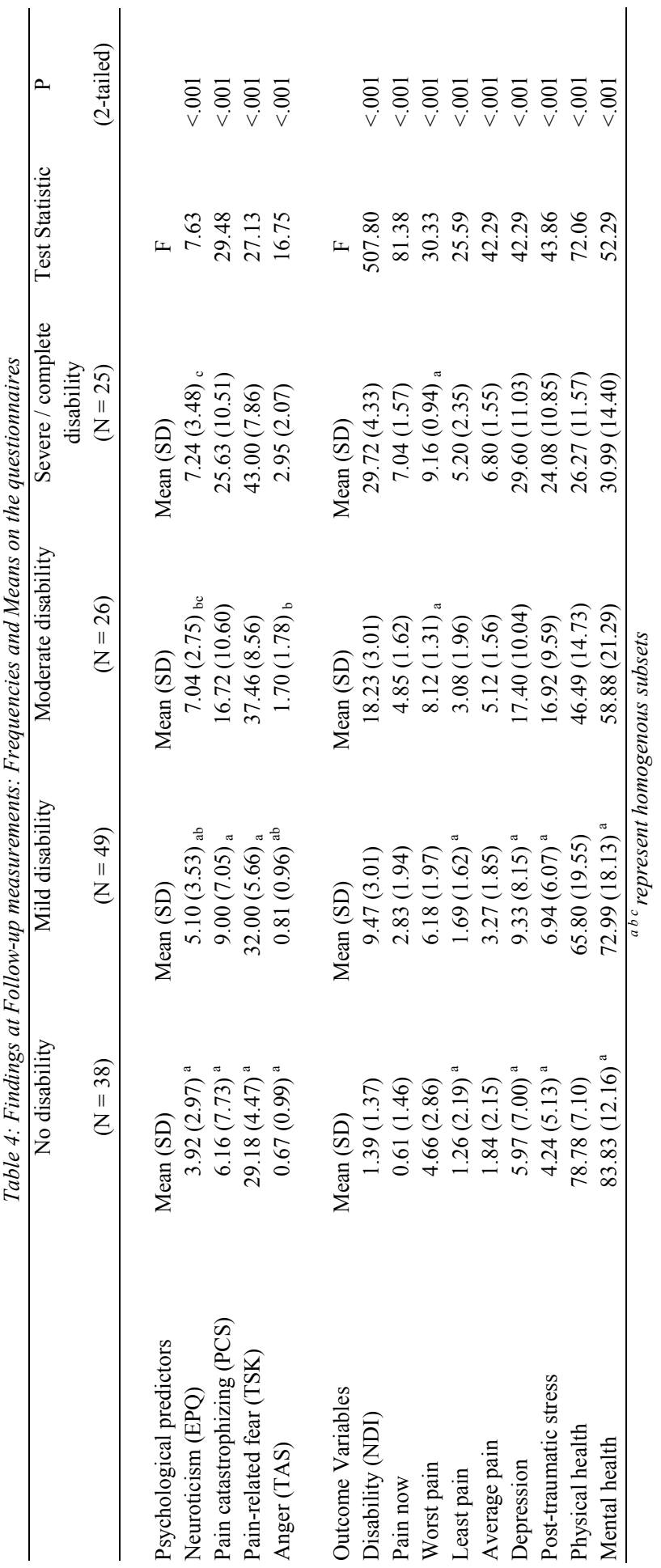


However, the groups differ on other pre-MVA musculoskeletal complaints and other pre-existing complaints..

Patients showed significant differences on the questionnaire data at follow-up measurement, according to their disability level. Table 4 shows that higher levels of disability are related to higher levels of neuroticism, pain catastrophizing, fear of movement, anger, all measures of pain, depression, and post-traumatic stress, and lower levels of quality of life at follow up.

Tables 5, 6 and 7 show the results of step 4 of the regression analyses for all outcome variables. This step tests the prognostic value of the variables derived from the Fear-avoidance model. In addition, the additional predictive value of anger (step 5) is shown in the lower part of the tables.

\section{Prediction of disability and average pain at 6-months follow-up}

Disability: The strongest predictor of disability at 6 months follow-up was disability in the first weeks after the MVA. Of the demographic and pre-MVA variables, age and pre-MVA neck pain reached significance. Older individuals and individuals with neck pain before the MVA showed less decline in disability from immediately after the accident to 6 months follow up. Neuroticism was not significantly related to persistence of disability at follow up. Regarding the variables from the Fearavoidance model, pain catastrophizing was significantly associated with persistence of disability at follow-up $(\beta=.125, \mathrm{p}=.045)$. Fear of movement $(\beta=-.021, \mathrm{p}=.713)$ was no significant predictor and was removed from the model. The lower part of table 5 shows that entering anger as an addition predictor variable significantly improved the model. Anger was significantly and positively related to persistence of disability at follow up, and adding anger to the model reduced the predictive value of pain catastrophizing which was now no longer significant (table 5).

Table 5: regression analyses for disability and pain

\begin{tabular}{|c|c|c|c|c|c|c|c|}
\hline \multicolumn{4}{|c|}{ Dependent: NDI follow up } & \multicolumn{4}{|c|}{ Dependent: PAIN Follow up } \\
\hline $\begin{array}{ll}\text { Step } 4 & \text { R2 }=.73\end{array}$ & $\mathrm{p}=<.001$ & $F=45.28$ & & Step 4 R2 $=.74$ & $\mathrm{p}=<.001$ & $\mathrm{~F}=30.03$ & \\
\hline Gender & $\beta=-.083$ & & .101 & Gender & $\beta=-.029$ & & .640 \\
\hline Age & $\beta=.130$ & & .009 & Age & $\beta=.071$ & & .253 \\
\hline Education (high/low) & $\beta=-.098$ & & .058 & Education (high/low) & $\beta=-.151$ & & .020 \\
\hline EPQ & $\beta=.015$ & & .772 & EPQ & $\beta=.072$ & & .246 \\
\hline NDI baseline & $\beta=.692$ & & $<.001$ & PAIN baseline & $\beta=.665$ & & $<.001$ \\
\hline Pre-MVA neck & $\beta=.118$ & & .017 & & & & \\
\hline PCS & $ß=.118$ & & .046 & & & & \\
\hline $\mathrm{R} 2=.75$ & $\mathrm{p}=<.001$ & $\Delta F=8.94$ & $\mathrm{p}=.003$ & Step $5 \mathrm{R} 2=.76$ & $\mathrm{p}=<.001$ & $\Delta \mathrm{F}=6.14$ & $\mathrm{p}=.015$ \\
\hline$\overline{\mathrm{PCS}}$ & $\beta=.098$ & & .090 & & & & \\
\hline TAS & $\beta=.168$ & & .003 & TAS & $\beta=.172$ & & .015 \\
\hline
\end{tabular}


We performed additional analyses for disability at 6-months follow up for the subgroup of 68 patients that had a baseline measurement of Range of Motion (ROM) of the neck. Similar to previous models, we first entered socio-demographic variables and next baseline levels of neuroticism and disability. In model 3 we entered pre-MVA neck complaints. Movements for passive range of motion were entered one by one in model 4 . None of the movements were a significant addition to the model.

Pain: Of the demographic and pre-MVA variables, only education reached significance in model 4. Individuals with lower levels of education reported more average pain at 6 months follow up. Neuroticism was not significantly related to persistence of pain at follow up. Baseline pain was the strongest predictor of pain at follow up. Neither fear of movement $(\beta=.022, \mathrm{p}=.751)$, nor pain catastrophizing $(\beta=.086, \mathrm{p}$ $=.271$ ) were significantly associated with persistence of pain at follow-up. Anger as a predictor variable significantly improved the model. Anger was significantly and positively related to persistence of pain at follow up (table 5).

\section{Prediction of Depression and Post-Traumatic Stress at 6-months follow-up}

Depression: None of the socio-demographic and pre-MVA variables reached significance. Baseline depression was a significant predictor of depression at follow-up, but again neuroticism was not. Regarding the variables of the FA-model, fear of movement was not a significant predictor $(\beta=-.006, \mathrm{p}=.927)$, but higher pain catastrophizing was significantly related to a higher depression score at follow up. The addition of anger in step 5 significantly improved the model. Anger was a significant predictor of levels of depression at 6 months follow-up.

Post-traumatic stress: The strongest predictor of disability at 6 months follow-up was post-traumatic stress in the first weeks after the MVA. None of the demographic and pre-MVA variables reached significance and neither was neuroticism significantly related to persistence of post-traumatic stress complaints at follow up. Regarding the variables from the Fear-avoidance model, neither fear of movement ( $\beta=$ $.027, \mathrm{p}=.658)$, nor pain catastrophizing $(\beta=.119, \mathrm{p}=.089)$ were significant predictors. The lower part of table 6 shows that anger was significantly and positively related to persistence of post-traumatic stress at follow up. 
Table 6: regression analyses for Depression and Post-Traumatic Stress

\begin{tabular}{|c|c|c|c|c|c|c|c|}
\hline \multicolumn{4}{|c|}{ Dependent: Depression follow-up } & \multicolumn{4}{|c|}{ Dependent: Post-Traumatic Stress Follow up } \\
\hline $\mathrm{R} 2=.64$ & $\mathrm{p}=<.001$ & $\mathrm{~F}=36.14$ & & $\mathrm{R} 2=.66$ & $\mathrm{p}=<.001$ & $\mathrm{~F}=46.72$ & \\
\hline Gender & $ß=-.044$ & & .437 & Gender & $\beta=-.044$ & & .437 \\
\hline Age & $\beta=.042$ & & .452 & Age & $\beta=.042$ & & .452 \\
\hline Education (high/low) & $ß=-.070$ & & .221 & Education (high/low) & $ß=-.070$ & & .221 \\
\hline EPQ & $\beta=.064$ & & .304 & EPQ & $\beta=.072$ & & .246 \\
\hline CES-D baseline & $ß=.647$ & & $<.001$ & PSS-SR baseline & $\beta=.665$ & & $<.001$ \\
\hline PCS & $\beta=.146$ & & .031 & & & & \\
\hline $\mathrm{R} 2=.66$ & $\mathrm{p}=<.001$ & $\Delta \mathrm{F}=5.98$ & $\mathrm{p}=.016$ & $\mathrm{R} 2=.68$ & $\mathrm{p}=<.001$ & $\Delta \mathrm{F}=7.93$ & $\mathrm{p}=.006$ \\
\hline PCS & $ß=.144$ & & .030 & & & & \\
\hline TAS & $ß=.176$ & & .016 & TAS & $ß=.198$ & & .006 \\
\hline
\end{tabular}

\section{Prediction of Quality of Life at 6 months follow-up}

Physical health: Of the demographic and pre-MVA variables, gender and pre-MVA musculoskeletal complaints were significantly related to physical health at follow up. Men and people without previous musculoskeletal complaints reported better physical health at 6 months follow up. Neuroticism was not significantly related to worse physical health at follow up. Baseline physical health was the strongest predictor for physical health at follow-up. Regarding the variables from the Fearavoidance model, pain catastrophizing was significantly associated with physical health at follow-up, with people scoring low on catastrophizing, reporting better physical health, corrected for baseline levels of physical health. Fear of movement was not a significant predictor $(\beta=-.084, p=.288)$. Again, entering anger in step 5 significantly improved the model. Anger at baseline significantly predicted physical health at follow up, with people being less angry reporting better physical health.

Mental health: The strongest predictor of mental health at 6 months follow-up was mental health in the first weeks after the MVA. None of the demographic variables reached significance. Regarding the pre-MVA variables, only pre-MVA other complaints reached significance. People reporting having more other complaints before the accident report less mental health at 6 months follow-up. Neuroticism was not significantly related to mental health. For the variables from the Fear-avoidance model, pain catastrophizing was significantly associated with mental health, with persons reporting low levels of pain catastrophizing reporting better mental health at follow-up. Fear of movement was not a significant predictor $(\beta=-.079 \mathrm{p}=.315)$. In step 5, anger significantly improved the model and adding anger to the model reduced the predictive value of pain catastrophizing which was now no longer significant. Higher levels of anger were related to worse mental health at follow up (table 7). 
Table 7: regression analyses for Physical health and Mental health

\begin{tabular}{|c|c|c|c|c|c|}
\hline \multicolumn{3}{|c|}{ Dependent: Physical health follow-up } & \multicolumn{3}{|c|}{ Dependent: Mental Health Follow up } \\
\hline Step $4 \quad \mathrm{R} 2=.52$ & $\mathrm{p}=<.001$ & $\mathrm{~F}=16.56$ & $\mathrm{R} 2=.51$ & $\mathrm{p}=<.001 \mathrm{~F}=16.22$ & \\
\hline Gender & $\beta=.178$ & .011 & Gender & $\beta=.053$ & .464 \\
\hline Age & $\beta=-.058$ & .408 & Age & $\beta=.058$ & .414 \\
\hline Education (high/low) & $\beta=.047$ & .505 & Education (high/low) & $\beta=.018$ & .808 \\
\hline EPQ & $\beta=-.048$ & .508 & EPQ & $\beta=-.038$ & 626 \\
\hline Physical health baseline & $\beta=.412$ & $<.001$ & Mental health baseline & $\beta=.512$ & $<.001$ \\
\hline Pre-MVA musculoskeletal & $\beta=.-.214$ & .004 & Pre-MVA other & $\beta=-.206$ & .004 \\
\hline PCS & $\beta=-.214$ & .009 & PCS & $\beta=-.205$ & .016 \\
\hline Step $5 \quad$ R2 $=.59$ & $\mathrm{p}=<.001$ & $\Delta \mathrm{F}=2.57 \mathrm{p}=<.001$ & $\mathrm{R} 2=.58$ & $\mathrm{p}=<.001 \Delta \mathrm{F}=17.8$ & $<.001$ \\
\hline$\overline{\mathrm{PCS}}$ & $\beta=-.170$ & .024 & PCS & $\beta=-.153$ & .056 \\
\hline TAS & $\beta=-.319$ & $<.001$ & TAS & $\beta=-.381$ & $<.001$ \\
\hline
\end{tabular}

\section{DISCUSSION}

By following 141 patients for six months after their motor vehicle accident, the present study found that up to $72 \%$ of patients still reported being somewhat disabled as measured by the Neck Disability Index. The most prominent predictor for neck disability but, also for pain, depression, post-traumatic stress complaints and quality life, was the baseline levels of all these outcome variables. This indicates that the initial complaints patients experience within the first three to four weeks of the accident are the best predictors for outcome at six-months follow-up. Two additional predictors for physical and psychological complaints were identified, being pain catastrophizing and anger. When controlled for demographic variables, baseline levels of the outcome variables, neuroticism and pre-MVA complaints, pain catastrophizing at baseline was a significant predictor of disability, depression, physical health and mental health at 6-months follow-up. However, the significant effect of pain catastrophizing on disability and mental health disappeared when anger at baseline was entered into the model. Anger at baseline was a significant predictor for all outcome variables. Fear of movement at baseline was not significantly related to any of the outcome variables.

The findings of this study that initial complaints are the strongest predictors for prolonged complaints are in line with previous research on the transition from acute whiplash injury to chronic whiplash syndrome. The results of the meta-analysis by Scholten-Peeters et al. (2003) and recent research by Berglund et al. (2006) demonstrated that high initial pain intensity is an important predictor for delayed functional recovery. In addition, Nederhand et al. (2004) found that a simple rating of the baseline Neck Disability Index (NDI) can be used to predict which patients will be still disabled 6 months after a whiplash injury. 
The primary goal of this study was to test the role of two major concepts of the FAmodel, being fear of movement and pain catastrophizing for the development of persistent physical and psychological complaints after a motor vehicle accident. The 6-month follow-up assessment indeed showed that pain catastrophizing was a significant predictive variable for most outcome variables. Unexpectedly, we did not find any evidence for the predictive role of fear of movement in the development of chronic complaints. Previous research in patients with whiplash injury did not consistently find evidence for fear of movement as a predictor of persistent pain and disability. This is the first study to include both fear of movement and pain catastrophizing as predictors for several outcome variables including pain and disability.

The finding that pain catastrophizing had more predictive value than fear of movement contradicts research in low back pain patients, were mainly fear of movement seems to be of influence on the onset of new pain episodes and persistence of complaints (Buer and Linton, 2002; Boersma and Linton, 2006). A possible explanation could be that many patients with low back pain suffer from recurrent episodes of pain. Most patients included in previous studies may have had previous episodes of low back pain before, and might have better knowledge and understanding on the natural course of their complaints. They might have realized that episodes of acute low back pain are self-limiting. In contrast, the minority with increased fear of movement are likely to be at risk for developing chronic pain and disability as a results of exaggerated avoidance and hypervigilance. Most patients with acute whiplash injury will experience these types of complaints for the first time, resulting in experiencing fear for the unknown. Thus, in this acute phase, fear of movement may be common to all patients. In addition, also in patients with low back pain, fear of movement in the acute phase has not consistently been found to be related to chronic pain and disability. Sieben et al. (2003) found that not baseline levels of fear of movement but the increase of fear of movement in the acute pain episode characterized patients at risk for developing persistent complaints. It may be speculated that pain catastrophizing in the acute phase of whiplash injury has more predictive value because it is suggested to be a more stable concept than fear of movement, less reactive on present pain or disability levels. This hypothesis is in concordance with our results. Fear of movement decreased, but pain catastrophizing remained stable from 4 weeks after the accident to 6 months follow-up.

We also investigated whether the absence of a significant effect of fear of movement, was due to multicollinearity. Multicollinearity can occur when predictor variables are strongly intercorrelated. Although pain catastrophizing and fear of movement were significantly correlated to each other, the variance inflation factor and its' associated tolerance statistics did not suggest that multicollinearity was a problem. Moreover, we repeated analyses with only fear of movement as a predictive variable (data not shown), but this yielded only a significant predictive effect of 
fear of movement for physical health. In none of the other analyses fear of movement was a significant predictor of outcome.

Recent studies found that helplessness may be strongly associated with the experience of chronic pain (Sullivan et al., 2005; Samwel et al., 2006). A recent prospective study in patients with acute whiplash injury gave evidence for this hypothesis (Berglund et al., 2006). Berglund et al. (2006) demonstrated that feelings of helplessness measured in the acute stage of whiplash injury were a significant predictor of neck pain intensity, disability, anxiety and depression. Post hoc analyses on our data revealed similar results. The Helplessness dimension of the PCS was a significant predictor for all outcome measures (including those variables for which the sum score of PCS did not reach significance), whereas Magnification and Rumination were not. Moreover, the significant effect of Helplessness was less influenced by adding anger to the model. Only for pain as outcome variable, the effect of Helplessness disappeared. It is suggested that a helplessness orientation to pain might be associated with the use of other passive or avoidant strategies, such as resting that might contribute to heightened pain (Samwel et al., 2006).

In contrast to other research we did not find evidence that range of motion is predictive for the maintenance of perceived disability. The first explanation could lie in the fact that patients were free to seek treatment for their complaints. Although we cannot conclude this from our results, it is likely that their restricted range of motion will be their first target for requesting treatment as opposed to psychological complaints. Further research is warranted to see whether treatment in the first six months has an influence on perceived disability and on restricted range of motion. Second we included passive range of motion in our analyses, since this may be a more objective measure of range of motion than active range of motion, which may be influenced by pain and avoidance. Other researchers mainly used active range of motion (e.g. Sterling et al., 2005). However, when reanalyzing our data with measures of active range of motion we did not find a significant effect either.

We also tested the influence of the explorative factor anger on all outcome variables. Anger appeared to be a strong predictor for all outcome variables. Notably, when anger was entered to the model, pain catastrophizing was no longer a significant predictor of disability and mental health. To our knowledge this is the first study that has investigated the prognostic value of anger in a prospective study and in relation to multiple outcome measures. Although our study shows that anger and pain catastrophizing are significantly related to each other (Pearson's $r=.335, \mathrm{p}=$ $<.001$ ), our study does not provide insight in the mechanisms involved. Chemtob et al. (1997) described the "survival mode theory". This model states that patients with post-traumatic stress have a lower threshold to perceive situations as being dangerous and under certain conditions may respond with a context-inappropriate activation of a "survival-mode" of functioning. The experience of danger will activate a 
biological predisposed survival mode with both fear and flight reactions as well as anger and fight reactions. The model suggests that both fear and anger responses are activated when encountering a threatening event and that they are linked in a reciprocal feedback loop. This model was proposed in research with people suffering from post-traumatic stress disorder, but our results indicate that in patients with acute whiplash injury feelings of "fight" (anger) and "flight" (pain catastrophizing) are also both activated. Our results do not answer the question why for most outcome variables the effect of anger is stronger than the effect of fear. Foa et al. (1995) suggests that victims of trauma are motivated to avoid trauma-related feelings of anxiety by feeling angry. When experiencing an intrusion they will not respond by fear but by anger. Anger is seen as having a more positive valence than anxiety and in their "fear avoidance" theory in relation to PTSD, anger has the function of diverting the attention away from anxiety. A similar reaction may be proposed to occur in individuals experiencing a motor vehicle accident, especially when they suffer from a high degree of complaints after the event.

It also may be the case that although anger is related to pain in different pain populations and healthy controls, it could be a variable of specific influence in patients whose pain complaints are the result of an injury arising from a mishap or accident in which someone may be held answerable (Fernandez and Turk, 1995). This is probably the case in the majority of patients suffering from whiplash injury since in our study $82 \%$ of patients indicated that they were not to blame for the motor vehicle accident. The anger in these MVA victims may be specifically directed towards the person responsible for the accident. Our first preliminary analyses using the item "anger towards person to blame" as a predictor instead of the mean anger score, indicated that this might be the case for depression, post-traumatic stress and quality of life, but not for disability and pain.

It is notable that our study has a high percentage of patients still reporting complaints at follow-up. Approximately $72 \%$ of patients at follow-up still reported complaints as a result of their Motor Vehicle Accident. This percentage is higher than earlier prospective studies, reporting percentages ranging from 0 to 50 and suggests sample bias. When we recalculate our numbers including the drop-outs, the percentage of people still reporting complaints is more in line with previous research. We retrieved information from 211 patients on whether they still had complaints (see table 1). Taking these drop-outs into account, approximately $55 \%$ of all patients that filled in the questionnaires at baseline, still reported having some degree of pain or disability.

The 6-months prevalence of psychological complaints also proved to be very high. Using the clinical cut-off scores, up to $37 \%$ of participants reported depression and $42 \%$ was classified as having Post-Traumatic Stress Disorder. However, the clinical cut-of on the PSS-SR for PTSD is quite low, and recalculating it to a score higher 
than 28 (Coffey et al., 1998), changed the percentage to $11 \%$. The high percentage of patients still reporting complaints is unexpected, since the institutions that referred patients to our study where specifically selected for their diversion in possible participants. In addition to emergency departments, we also selected a Traffic Police Department to refer MVA victims to us. This department had a higher chance of referring patients to us that underwent the same event (being the motor vehicle accident), but probably not experiencing complaints severe enough to attend an emergency care department and possibly no complaints at all.

Several aspects of the study could have affected the validity of the results. First, the drop-out in our study was much higher than the expected $20 \%$. More than $50 \%$ of our patients did not fill in follow-up questionnaires. The majority of patients in the drop-out recovered, but a large proportion still complained of having pain or disability as a result of their motor vehicle accident. The large drop-out may interfere with the generalizibility of our results. Second, although we found significant results for anger, it is necessary to underline the fact that we did not used a standardized questionnaire to measure this concept, but an adapted version of the Targets of Anger Scale. Further research is necessary to investigate the validity and reliability of this questionnaire

In conclusion, this study shows that pain catastrophizing and anger are predictors of physical and psychological complaints, six months after a motor vehicle accident. Pain catastrophizing and anger therefore present us with tools to screen patients at risk at the early stages of acute whiplash injury. Furthermore, pain catastrophizing provides us targets for implementing early intervention strategies, aimed at reducing catastrophizing and fearful thoughts about pain and disability. Anger shows promising results, but more research is needed to make strong recommendations regarding its predictive value, underlying mechanisms and clinical use.

\section{Acknowledgments}

This research was supported by grant 940-31-071 from the Dutch Organisation for Scientific Research. The authors are grateful to the Emergency Care Units of Ziekenhuis Oost Limburg Genk, Salvator Hasselt, Academisch Ziekenhuis Maastricht, Atrium Heerlen and Maaslandziekenhuis Sittard and the Dutch Traffic Police (ZuidLimburg) for referring patients to our study. 


\section{REFERENCES}

Beekman ATF, van Limbeek J, Deeg DJH, Wouters L, van Tilburg W. Een screeningsinstrument voor depressie bij ouderen in de algemene bevolking: de bruikbaarheid van de Center for Epidemiologic Studies Depression Scale (CES-D). Tijdschrift voor Gerontologie en Geriatrie 1994;25:95-103.

Berglund A, Alfredsson L, Cassidy JD, Jensen I, Nygren A. The association between exposure to a rearend collision and future neck or shoulder pain: a cohort study. Journal of Clinical Epidemiology 2000;53:1089-1094.

Berglund A, Bodin L, Jensen I, Wiklund A, Alfredsson L. The influence of prognostic factors on neck pain intensity, disability, anxiety and depression over a 2-year period in subjects with acute whiplash injury. Pain 2006;125(3):244-256.

Boersma K, Linton SJ. Expectancy, fear and pain, in the prediction of chronic pain and disability: A prospective analysis. European Journal of Pain 2006;10(6):551-557.

Buer N, Linton SJ. Fear-Avoidance beliefs and catastrophizing: occurence and risk factor in back pain and ADL in the general population. Pain 2002;99(3):485-491.

Buitenhuis J, Jaspers JPC, Vaclav F. Can Kinesiophobia Predict the Duration of Neck Symptoms in Acute whiplash? The Clinical Journal of Pain 2006;22(3):272-277.

Chemtob CM, Novaco RW, Hamada RS, Gross DM, Smith G. Anger Regulation Deficits in CombatRelated Posttraumatic Stress Disorder. Journal of Traumatic Stress 1997;10(1):17-36.

Coffey SF, Dansky BS, Falsetti SA, Saladin ME, Brady KT. Screening for PTSD in a substance abuse sample: psychometric properties of a modified version of the PTSD Symptom Scale Self-Report. Journal of Traumatic Stress 1998;11(2):393-399.

Côté P, Cassidy JD, Carroll L, Frank JW, Bombardier C. A systematic review of the prognosis of acute whiplash and a new conceptual framework to synthesize the literature. Spine 2001;26(19):E445E458.

Fernandez E, Turk DC. The scope and significance of anger in the experience of chronic pain. Pain 1995;61(165-175):165-175.

Foa EB, Riggs DS, Dancu CV, Rothbaum BO. Reliability and validity of a brief instrument for assessing post-traumatic stress disorder. . Journal of Traumatic Stress 1993;6(4):459-473.

Foa EB, Riggs DS, Dancu CV, Rothbaum BO. The impact of fear activation and anger on the efficacy of exposure treatment for posttraumatic stress disorder. Journal of Traumatic Stress 1995;6:459-473.

Goubert L, Crombez G, Van Damme S. The role of neuroticism, pain catastrophizing and pain-related fear in vigilance to pain: a structural equations approach. Pain 2004;107:234-241.

Helmerson Ackelman B, Lindgren U. Validity and reliability of a modified version of the neck disability index. Journal of Rehabilitation Medicine 2002;34:284-287.

Karlsborg M, Smed A, Jespersen H, Stephensen S, Cortsen M, Jennum P, Herning M, Korfitsen E, Werdelin L. A prospective study of 39 patients with whiplash injury. Acta Neurologica Scandinavica 1997;95:65-72.

Kasch H, Bach FW, Jensen TS. Handicap after acute whiplash injury. A 1-year prospective study of risk factors. Neurology 2001a;56:1637-1643.

Kasch H, Stengaard-Pedersen K, Arendt-Nielsen L, Jensen TS. Headache, neck pain and neck mobility after acute whiplash injury. A prospective study. Spine 2001b;26(11):1246-1251.

Kori SH, Miller RP, Todd DD. Kinesiophobia: a new view of chronic pain behaviour. Pain Management 1990;january/february:35-43.

Linton SJ. Do psychological factors increase the risk for back pain in the general population in both a cross-sectional and prospective analysis? European Journal of Pain 2005;9(4):355-361.

Miller RP, Kori SH, Todd DD. The Tampa Scale 
Nederhand MJ, Hermens HJ, Ijzerman MJ, Groothuis KGM, Turk DC. The effect of fear of movement on muscle activation in posttraumatic neck pain disability. The Clinical Journal of Pain 2006;22(6):519525 .

Nederhand MJ, Ijzerman MJ, Hermens H, Zilvold G. Predictive value of fear avoidance in developing chronic neck pain disability: consequences for clinical decision making. Archives of Physical Medicine and Rehabilitation 2004;85(3):496-501.

Okifuyi A, Turk DC, Curran SL. Anger in chronic pain: investigations of anger targets and intensity. Journal of Psychosomatic Research 1999;47(1):1-12.

Olsson I, Bunketorp O, Carlsson SG, STyf J. Prediction of Outcome in Whiplash-Associated Disorders Using West Haven-Yale Multidimensional Pain Inventory. The Clinical Journal of Pain 2002;18:238244.

Radloff LS. the CES-D scale: a self-report depression scale for research in the general population. Applied Psychological Measurement 1977;1(3):385-401.

Rodriquez AA, Barr KP, Burns SP. Whiplash: pathophysiology, diagnosis, treatment, and prognosis. Muscle \& Nerve 2004;29:768-781.

Roelofs J, Goubert L, Peters ML, Vlaeyen J, Crombez G. The Tampa Scale for Kinesiophobia: further examination of psychometric properties in patients with chronic low back pain and fibromyalgia. European Journal of Pain 2004;8(5):495-502.

Samwel HJA, Evers AWM, Crul BJP, Kraaimaat FW. The Role of Helplessness, Fear of Pain, and Passive Pain-Coping in Chronic Pain Patients. The Clinical Journal of Pain 2006;22(3):245-251.

Sanderman R, Arrindell WA, Ranchor AV, Eysenck HJ, Eysenck SBG. Het meten van persoonlijkheidskenmerken met de Eysenck Personality Questionnaire (EPQ). Groningen: Stichting Drukkerij C. Regenboog.

Scholten-Peeters GGM, Verhagen AP, Bekkering GE, van der Wint DAWM, Barnsley L, Oostendorp RAB, Hendriks EJM. Prognostic factors of whiplash-associated disorders: a systematic review of prospective cohort studies. Pain 2003;104:303-322.

Severeijns R, Vlaeyen JWS, Van den Hout MA, Picavet HSJ. Pain Catastrophizing and consequences of musculoskeletal pain: A prospective study in the Dutch community. The Journal of Pain 2005;6(2):125-132.

Sterling M, Jull G, Vicenzino B, Kenardy J, Darnell R. Development of motor system dysfunction following whiplash injury. Pain 2003a;103:65-73.

Sterling M, Jull G, Vicenzino B, Kenardy J, Darnell R. Physical and psychological factors predict outcome following whiplash injury. Pain 2005;114:141-148.

Sterling M, Kenardy J, Jull G, Vicenzino B. The development of psychological changes following whiplash injury. Pain 2003b;106:481-489.

Sterner Y, Toolanen G, Gerdle B, Hildingson C. The Incidence of Whiplash Trauma and the Effects of Different Factors on Recovery. Journal of Spinal Disorders \& Techniques 2003;16(2):195-199.

Sullivan MJL, Bishop SR, Pivik J. The Pain Catastrophizing Scale: Development and validation. Psychological Assessment 1995;7(4):524-532.

Sullivan MJL, Lynch ME, Clark AJ. Dimensions of catastrophic thinking associated with pain experience and disability in patients with neuropathic pain conditions. Pain 2005;113:310-315.

Sullivan MJL, Stanish W, Waite H, Sullivan M, Tripp DA. Catastrophizing, pain and disability in patients with soft-tissue injuries. Pain 1998;77:253-260.

Swinkels-Meewisse EJCM, Swinkels RAHM, Verbeek ALM, Vlaeyen JWS, Oostendorp RAB. Psychometric properties of the Tampa Scale for Kinesiophobia and the fear-avoidance beliefs questionnaire in acute low back pain. Manual Therapy 2003;8(1):29-36. 
Van Damme S, Crombez G, Bijttebier P, Goubert L, Van Houdenhove B. A confirmatory factor analysis of the Pain Catastrophizing Scale: invariant factor structure across clinical and non-clinical populations. Pain 2002;96:319-324.

van der Zee KI, Sanderman R. Het meten van de algemene gezondheidstoestand met de RAND-36: een handleiding. Groningen: Noordelijk centrum voor gezondheidsvraagstukken, 1993.

Vernon H. The Neck Disability Index: Patient Assessment and Outcome Monitoring in Whiplash. Journal of Musculoskeletal Pain 1996;4:95-104.

Vernon H. Correlations among ratings of pain, disability and impairment in chronic whiplash-associated disorders. Pain Research Management 1997;2(4):207-213.

Vlaeyen JWS, Kole-Snijders AMJ, Boeren RGB, van Eek H. Fear of movement/(re)injury in chronic low back pain and its relation to behavioral performance. Pain 1995;62:363-372. 
Chapter 6

\section{An experimental investigation on attentional interference by threatening fixations of the neck in patients with chronic whiplash syndrome}

Karoline Vangronsveld, Stefaan Van Damme, Madelon Peters, Johan Vlaeyen, Mariëlle Goossens, Geert Crombez 


\begin{abstract}
Previous studies using a primary task procedure have demonstrated that an experimental pain stimulus interrupts ongoing task performance in healthy volunteers and patients, and that this interruption is intensified by catastrophic thinking about pain and the perceived threat value of the pain stimulus. However, no studies have investigated the interruption of attention by relevant threatening stimuli in specific patient samples. In the present study, 40 patients with chronic whiplash syndrome and 40 healthy controls performed a primary task while simultaneously a potentially threatening neck fixation (i.e., extension and rotation) was imposed. Pain catastrophizing, fear of movement/(re)injury, hypervigilance, and depression were assessed. The patients showed a more pronounced deterioration of performance compared to controls when the neck rotation and extension fixations were introduced. Within the groups, neither catastrophic thinking nor fear predicted the magnitude of the performance deterioration.
\end{abstract}




\section{INTRODUCTION}

Psychosocial factors, such as pain catastrophizing and pain-related fear, have been found to be important in the exacerbation and maintenance of chronic low back pain problems (Vlaeyen et al., 1995a; Vlaeyen et al., 1995b; Vlaeyen and Linton, 2000). Few studies have explored the role of these variables in other pain syndromes. For example, it is plausible that these variables are also of value in patients with chronic neck pain after a motor vehicle accident. Indeed, some of these patients report high levels of pain catastrophizing and pain-related fear (Nederhand, 2004). Accordingly, it is reasonable to assume that similar psychosocial mechanisms as in chronic low back pain apply. In this study we explore one of these mechanisms, i.e. attention.

When pain is interpreted as a physical threat, it demands attention and interrupts ongoing activities. This is a normal mechanism related to the activation of a primitive defensive system that urges escape from somatic threat (Eccleston and Crombez, 1999). However, when pain is chronic and no immediate cure is available, patients may become overalert for pain and its cues, resulting in a persistent disruption of attention and behavior. Such overalertness, or "hypervigilance" emerges when patients experience intense pain, have catastrophic thoughts about pain, and become fearful of pain (Goubert et al., 2004; Crombez et al., 2005).

Studies investigating the variables that are implicated in (hyper)vigilance, have most often used a primary task paradigm (Crombez et al., 1994; Eccleston, 1994), in which participants are instructed to perform an attention-demanding task (e.g., differentiating two different tones) while experiencing pain (e.g., an electrocutaneous stimulus). A decrease in task performance during pain is considered a measure for the attentional interruption by pain. Interference by pain has been demonstrated in both healthy volunteers and pain patients ((Crombez et al., 1996; 1998a; Crombez et al., 1999; Crombez et al., 2002). Attentional interruption has been found to be amplified by (1) the novelty of pain (Crombez et al., 1994), (2), the threat of intense pain (Crombez et al., 1998a), (3) increased somatic awareness (Eccleston et al., 1997), (4) pain-related fear (Crombez et al., 1999) and (5) pain catastrophizing (Crombez et al., 1998b; Peters et al., 2000; Peters et al., 2002; Vancleef and Peters, In Press).

In the current experiment we investigated attentional disruption in patients with chronic whiplash syndrome using the primary task paradigm. We used (potentially) noxious stimuli with particular relevance to this patient group. Pilot testing with several movements indicated that especially rotating and extending the neck is considered threatening by these patients. Therefore as a threatening stimulus we used fixations of the neck in a rotated or extended position during task performance. We hypothesized that patients would show stronger interference of task performance during neck fixations than healthy controls. We also expected that within the patient 
group, high pain catastrophizing and high pain-related fear would be associated with stronger interference.

\section{METHOD}

\section{Participants}

Forty chronic whiplash patients who responded to an advertisement in a journal of the Dutch and Belgian Whiplash patients' associations and 40 healthy control persons who were recruited from a list of volunteers completed the experiment. The groups were matched for sex and age (65\% females, in both groups; mean age of the control group 47 years, [SD $=11.2]$; mean age of the patient group 47 years, [SD = 11.0]). Patients had complaints of neck pain after a motor vehicle accident for a minimum of 6 months $($ Mean $=6.7$ years, $\mathrm{SD}=3.4)$. 57,5 percent of the controls had a paid job of more than 20 hours a week, compared to 47,5 percent in the patient group. All participants gave informed consent and were free to terminate the experiment at any time.

\section{Questionnaires}

Disability: The Dutch version of the Neck Disability Index (NDI) consists of 10 items concerning functional activities, pain intensity, concentration and headache. The 10 items are scored 0 (no activity limitations) to 5 (major activity limitations) and summed to yield a total score. The NDI is a valid and reliable instrument, sensitive to measure changes within a population of neck pain patients (Vernon, 1997; Helmerson Ackelman and Lindgren, 2002).

Pain Catastrophizing: Participants completed the Dutch version of the Pain Catastrophizing Scale (PCS; (Sullivan et al., 1995)). Respondents are asked to reflect on past painful experiences and to indicate the degree to which they experienced each of the 13 thoughts or feelings during pain on a five point scale from 0 (not at all) to 4 (all the time). The Dutch version of the PCS has been shown to be valid and reliable (Van Damme et al., 2002a).

Fear of movement/(re)injury: The Dutch version of the Tampa Scale for Kinesiophobia (TSK: (Miller et al., 1991)) was used to measure fear of movement/(re)injury. The 17 items are scored on a four point scale from "I don't agree at all" (1) to "I absolutely agree" (4). The scale has a good internal consistency and a good test - retest reliability (Swinkels-Meewisse et al., 2003; Roelofs et al., 2004). Attention to pain: The Dutch version of the Pain Vigilance and Awareness Questionnaire (PVAQ; (McCracken, 1997) is a 16 items scale used to measure attention 
to pain. Subjects are instructed to think back to their pain experiences in the last two weeks and rate the frequency with which they attended to pain from 0 (never) to 5 (always). The Dutch version of the PVAQ has good internal consistency and good construct validity (McWilliams and Asmundson, 2001; Roelofs et al., 2003).

Depression: The Center for Epidemiological Studies Depression Scale (CES-D; (Radloff, 1977)) consists of 20 items to measure different dimensions of depression. Questions are rated on a four point scale (0-3). The Dutch version of the CES-D has a good internal consistency and a very good sensitivity and specificity (Beekman et al., 1994).

Manipulation check: Pain was assessed using visual analog scales (VAS) consisting of a $100 \mathrm{~mm}$ horizontal line anchored with two labels "no pain at all" on the left side and with "worst pain ever" on the right side (Price et al., 1983). For the threat value and the unpleasantness of the fixations VAS's were used with the anchors "not at all threatening" and "extremely threatening" and "not at all unpleasant" and "extremely unpleasant".

\section{Primary task}

The primary task paradigm was programmed and presented by the E-prime software package (Psychology Software Tools, Inc, 2002) on an AMD Athlon $500 \mathrm{Mhz}$ computer with a $85 \mathrm{~Hz}, 17$-inch color monitor. E-prime measures response times with millisecond accuracy.

The frequencies of the tones were adopted from previous experimental studies (Crombez et al., 1996; 1998b; Crombez et al., 1999). High (1000 Hz) and low (250 $\mathrm{Hz}$ ) pitch tones (200 ms duration) were emitted by the speakers of the computer. Participants responded with two fingers by pressing the left or the right button on a response box. Which button (left or right) corresponded to which tone (high or low) was counter-balanced. Tones were randomized via E-prime with the restriction that no more than three consecutive trials consisted of a tone with the same pitch. The task was presented five times (see below) with each phase consisting of 54 trials. There was no fixed inter-trial interval. Participants had to press a button on the response box to generate the next tone.

\section{Procedure}

The experiment was approved by the Medical Ethical Committee of the University Hospital Maastricht. Participants were tested individually in a sound attenuated room designed for psychophysiological experiments. Participants gave informed consent. At the start of the experiment participants were asked to rate their current pain on a VAS. Participants were then seated in front of a computer to perform the 
task. All instructions were presented on the computer screen. Participants were instructed to respond to the high and low tones as quickly as possible without sacrificing accuracy.

The auditory discrimination task was performed during five phases.

Baseline phase 1: participants completed the tone task without any distraction.

Rotation Phase: participants performed the tone discrimination task while the head was fixated in a rotated position. More specifically, participants wore a regular somi-brace with thorax-fixating neck collars, which was adapted for this experiment with a flexible and removable chin rest (see figure 1). The head was rotated and fixated at $45^{\circ}$ degrees to the side that participants themselves indicated as their "worst" side, or in the case there was no worst side, to the left.

Baseline Phase 2: the brace was removed and participants only performed the tone discrimination task.

Extension Phase: participants performed the tone discrimination task while the head was fixated in an extended position. This time participants had to extend their head as far as possible, while their chin was placed on the chinrest.

Baseline Phase 3: the brace was removed and participants again performed only the tone discrimination task.

Manipulation check: immediately after baseline phase 3, participants rated to what extent they found the rotation and the extension of the head threatening, painful and unpleasant on the VAS scale. Finally, at the end of the experiment participants rated again their current pain.

Each phase lasted 5 to 6 minutes, depending on the patients' speed. Between each phase there was a short period of a few minutes of rest in which the brace was attached or removed and in which patients received the new instruction.

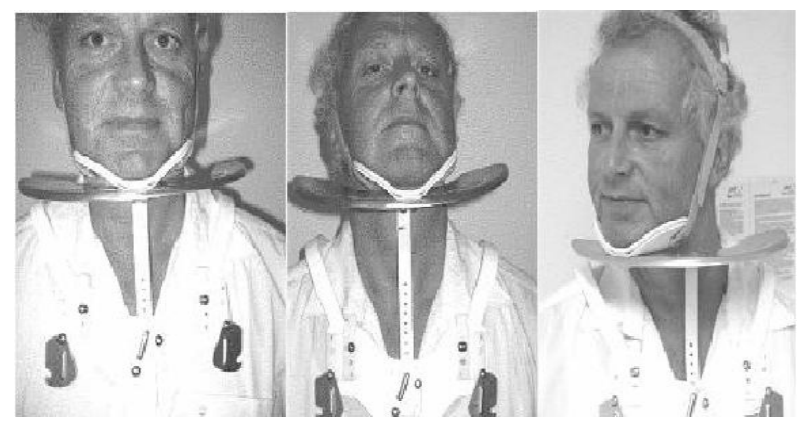

Figure 1: the modified somi brace. The chin can rest on a modified chin rest and can be fixated in a rotated and extended position 


\section{Statistical analyses}

Analyses were conducted with the Statistical Package for the Social Sciences version 11.0 (SPSS Inc., 444N. Wacker Drive, Chicago, IL, 60606, USA). The main analyses used repeated measures analysis of variance (ANOVA) with phase as the within subject factor and group as the between subjects factor.

\section{RESULTS}

\section{Self-report data}

Patients reported significantly higher scores than controls for neck pain disability, pain catastrophizing, fear of movement/(re)injury, attention to pain and depression. Table 1 presents an overview. Though patients showed elevated scores on the CES$\mathrm{D}$, they can not be considered clinically depressed. As expected, patients rated both fixations (rotation and extension of the neck) as more threatening, more painful and more unpleasant than controls (table 1).

Table 1: Summary scores of questionnaires, Vas-scales of fixations and interference indexes: mean scores, standard deviations, and Independent samples t-test

\begin{tabular}{|c|c|c|c|c|}
\hline & $\begin{array}{c}\text { Controls } \\
\text { Mean (SD) }\end{array}$ & $\begin{array}{c}\text { Patients } \\
\text { Mean (SD) }\end{array}$ & $t(d f)$ & Sig. (2-tailed) \\
\hline$\overline{\mathrm{NDI}}$ & $3.83(5.38)$ & $23.87(7.68)$ & $-13.53(78)$ & $<.001$ \\
\hline TSK & $31.08(6.25)$ & $36.63(6.77)$ & $-3.59(78)$ & $<.001$ \\
\hline PCS & $9.10(9.04)$ & $15.08(10.72)$ & $-2.70(78)$ & .009 \\
\hline PVAQ & $27.78(12.09)$ & $33.57(9.29)$ & $-2.41(78)$ & .019 \\
\hline CES-D & $15.70(6.78)$ & $19.05(6.44)$ & $-2.27(78)$ & .026 \\
\hline Baseline PAIN & $7.30(14.59)$ & $48.85(23.23)$ & $-9.58(78)$ & $<.001$ \\
\hline PAIN after exeperiment & $3.38(11.78)$ & $51.03(25.46)$ & $-10.74(78)$ & $<.001$ \\
\hline rotation: threat & $10.20(19.62)$ & $43.10(29.04)$ & $-5.94(78)$ & $<.001$ \\
\hline rotation: pain & $6.75(14.68)$ & $46.28(27.23)$ & $-8.08(78)$ & $<.001$ \\
\hline rotation: unpleasantness & $18.88(27.95)$ & $54.68(27.03)$ & $-5.82(78)$ & $<.001$ \\
\hline extension: threat & $16.55(23.56)$ & $62.13(30.0)$. & $-7.52(78)$ & $<.001$ \\
\hline extension: pain & $10.30(18.16)$ & $64.28(25.32)$ & $-10.91(78)$ & $<.001$ \\
\hline extension: unpleasantness & $30.28(32.65)$ & $72.67(27.53)$ & $-6.23(78)$ & $<.001$ \\
\hline$\Delta$ RT2-RT1 & $7.53(60.98)$ & 93.15 (166.77) & $-3.05(78)$ & .003 \\
\hline$\Delta$ RT4-RT3 & $7.23(44.88)$ & $95.42(187.32)$ & $-2.90(78)$ & .005 \\
\hline
\end{tabular}




\section{Primary task data}

For the analyses of the reaction times (RT's), the first 10 trials of each phase were considered familiarization trials and were therefore removed from statistical analyses. Within subjects, outliers in the RT data were also removed (range: individual mean RT +/- 2 individual SD) (Ratcliff, 1993). Figure 2 shows the mean response times (RT) per phase for each group.

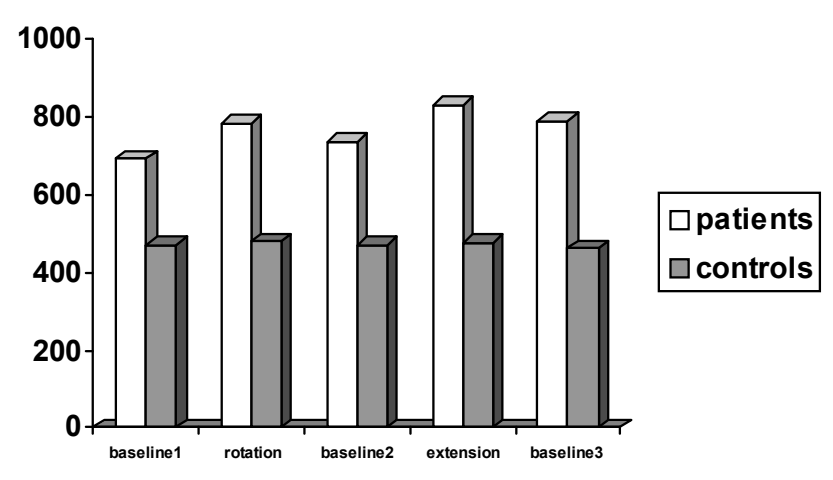

Figure 2: Mean RT's per phase for each group

A 2 (group: control, patient) x 5 (Phase: baseline 1, rotation, baseline 2, extension, baseline 3) ANOVA with repeated measures showed that there was a main effect for group $(\mathrm{F}(1,78)=38.60, \mathrm{p}<0.001)$. Patients $(\mathrm{M}=766 \mathrm{~ms}, \mathrm{SD}=285)$ were overall slower than controls $(\mathrm{M}=472 \mathrm{~ms}, \mathrm{SD}=91)$. There was also a main effect for phase, $(\mathrm{F}(4,75)=4.91, \mathrm{p}=0.001)$ which was further qualified by a phase $\mathrm{x}$ group interaction, $(F(4,75)=4.05, p=0.005)$. Repeated contrasts showed that the phase $x$ group interaction reached significance for the baseline 1 to rotation phases contrast $(\mathrm{F}(1,78)=9.3, \mathrm{p}=0.003)$ and for the baseline 2 to extension phase contrast $(\mathrm{F}(1,78)$ $=8.38, \mathrm{p}=0.005)$. Whereas patients showed increased RT's during both threat conditions compared to the previous baseline condition, controls did not show this delay. Simple first contrasts showed that patients did return to baseline in baseline 2 $(\mathrm{F}(1,78)=1.77, \mathrm{p}=0.188)$, but in baseline 3 there was still a significant increase in RT's compared to phase $1(\mathrm{~F}(1,78)=6.66, \mathrm{p}=0.012)$.

\section{Moderation and mediation}

Performance decrements were further analyzed by computing the differences in RT's for the two experimental phases minus baseline RT (RT rotation phase - RT baseline 1, RT extension phase - RT baseline 2) (see table 1). To test whether the delayed RT's were related to pain-related fear or pain catastrophizing, either in the whole group or specifically in patients, both interference indexes were subjected to hierarchical regression analyses with the factor group and total scores on the TSK 
and PCS as predictor variables in step 1, and the interactions between group x TSK and group x PCS as predictor variables in step 2. All variables met the assumption of homogeneity of variance. Only a significant effect of group was found. Pain-related fear nor pain catastrophizing contributed to the delay in RT's during rotation or extension. There were no significant interaction effects (see table 2).

Table 2: linear regression model

Independent: $\Delta$ RT2-RT1

\begin{tabular}{|c|c|c|c|c|c|c|c|}
\hline Step 1: & $\mathrm{R} 2=.12$ & $F=5.33$ & $\mathrm{p}=.007$ & Step 1: & $\mathrm{R} 2=.13$ & $F=5.75$ & $\mathrm{p}=.005$ \\
\hline & & $\beta$ & $\mathrm{P}$ & & & $\beta$ & $\mathrm{P}$ \\
\hline group & & .27 & .021 & Group & & .37 & .001 \\
\hline TSK & & .13 & .254 & PCS & & -.16 & .155 \\
\hline Step 2: & $\mathrm{R} 2=.13$ & $\mathrm{~F}=3.85$ & $\mathrm{p}=.013$ & Step 2: & $\mathrm{R} 2=.15$ & $\mathrm{~F}=4.30$ & $\mathrm{p}=.007$ \\
\hline \multicolumn{2}{|c|}{ group x TSK } & $\beta=.59$ & $\mathrm{p}=.341$ & $\overline{\text { group } \mathrm{x}}$ & & $\beta=-.27$ & $\mathrm{p}=.250$ \\
\hline
\end{tabular}

Independent: $\Delta$ RT4-RT3

\begin{tabular}{|c|c|c|c|c|c|c|c|}
\hline Step 1: & $\mathrm{R} 2=.10$ & $F=4.46$ & $\mathrm{p}=.015$ & Step 1: & $\mathrm{R} 2=.1$ & $F=4.30$ & $\mathrm{p}=.017$ \\
\hline & & $\beta$ & $\mathrm{P}$ & & & $\beta$ & $\mathrm{p}$ \\
\hline group & & .35 & .004 & Group & & .33 & .005 \\
\hline TSK & & -.09 & .448 & PCS & & -.06 & .596 \\
\hline Step 2: & $\mathrm{R} 2=.11$ & $\mathrm{~F}=3.03$ & $\mathrm{p}=.035$ & Step 2: & $\mathrm{R} 2=.11$ & $\mathrm{~F}=3.04$ & $\mathrm{p}=.034$ \\
\hline \multicolumn{2}{|c|}{ group x TSK } & $\beta=-.31$ & $\mathrm{p}=.622$ & \multicolumn{2}{|c|}{ group $x$ PCS } & $\beta=-.18$ & $\mathrm{p}=.446$ \\
\hline
\end{tabular}

Finally, we tested whether the delay in RT's was mediated by perceived threat or perceived painfulness of the rotation or extension. We tested mediation according to the guidelines by Baron and Kenny (1986). We used dummy variables ( $0=$ control, 1 = patient) for group identity. Group was a significant predictor of the delay in RT's as well as of the perceived threat and perceived pain during rotation and extension. However, as illustrated in figure 3, when group and perceived threat or perceived pain were simultaneously entered into the model as predictors of delayed RT's, the factor group remained the most prominent predictor. We repeated analyses with the factors group and pain increase (baseline pain - pain after experiment), but these analyses did not give evidence for mediation either. Thus the delay in RT's in the patient group does not seem to be mediated by their increased perception of threat or pain during fixations or by pain increase. 


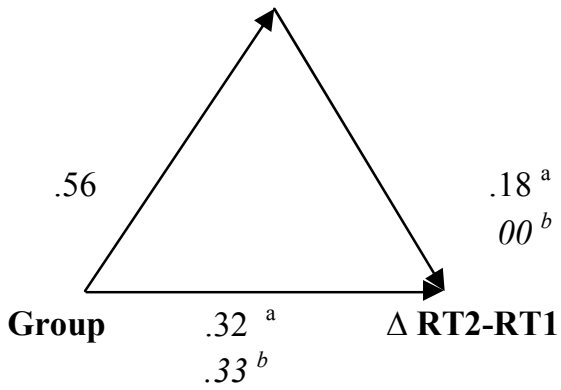

VAS threat extension

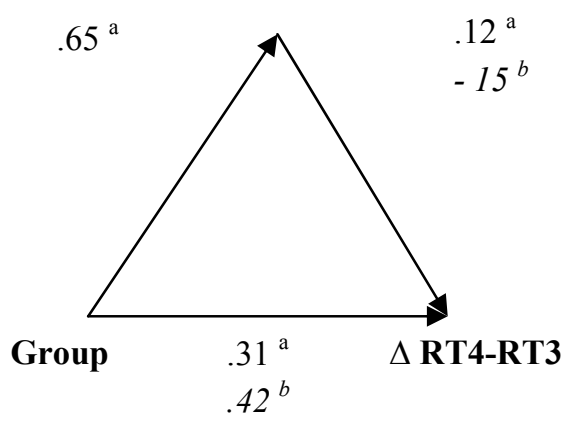

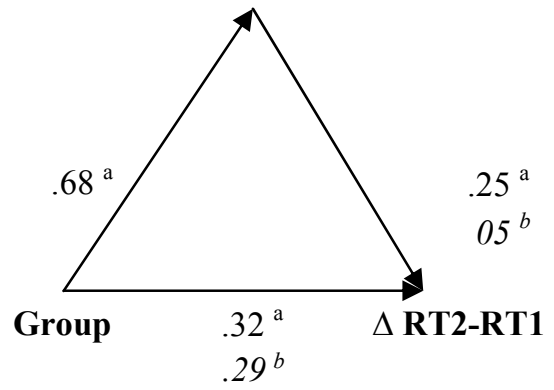

VAS pain extension

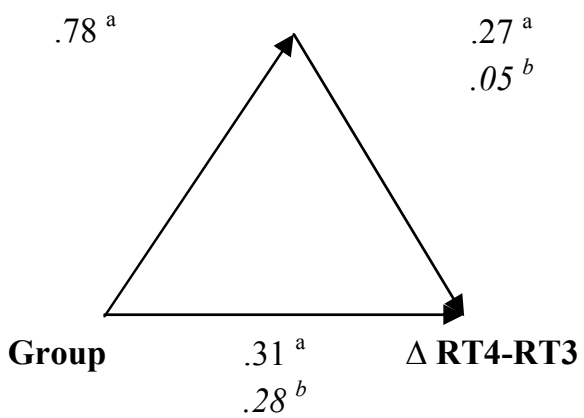

Figure 3: Analysis of mediator variables

${ }^{a}$ are the zero-order coefficients

${ }^{b}$ are the coefficients provided by de mediational model

\section{DISCUSSION}

The present study examined attentional interference by (potentially) noxious stimuli in patients with chronic whiplash syndrome and healthy controls. Fixation of the head and neck in either an extended or rotated position was used as noxious stimulation with particular relevance for patients with chronic whiplash syndrome. Patients showed performance decrements on a simple auditory reaction time task during neck fixations, whereas controls did not show interference by these fixations. The only significant predictor of performance decrement was group membership (being a patient or a healthy control). Individual differences in pain-related fear and catastrophizing nor perceived painfulness or threat of the fixation significantly affected the degree of interference. 
Our results reveal that activities that are perceived as threatening by patients demand attention and interfere with ongoing activity in patients with chronic whiplash syndrome. Previous studies have demonstrated that interference of performance by pain stimuli is present in both healthy subjects and in pain patients, and that this interference is increased by the threat value of the painful stimulus (Crombez et al., 1996; Eccleston et al., 1997; Crombez et al., 1998a; Crombez et al., 1999; Crombez et al., 2002; Vancleef and Peters, In Press). In the present study we used a somatic stimulus with particular relevance for patients with chronic whiplash syndrome. Indeed the neck fixations were perceived as more threatening in patients than in healhy controls. The fixations were also scored as more painful by patients. Thus the increased interference in patients versus controls may be a function of the higher threat value of the fixation, the higher pain experience during the fixations or both. However, we could not identify threat value or pain experience as mediators of the performance decrement. A shortcoming of the study was that we assessed pain levels, threat value and unpleasantness retrospectively at the end of the experiment. This may have caused a recall bias. Future experiments should assess these potential mediators during and immediately after task performance.

We further predicted that participants with higher levels of pain-related fear and pain catastrophizing would show more interference than participants with lower levels of pain-related fear and catastrophizing (Eccleston et al., 1997; Peters et al., 2000; de Gier et al., 2003). However, we only found a significant effect of group. None of the other variables were significant in explaining attentional interference. Also, the effect of pain-related fear or catastrophic thinking about pain did not differ between patients and healthy controls. We did not find moderation effects. One possible explanation for the absence of effects of individual differences is the overall low level of pain catastrophizing in our sample of patients. Catastrophic thinking about pain in other samples of patients with whiplash injuries (Sullivan et al., 1998; Sullivan et al., 2002a; Sullivan et al., 2002b) are almost twice as high as in the present study. A low level of pain catastrophizing may have reduced the power to detect significant effects. However, the scores of pain-related fear (TSK) are not in line with this argument. The TSK scores were in line with those of other samples of chronic pain patients (Peters et al., 2002; Nederhand et al., 2004). Furthermore, as was expected, pain-related fear and pain catastrophizing were highly interrelated in our sample

A plausible explanation for our findings may be found in our choice of neck fixations as experimental stimulus. In previous studies, electrocutaneous stimuli, that were rated as mildly or moderately threatening, were used (Crombez et al., 1996; 1998a; b; Crombez et al., 2002; Peters et al., 2002). In this study, patients rated the neck fixations as highly aversive in our sample. This may have limited the impact of individual differences in pain catastrophizing and pain-related fear. It is possible that 
all patients experienced the neck fixations as highly threatening and attentionally demanding. Indeed, according to some theoretical models (Eccleston and Crombez, 1999; (Mogg and Bradley, 1998) everybody should attend to threat or pain when it is perceived as highly threatening. Future studies may choose less threatening stimuli that allow more variation between patients.

It should be noted that patients were also slower in their task performance during baseline conditions in comparison with the healthy controls. This parallels earlier findings of studies comparing reaction time performance between patients with pain complaints and healthy controls (Peters et al., 2000; Peters et al., 2002)). In patients with chronic whiplash syndrome, this slowed-down performance may be a particular prominent feature. Indeed, patients suffering neck pain after a motor vehicle accident often complain of impairment in cognitive processes, such as divided attention (Radanov and Dvorak, 1996). A meta-analysis of cognitive disorders in these patients showed that they perform badly on various neuropsychological tests of attentional performance such as the PASAT (Paced Auditory Serial Task) or the Stroop Colour-Word Test (Kessels and Aleman, 2000). At present it is unknown whether these attentional deficits are the result of physical injuries or the result of interference by pain and threat value of perceived symptoms and disability. However, our study shows that this attentional deficit may be differentially affected by experiences that are perceived as threatening and painful by patients.

We may conclude that there is an apparent effect of incoming (threatening) stimuli on the current allocation of attention. Patients with chronic whiplash syndrome show attentional interference due to threatening and painful fixations of the neck, but the degree of interference is not associated with elevated levels of perceived pain or threat. In further research, a more in depth analysis should be made to establish whether the attentional interference is enhanced by the pain sensation (sensory characteristics) or by its threat value (affective characteristics), or by the interplay of both factors. Though we used the most common mediational analysis in psychological research (Baron and Kenny, 1986), this method lacks power and could be responsible for not finding small or moderate effects. Though it's very unlikely to make a Type I error with this method, it is most likely to miss real effects. This problem could be solved by increasing the sample size in further research (MacKinnon et al., 2002). Furthermore, the different components of attention could be investigated which would provide more detailed information on retarded task performance. Based on findings in the anxiety literature (Fox et al., 2001; Koster et al., 2004), it has been argued that three components of attention for pain can be distinguished (Van Damme et al., 2002b): (1) an initial temporary shift of attention towards the threatening stimulus (attentional shift), (2) a long captivation of attention by the threatening stimulus (engagement) and (3) releasing the attention from the threatening stimulus (disengagement). Recent studies have indicated that the 
attentional demand of pain is particularly related to difficulties disengaging attention from pain and signals of impending pain (Van Damme et al., 2002b; 2004a; Van Damme et al., 2004b). However, this difficulty in disengaging from pain has only been demonstrated in healthy controls. In future research it would be interesting to investigate the different components of attention to relevant pain sensations in specific clinical populations.

\section{Acknowledgements}

This research was supported by grant 940-31-071 from the Dutch Organisation for Scientific Research. The authors are grateful to the Belgian and Dutch Whiplash Patients Association for their help in contacting the patients and to Livit Orthopedics, Maastricht, The Netherlands for manufacturing the modified somi-brace. 


\section{REFERENCES}

Baron, R. M. and Kenny D.A. The Moderator-Mediator Variable Distinction in

Social Psychological Research: Conceptual, Strategic, and Statistical Considerations. J Pers Soc Psychol 1986:51(6): 1173-1182.

Beekman ATF, van Limbeek J, Deeg DJH, Wouters L, van Tilburg W. Een screeningsinstrument voor depressie bij ouderen in de algemene bevolking: de bruikbaarheid van de Center for Epidemiologic Studies Depression Scale (CES-D). Tijdschrift voor Gerontologie en Geriatrie 1994;25:95-103.

Crombez G, Baeyens F, Eelen P. Sensory and temporal information about impending pain: the influence of predictability on pain. Behaviour research and therapy 1994;32(6):611-622.

Crombez G, Eccleston C, Baeyens F, Eelen P. The disruptive nature of pain: an experimental investigation. Behaviour research and therapy 1996;34(11-12):911-918.

Crombez G, Eccleston C, Baeyens F, Eelen P. attentional disruption is enhanced by the threat of pain. Behaviour research and therapy 1998a;36:195-204.

Crombez G, Eccleston C, Baeyens F, Eelen P. When somatic information threatens, catastrophic thinking enhances attentional interference. Pain 1998b;75:187-198.

Crombez G, Eccleston C, Baeyens F, Van Houdenhove B, van den Broeck A. Attention to chronic pain is dependent upon pain-related fear. Journal of Psychosomatic Research 1999;47(5):403-410.

Crombez G, Eccleston C, van den Broeck A, Van Houdenhove B, Goubert L. The effects of catastrophic thinking about pain on attentional interference by pain: no mediation of negative affectivity in healthy volunteers and in patients with low back pain. Pain research and management 2002;7(1):3139.

Crombez G, Van Damme S, Eccleston C. Hypervigilance to pain: an experimental and clinical analysis. Pain 2005;116:4-7.

de Gier M, Peters ML, Vlaeyen JWS. Fear of pain, physical performance, and attentional processes in patients with fybromyalgia. Pain 2003;104:121-130.

Eccleston C, Crombez G, Aldrich S, Stannard C. Attention and somatic awareness in chronic pain. Pain 1997;72:209-215.

Fox E, Russo R, Bowles R, Dutton K. Do threatening stimuli draw or hold attention in subclinical anxiety? Journal of Experimental Psychology 2001;130:681-700.

Goubert L, Crombez G, Van Damme S. The role of neuroticism, pain catastrophizing and pain-related fear in vigilance to pain: a structural equations approach. Pain 2004;107:234-241.

Helmerson Ackelman B, Lindgren U. Validity and reliability of a modified version of the neck disability index. Journal of Rehabilitation Medicine 2002;34:284-287.

Kessels RPC, Aleman A. Cognitieve stoornissen bij patiënten met het whiplashsyndroom. Een metaanalyse. Gedrag \& Gezondheid 2000;28(4):229-234.

Koster EHW, Crombez G, Verschuere B, De Houwer J. Selective attention to threat in te dot probe paradigm: differentiating vigilance and difficulty to disengage. Behaviour research and therapy 2004;42(10):1183-1192.

McCracken LM. "Attention" to pain in persons with chronic pain: A behavioral approach. Behavior Therapy 1997;28(2):271-284.

McWilliams LA, Asmundson GJG. Assessing individual differences in attention to pain: psychometric properties of the Pain Vigilance and Awareness Questionnaire modified for a non-clinical sample. Personality and individual differences 2001;31:239-246.

Miller RP, Kori SH, Todd DD. The Tampa Scale

Mogg K, Bradley BP. A Cognitive-motivational analysis of anxiety. Behaviour research and therapy 1998;36:809-848. 
Nederhand MJ, Ijzerman MJ, Hermens H, Zilvold G. Predictive value of fear avoidance in developing chronic neck pain disability: consequences for clinical decision making. Archives of Physical Medicine and Rehabilitation 2004;85(3):496-501.

Peters ML, Vlaeyen JWS, Kunnen AMW. Is pain-related fear a predictor of somatosensory hypervigilance in chronic low back pain patients? Behaviour Research and Therapy 2002;40:85-103.

Peters ML, Vlaeyen JWS, van Drunen C. Do fybromyalgia patients display hypervigilance for innocuous somatosensory stimuli? Application of a body scanning reaction time paradigm. Pain 2000;86:283292.

Price DD, McGrath PA, Rafii A, Buckingham B. The validation of visual analogue scales as ratio scale measures for chronic and experimental pain. Pain 1983;17:45-56.

Radanov BP, Dvorak J. Impaired cognitive functioning after whiplash injury of the cervical spine. Spine 1996;21(3):392-397.

Radloff LS. the CES-D scale: a self-report depression scale for research in the general population. Applied Psychological Measurement 1977;1(3):385-401.

Ratcliff R. Methods for dealing with reaction time outliers. Psychological Bulletin 1993;114(3):510-532.

Roelofs J, Goubert L, Peters ML, Vlaeyen J, Crombez G. The Tampa Scale for Kinesiophobia: further examination of psychometric properties in patients with chronic low back pain and fibromyalgia. European Journal of Pain 2004;8(5):495-502.

Roelofs J, Peters ML, McCracken L, Vlaeyen JWS. The pain vigilance and awareness questionnaire (PVAQ): further psychometric evaluation in fibromyalgia and other chronic pain syndromes. Pain 2003;101:299-306.

Sullivan MJL, Bishop SR, Pivik J. The Pain Catastrophizing Scale: Development and validation. Psychological Assessment 1995;7(4):524-532.

Sullivan MJL, Stanish W, Sullivan ME, Tripp D. Differential predictors of pain and disability in patients with whiplash injuries. Pain Research Management 2002a;7(2):68-74.

Sullivan MJL, Stanish W, Waite H, Sullivan M, Tripp DA. Catastrophizing, pain and disability in patients with soft-tissue injuries. Pain 1998;77:253-260.

Sullivan MJL, Sullivan ME, Adams HM. Stage of chronicity and cognitive correlates of Pain-related disability. Cognitive Behaviour Therapy 2002b;31(3):111-118.

Swinkels-Meewisse EJCM, Swinkels RAHM, Verbeek ALM, Vlaeyen JWS, Oostendorp RAB. Psychometric properties of the Tampa Scale for Kinesiophobia and the fear-avoidance beliefs questionnaire in acute low back pain. Manual Therapy 2003;8(1):29-36.

Van Damme S, Crombez G, Bijttebier P, Goubert L, Van Houdenhove B. A confirmatory factor analysis of the Pain Catastrophizing Scale: invariant factor structure across clinical and non-clinical populations. Pain 2002a;96:319-324.

Van Damme S, Crombez G, Eccleston C. Retarded disengagement from pain cues: the effects of pain catastrophizing and pain expectancy. Pain 2002b;100:111-118.

Van Damme S, Crombez G, Eccleston C. Disengagement from pain: the role of catastrophic thinking about pain. Pain 2004a;107:70-76.

Van Damme S, Lorenz J, Eccleston C, Koster EHW, De Clercq A, Crombez G. Fear-conditioned cues of impending pain facilitate attentional engagement. Clinical Neurophysiology 2004b;In Press.

Vancleef LMG, Peters ML. Pain Catastrophising, but not Injury/Iness Sensitivity or Anxiety Sensitivity enhances attentional interference in pain. Journal of Pain In Press.

Vernon H. Correlations among ratings of pain, disability and impairment in chronic whiplash-associated disorders. Pain Research Management 1997;2(4):207-213.

Vlaeyen JWS, Kole-Snijders AMJ, Boeren RGB, van Eek H. Fear of movement/(re)injury in chronic low back pain and its relation to behavioral performance. Pain 1995a;62:363-372. 
CHAPTER 6

Vlaeyen JWS, Kole-Snijders AMJ, Rotteveel AM, Ruesink R, Heuts PHTG. The role of fear of movement/(re)injury in pain disability. Journal of Occupational Rehabilitation 1995b;5(4):235-252.

Vlaeyen JWS, Linton SJ. Fear-avoidance and its consequences in chronic musculoskeletal pain: a state of the art. Pain 2000;85:317-332. 
Chapter 7

\section{The relationship of self-discrepancies, mood, Fear of movement and pain catastrophizing in patients with acute whiplash injury}

Karoline Vangronsveld, StephenMorley, Madelon Peters, Mariëlle Goossens, Johan Vlaeyen, 


\begin{abstract}
When pain becomes chronic and interferes repeatedly with major goals in life it will have an impact on the self-schemata and, thereby on the person's identity. The identity of the person is being taken over by pain and important aspects of the self are trapped by pain. People will undertake actions or set goals to either approach an ideal self or avoid a feared self. These approach and avoidance behaviours could be linked to or guided by specific fears, such as fear of movement and pain catastrophizing.
\end{abstract}

A single cohort of 60 patients with acute whiplash injury filled out a set of baseline questionnaires on pain, disability, fear of movement, pain catastrophizing and selfdiscrepancies and self-pain enmeshment (SPE) within one month after their motor vehicle accident. During 21 days, participants kept daily diaries and recorded details of pain, mood, self-discrepancies, pain catastrophizing and fear of movement. Follow-up assessment of the self-discrepancy questionnaire and self-pain enmeshment questionnaire was obtained at day 21 .

Self-discrepancies as measured by the questionnaires remained stable over time, while SPE significantly decreased over time. In the diary, the actual-ideal (AI) concordance significantly improved over time. For the questionnaires, significant associations with mood were found for the AI-discrepancy but not with the Actualfeared (AF) discrepancy or SPE. There were no significant associations between the AI-discrepancy, SPE and pain or disability. Fear of Movement was not related to any of the questionnaires, but Pain Catastrophizing significantly correlated with SPE. In the diary we found significant relationships with improvement on the AIconcordance and increase in positive mood and a decrease in levels of pain, disability and fear of movement. Multilevel analyses on the diary revealed that in the acute stage of whiplash injury self-discrepancies are present and that they are related to mood, pain, disability, fear of movement and pain catastrophizing. 


\section{INTRODUCTION}

Pain has the capacity of demanding attention and interrupting ongoing activities. This is a normal mechanism related to the activation of a primitive defensive system that urges escape from somatic threat (Eccleston et al. 1999). However, when pain has no immediate cure, patients may become over alert for pain and its cues, resulting in a persistent disruption of attention and behaviour. The repeated experience of pain while executing a task may result in interference, either because the sufferer cannot complete the task or because the repeated interruption by the pain degrades performance so much that the person judges it as unsatisfactory when assessed against their implicit standards or another person's real or perceived demands (Pincus and Morley, 2001). When pain becomes chronic and interferes repeatedly with major goals in life it will have an impact on the self-schemata and, thereby on the person's identity (Leventhal et al., 1999). Eventually cognitive self representations will become more and more enmeshed with cognitive representations about pain. The identity of the person is being taken over by pain and important aspects of the self are trapped by pain (Pincus and Morley, 2001; Waters et al., 2004; Morley et al., 2005).

The concept of possible selves provides us with a method to quantify the amount of enmeshment between pain and identity. Possible selves are the ideal selves that we would very much like to become. They are also the selves we could become, and the selves we are afraid of becoming (Markus and Nurius, 1986). People develop a discrepancy when they experience no concordance between the person they are now and the person they ideally would like to be (actual-ideal discrepancy). However, with regards to the feared possible self, people do not want to experience any concordance between their actual self and their feared self. A large actual-ideal discrepancy can lead to feelings of discomfort, depression and higher levels of pain and is of influence on mental and physical health (Higgins et al., 1986; Carver et al., 1999; Heidrich and Powwattana, 2004; Waters et al., 2004; Morley et al., 2005). The small actual-feared discrepancy can lead to feelings of anxiety and helplessness. People will undertake actions or set goals to either approach an ideal self or avoid a feared self. Approaching the ideal self and therefore, reducing the actual-ideal discrepancy will lead to feelings of happiness and enrapture. Avoiding the feared self and therefore increasing the actual-feared discrepancy can lead to feelings of relief (Carver et al., 1999). These approach and avoidance behaviours could be linked to or guided by specific fears. Research suggested that chronic pain patients show a wide variety of objects of fears. One of the best known fears in the field of chronic pain is fear of movement. Fear of movement could be associated to the actual-feared discrepancy in the sense that it might lead to avoidance behaviour with the goal of enlarging the actual feared discrepancy (eg. keeping away from becoming fully disabled). Fear of 
movement is derived from the fear-avoidance model, in which also pain catastrophizing is a factor of influence. In the fear-avoidance model pain catastrophizing is regarded as a variable preceding fear of movement and related to pain and disability. Both fear of movement and pain catastrophizing will be included in this study.

Up until now, no research has been performed to investigate whether selfdiscrepancies are present in acute pain and if they are involved in the transition from acute to chronic pain. In the current study we investigated the hypothesized relationships between self-discrepancies, mood, fear of movement and pain catastrophizing by means of a three week diary in patients with acute whiplash injury. We hypothesized that a large actual-ideal discrepancy and a small actual-feared discrepancy would be associated with negative mood. Moreover, we hypothesized that patients with high levels of pain, disability, fear of movement and pain catastrophizing would also experience a large actual-ideal discrepancy, a small actual-feared discrepancy and more self-pain enmeshment.

\section{METHOD}

\section{Design}

A single cohort of patients with acute whiplash injury was assessed with a set of baseline questionnaires and two self-discrepancy questionnaires within one month after their motor vehicle accident. During 21 days, participants kept daily diaries and recorded details of pain, mood, goal achievement, self-discrepancies, pain catastrophizing and fear of movement. At day 21 patients again completed two selfdiscrepancy questionnaires.

\section{Participants}

A total number of 60 participants were recruited in this study. Participants were referred by the emergency care units of five hospitals and the traffic police of Limburg Zuid (the Netherlands). Participants had to be between the age of 18 and 65 and were involved in a car accident no longer than four weeks prior to baseline assessment. There were four major exclusion criteria, being (1) head injury, (2) unconsciousness after the accident, (3) fracture or dislocation of the spine and, (4) pregnancy. Furthermore patients were excluded if they didn't speak Dutch fluently. Due to dropping out of a number of participants, only 45 participants could be included in the statistical analyses for day 1, and 37 for day 21. The reasons for dropping out were: lack of time, no more complaints, severe aggravation of complaints and feeling like discontinuing the study. 


\section{Baseline Questionnaires}

Disability: The Dutch version of the Neck Disability Index (NDI) consists of 10 items concerning limitations in functional activities and symptoms. The 10 items are scored 0 (no limitations/symptoms) to 5 (severe limitations/symptoms) and summed to yield a total score (0-50). The NDI is a valid and reliable instrument, sensitive to measure changes within a population of neck pain patients (Vernon, 1997; Helmerson Ackelman and Lindgren, 2002).

Pain: Pain was assessed using an 11-point likert scale anchored with two labels "no pain at all" on the left side and with "worst pain ever" on the right side. Patients rated their pain on four levels, being (1) current pain, (2) worst pain since the accident, (3) least pain since the accident, and (4) average pain.

Pain Catastrophizing: Participants completed the Dutch version of the Pain Catastrophizing Scale (PCS: Sullivan et al., 1995). Respondents are asked to reflect on past painful experiences and to indicate the degree to which they experienced each of the 13 thoughts or feelings during pain on a five point scale from 0 (not at all) to 4 (all the time). The Dutch version of the PCS has been shown to be valid and reliable (Van Damme et al., 2002).

Fear of movement/(re)injury: The Dutch version of the Tampa Scale for Kinesiophobia (TSK: Miller et al., 1991) was used to measure fear of movement/(re)injury. The 17 items are scored on a four point scale from "I strongly disagree" (1) to "I strongly agree" (4). The scale has a good internal consistency and a good test retest reliability (Swinkels-Meewisse et al., 2003; Roelofs et al., 2004a)

Depression: The Centre for Epidemiological Studies Depression Scale (CES-D: Radloff, 1977) consists of 20 items to measure different dimensions of depression. Questions are rated on a four point scale (0-3). The Dutch version of the CES-D has a good internal consistency and a very good sensitivity and specificity (Beekman et al., 1994).

\section{Self-discrepancies and self-pain enmeshment:}

We developed a checklist measure to assess self-discrepancies and self-pain enmeshment that could be administered within a reasonable period of time. The checklist comprised 38 adjectives, selected from previous studies on selfdiscrepancies. The adjectives were repeatedly presented and administered in a fixed order to assess the actual, ideal and feared selves (part 1) and self-pain enmeshment (part 2). The measure is reported in full in the appendix. In part 1, participants were asked to endorse 10 to 15 items in each list that described their current self. We constrained the number of choices as an attempt to control acquiescence response bias. They were then instructed to endorse 10 to 15 items that reflected how they 
ideally like to be, and this was followed by an instruction to endorse 10 to 15 items that represented what they feared they might become. In part two, the instructions were to make a judgement about each word in the list. On the first occasion they were instructed to endorse the adjectives with yes if they thought that they could possess this attribute while experiencing pain. On the second occasion they were asked to make the judgement of whether they could have this attribute if they did not have pain.

\section{Diary}

Participants were instructed to fill in a paper diary each evening for 21 consecutive days. All baseline questionnaires were represented in the diary by means of two or three items per questionnaire.

Current pain intensity and average pain during the day were assessed by means of an 11 point Likert Scale. Disability was measured on a daily base by all the items derived from the Neck Disability Index (NDI), except current pain, since it was already assessed by a previous question. All items were transferred to a 7-point Likert scale. The six items measuring functional limitations were anchored with " 0 " meaning 'not being able to perform this activity at all' and " 6 " meaning "being able to perform this activity very well'. Two items assessing complaints (headache and concentration problems) were anchored with " 0 " meaning "no complaints at all today" and " 6 " meaning "experienced severe complaints today". The two items measuring complaints were first recoded. A composite score was computed by summing up all NDI items and the current pain intensity item. A high score on this composite measure reflects low disability levels. Two items reflecting fear of movement were derived from the Tampa Scale of Kinesiofobia (TSK). The item "Today, moving was harmful for my body" reflected the Harm subscale. The item "Today, I avoided activities that caused me pain" reflected the Avoidance subscale. To measure Pain Catastrophizing, three items were derived from the Pain Catastrophizing Scale (PCS). Every item reflected one subscale. The item "Today, I kept thinking how much it hurts" represented the subscale "Rumination". The item "Today, I became afraid that the pain may get worse" represented the subscale "Magnification and "Today, I felt as if the pain overwhelmed me" represented the subscale "helplessness". All items were rated on a 7-point Likert scale labelled 'not at all' to 'very much'. Mood was assessed by 10 items rated on a 7-point Likert Scale on which participants had to indicate which feelings they had experienced during the day. There were 4 positive mood items (happy, relaxed, satisfied and delighted), and 6 negative mood items (irritated, depressed/sombre, sad, anxious, tired, frustrated). Finally, Actual-Ideal discrepancy was measured on 5 domains, being (1) physical health, (2) mental health, (3) situation at work, (4) situation at home, and (5) activity 
level. Participants indicate on a 7-point likert scale how much they perceived their actual self to be in concordance with their ideal self.

For practical reasons and because of the explorative nature of these diary items, the actual-feared discrepancy and self-pain enmeshment were not measured in the diary. All items, accept for the self-discrepancy items have been used in a previous study (Roelofs et al., 2004b). Seventeen additional questions were also included in each diary. However, since these data are not considered below, a detailed presentation of these questions is omitted. A complete diary with all items is represented in appen$\operatorname{dix} 2$.

\section{Procedure}

The study was approved by the Medical Ethical Committee of the University Hospital Maastricht. Patients were contacted by the researcher to inform them about the study and to ask for their participation. If patients agreed to participate they were then scheduled for an appointment in their home within a month after the accident. Verbal and written information about the study was given and all participants gave signed informed consent. The research assistant demonstrated how the diaries and the questionnaires were to be completed and how the participants could return all diaries and questionnaires by means of pre-stamped envelopes. The participants were asked to return a set of 7 envelopes each week, and the baseline questionnaires in week one by using the envelopes. Patients that completed all questionnaires and diaries received a gift certificate. All patients gave informed consent and were free to terminate the experiment at any time.

\section{Data reduction and Statistical analyses}

Analyses were conducted with the Statistical Package for the Social Sciences version 13.0 (SPSS Inc., 44N. Wacker Drive, Chicago, IL, 60606, USA). The main analyses used Paired Sample t-test, and Pearsons correlations. The diary data were analysed with multilevel regression analyses. In multi-level modelling, the repeated observations (daily diaries) are called level 1 units. These observations are organized within level 2 units. In this study level 2 represents the individual. This implies that there is one between subjects level (participant level) and one within subject level (day level). All analyses were performed by MLWin version 1.1 and the significance of variances was determined by the likelihood ratio test. Beta values are standardized for presentation.

For most variables we needed to compute proportions, sum scores or difference scores. We computed scores for the following variables: 
Self-discrepancy questionnaire: From the Self-Questionnaire we calculated two selfdiscrepancy measures, being the actual-ideal discrepancy, and the actual-feared discrepancy. The discrepancies were computed as the ratio of numbers of attributes uniquely endorsed (i.e. attributes endorsed in only one of the pair of lists) to the sum of the number of unique and shared attributes endorsed. The latter (denominator) therefore ipsatizes the discrepancy by ensuring that only those attributes deemed relevant to each individual are considered in the discrepancy score. The ratio nature of the discrepancy scores ensures that the value lies between 0 and 1 . For the actualideal discrepancy a score of 0 represents no discrepancy while 1 represents maximum discrepancy i.e. there are no attributes shared between the actual and ideal selves. For the actual- feared discrepancy a score of 0 represents no discrepancy i.e. a complete overlap of the actual and feared selves, while a score of 1 represents maximum separation of the actual and feared self. Thus according to self discrepancy and self control theories for the actual-ideal self (AI-discrepancy) a low proportion is preferred, where in the actual-feared self (AF-discrepancy) a high proportion is preferred. Difference scores were calculated between day 1 and day 21 to investigate time trends of the discrepancies.

Self-pain enmeshment: For the proportion of self-pain enmeshment we used all the 38 adjectives as the denominator since participants had to endorse all adjectives. For the numerator we summed up all adjectives which were endorsed in only one of the two lists. The higher the proportion, the more self-pain-enmeshed a patient will be, indicating that this person endorsed a lot of different adjectives for each list. To investigate whether there were time trends in self-pain enmeshment, we calculated difference scores between day 1 and day 21 .

Diary data: For the diary item on the actual-ideal discrepancy we calculated a composite score over the 5 domains. The higher the score, the more concordance participants perceived between their actual and ideal self (i.e. less discrepancy). With regards to disability a composite score was computed by summing up all NDI items and the current pain intensity item and then reversed, so that a high score on this composite measure reflects high disability levels. For fear of movement and pain catastrophizing composite scores were computed by adding up the scores of the two items for fear of movement and three items of pain catastrophizing respectively. For pain we only used the item that measured average pain. For mood, items were summed up for two subscales, being positive mood (4 items) and negative mood (6 items) 


\section{RESULTS}

\section{Descriptive analyses}

The final sample of 45 participants consisted out of $37.5 \%$ men. Mean age of the sample was 36 years $(\mathrm{SD}=13.51)$. Compared to the drop-outs $(60 \%$ men and mean age $42(\mathrm{SD}=11.00))$, the participants in the analyses were not significantly younger $(\mathrm{t}=1.70, \mathrm{p}=0.09)$ and neither did they differ on gender $\left(\mathrm{X}^{2}=1.22, \mathrm{p}=0.221\right)$.

Baseline current pain was measured by means of an 11 point Likert Scale. Mean score on this measure at the start of the diaries is $4.1(\mathrm{SD}=2.8)$. Mean disability score on the NDI at baseline is 13.9 ( $\mathrm{SD}=9.5)$, indicating that subjects on average were mildly disabled. Mean Baseline rating of Pain Catastrophizing is 16.9 (11.9) and $32.4(\mathrm{SD}=5.1)$ for Fear of Movement. Mean baseline Depression rating is 12.8 $(\mathrm{SD}=9.5)$.

Table 1: questionnaires and diary items: mean scores, standard deviations, and Paired sample t-test

\begin{tabular}{lrrrr}
\hline & $\begin{array}{c}\text { DAY 1 } \\
\text { Mean (SD) }\end{array}$ & $\begin{array}{c}\text { DAY 21 } \\
\text { Mean (SD) }\end{array}$ & $\mathrm{t}$ & Sig. (2-tailed) \\
\hline Questionnaires (potential range) & & & & \\
Actual Ideal Discrepancy (0-1) & $.70(0.22)$ & $.66(0.23)$ & .84 & .407 \\
Actual Feared Discrepancy (0-1) & $.84(0.17)$ & $.89(0.18)$ & -.66 & .515 \\
Self Pain Enmeshment (0-1) & $.41(0.23)$ & $.27(0.26)$ & 3.74 & .001 \\
Diary items & & & & \\
Actual ideal concordance (0-30) & $15.80(6.72)$ & $22.08(7.42)$ & -5.27 & $<.001$ \\
$*$ physical health (0-5) & $2.38(1.85)$ & $4.09(1.71)$ & -4.68 & $<.001$ \\
$*$ mental health (0-5) & $3.74(1.78)$ & $4.65(1.50)$ & -2.53 & .016 \\
* situation at home (0-5) & $3.74(1.78)$ & $4.71(1.38)$ & -2.88 & .007 \\
$*$ situation at work (0-5) & $3.27(2.07)$ & $4.47(1.73)$ & -3.33 & .002 \\
$*$ activity level (0-5) & $2.64(1.71)$ & $4.18(1.93)$ & -5.29 & $<.001$ \\
PAIN (average during day) (0-10) & $4.93(2.37)$ & $2.47(2.23)$ & 5.83 & $<.001$ \\
Disability (0-64) & $28.75(9.78)$ & $21.75(8.69)$ & 5.47 & $<.001$ \\
Fear of Movement (0-6) & $2.23(1.54)$ & $1.17(1.47)$ & 3.66 & .001 \\
Pain Catastrophizing (0-6) & $1.76(1.77)$ & $0.42(0.76)$ & 3.42 & .002 \\
Positive mood (0-24) & $12.00(5.32)$ & $15.41(6.24)$ & -2.57 & .015 \\
Negative mood (0-36) & $9.75(7.03)$ & $5.21(5.69)$ & 3.05 & .005 \\
\hline
\end{tabular}

$N$ day $1=45, N$ day $21=37$.

Both the AI-discrepancy and the AF-discrepancy are fairly high and remain stable over time (see table 1). This means that people perceive themselves a being far away from both their actual and feared self. Though the proportion of self-pain enmeshment is fairly high on day 1 , it significantly decreases over time (see table 1). The composite score on the actual-ideal concordance in the diary is moderately high on day 1 and significantly improves over time (day 21) (see table 1). When looking at the domains, participants perceive the lowest concordance on their physical health 
and activity level, but these domains return to the same level as the other domains on day 21. Participants also showed significant decreases over time on the variables average pain, disability, fear of movement, pain catastrophizing and negative mood and a significantly increased score on positive mood.

\section{Associations for Discrepancy and Enmeshment questionnaire on day 1}

The AI-discrepancy is not related to the AF-discrepancy, indicating that these might be two different concepts. The AI-discrepancy is related to Self-Pain Enmeshment on day 1 (see table 2).

Mood: The basic assumption that an AI-discrepancy is related to depression could be confirmed by the significant correlation between AI-discrepancy and CESD on day 1. The AF-discrepancy and Self-Pain enmeshment show no significant correlations with the depression questionnaire, although there was a trend for selfpain enmeshment $(p=.058)$ (see table 3$)$.

Table 2: Correlationmatrix of self-discrepancy proportions in the questionnaire and the diary items

\begin{tabular}{|c|c|c|c|c|c|c|c|}
\hline & $\begin{array}{c}\text { AI day } 1 \\
\text { Questionnaire }\end{array}$ & $\begin{array}{c}\text { AI day } 21 \\
\text { Questionnaire }\end{array}$ & $\begin{array}{c}\text { AF day } 1 \\
\text { Questionnaire }\end{array}$ & $\begin{array}{c}\text { AF day } 21 \\
\text { Questionnaire }\end{array}$ & $\begin{array}{c}\text { SPE day } \\
1\end{array}$ & $\begin{array}{c}\text { SPE day } \\
21\end{array}$ & $\begin{array}{c}\text { AI day } 1 \\
\text { diary }\end{array}$ \\
\hline AI day 21 & $.47 * *$ & & & & & & \\
\hline \multicolumn{8}{|c|}{ Questionnaire } \\
\hline AF day 1 & -.10 & -.19 & & & & & \\
\hline \multicolumn{8}{|c|}{ Questionnaire } \\
\hline AF day 21 & .08 & -.10 & .28 & & & & \\
\hline \multicolumn{8}{|c|}{ Questionnaire } \\
\hline SPE day 1 & $.35 *$ & .21 & .10 & .22 & & & \\
\hline SPE day 21 & .14 & .12 & .17 & .19 & $.53 * *$ & & \\
\hline AI day 1 & -.01 & -.25 & $.42 * *$ & $.41 * *$ & -.08 & .26 & \\
\hline \multicolumn{8}{|l|}{ Diary } \\
\hline AI day 21 & .16 & -.21 & $.42 * *$ & $.42 * *$ & -.01 & -.10 & $.69 * *$ \\
\hline Diary & & & & & & & \\
\hline
\end{tabular}

Disability and Pain: There is no significant association with the AI-discrepancy, but the AF-discrepancy is associated with higher levels of disability and pain on day one. There are no significant relationships between pain and disability and Self-Pain enmeshment.

Fear of Movement and Pain Catastrophizing: The AI-discrepancy and AFdiscrepancy are neither related with fear of movement, nor with pain catastrophizing. Pain catastrophizing is associated with more pain enmeshment on day 1. 
Table 3: Correlationmatrix of proportions in the discrepancy questionnaires and questionnaires on depression, disability, pain, fear of movement, and pain catastrophizing on day one

\begin{tabular}{|c|c|c|c|c|c|c|c|}
\hline & $\begin{array}{c}\mathrm{AI} \\
\text { questionnaire }\end{array}$ & $\begin{array}{c}\mathrm{AF} \\
\text { questionnaire }\end{array}$ & SPE & CES-D & PAIN & NDI & TSK \\
\hline$\overline{\text { CES-D }}$ & $.38 *$ & -.06 & $.33^{\mathrm{a}}$ & & & & \\
\hline PAIN & .01 & $-.38 *$ & .11 & $.42 *$ & & & \\
\hline NDI & .04 & $-.48 * *$ & .16 & $.48^{* *}$ & $.83^{* *}$ & & \\
\hline TSK & .09 & -.27 & .22 & $.39 *$ & $.36^{*}$ & $.39^{*}$ & \\
\hline PCS & .03 & -.01 & $.51^{* *}$ & $.43 * *$ & .23 & .22 & $.53 * *$ \\
\hline
\end{tabular}

\section{Univariate associations for the Diary Concordance Score}

Validity of the discrepancy measured by the diary was tested through correlations with the Self-Questionnaire. The AI-concordance score in the diary was not significantly correlated with the AI discrepancy score of the questionnaire. However, there was a significant association with the AF-discrepancy as measured by the questionnaire on day 1 and day 21 . The positive association indicates that participants with a higher concordance between their actual and ideal self as measured by the diary experience a larger discrepancy between their actual and feared self as measured by the questionnaire (see table 2). Improvement on the diary (measured by a difference score) is not correlated with improvement on the AI-discrepancy or AF-discrepancy as measured by the questionnaire.

Mood: In the diary we again found the hypothesized relationship between mood and actual-ideal concordance score. An increase in positive mood is associated with an increase in concordance between the actual and ideal self, and increase in negative mood is associated with a decrease in concordance from day 1 to day 21 . It was also investigated whether the concordance score was related to specific items of depression and anxiety. The increase in the actual ideal concordance score was significantly related to a decrease for the depression item $(r=-.423, p=.014)$, but not with a decrease for the anxiety item $(\mathrm{r}=.325, \mathrm{p}=.065)$.

Disability and Pain: An increase in the concordance between the actual and the ideal self is significantly associated with a decrease in pain and disability during the 21 days of data collection. 
Table 4: Correlationmatrix of self-concordance items in the diary and items of positive and negative mood, disability, pain, fear of movement and, pain catastrophizing

\begin{tabular}{|c|c|c|c|c|c|c|}
\hline & $\begin{array}{c}\Delta \\
\text { AI diary }\end{array}$ & $\begin{array}{c}\Delta \\
\text { PosMood }\end{array}$ & $\begin{array}{c}\Delta \\
\text { NegMood }\end{array}$ & $\begin{array}{c}\Delta \\
\text { Pain }\end{array}$ & $\begin{array}{c}\Delta \\
\text { Disability }\end{array}$ & $\begin{array}{l}\Delta \text { Fear of } \\
\text { movement }\end{array}$ \\
\hline$\Delta$ PosMood & $.60 * *$ & & & & & \\
\hline$\Delta$ NegMood & $-.54 * *$ & $-.65 * *$ & & & & \\
\hline$\Delta$ Pain & $-.41 *$ & -.22 & -.31 & & & \\
\hline$\Delta$ Disability & $-.46^{* *}$ & -.34 & .27 & .21 & & \\
\hline$\Delta$ Fear of Movement & $-.50 * *$ & -.10 & $.58 * *$ & .32 & .06 & \\
\hline$\Delta$ Pain Catastrophizing & -.15 & -.12 & $.52 * *$ & .33 & .14 & $.43 *$ \\
\hline
\end{tabular}

Fear of Movement and Pain Catastrophizing: decreases in levels of fear of movement are significantly related to an increase in concordance between the actual and ideal-self. However, this is not the case for pain catastrophizing.

\section{Multilevel associations for the Diary Concordance Score.}

The diary data were also analysed with multilevel regression analyses to investigate the specific explained variance of each variable. In multi-level modelling, the repeated observations (daily diaries) are called level 1 units. These observations are organized within level 2 units. In this study level 2 represents the individual. This implies that there is one between subjects level (participant level) and one within subject level (day level).

First the time trend of the actual-ideal concordance score was investigated over the 21 consecutive days. Second, levels of disability were included in the analyses. Pain was not entered as a separate predictor since it was already included in the composite score of disability as measured in the diary. Next, pain catastrophizing and fear of movement were entered into the models as predictors of the actual-ideal discrepancy. The final model shows that all variables significantly contribute to the model (table 5). The actual-ideal concordance score increases over time and is negatively related to disability, meaning that high levels of disability are related to less concordance between the actual and ideal self. Moreover, high levels of fear of movement and pain catastrophizing are predictors of less concordance between the actual and ideal self. 
Table 5: Concurrent associations with day, disability, fear of movement and pain catastrophizing as predictors and Actual-Ideal concordance as dependent variable

\begin{tabular}{lrcc}
\hline & \multicolumn{3}{c}{ Concurrent final model } \\
\cline { 2 - 4 } Actual-Ideal concordance & \multicolumn{3}{c}{$-2 * \log (\mathrm{lh})=3928.42$} \\
\hline Intercept & 1.428 & SE & Beta \\
Day & 0.135 & 0.018 & 0.106 \\
Disability & -0.429 & 0.020 & 0.586 \\
Fear of Movement & -0.197 & 0.063 & -.081 \\
Pain Catastrophizing & -0.158 & 0.047 & -.079 \\
\hline
\end{tabular}

\section{DISCUSSION}

This study was the first to investigate the presence of self-discrepancies and selfpain enmeshment in acute pain. Both the AI-discrepancy and the AF-discrepancy as measured by the questionnaires remained stable over time. The proportion of selfpain enmeshment significantly decreased over time. In contrast to the questionnaire, the composite score on the actual-ideal-concordance score in the diary also showed a significant improvement over time. Although all 5 domains of this measurement in the diary improved over time, the largest improvement was found in physical health and activity level.

The results show that in the acute stage of whiplash injury self-discrepancies and self-pain enmeshment are related to pain, disability, mood, fear of movement, and pain catastrophizing. Moreover, data from the questionnaires showed that those relationships were highly specific. The AI-discrepancy was related to depression as measured with the CES-D, the AF-discrepancy was significantly related to pain and disability (NDI) and self-pain enmeshment was related to pain catastrophizing (PCS).

Our results on discrepancies and mood are in concordance with the research by Waters et al. (2004) and Morley et al. (2005) who also found a relationship between AI-discrepancies and negative mood in patients with chronic pain. As predicted by the self-discrepancy theory, being far away from the ideal self is associated with dejection-related emotions (Higgins, 1987). These affects represent a perceived failure to attain positive reinforcement.

The AF-self-discrepancy is known to be associated with both dejection-related as with agitation-related emotions (Carver et al., 1999). However, we did not found a significant relationship between the AF-discrepancy and depression which is a dejection-related emotion. We did find that the AF-discrepancy on day one was associated with higher levels of disability and pain. The more complaints a person experiences, the more concordance one might experience between the actual and 
feared self. When a person is too near the feared value, the predominant concern is getting away from it.

Self-pain enmeshment on day 1 was significantly associated with pain catastrophizing (PCS) on day 1. This result suggests that the different cognitive dimensions of pain catastrophizing, such as rumination, magnification and feeling helpless are associated with people perceiving the experience of pain as part of their identity.

The results for the diary data were not completely in agreement with those of the questionnaires. For practical reasons, we only measured one discrepancy (AIdiscrepancy) in the diary and not the AF-discrepancy or SPE. The diary data confirmed the relationships found by the questionnaires that AI-discrepancy is related to negative mood. In the diary data, an increase in negative mood was associated with a deterioration of the actual ideal concordance score. In addition to the questionnaires, the diary data also showed that an increase in positive mood was associated with an improvement on the actual-ideal concordance score. In contrast to the questionnaire data we also found a significant relationship in the diary for pain, disability and fear of movement. An increase in the actual-ideal concordance was associated with a decrease in pain, disability and fear of movement. There was no significant relationship with pain catastrophizing. However, the multilevel analyses revealed that pain catastrophizing was a significant predictor of the actual-ideal concordance the next day in addition to pain, disability and fear of movement.

The diary suggests that a subgroup of patients experiencing fear of movement may be at risk for developing prolonged complaints, since an increase in fear of movement was associated with a decrease in the actual-ideal concordance in the diary. This suggestion was already made by Sieben et al. (2002) who found that an increase in fear of movement in the acute stage of low back pain was associated with worse functional outcome. This might also be the case for predicting enlargement of discrepancies. Moreover, this hypothesis was confirmed by our multilevel analyses indicating that both fear of movement and pain catastrophizing are significant predictors for actual-ideal concordance, when controlled for time trend and disability.

How the results from the diary and the questionnaires relate to each other is as yet unclear. The absence of a correlation between the diary AI concordance score and the questionnaire AI discrepancy score suggests that these are not equivalent measures. Surprisingly, the AI concordance score in the diary was significantly correlated to the AF-discrepancy score in the questionnaire. It could be the case that our items in the diary, although designed to measure actual-ideal concordance, were more a reflection of an actual-feared discrepancy. If this was the case, the AI concordance score should be more related to anxiety levels than to depression levels. However, additional analyses on the anxiety and depression items separately revealed that this was not the case. 
Although we found interesting results, most of the hypotheses could only be confirmed by the analyses on the diary data. One of the limitations of the study was the use of a non validated questionnaire to measure the self-discrepancies. Research of the data revealed that several patients had difficulties in filling in the questionnaires or that they made mistakes. This could be due to a misinterpretation of the instruction on the questionnaire. Some patients did not endorse enough adjectives or only endorsed enough adjectives in one column. We tried to develop a questionnaire that first of all was suitable for computing proportion scores and executing statistical analyses and second was less time consuming and less abstract than other measures of self-discrepancies (Hardin, 2002). However, a more thorough investigation is needed to establish the validity and reliability of our questionnaires, compared to for example the "Selves Questionnaire" (Higgins et al., 1985).

Another limitation of the study was the small number of patients. Furthermore, a large number of patients improved during the three-week period, not only in pain and disability but also in their discrepancies. This could reduce statistical power and may have lessened our ability to accurately assess our hypothesized relationships. Additional studies with larger sample sizes are needed to investigate more thoroughly the relationships found in this study.

Overall, the study results show that the effects of acute pain due to a motor vehicle accident extend beyond increased disability and distress levels, and they affect the integrity of the persons' identity. The study of self-discrepancies promises to be a valuable addition to our current cognitive-behavioural conceptualization of pain, and deserves further scientific attention. 


\section{REFERENCES}

Beekman ATF, van Limbeek J, Deeg DJH, Wouters L, van Tilburg W. Een screeningsinstrument voor depressie bij ouderen in de algemene bevolking: de bruikbaarheid van de Center for Epidemiologic Studies Depression Scale (CES-D). Tijdschrift voor Gerontologie en Geriatrie 1994;25:95-103.

Carver CS, Lawrence JW, Scheier MF. Self-Discrepancies and Affect: Incorporating the Role of Feared Selves. Personality and social psychology bulletin 1999;25(7):783-792.

Eccleston C, Crombez G. Pain demands attention: a cognitive-affective model of the interruptive function of pain. Psychological Bulletin 1999;125(3):356-366.

Hardin EE. Measure of self-discrepancies

Heidrich SM, Powwattana A. Self-discrepancy and mental health in older women with chronic illnesses. Journal of adult development 2004;11(4):251-259.

Helmerson Ackelman B, Lindgren U. Validity and reliability of a modified version of the neck disability index. Journal of Rehabilitation Medicine 2002;34:284-287.

Higgins ET. Self-discrepancy: a theory relating self and affect. Psychological review 1987;94(3):319-340.

Higgins ET, Bond RN, Klein R, Strauman T. Self-discrepancies and emotional vulnerability: how magnitude, accessibility and type of discrepancy influence affect. Journal of Personality and Social Psychology 1986;51(1):5-15.

Higgins ET, R. K, Strauman T. Self-concept discrepancy theory: A psychological model for distinguishing among different aspects of depression and anxiety. Social Cognitiona 1985;3:51-76.

Leventhal H, Idler EL, Leventhal EA. The impact of chronic illness on the self system. In: RJ Contrada, RD Ashmore, editors|. Book Title|, Vol. Volume|. City|: Publisher|, Year|. p.`pp. Pages|.

Markus H, Nurius P. Possible Selves. American Psychologist 1986;41(9):954-969.

Miller RP, Kori SH, Todd DD. The Tampa Scale

Morley S, Davies C, Barton S. Possible selves in chronic pain: self-pain enmeshment, adjustment and acceptance. Pain 2005;115:84-94.

Pincus T, Morley S. Cgonitive-Pocessing Bias in Chronic Pain: A Review and Integration. Psychological Bulletin 2001;127(5):599-617.

Radloff LS. the CES-D scale: a self-report depression scale for research in the general population. Applied Psychological Measurement 1977;1(3):385-401.

Roelofs J, Goubert L, Peters ML, Vlaeyen J, Crombez G. The Tampa Scale for Kinesiophobia: further examination of psychometric properties in patients with chronic low back pain and fibromyalgia. European Journal of Pain 2004a;8(5):495-502.

Roelofs J, Peters ML, Patijn J, Schouten EGW, Vlaeyen JWS. Electronic diary assessment of pain-related fear, attention to pain, and pain intensity in chronic low back pain patients. Pain 2004b;112:335-342.

Sieben JM, Vlaeyen JWS, Tuerlinckx S, Portegijs PJM. Pain-related fear in acute low back pain: the first two weeks of a new episode. European Journal of Pain 2002;6:229-237.

Sullivan MJL, Bishop SR, Pivik J. The Pain Catastrophizing Scale: Development and validation. Psychological Assessment 1995;7(4):524-532.

Swinkels-Meewisse EJCM, Swinkels RAHM, Verbeek ALM, Vlaeyen JWS, Oostendorp RAB. Psychometric properties of the Tampa Scale for Kinesiophobia and the fear-avoidance beliefs questionnaire in acute low back pain. Manual Therapy 2003;8(1):29-36.

Van Damme S, Crombez G, Bijttebier P, Goubert L, Van Houdenhove B. A confirmatory factor analysis of the Pain Catastrophizing Scale: invariant factor structure across clinical and non-clinical populations. Pain 2002;96:319-324.

Vernon H. Correlations among ratings of pain, disability and impairment in chronic whiplash-associated disorders. Pain Research Management 1997;2(4):207-213. 
Waters SJ, Keefe FJ, Strauman TJ. Self-discrepancy in chronic low back pain: relation to pain, depression and psychological distress. Journal of Pain and Symptom Management 2004;27(3):251-259. 


\section{APPENDIX 1: THE "SELF"- QUESTIONNAIRE}

Instruction

Before you fill in this questionnaire, pleas read this instruction carefully. All through the questionnaire you'll find more instructions on how to fill in this questionnaire and on when you can go to the next page. Fill in this questionnaire step by step. You'll first find Part 1 of the questionnaire. Instructions will be given on when you can go to Part 2. Start filling in the questionnaire, beginning with Part 1, Step 1.

\section{$\underline{\text { PART } 1}$}

Step 1

Think about the person you are now. Which qualities (positive of negative) could you sum up to describe yourself or which words (positive of negative) do others use to describe you? Go to the next page, first column and check of between 10 and 15 words that describe you as the person you are now.

Step 2

Now think about the person you wish or desire to be. Is this the same person as you are now? What qualities (positive or negative) would you ideally like to possess? Go to the next page, second column and check of between 10 and 15 words that describe you as the person you ideally would like to be.

Step 3

Now think about the person you certainly do not want to be. Is this the same person as you are now? Are there qualities (positive or negative) that you do not want to possess or that are undesired? Which type of person would you never want to be or are you afraid of becoming? Go to the next page, column three and check of between 10 and 15 words that describe you as the person you are afraid of becoming. 
$\underline{\text { PART } 1}$

\begin{tabular}{|c|c|c|c|c|c|}
\hline & STEP 1 & & STEP 2 & & STEP 3 \\
\hline \multirow[t]{40}{*}{$\mathbf{X}$} & I am now ... & $\mathbf{X}$ & $\begin{array}{l}\text { I would like to be } \\
\ldots\end{array}$ & $\mathbf{X}$ & $\begin{array}{l}\text { I'm afraid } \\
\text { becoming ... }\end{array}$ \\
\hline & happy & & inferior & & creative \\
\hline & creative & & efficient & & assertive \\
\hline & sensitive & & independent & & inferior \\
\hline & dependable & & friendly & & relaxed \\
\hline & caring & & relaxed & & aggressive \\
\hline & independent & & creative & & somber \\
\hline & lonely & & lonely & & independent \\
\hline & cheerful & & optimistic & & dependable \\
\hline & humorous & & disabled & & bitter \\
\hline & frustrated & & tired & & friendly \\
\hline & frightened & & caring & & hardworking \\
\hline & efficient & & dependable & & moody \\
\hline & alert & & bitter & & Ionely \\
\hline & disabled & & worrying & & pessimistic \\
\hline & content & & humorous & & admirable \\
\hline & somber & & content & & alert \\
\hline & inferior & & sensitive & & efficient \\
\hline & fit & & Fit & & worrying \\
\hline & bitter & & admirable & & persistent \\
\hline & insecure & & assertive & & caring \\
\hline & enthusiastic & & alert & & cheerful \\
\hline & energetic & & energetic & & healthy \\
\hline & pessimistic & & persistent & & frustrated \\
\hline & nervous & & frustrated & & fit \\
\hline & admirable & & social & & insecure \\
\hline & healthy & & hardworking & & frightened \\
\hline & assertive & & confident & & social \\
\hline & tired & & somber & & nervous \\
\hline & persistent & & pessimistic & & confident \\
\hline & hardworking & & insecure & & disabled \\
\hline & moody & & happy & & sensitive \\
\hline & aggressive & & cheerful & & humorous \\
\hline & worrying & & healthy & & tired \\
\hline & social & & aggressive & & happy \\
\hline & confident & & nervous & & optimistic \\
\hline & friendly & & frightened & & content \\
\hline & relaxed & & moody & & enthusiastic \\
\hline & optimistic & & enthusiastic & & energetic \\
\hline & $\begin{array}{l}\text { When you are } \\
\text { finished with this } \\
\text { column, return to } \\
\text { the instruction and } \\
\text { read step } 2 \text {. }\end{array}$ & & $\begin{array}{l}\text { When you are } \\
\text { finished with this } \\
\text { column, return to } \\
\text { the instruction and } \\
\text { read step 3. }\end{array}$ & & $\begin{array}{l}\text { When you are finished } \\
\text { with this column, you } \\
\text { can proceed with part } \\
2 \text { of the questionnaire } \\
\text { (next page). }\end{array}$ \\
\hline
\end{tabular}




\section{PART 2}

Filling in Part 2 of the questionnaire will also take place in different steps. Read the instruction carefully and fill in the questionnaire step by step. You can start filling in the questionnaire, beginning with Step 1.

Step 1

Read every word on the next page in column 1 very carefully. Ask yourself the following question with every word: "Could I be like this if my (pain)complaints would continue?". You can put a mark at YES or NO. You can start filling in column 2.

\section{Stap 2}

Read every word on the next page in column 2 very carefully. Ask yourself the following question with every word: "Could I be like this if my (pain)complaints would no longer exist?". You can put a mark at YES or NO. You can start filling in column 2.

When you are finished with column 2, you have completed the questionnaire. 


\section{PART 2}

\begin{tabular}{|l|l|l|}
\hline STEP 1 & & \\
\hline With pain I am ... & YES & NO \\
\hline energetic & & \\
\hline optimistic & & \\
\hline inferior & & \\
\hline confident & & \\
\hline humorous & & \\
\hline somber & & \\
\hline alert & & \\
\hline caring & & \\
\hline cheerful & & \\
\hline tired & & \\
\hline nervous & & \\
\hline independent & & \\
\hline moody & & \\
\hline dependable & & \\
\hline friendly & & \\
\hline bitter & & \\
\hline lonely & & \\
\hline fit & & \\
\hline worrying & & \\
\hline hardworking & & \\
\hline aggressive & & \\
\hline happy & & \\
\hline pessimistic & & \\
\hline persistent & & \\
\hline creative & & \\
\hline sensitive & & \\
\hline frustrated & & \\
\hline healthy & & \\
\hline efficient & & \\
\hline admirable & & \\
\hline assertive & & \\
\hline disabled & \\
\hline insecure & \\
\hline frightened & \\
\hline content & & \\
\hline enthusiastic & \\
\hline relaxed & & \\
\hline social & & \\
\hline instruction and read step & \\
\hline
\end{tabular}

\begin{tabular}{|l|l|l|}
\hline STEP 2 & & \\
\hline Without pain I am ... & YES & NO \\
\hline relaxed & & \\
\hline optimistic & & \\
\hline independent & & \\
\hline sensitive & & \\
\hline worrying & & \\
\hline happy & & \\
\hline tired & & \\
\hline frustrated & & \\
\hline persistent & & \\
\hline admirable & & \\
\hline energetic & & \\
\hline disabled & & \\
\hline humorous & & \\
\hline hardworking & & \\
\hline bitter & & \\
\hline frightened & & \\
\hline alert & & \\
\hline nervous & & \\
\hline pessimistic & & \\
\hline enthusiastic & & \\
\hline dependable & & \\
\hline efficient & & \\
\hline confident & & \\
\hline insecure & & \\
\hline content & & \\
\hline lonely & & \\
\hline assertive & & \\
\hline moody & & \\
\hline social & & \\
\hline creative & & \\
\hline aggressive & & \\
\hline caring & & \\
\hline friendly & & \\
\hline somber & & \\
\hline healthy & & \\
\hline cheerful & & \\
\hline inferior & & \\
\hline fit & & \\
\hline End of the quire & \\
\hline
\end{tabular}




\section{Appendix 2: Diary}

\section{Write down three activities that are important to you to do tomorrow}

1.

2.

3.

\section{PPNR}

\section{DAY}

Today was a

\section{date:}

\section{time:}

day at work / day off

Circle the right answer

\section{Endorse the answers for the following questions}

When you think back at the three activities you listed on the top of this page yesterday, did you actually executed these activities today?

Activity 1:

Activity 2:

Activity 3:

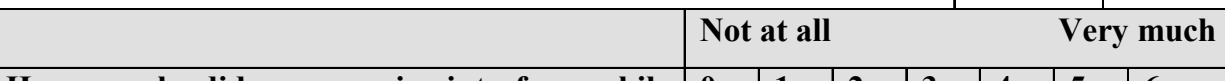

\begin{tabular}{|l|l|l|l|l|l|l|l|}
\hline $\begin{array}{l}\text { How much did your pain interfere while } \\
\text { performing your activities? }\end{array}$ & $\mathbf{1}$ & $\mathbf{1}$ & $\mathbf{3}$ & $\mathbf{4}$ & $\mathbf{5}$ & $\mathbf{6}$ \\
\hline Activity 1: & & & & & & & \\
\hline Activity 2: & & & & & & & \\
\hline Activity 3: & & & & & & \\
\hline Do you think you performed the activities to & $\mathbf{0}$ & $\mathbf{1}$ & $\mathbf{2}$ & $\mathbf{3}$ & $\mathbf{4}$ & $\mathbf{5}$ & $\mathbf{6}$ \\
\hline Activity 1: & & & & & & & \\
\hline Activity 2: & & & & & & & \\
\hline Activity 3: & & & & & & & \\
\hline
\end{tabular}




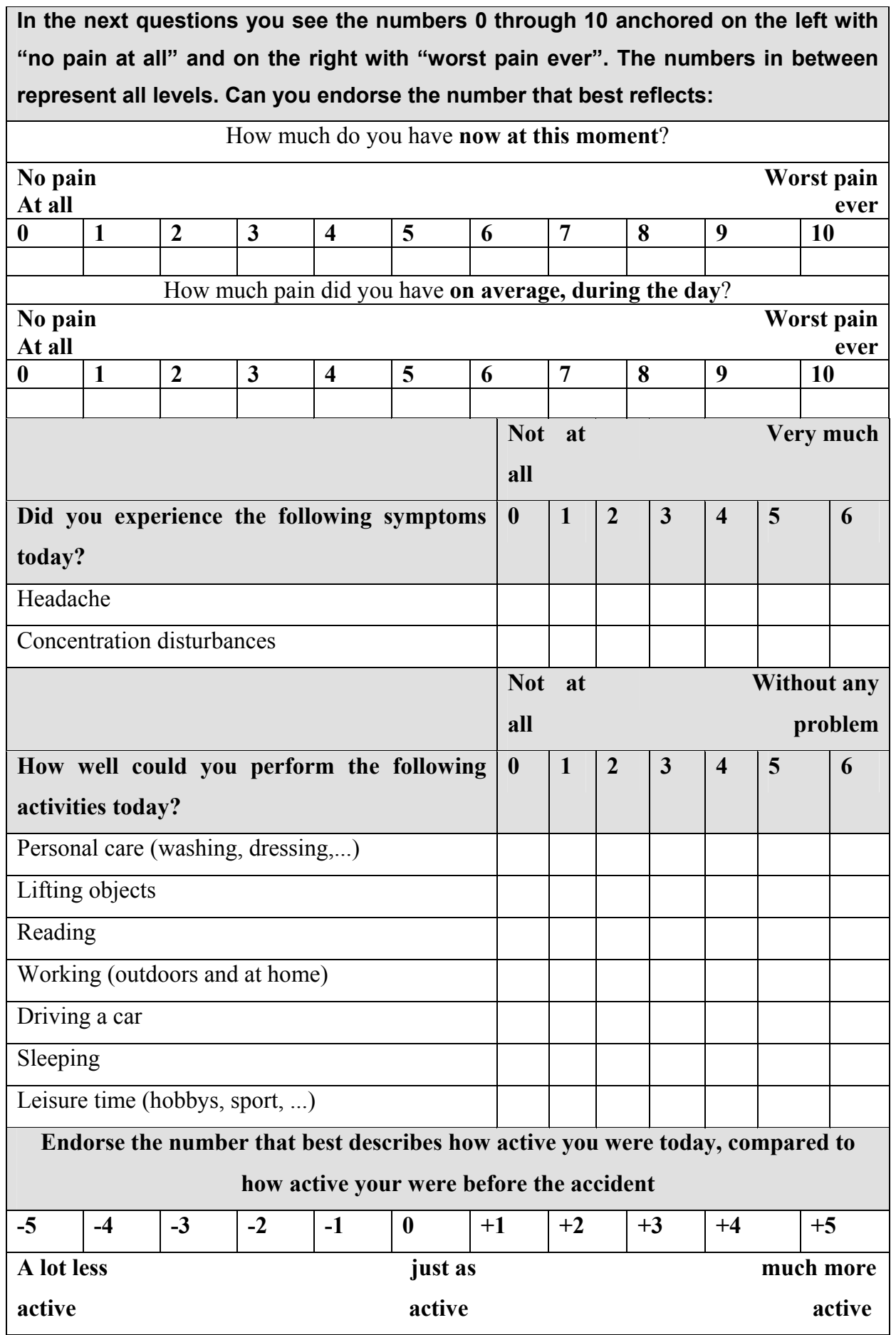




\begin{tabular}{|c|c|c|c|c|c|c|c|c|c|c|}
\hline \multicolumn{9}{|c|}{$\begin{array}{l}\text { Did you receive information today about your (pain)complaints } \\
\text { from the following persons or in the following situations? Endorse } \\
\text { yes or no and whether this information changed your opinion. }\end{array}$} & YES & NO \\
\hline \multicolumn{11}{|c|}{ docter } \\
\hline-5 & -4 & -3 & -2 & -1 & 0 & +1 & +2 & +3 & +4 & +5 \\
\hline \multicolumn{9}{|c|}{ More worry } & \multicolumn{2}{|c|}{ more reassurance } \\
\hline \multicolumn{9}{|c|}{ fysiotherapist } & & \\
\hline-5 & -4 & -3 & -2 & -1 & 0 & +1 & +2 & +3 & +4 & +5 \\
\hline \multicolumn{9}{|c|}{ More worry } & \multicolumn{2}{|c|}{ more reassurance } \\
\hline \multicolumn{9}{|c|}{ media (newspaper, magazine, tv) } & & \\
\hline-5 & -4 & -3 & -2 & -1 & 0 & +1 & +2 & +3 & +4 & +5 \\
\hline \multicolumn{9}{|c|}{ More worry the same } & \multicolumn{2}{|c|}{ more reassurance } \\
\hline \multicolumn{9}{|c|}{ internet } & & \\
\hline-5 & -4 & -3 & -2 & -1 & 0 & +1 & +2 & +3 & +4 & +5 \\
\hline \multicolumn{9}{|c|}{ More worry } & \multicolumn{2}{|c|}{ more reassurance } \\
\hline \multicolumn{9}{|c|}{ family and/or friends } & & \\
\hline-5 & -4 & -3 & -2 & -1 & 0 & +1 & +2 & +3 & +4 & +5 \\
\hline \multicolumn{9}{|c|}{ More worry } & \multicolumn{2}{|c|}{ more reassurance } \\
\hline \multicolumn{9}{|c|}{ Other(s) } & & \\
\hline-5 & -4 & -3 & -2 & -1 & 0 & +1 & +2 & +3 & +4 & +5 \\
\hline \multicolumn{11}{|c|}{ More worry } \\
\hline
\end{tabular}

\begin{tabular}{|l|l|l|l|l|l|l|l|}
\hline Endorse the number that best describes how you felt today \\
\hline Today I felt & $\begin{array}{l}\text { Not } \\
\mathbf{0}\end{array}$ & $\mathbf{1}$ & $\mathbf{2}$ & $\mathbf{3}$ & $\mathbf{4}$ & $\mathbf{5}$ & $\begin{array}{l}\text { A lot } \\
\mathbf{6}\end{array}$ \\
\hline Happy & & & & & & & \\
\hline Irritated & & & & & & & \\
\hline Somber & & & & & & & \\
\hline Relaxed & & & & & & & \\
\hline Sad & & & & & & & \\
\hline Anxious & & & & & & & \\
\hline Satisfied & & & & & & & \\
\hline Tired & & & & & & & \\
\hline Delighted & & & & & & & \\
\hline Frustrated & & & & & & \\
\hline
\end{tabular}




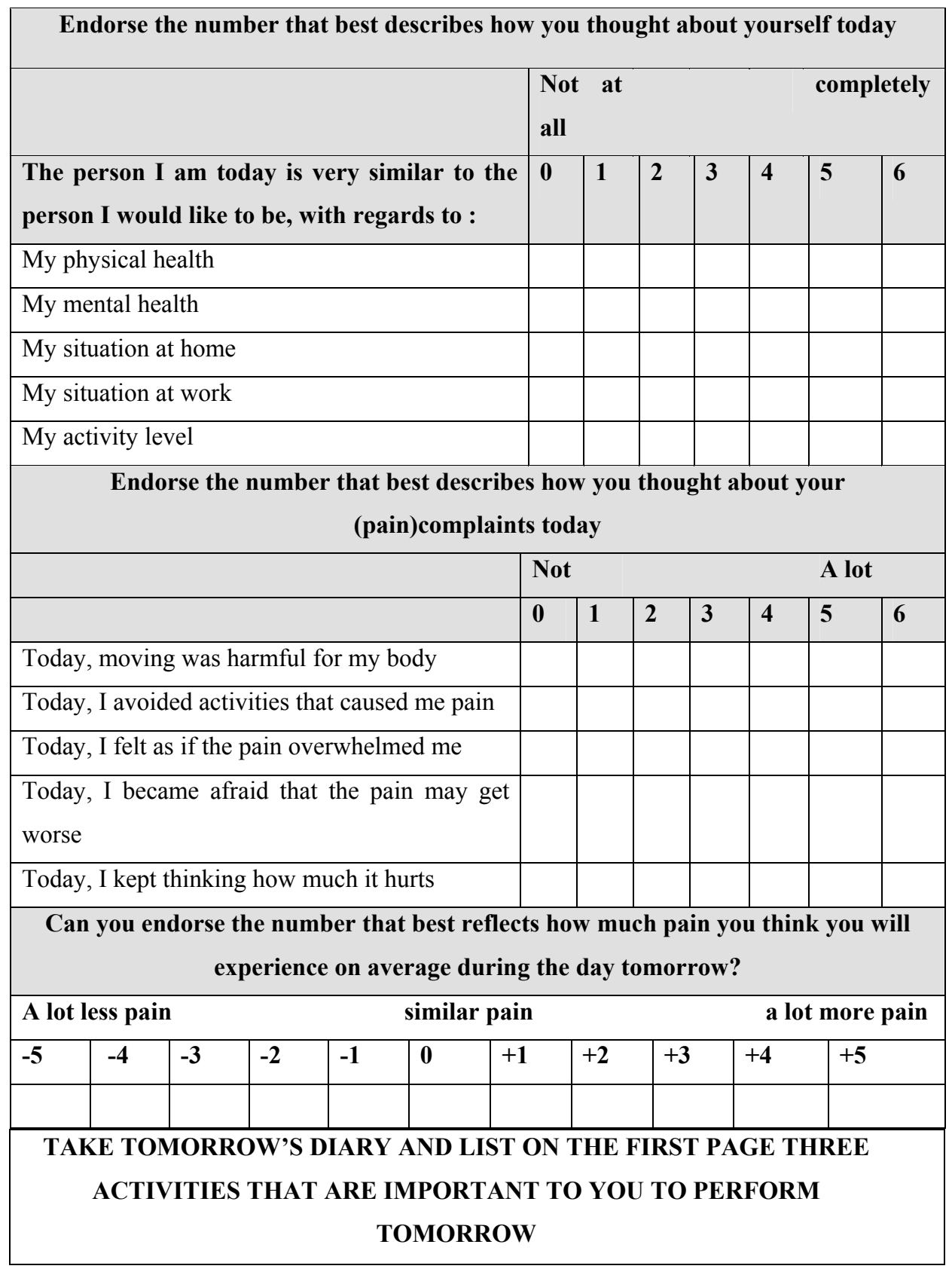



Chapter 8

\section{Reduction of pain-related fear and disability in posttraumatic neck pain: a replicated single case experimental study of exposure in vivo.}

Jeroen de Jong, Karoline Vangronsveld, Madelon Peters, Mariëlle Goossens, Johan Vlaeyen 


\begin{abstract}
For patients with acute posttraumatic neck pain, caused by a whiplash injury, painrelated fear has been identified as a potential predictor of chronic disability. If such is the case, fear reduction should enhance the prevention of further pain disability and distress after traumatic neck pain disability. Although exposure-based treatments have shown to be successful in patients with chronic low back pain, they have not been tested in patients with posttraumatic neck pain. Using a replicated singlecase crossover phase design with multiple measurements, this study examined whether the validity of a graded exposure in vivo (GEXP), as compared to usual graded activity (GA), extends to patients with posttraumatic chronic neck pain disability. The main research question of this study was whether the reduction of pain-related fear through GEXP also resulted in a decrease of pain and pain disability in a subgroup of patients with posttraumatic neck pain who report substantial pain-related fear. Eight patients were included in the study. To assess daily changes in pain intensity, pain-related fear, pain catastrophizing, and activity goal achievement, a diary was used. Before and after each intervention, and at 6-month followup, standardized questionnaires of pain-related fear and pain disability were administered, and, to assess the level of physical activity in the home situation, patients carried an accelerometry-based activity monitor. The results showed decreasing levels of self-reported pain-related fear, pain intensity, disability, and improvements in physical activity in the home situation only when GEXP was introduced, and not in the GA condition. The results are discussed in the context of the search for customized treatments for patients with chronic pain.
\end{abstract}




\section{INTRODUCTION}

An increasing number of both experimental and clinical studies, mainly performed in chronic low back pain patients, have shown that pain-related fear is one of the most potent predictors of observable physical performance, self-reported disability levels in daily life situations and work loss (Buer \& Linton, 2002; Crombez, Vlaeyen, Heuts \& Lysens, 1999; Fritz, George \& Delitto, 2001; Vlaeyen \& Linton, 2000; Waddell, Newton, Henderson, Somerville \& Main, 1993). The basic tenet of the Fear-Avoidance model of pain is that the way in which pain is interpreted may lead to two different pathways. When pain is catastrophically (mis)interpreted, a number of safety behaviors are initiated that may be adaptive in acute pain, but paradoxically worsen the problem in the case of long lasting pain. Typical safety behaviors are avoidance and escape behaviors and hypervigilance, and the prolonged use of them maintains the fear level rather than reducing it. Patients who avoid have a risk of getting mired in a downward cycle of pain, avoidance/escape behaviors, increased disability, hypervilance, and more pain. In contrast, when acute pain is perceived as non-threatening, patients are likely to maintain their engagement in daily activities, through which functional recovery is promoted (Asmundson, Norton \& Norton, 1999; Vlaeyen \& Linton, 2000). The Fear-Avoidance model has been successfully tested in patients with back pain (Picavet \& Schouten, 2000; Swinkels et al., 2004; Turner, Franklin, Fulton-Kehoe, Sheppard, Wichizer, Wu, Gluck \& Ega, 2006), osteoarthritis (Heuts, Vlaeyen, Roelofs, de Bie, Aretz, van Weel \& van Schayck, 2004), and burn patients (Sgroi, Willebrand, Ekselius, Gerdin \& Anderson, 2005).

If pain-related fear is indeed one of the important mechanisms responsible for the development and maintenance of chronic pain disability, fear reduction should enhance the prevention of further pain-disability and distress after traumatic neck pain disability. Well-designed procedures exist for the treatment of specific fears and phobias and usually these involve repeated and systematic exposure to fearprovoking stimulus, often presented in the context of behavioral experiments (Clark, 1986; Barlow, 2002; Butler, Chapman, Forman \& Beck, 2006). Although Philips (1987) argued for the application of exposure techniques to chronic pain some time ago, the first systematic evaluation in patients with chronic back pain was carried out more recently (Boersma, Linton, Overmeer, Jansson, Vlaeyen \& de Jong, 2004; de Jong, Vlaeyen, Onghena, Goossens, Geilen \& Mulder, 2005; Vlaeyen, de Jong, Geilen, Heuts \& van Breukelen, 2001, 2002a; Vlaeyen, de Jong, Onghena, Kerckhoffs-Hanssen \& Kole-Snijders, 2002b). Given the beneficial effects of cognitive behavioral interventions for chronic pain (Morley, Eccleston \& Williams, 1999), CBT programs have been developed for patients with posttraumatic neck pain disability as well (Foster, Pincus, Underwood, Vogel, Breen \& Harding, 2003; 
Jaspers, 1998; Linton \& Anderson, 2000; Linton \& Ryberg, 2001; Soderlund \& Lindberg, 2001; Sterner, Toolanen, Knibestol, Gerdle \& Hildingsson, 2001), of which those promoting physical activity have proven to be the most effective (Crowford, Khan \& Varley, 2004; Provinciali, Baroni, Illuminati \& Ceravolo, 1996; Rosenfeld, Seferiadis, Carlsson \& Gunnarson, 2003; Soderlund \& Lindberg, 2001; Vassiliou, Kaluza, Putzke, Wulf \& Schnabel, 2006; Vendrig, van Akkerveen \& McWhorter, 2000). Although these studies suggest that activity increase is associated with faster return to work and a decrease in pain and disability levels, there is evidence showing that these changes are mediated by the reduction of the catastrophic (mis)interpretations of pain (Mannion, Muntener, Taimela \& Dvorak, 1999; Smeets, Vlaeyen, Kester \& Knottnerus, 2006; Spinhoven, Ter Kuile, Kole-Snijders, Hutten Mansfeld, Den Ouden \& Vlaeyen, 2004). Therefore, we decided to test the effectiveness of an intervention that has catastrophic interpretations and associated pain-related fear as its primary target. Given the beneficial results of graded exposure in vivo in patients with chronic low back pain and since pain-related fear has shown to be associated with neck pain disability (Nederhand, IJzerman, Hermens, Turk \& Zilvold, 2004), there are good reasons to believe that an exposure in vivo treatment would be beneficial for the posttraumatic neck pain population as well.

Using a replicated crossover single-case experimental phase-design with multiple measurements, we examined whether the validity of a graded exposure in vivo (GEXP), as compared to usual graded activity program (GA), extends to patients with posttraumatic chronic neck pain disability. We expected that GEXP was superior to GA.

\section{MATERIALS AND METHOD}

\section{Study design}

A replicated crossover single-case experimental phase-design was employed. Patients were randomly assigned to one of the two conditions contrasted. Randomisation occurred after the 14 baseline days (BAS) and was done by a computer system providing allocations in a locked, unreadable file that could be assessed only by an independent research administrator. In condition A, patients received GEXP first, followed by GA. In condition B, the sequence of treatment modules was reversed. The participating therapists remained constant in each condition and performed both treatments. In order to measure the effect of the GEXP in terms of effective mechanisms, only the treatment mechanisms differed between both conditions. 


\section{Participants}

Eight consecutive patients who developed chronic neck pain ( $>12$ weeks) after a motor vehicle accident were included in the study. The sample consisted of five male and three female patients, with a mean age of $45 \pm 10.30$ (SD) years and a mean duration of pain disability of 44.4 months (range 27.6-67.2 months). The patients were referred for outpatient behavioral rehabilitation at the department of rehabilitation of the Maastricht University hospital or the Hoensbroek Rehabilitation Center, and reported substantial fear of movement/(re)injury (Tampa scale for kinesiophobia [TSK; Miller, Kori \& Todd, 1991] score $\geq 40$ ). Patients with signs of a concussion, retrograde or posttraumatic amnesia, serious injuries (e.g., fractures, traumatic internal organic pathology), and any neurological signs were excluded. Other exclusion criteria were illiteracy, pregnancy, alcohol or drug abuse, non-Dutch speaking and serious psychopathology. To check the latter, pre-set criteria based on Dutch norms were applied on the SCL-90 (Arrindell \& Ettema, 1986).

\section{Procedure and program overview}

Patients were first evaluated by the rehabilitation physician who conducted a full physical examination, evaluated previous diagnostic tests, and who informed participants about the study. When patients agreed to participate, the researcher sent additional written information, along with an informed consent form, TSK and SCL90. If patients scored $\geq 40$ on the TSK and fulfilled the pre-set SCL-90 criteria, they were invited for an intake procedure.

During the intake procedure information was gathered to complete a behavioural analysis of the pain problem with special attention to the patients catastrophic interpretations of his/her pain problem. At the end of the interview, the therapist encouraged the patient to formulate specific treatment goals, preferably in terms of concrete activities that had been avoided such as household chores, leisure or work activities. An hierarchy of fear-eliciting movements and activities was made using the Photograph series of Daily Activities for the upper extremities (PHODA; Dubbers, Vikström \& de Jong, 2003), a standardised method during which patients are requested to judge the harmfulness of 125 diverse physical movements from daily life activities represented by photographs. Using a (fear) thermometer, each picture is given a rating between zero (representing the situation which is not harmful for neck) to 100 (representing the situation which is absolutely damaging the neck). The PHODA has been used successfully in previous studies (De Jong et al., 2005).

After this assessment procedure patients started with BAS, a no-treatment 2-week period, during which they completed daily measures at home. During the second week of BAS patients wore accelerometry-based activity monitors to register daily 
activity levels. After this first period, the 8 patients were randomly allocated to one of two intervention sequences, operant graded activity (GA) followed by graded exposure (GEXP) or vice versa. GA consisted of 20 sessions of one hour during 10 weeks. GEXP consisted of 12 sessions of one hour during 6 weeks. After GEXP and GA, patients carried the accelerometry-based activity monitor for one week with the instruction to resume their daily activities as much as possible. The fourth period was a 6-month follow-up at the end of which patients once more carried the accelerometry-based activity monitor for one week. Questionnaires were completed before and after BAS, after GA, EXP, and at follow-up.

\section{Interventions}

GEXP was carried out by a behavioral therapist, who was experienced in the cognitive-behavioral treatment of patients with chronic pain. An outpatient multidisciplinary team provided the GA, consisting of a psychologist and an occupational or physical therapist experienced in the behavioral rehabilitation of patients with chronic pain. GEXP as well as GA are highly structured and protocolized, and aim to restore a normal pattern of daily function, including complete return to work. Decreasing pain intensity is not a direct goal of both interventions. Patients received their treatment individually in both treatment conditions.

\section{Graded exposure in vivo (GEXP)}

The GEXP consists of several components: goal identification, education, exposure in vivo, and generalization. Goal identification: First the patient is invited to formulate his or her own treatment goals. The therapist makes clear that GEXP never primarily aims at reducing pain but at the restoration of functional abilities despite pain. Subsequently, the patient and therapist agree on one or more realistic and specific goals that are formulated in positive terms. Activities (e.g. lifting weights) that are in line with these goals (e.g. return to work) are those that will be included in the graded exposure sessions. Education: Patients are given a careful explanation of the fear-avoidance model (see Vlaeyen, Kole-Snijders, Boeren \& van Eek, 1995a; Vlaeyen, Kole-Snijders, Rotteveel, Ruesink \& Heuts, 1995b), using their own individual symptoms, beliefs and behaviors in relation to their pain complaints. The therapist illustrates the paradoxical and dysfunctional effects of avoidance as a safety behavior, and offers the patient a new view on pain as a common condition that can be self-managed, rather than as a serious disease or a condition that needs careful protection. One of the major goals of the educational component is to help the patient understand that the consequences of pain are overestimated catastrophically. Exposure in vivo: Individually tailored practice tasks are developed based on the graded hierarchy of fear eliciting activities and/or movements. The exposure 
takes the form of a series of behavioural experiments in which irrational assumptions are explicitly being challenged. These assumptions take the form of "If $P$, then Q" statements (e.g. "If I lift up my child, then nerves in the neck region will ruptureand my muscles will get blocked") and are empirically tested during a behavioural experiment. Generalization: To enhance generalization and maintenance exposure is provided to the full spectrum of contexts and natural settings in which fear has been experienced, and the stimuli are varied. For example, bicycling can be done on a city bike and/or mountain bike, uphill as well as downhill, on rough as well as even terrain, and so on. The exposure procedure included activities extended from PHODA to other activities as well. A more detailed description of GEXP can be found in Vlaeyen, de Jong, Sieben \& Crombez (2002c) and Vlaeyen, de Jong, Leeuw \& Crombez (2004).

\section{Graded activity (GA)}

The GA is based on the programs originally described by Fordyce (1976), and updated by Sanders (2002). The main goal of GA is the systematic removal of the contingent relationship between an overt pain behavior and its positive consequences. This implies that GA is guided by the patients' functional abilities and a time-contingent rather than a pain-contingent regimen. In this study GA consisted of the following components: education, identification of goals, establishment of a baseline, successive approximation, generalization. Education: The educational session is done similarly as in the GEXP, except that the focus is on the detrimental effects of inactivity and not on the dysfunctional beliefs. Identification of goals: Similar to GEXP, realistic and concrete treatment goals are formulated based on the patients' main complaints. Goals are split up in separate activities in the quota system. Establishing baseline levels: For each of these activities, a baseline level is determined based on a pain-contingent principle ("go on with this activity until your pain makes you feel like discontinuing"). Afterwards, time-contingent treatment quotas for each activity are developed, always starting below the mean baseline value. Successive approximation: During the treatment phase, the patient systematically increases the time-contingent quotas to enable them to reach their personal goals within the pre-set therapy time period. The patient practices at home and documents every activity or exercise on a performance chart. These charts are discussed in each treatment session, and all team members positively reinforce the individual progress and successive approximations towards predefined (sub)goals. Generalization: at the end of the treatment, activities are planned outside the hospital, and preferably in the home and work setting in order to enhance response generalization. A more detailed description of GA can be found in Sanders (2002). 


\section{Manipulation check}

In order to check whether the threat value of physical activities has diminished as a result of GEXP, the PHODA for upper extremities was repeated after baseline, GA, and GEXP. Each photograph is given a rating according to the position on the fear thermometer. A total score ranging from 0 to 100 is calculated as the sum of each rating, divided by 125 (the maximum total score).

\section{Outcome measures}

The primary outcome measures are self-reported achievement of goals, and pain disability. Secondary outcome measures are pain intensity, pain-related fear, pain catastrophizing, and physical activity levels in the home situation.

\section{Daily diary measures}

To check whether the GEXP and/or GA indeed modified activity goal achievement, pain-related fear, and pain intensity, a short questionnaire was used consisting of 14 visual analog scales. The first 11 items represented the main factors of existing questionnaires for fear of movement/(re)injury (Tampa Scale for Kinesiophobia (TSK); Goubert, Crombez, Van Damme, Vlaeyen, Bijttebier \& Roelofs, 2004; Miller et al., 1991; Roelofs, Goubert, Peters, Vlaeyen \& Crombez, 2004;), fear of pain (Pain Anxiety Symptoms Scale (PASS); McCracken, Zayfert \& Gross, 1992; McCracken, Spertus, Janeck, Sinclair \& Wetzel, 1999), pain catastrophizing (Pain Catastrophizing Scale (PCS); Van Damme, Crombez, Bijttebier, Goubert \& Van Houdenhove, 2002; Sullivan, Bishop \& Pivik, 1995). All items were scored on 10 cm visual analogue scales (VAS), anchored 'totally disagree' - 'totally agree'. Pain intensity was measured with an additional VAS anchored with "no pain at all" at one extreme and "worst pain experienced" at the other. The last two VAS referred to the performance of personally relevant activities that represented two main goals. Each scale consists of the same question: "How difficult was it to perform this activity today?" The scale was anchored with "no problem at all" at one extreme and "impossible" at the other. The diary was administered during the whole duration of the study and the follow-up period of one week. The patients were requested to complete the diary each evening and to send the package by mail the next day to the researchers. The diary has been shown to be sensitive to graded exposure in vivo in previous studies (e.g. de Jong et al., 2005; Vlaeyen et al., 2001;).

\section{Functional disability}

The Neck Disability Index (NDI) is a 10-item self-reporting instrument for the assessment of physical disability of subjects with neck pain, particularly from 
whiplash-type injuries (Vernon \& Mior, 1991). Each item is scored from 0 to 5 . The NDI has been shown to have a high degree of test-retest reliability, internal consistency, and acceptable level of validity being sensitive to severity levels and to changes in severity over time (Riddle \& Stratford, 1998; Vernon \& Mior, 1991). Disability categories for the NDI are: 0-4 = 'no disability', 5-14 = 'mild disability', 15-24 = 'moderate disability', 25-34 = 'severe disability', and above 34 = 'complete disability'. We used a Dutch version (Köke, Heuts, Vlaeyen \& Weber, 1999), which has shown to be a reliable and responsive instrument in patients with acute neck pain in general practice (Vos, Verhagen \& Koes, 2006).

\section{Pain-related fear}

The complete Dutch version of the TSK (Miller et al., 1991; Roelofs et al., 2004) was used. This questionnaire consists of 17 items, measuring fear of (re) injury due to movement, scored on a 4-point scale. The TSK has been found reliable and valid and was capable to predict chronic disability in neck pain (Nederhand et al., 2004; Nederhand, Hermens, IJzerman, Groothuis \& Turk, 2006).

\section{Physical activity}

To objectively assess the level of physical activity in the home situation of the patients, patients carried an accelerometry-based electronic activity monitor. The monitor was attached to a belt dorsally, at the height of the thoracic vertebras. Data was stored for one week and at the end of that week the data were downloaded to a computer via an infrared interface for data processing. Movement counts were summed over the entire measurement period and subsequently divided by the time the accelerometry-based activity monitor was carried. Patients kept a notebook daily in which they registered the time carrying the activity monitor and the kind of performed activities. The activity monitor used in our study appeared to have acceptable reliability for most research applications (Welk, Scaben \& Morrow, 2004).

\section{Statistical analyses}

For analyzing the data of the daily measures, a randomization test for single case experimental phase designs, based on the random determination of the moments of phase change or intervention points, was carried out (Edgington, 1975, 1980; Ferron \& Onghena, 1996; Onghena, 1992; Onghena \& Edgington, 2005). Because GEXP was expected to be superior to BAS, and GA, the null hypothesis that there is no differential effect for any of the measurement times is tested using a randomization test on the differences between GEXP and BAS, GA and BAS, GA and GEXP. While FU is expected to be superior to BAS and will not change in relation to GEXP, differences between FU and BAS, FU and GA, FU and GEXP are also tested 
using randomization tests. The analysis is performed using the SCRT software (Single-Case Randomization Tests, version 1.1; (Onghena \& Van Damme, 1994)). Finally, the test is repeated assuming delayed effects (effect lags of two weeks) until the minimal $\mathrm{P}$-value $(\mathrm{p}<0.05)$ has been reached (for the general formula and algorithms see Edgington, 1992; 1995; Wampold \& Furlong, 1981).

\section{Preset criteria for non-daily measures}

For the non-daily measures limited number of data made it impossible to use randomization tests. Therefore, we decided to formulate pre-set criteria to conclude whether the treatment could be considered successful. For the PHODA we estimated that a $50 \%$ decrease would give enough support that the threat value of the activities had decreased. For the NDI a five-point change is required to be clinically meaningful (Stratford, Riddle, Binkley, Spadoni, Westaway \& Padfield, 1999). For the TSK we estimated that a $30 \%$ decrease was considered relevant. For the accelerometrybased activity monitor, standardized z-scores were calculated for each patient individually by subtracting the mean number of baseline counts from the counts during each phase, and dividing these values by the baseline standard deviation for that individual. This is done for mean counts in the week after each treatment module and in the week of the $6^{\text {th }}$-month follow-up period. We estimated that an increase of $5 \mathrm{z}$-scores could be clinically relevant.

\section{RESULTS}

\section{Manipulation check}

Table 2 displays a drastic reduction in PHODA scores at the end of the GEXP, as compared to baseline ( $90 \%$ decrease) for condition $\mathrm{A}$ and to baseline $(91 \%$ decrease) and GA (88\% decrease) for condition B. For condition A, as compared to GEXP, GA and Fu did not resulted in a further reduction of more than $50 \%$, and for condition $\mathrm{B}$ at the end of GA, the reduction from baseline (decrease 20\%) was neither clinically relevant.

\section{Daily measures}

Because the patterns of change for fear of movement/(re)injury, fear of pain, and pain catastrophizing, within each condition are quite similar, we decided to calculate means of the three time series for these variables for each condition group, instead of each patient separately. This produced more stable time series and reduced the number of statistical tests. In addition of this similarity figure 1 shows the observations across time for fear of movement/(re)injury and pain experience. 


\section{Condition A (baseline-GEXP-GA-FU)}

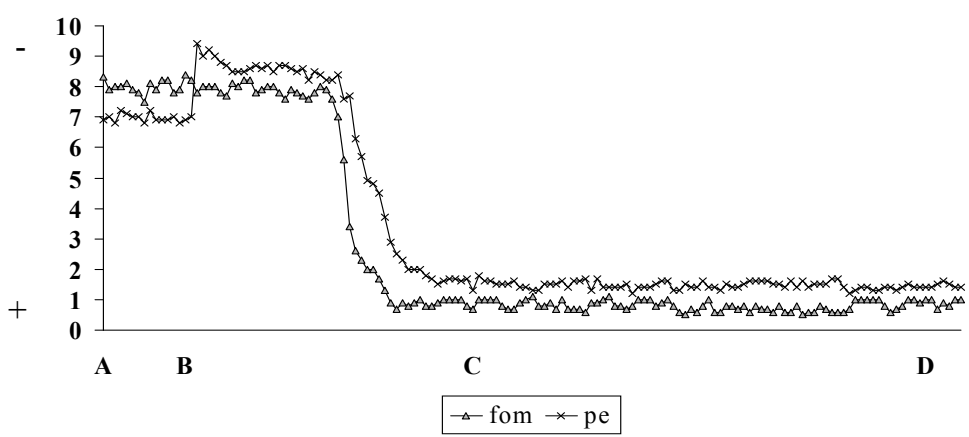

Condition B (baseline-GA-GEXP-FU)

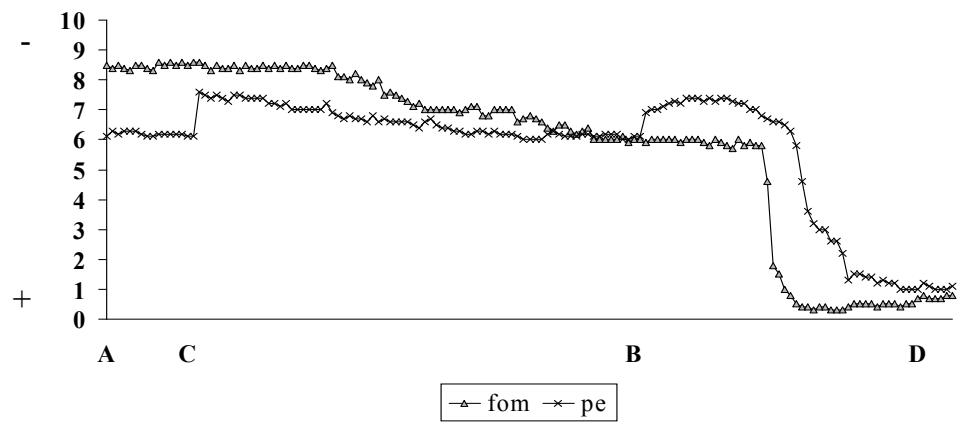

Figure 1: Mean daily measures for the patients in condition A and B of fear of movement/(re)injury (fom) and pain experience (pe), across baseline (A), graded exposure in vivo (B), graded activity (C), and 6month follow-up period $(D)$. $A=14$ days, $B=42$ days $(12$ sessions of $1 \mathrm{~h})+7$ days activity monitor, $C=$ 70 days $(20$ sessions of $1 \mathrm{~h})+7$ days activity monitor, $D=7$ days

Visual inspection reveals that trend changes occur after the introduction of GEXP only, and that these changes are still present during the 6-month follow-up period. By contrast, the introduction of GA does not lead to observable trend changes. These patterns suggests for patients who reported substantial pain-related fear that fear of movement/(re)injury and pain experience are reduced only by the GEXP. Given the similar patterns this also applies for pain catastrophizing and fear of pain. 


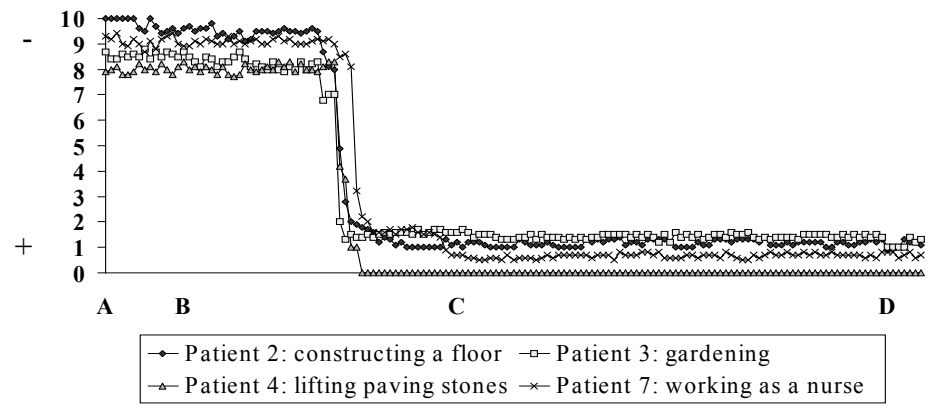

Condition B (baseline-GA-GEXP-FU)

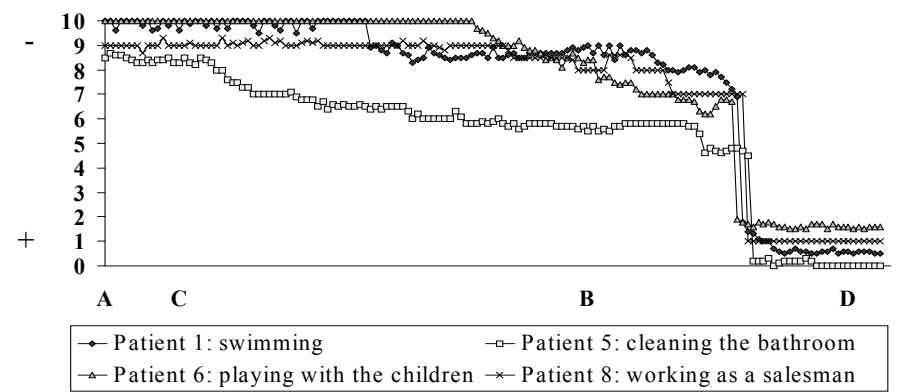

Figure 2: Mean daily measures for each patient in condition $A$ and $B$ for one of the two selected personally relevant activities, across baseline (A), graded exposure in vivo (B), graded activity (C), and 6-month follow-up period (D). $A=14$ days, $B=42$ days ( 12 sessions of $1 \mathrm{~h})+7$ days activity monitor, $C=70$ days $(20$ sessions of $1 \mathrm{~h})+7$ days activity monitor, $D=7$ days.

The graphical representations of personally relevant activities are displayed in figure 2. Given that in each patient both selected activities show the same patterns of change, only one activity per person is presented. Visual inspection of the patterns for each patient reveals that also for the performance of personally relevant activities only the GEXP produced substantial trend changes. 
Table 1 displays the effect lag within the GEXP (one lag is 1 week or two sessions of therapy) in which significance was reached for the phase design randomization tests on the raw data. The results confirm the conclusions of the graphical display. Independently of the condition, for the performance of relevant activities in each patient individually significant changes are only observed during GEXP, namely in the fifth week. In condition A the improvements remain during the GA and the same goes for the FU in both conditions.

Table 1: The effect lag (one lag is one week or 2 sessions of exposure therapy) during the graded exposure in vivo in which the minimum $P$-values for the randomization tests with one observation per phase has been reached for each patient in condition A (baseline-graded exposure in vivo-graded activity-follow-up) and condition B (baseline-graded activity-graded exposure in vivo-follow-up) for fear of movement (FOM), fear of pain (FOP), pain catastrophizing (PC), pain experience, and two personally

\begin{tabular}{lllll}
\multicolumn{5}{c}{ relevant activities. } \\
\hline Condition & FOM, FOP and PC & Pain experience & Activity 1 & Activity 2 \\
\hline Condition A & & & & \\
patient 2 & $5(\mathrm{P}=0.024)$ & $5(\mathrm{P}=0.029)$ & $5 \mathrm{a}(\mathrm{P}=0.024)$ & $5 \mathrm{~b}(\mathrm{P}=0.024)$ \\
patient 3 & $5(\mathrm{P}=0.024)$ & $5(\mathrm{P}=0.024)$ & $5 \mathrm{c}(\mathrm{P}=0.024)$ & $5 \mathrm{~d}(\mathrm{P}=0.024)$ \\
patient 4 & $5(\mathrm{P}=0.021)$ & $5(\mathrm{P}=0.024)$ & $5 \mathrm{e}(\mathrm{P}=0.021)$ & $5 \mathrm{f}(\mathrm{P}=0.021)$ \\
patient 7 & $5(\mathrm{P}=0.029)$ & $5(\mathrm{P}=0.037)$ & $5 \mathrm{~g}(\mathrm{P}=0.029)$ & $5 \mathrm{~h}(\mathrm{P}=0.029)$ \\
Condition B & & & & \\
patient 1 & $5(\mathrm{P}=0.013)$ & $5(\mathrm{P}=0.013)$ & $5 \mathrm{i}(\mathrm{P}=0.013)$ & $5 \mathrm{j}(\mathrm{P}=0.016)$ \\
patient 5 & $5(\mathrm{P}=0.016)$ & $5(\mathrm{P}=0.024)$ & $5 \mathrm{k}(\mathrm{P}=0.016)$ & $51(\mathrm{P}=0.016)$ \\
patient 6 & $4(\mathrm{P}=0.024)$ & $5(\mathrm{P}=0.024)$ & $5 \mathrm{~m}(\mathrm{P}=0.024)$ & $5 \mathrm{n}(\mathrm{P}=0.024)$ \\
patient 8 & $4(\mathrm{P}=0.029)$ & $5(\mathrm{P}=0.037)$ & $5 \mathrm{o}(\mathrm{P}=0.029)$ & $5 \mathrm{p}(\mathrm{P}=0.024)$
\end{tabular}

${ }^{a}$ Mountain bike, ${ }^{b}$ Construct a floor,${ }^{c}$ Garden, ${ }^{d}$ Jogging, ${ }^{e}$ Lift paving stones, ${ }^{f}$ Play soccer, ${ }^{g}$ Ride, ${ }^{h}$ Work as nurse, ${ }^{i}$ Swim, ${ }^{j}$ Look back, ${ }^{k}$ Clean the bathroom, ${ }^{l}$ Cycle, ${ }^{m}$ Dance, ${ }^{n}$ Having a romp with the children, ${ }^{o}$ Drive a car, ${ }^{p}$ Work as salesman

The results of the randomization tests for fear of movement, fear of pain, pain catastrophizing, and pain experience are also displayed in table 1. In accordance with the results of the performance of relevant activities in both conditions significant changes are only observed during GEXP and on top of that always in the same effect lag. In condition A, for fear of movement, fear of pain, and pain catastrophizing significance was reached for all the patients (patient 2-4, 7) in week 5 (session 910) of the GEXP, and in condition B for patients 6 and 8 in week 4 (session 7-8) and for patients 1 and 5 in week 5 (sessions 9-10) of the GEXP. With regard to pain experience significance was reached for both conditions in week 5 (session 9-10) of the GEXP. The measurement periods after the GEXP (GA and/or FU) did not provide any other significant changes with regard to a positive improvement or a possible relapse. 


\section{Pain disability}

At the start of both conditions the mean score of the NDI equates with "complete disability". Clinically meaningful changes are observed both when GA (mean score of 35.5 to 27) and GEXP (mean score of 37.8 to 7.5) are introduced first (table 2). However, considering the disability categories for the NDI, patients in condition B are still 'severely disabled' at the end of GA. When GEXP follows GA the mean score for the NDI decreased further (mean score of 27 to 8.5), which means that the GEXP provide for a situation in which patients are 'mildly disabled'. The decrease in pain disability remained at GA and follow-up in condition A and at follow-up in condition B.

Table 2: Mean scores (range) for pain-related fear (TSK and PHODA) and pain disability (NDI), determined at baseline, before and after each treatment module, and at the 6-month follow-up for condition $A(n=4)$ and condition $B(n=4)$.

\begin{tabular}{lccc}
\hline $\begin{array}{l}\text { Condition: } \\
\text { interval }\end{array}$ & NDI & TSK & PHODA \\
$(0-50)$ & $(17-68)$ & \\
\hline Condition A & & & 83 \\
Baseline & 37.8 & 47.5 & 86 \\
Start GEXP & 37.8 & 47.5 & 9 \\
End GEXP & 7.5 & 24 & 9 \\
Start GA & 7.5 & 24 & 7 \\
End GA & 7.5 & 24 & 8 \\
FU & 8.5 & 25 & \\
Condition B & & & 85 \\
Baseline & 35.5 & 48 & 85 \\
Start GA & 35.5 & 48 & 68 \\
End GA & 27 & 41 & 69 \\
Start GEXP & 27 & 41 & 8 \\
End GEXP & 8.5 & 23 & 8 \\
FU & 8.5 & 23 & Graded
\end{tabular}

\section{Pain-related fear}

Table 2 shows that both in condition A and B TSK scores show a clinically relevant decrease $(>30 \%)$ ) only when GEXP is delivered and not during/after GA. The mean TSK scores of condition A decrease from 47.5 at the start of GEXP to a mean TSK score of 24 at the end of the GEXP. This reduction of almost $50 \%$ remains after GA and at follow-up. For condition B there is first a slight decrease of the mean TSK score from 48 to 41 as the result of GA, and a clinically relevant decrease to 23 at the end of GEXP, which remains until the 6-month follow-up period. In comparison to the baseline this decrease is even $52 \%$ and to GA $44 \%$. 


\section{Physical activity}

Figure 3 shows the mean standardized sores of the activity monitor for patients in both conditions separately. Again, a marked increase is observed after GEXP and not after GA. For condition A the increase in movement counts after GEXP, as compared to baseline, equals a mean z-score of 22.44 (range \pm 1.66 ). After GA and $\mathrm{FU}$, as compared to baseline, the mean z-scores were 27.58 (range \pm 1.71 ) and 27.91 (range \pm 1.91 ) respectively. For intervention group B the mean z-score after GA, as compared to baseline, was 10.05 (range \pm 1.18 ), and for GEXP and FU these scores were 26.49 (range \pm 1.77 ) and 28.07 (range \pm 2.99 ).

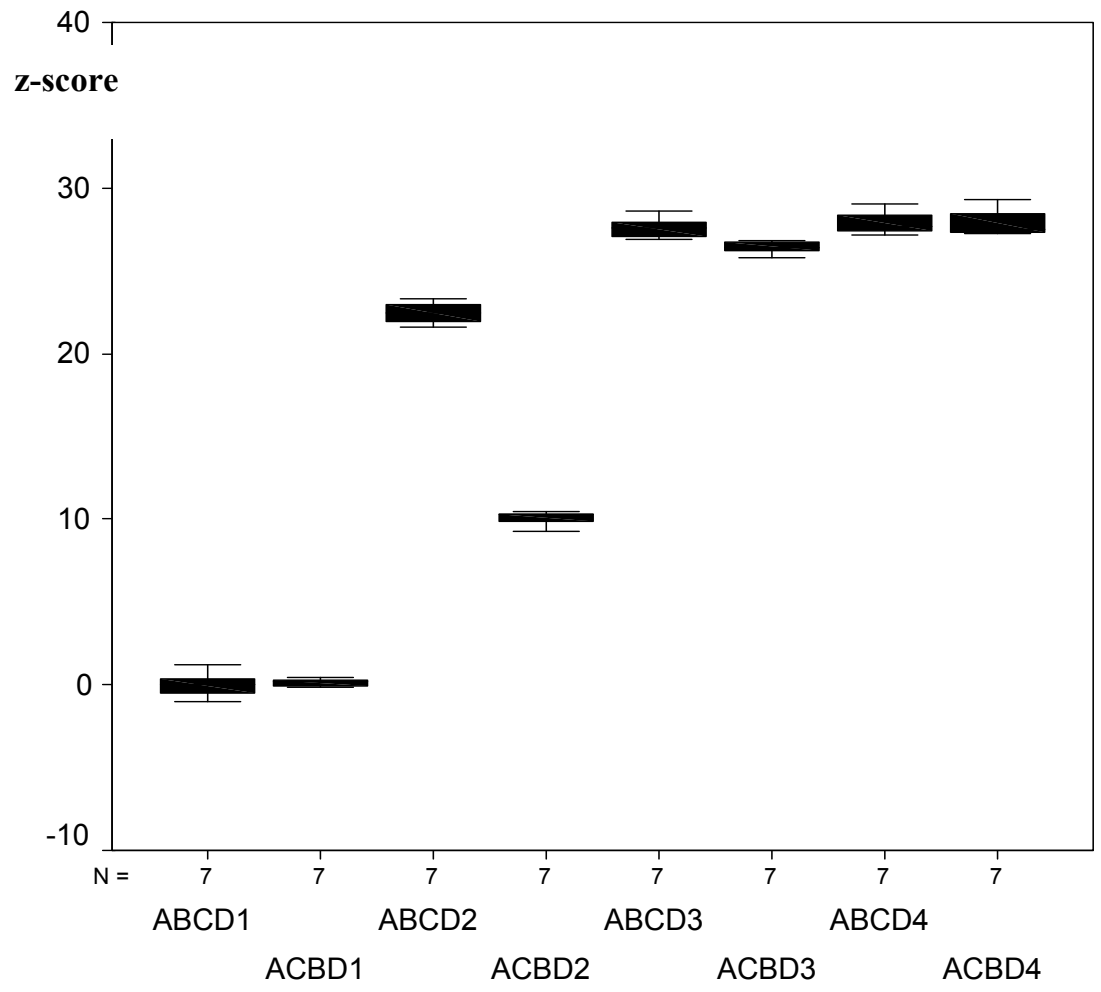

Figure 3: Standardized z-scores for the accelerometry-based activity monitor, calculated for condition A $(A B C D)$ and $B(A C B D)$, in the week ( $N=7$ days) after each treatment module $(1,2,3)$ and in the week of the $6^{\text {th }}$-month follow-up period (4).

$A=$ baseline, $B=$ graded exposure in vivo, $C=$ graded activity, $D=6^{\text {th }}$-month follow-up 


\section{DISCUSSION}

This is the first study showing that the effects of graded exposure in vivo that were seen in patients with chronic back pain generalizes to patients with chronic posttraumatic neck pain. By using a replicated single-case crossover experimental phasedesign, the aim of this study was to examine the effectiveness of a graded exposure in vivo treatment as compared to a usual graded activity program in reducing painrelated fears, catastrophizing, and pain disability in eight chronic posttraumatic neck pain patients reporting substantial fear of movement / (re)injury. The patients were referred for outpatient behavioral rehabilitation. Both the randomization tests on the daily measures and clinically relevant changes in measures that were taken before and after each treatment phase, showed that compared to a baseline period and GA, the GEXP was superior in decreasing levels of pain-related fear, pain catastrophizing, pain disability, and pain experience. Not only were improvements found in the self-report measures, but also in physical activity in the home situation as measured with ambulatory activity monitors. The treatment gains remained at the 6-month follow-up. Because the experimental design did not include washout periods between the different treatment components, carry-over effects likely occurred. Indeed, when GEXP was followed by GA the improvements remained stable, which is also consistent with the favorable 6-month follow-up results.

Earlier GEXP has already successfully been applied to chronic low back pain (CLBP) patients (Boersma et al., 2004; de Jong et al., 2005; Vlaeyen et al., 2001, 2002). However, the number of exposure sessions necessary for trend changes and significant effects between CLBP patients and the posttraumatic neck pain patients in this study is not totally comparable. As measured with the same daily diary, in CLBP GEXP resulted in an immediate significant reduction of pain-related fear and disability, whereas in this study these effects were realized between the seventh and tenth exposure session.

A possible explanation of this difference in time of effect is that the meanings associated with the overall medical condition of persistent pain may characterize the quality and magnitude of suffering. Beyond neck pain, symptoms such as headache, visual disturbances, dizziness, weakness, paraesthesia, nausea, both upper and lower limb numbness and tingling, tinnitus, and cognitive problems (concentration and memory disturbances) are common in the acute stage after a traumatic event (Barnsley, Lord \& Bogduk, 1994; Ferrari, Russell, Carroll \& Cassidy, 2005). In low back pain, patients' main concern is overall the experienced pain interfering with daily life activities. For this reason, it might have been easier to modify the meaning attached to their pain as compared to neck pain patients who report besides pain also other signs and symptoms as a consequence of the posttraumatic neck pain. 
Furthermore, a possible explanation for the delayed effect could lie in the concerns of the posttraumatic neck pain patients. Compared to the typical thoughts of back pain patients; "if. . . . . activity and/or movement, then. . . . catastrophe" (e.g. "If I lift then I damage my back"), it is possible that concerns of the neck pain patients are more difficult to challenge (e.g. "If I would lift heavy weights, then I have not the full control of my neck, which will worsen the pain complaints, resulting in that I will not be able to do my job in the future"). The disconfirmation is perhaps hampered because of the above mentioned multiple complaints and connected thoughts, who cannot all be challenged in one behavioural experiment.

In addition to CLBP it seems that GEXP is a successful strategy for patients with chronic posttraumatic neck pain disability and substantial pain-related fear. On the basis of literature on extinction and fear processes, we hypothesize that the actual experience with or the exposure to the personally relevant and specific pain-related fear stimuli is likely to produce the greatest changes. Of particular interest is that all improvements remained after 6-month, suggesting that extinction of fear generalized to situations outside the treatment setting. This is remarkable because there is growing evidence that exposure cannot simply be equated with unlearning (Bouton, 1988, 2000; Goubert, Francken, Crombez, Vansteenwegen \& Lysens, 2002). It is plausible that in our study generalization was facilitated by the repeated exposure to essential and individually identified stimuli, as measured with the PHODA. Another explanation could be that the background context of each exposure session differs from each other. Whenever possible, the GEXP sessions were carried out in the context of daily life and not in the clinical setting. However, this aspect did not differ from GA, in which the patient was also encouraged to increase activity level by the use of daily life activities. The finding that activity monitor data show the same pattern as the self-reported measures further supports the assumption that treatment gains produced during the exposure to activities typical for the treatment setting do generalize to the home setting and in the absence of the therapist.

Of interest is that current pain experience was also affected by GEXP. Similar results are observed in effectiveness studies of GEXP in chronic low back pain (de Jong et al., 2005; Vlaeyen et al., 2001, 2002a, 2002b). However, such strong reduction in pain is not common in usual cognitive-behavioral treatments for chronic pain (Morley et al., 1999; Kole-Snijders, Vlaeyen, Goossens, Rutten-van Molken, Heuts, van Breukelen \& van Eek, 1999). How can this unexpected result be explained? Experimental studies on the role of attention and pain-related fear have shown that exposure also results in decreases of pain vigilance (Asmundson, Kuperos \& Norton, 1997; Peters, Vlaeyen \& Kunnen, 2002). This finding corroborates the idea that the most important function of anxiety is the early detection of potentially threatening situations. It is likely that the decrease in pain experience during GEXP was mediated by a process in which the reduction of the threat value of previously fear- 
eliciting stimuli also produced a redirection of the attention away from pain and bodily sensations. Alternatively, pain reduction might directly be the result of the diminished threat value of the physical activities (Arntz \& Claassens, 2004).

Although, no electromyographic (EMG) recording has been performed in this study, Nederhand et al. (2006) suggested that pain-related fear is associated with the level of muscle activation. By avoiding the use of painful muscles to prevent the amplification of pain and further injury, muscle activation is decreased. In addition, it is likely that fear reduction is associated with an increase in muscle activation (Nederhand et al., 2006), which in turn may be associated with a reduction of pain experience (Flor, Turk \& Birbaumer, 1985).

Finally, several limitations of the study should be mentioned. First, this study is limited in that it included only eight patients. However, a replicated crossover single-case experimental design was chosen with a customized randomization test to perform statistical analyses, which is an added value to detect idiosyncratic functional relationships and behavioural laws. Second, because in the crossover design all patients received both GEXP and GA, long-term differential effects could not be established. Replication studies in the form of randomized controlled trials using larger samples are warranted. However, single-case experiments have higher practicality as compared to RCT and therefore are more useful to demonstrate accountability in a clinical setting on a more regular basis (Persons \& Silverschatz, 1998). In addition, the application of single-case experiments is an obvious option if the research interest is in the evaluation of individualized custom-made therapy (Onghena \& Edgington, 2005). Third, by definition it is within single case studies not possible to assess generality across subjects. However, interventions that produce dramatic effects are likely to generalize more than those with weaker effects, and this appears to be true in this study. Using randomization tests as time series analysis, we have demonstrated that the changes could not be attributed to chance. Besides, generalization may be derived from the fact that replications of eight different patients show consistently similar results in this study and in studies with chronic low back pain patients. So far, it seems justifiable to generalize the results to other patients with chronic posttraumatic neck pain who report substantial pain-related fear. Fourth, this study did not check whether pain behaviour has decreased as a result of GA. Finally, the follow-up period may not have been sufficient to determine the long-term effect on the treatment or long-term disability.

In sum, the current study supports a graded exposure in vivo approach in chronic posttraumatic neck pain patients reporting substantial levels of pain-related fear. The GEXP was successful in decreasing levels of self-reported pain-related fear, disability, pain experience, and increases the level of daily life physical activity as measured with an accelerometry-based activity monitor. These results underscore the idea that GEXP modifies the meaning people attach to their neck pain complaints, and 
those changes also influence the experienced painfulness. The results need to be verified in a wider chronic posttraumatic neck pain population. However, providing patients who report pain-related fear with a structured exposure in vivo program seems a promising treatment direction. 


\section{REFERENCES}

Arntz, A., \& Claassens, L. (2004). The meaning of pain influences its experienced intensity. Pain, 109, 20-25.

Arrindell, W.A., \& Ettema, J.H.M. (1986). Symptom checklist (SCL-90). Handleiding bij een multidimensionele psychopathologie-indicator. Lisse: Swets.

Asmundson, G.J., Kuperos, J.L., \& Norton, G.R. (1997). Do patients with chronic pain selectively attend to pain-related information?: preliminary evidence for the mediating role of fear. Pain, 72(1-2), 2732.

Asmundson, G.J., Norton, P.J., \& Norton, G.R. (1999). Beyond pain: the role of fear and avoidance in chronicity. Clin Psychol Rev, 19(1), 97-119.

Barlow, D.H. (2002). Anxiety and its disorders. The nature and treatment of anxiety and panic. New York: The guilford Press.

Barnsley, L., Lord, S., \& Bogduk, N. (1994). Whiplash injury. Pain, 58(3), 283-307.

Boersma, K., Linton, S. J., Overmeer, T., Jansson, M., Vlaeyen, J., \& de Jong, J. (2004). Lowering fearavoidance and enhancing function through exposure in vivo. A multiple baseline study across six patients with back pain. Pain, 108, 8-16.

Bouton, M.E. (1988). Context and ambiguity in the extinction of emotional learning: Implications for exposure therapy. Behav Res Ther, 26, 137-149.

Bouton, M.E. (2000). A learning theory perspective on lapse, relapse, and the maintenance of behaviour change. Health Psych, 19, 57-63.

Buer, N., \& Linton, S.J. (2002). Fear-avoidance beliefs and catastrophizing: occurrence and risk factor in back pain and ADL in the general population. Pain, 99(3), 485-491.

Butler, A.C., Chapman, J.E., Forman, E.M., \& Beck A.T. (2006). The empirical status of cognitivebehavioral therapy: a review of meta-analyses. Clin Psychol Rev, 26(1), 17-31.

Clark, D.M. (1986). A cognitive approach to panic. Behav Res Ther, 24, 461-470.

Crawford, J.R., Khan, R.J., \& Varley, G.W. (2004). Early management and outcome following soft tissue injuries of the neck-a randomised controlled trial. Injury, 35(9), 891-895.

Crombez, G., Vlaeyen, J.W.S., Heuts, P.H.T.G., \& Lysens, R. (1999). Fear of pain is more disabling than pain itself: evidence on the role of pain-related fear in chronic back pain disability. Pain, 80, 329-339.

de Jong, J.R., Vlaeyen, J.W.S., Onghena, P., Goossens, M.E.J.B., Geilen, M., \& Mulder, H. (2005). Fear of Movement/(Re)injury in Chronic Low Back Pain: Education or Exposure in Vivo as Mediator to Fear Reduction? Clin J Pain, 21(1), 9-17.

Dubbers, A.T., Vikström, M.H., \& de Jong J.R. (2003). The Photograph series of Daily Activities (PHODA): Cervical Spine \& Shoulder. CD-rom version 1.2: Hogeschool Zuyd, University Maastricht and Institute for Rehabilitation Research (iRv). The Netherlands.

Edgington, E.S. (1975). Randomization tests for one-subject operant experiments. J. Psychol, 90, 57-68.

Edgington, E.S. (1980). Overcoming obstacles to single-subject experimentation. J Education Stat, 5, 261-267.

Edgington, E.S. (1992). Nonparametric tests for single-case experiments. In Kratochwill TR \& Levin JR (Eds), Single-Case Research Design and Analysis: New Directions for Psychology and Education (pp. 133-157). Hillsdale, NJ: Lawrence Erlbaum Associates.

Edgington, E.S. (1995). Randomization Tests, 3rd edn. New York: Marcel Dekker.

Ferrari, R., Russell, A.S., Carroll, L.J., \& Cassidy, J.D. (2005). A re-examination of the whiplash associated disorders (WAD) as a systemic illness. Ann Rheum Dis, 64(9), 1337-1342.

Ferron, J., \& Onghena, P. (1996). The power of randomization tests for single-case phase designs. J. Exp. Educ., 64, 231-239. 
Flor, H., Turk, D.C., \& Birbaumer, N. (1985). Assessment of stress-related psychophysiological reactions in chronic back pain patients. J Consult Clin Psychol, 53(3), 354-364.

Fordyce, W.E. (1976). Behavioral methods for chronic pain and illness. St. Louis, MO: Mosby.

Foster, N.E., Pincus, T., Underwood, M., Vogel, S., Breen, A., \& Harding, G. (2003). Treatment and the process of care in musculoskeletal conditions. A multidisciplinary perspective and integration. Orthop Clin North Am, 34(2), 239-244.

Fritz, J.M., George, S.Z., \& Delitto, A. (2001). The role of fear-avoidance beliefs in acute low back pain: relationships with current and future disability and work status. Pain, 94(1), 7- 15.

Goubert, L., Francken, G., Crombez, G., Vansteenwegen, D., \& Lysens, R. (2002). Exposure to physical movement in chronic back pain patients: no evidence for generalization across different movements. Behav Res Ther, 40(4), 415-429.

Goubert, L., Crombez, G., Van Damme, S., Vlaeyen, J.W., Bijttebier, P., \& Roelofs J. Confirmatory factor analysis of the Tampa Scale for Kinesiophobia: invariant two-factor model across low back pain patients and fibromyalgia patients. Clin J Pain, 20(2), 103- 110.

Heuts, P.H., Vlaeyen, J.W., Roelofs, J., de Bie, R.A., Aretz, K., van Weel, C., \& van Schayck, O.C. (2004). Pain-related fear and daily functioning in patients with osteoarthritis. Pain, 110(1-2), 228235.

Jaspers, J.P. (1998). Whiplash and post-traumatic stress disorder. Dis Rehab, 20(11), 397-404.

Köke, A.J.A., Heuts, P.H.T.G., Vlaeyen, J.W.S. \& Weber, W.E.J. (1999). Meetinstrumenten chronische pijn: deel 1 functionele status. Pijn Kennis Centrum, academisch ziekenhuis Maastricht (azM). The Netherlands.

Kole-Snijders, A.M., Vlaeyen, J.W., Goossens, M.E., Rutten-van Molken, M.P., Heuts, P.H., van Breukelen, G., \& van Eek, H. (1999). Chronic low back pain: what does cognitive coping skills training add to operant behavioral treatment? Results of a randomized clinical trial. J Consult Clin Psychol, 67(6), 931-944.

Linton, S.J., \& Andersson, T. (2000). Can chronic disability be prevented? A randomized trial of a cognitive-behavior intervention and two forms of information for patients with spinal pain. Spine, 25(21), 2825-2831.

Linton, S.J., \& Ryberg, M. (2001). A cognitive-behavioral group intervention as prevention for persistent neck and back pain in a non-patient population: a randomized controlled trial. Pain, 90(1-2), 83-90.

Mannion, A.F., Muntener, M., Taimela, S., \& Dvorak, J. (1992). A randomized clinical trial of three active therapies for chronic low back pain. Spine, 24(23), 2435-2448.

McCracken, L.M., Zayfert, C., \& Gross, R.T. (1992). The Pain Anxiety Symptoms Scale: Development validation of a scale to measure fear of pain. Pain, 50, 67-73.

McCracken, L.M., Spertus, I.L., Janeck, A.S., Sinclair, D., \& Wetzel, F.T. (1999). Behavioral dimensions of adjustment in persons with chronic pain: pain-related anxiety and acceptance. Pain, 80, 283-90.

Miller, R.P., Kori, S.H., \& Todd, D.D. (1991). The Tampa Scale for Kinisophobia. Unpublished Report, Tampa, FL.

Morley, S., Eccleston, C., \& Williams, A. (1999). Systematic review and meta-analysis of randomized controlled trials of cognitive behaviour therapy and behaviour therapy for chronic pain in adults, excluding headache. Pain, 80(1-2), 1-13.

Nederhand, M.J., IJzerman, M.J., Hermens, H.J., Turk, D.C., \& Zilvold G. (2004). Predictive value of fear avoidance in developing chronic neck pain disability: consequences for clinical decision making. Arch Phys Med Rehabil, 85(3), 496-501.

Nederhand, M.J., Hermens, H.J., IJzerman, M.J., Groothuis, K.G.M., \& Turk, D.C. (2006). The Effect of Fear of Movement on Muscle Activation in Posttraumatic Neck pain Disability. Clin J Pain, 22, 519525 . 
Onghena, P. (1992). Randomization tests for extensions and variations of ABAB single-case experimental designs: a rejoinder. Behav Assess, 14, 153-171.

Onghena, P., \& Van Damme, G. (1994). SCRT 1.1: Single-case randomization tests. Behav Res Meth, Instruments, \& Computers, 26, 369.

Onghena, P., \& Edgington, E.S. (2005). Customization of Pain Treatments: Single-Case Design and Analysis. Clin J Pain, 21(1), 56-68.

Persons, J.B., \& Silberschatz, G. (1998). Are results of randomized controlled trials useful to psychotherapists? J Consult Clin Psychol, 66(1), 126-135.

Peters, M.L., Vlaeyen, J.W., \& Kunnen, A.M. (2002). Is pain-related fear a predictor of somatosensory hypervigilance in chronic low back pain patients? Behav Res Ther, 40(1), 85-103.

Philips, H.C. (1987). Avoidance behaviour and its role in sustaining chronic pain. Behav Res Ther, 25, 273-279.

Picavet, H.S., \& Schouten, J.S. (2000). Physical load in daily life and low back problems in the general population, the MORGAN study. Prev Med, 31(5), 506-512.

Provinciali, L., Baroni, M., Illuminati, L., \& Ceravolo, M. G. (1996). Multimodal treatment to prevent the late whiplash syndrome. Scan J of Rehab Medicine, 28, 105-111.

Riddle, D.L., \& Stratford, P.W. (1998). Use of generic versus region-specific functional status measures on patients with cervical spine disorders. Phys Ther, 78(9), 951-63.

Roelofs, J., Goubert, L., Peters, M.L., Vlaeyen, J.W.S., \& Crombez, G. (2004). The Tampa Scale for Kinesiophobia: further examination of psychometric properties in patients with chronic low back pain and fibromyalgia. Eur J Pain, 8(5), 495-502.

Rosenfeld, M., Seferiadis, A., Carlsson, J., \& Gunnarson, R. (2003). Active intervention in patients with whiplash-associated disorders improves long-term prognosis: a randomized controlled clinical trial. Spine, 28(22), 2491-2498.

Sanders, S.H. (2002). Operant Conditioning with Chronic Pain: Back to Basic. In: Turk, D.C., Gatchel, R.J., editors. Psychological Approaches to Pain Management. A practitioner's handbook. Second edition ed. (pp. 128-137). New York: Guilford.

Sgroi, M.I., Willebrand, M., Ekselius, L., Gerdin, B., \& Andersson, G. (2005). Fear-avoidance in recovered burn patients: association with psychological and somatic symptoms. J Health Psychol, 10(4), 491-502.

Smeets, R.J., Vlaeyen, J.W., Kester, A.D., \& Knottnerus, J.A. (2006). Reduction of pain catastrophizing mediates the outcome of both physical and cognitive-behavioral treatment in chronic low back pain. $\mathrm{J}$ Pain, 7(4), 261-271.

Soderlund, A., \& Lindberg, P. (2001). An integrated physiotherapy/cognitive-behavioural approach to the analysis and treatment of chronic whiplash associated disorders, WAD. Disabil Rehabil, 23(10), 436447.

Spinhoven, P., Ter Kuile, M., Kole-Snijders, A.M., Hutten Mansfeld, M., Den Ouden, D.J., \& Vlaeyen, J.W. (2004). Catastrophizing and internal pain control as mediators of outcome in the multidisciplinary treatment of chronic low back pain. Eur J Pain, 8(3), 211-219.

Sterner, Y., Toolanen, G., Knibestol, M., Gerdle, B., \& Hildingsson, C. (2001). Prospective study of trigeminal sensibility after whiplash trauma. J Spinal Disord,14(6), 479-486.

Stratford, P.W., Riddle, D.L., Binkley, J.M., Spadoni, G., Westaway, M.D., \& Padfield, B. (1999). Using the Neck Disability Index to make decisions concerning individual patients. Physiother Can, 51, 107112 .

Sullivan, M.J., Bishop, S.R., \& Pivik, J. (1995). The pain catastrophizing scale: development and validation. Psychol Assess, 7, 524-532. 
Swinkels-Meewisse, I.E., Roelofs, J., Oostendorp, R.A., Verbeek, A.L., \& Vlaeyen, J.W. (2006). Acute low back pain: pain-related fear and pain catastrophizing influence physical performance and perceived disability. Pain, 120(1-2), 36-43.

Turner, J.A., Franklin, G., Fulton-Kehoe, D., Sheppard, L., Wickizer, T.M., Wu, R., Gluck, J.V., \& Egan, $\mathrm{K}$. Worker recovery expectations and fear-avoidance predict work disability in a population-based workers' compensation back pain sample. Spine, 31(6), 682-689.

Van Damme, S., Crombez, G., Bijttebier, P., Goubert, L., \& Van Houdenhove, B. (2002). A confirmatory factor analysis of the Pain Catastrophizing Scale: invariant factor structure across clinical and nonclinical populations. Pain, 96(3), 319-324.

Vassiliou, T., Kaluza, G., Putzke, C., Wulf, H., \& Schnabel, M. (2006). Physical therapy and active exercises - An adequate treatment for prevention of late whiplash syndrome? Randomized controlled trial in 200 patients. Pain, 124(1-2), 69-76.

Vendrig, A. A., van Akkerveeken, P. F., \& McWhorter, K. R. (2000). Results of a multimodal treatment program for patients with chronic symptoms after a whiplash injury of the neck. Spine, 25(2), 238244.

Vernon, H., \& Mior, S. (1991). The Neck Disability Index: a study of reliability and validity. J Manipulative Physiol Ther, 14(7), 409-415.

Vlaeyen, J.W.S., Kole-Snijders, A.M.J., Boeren, R.G.B., \& van Eek, H. (1995a). Fear of movement/(re)injury in chronic low back pain and its relation to behavioral performance. Pain, 62, 363-72.

Vlaeyen, J.W.S., Kole-Snijders, A.M.J., Rotteveel, A., Ruesink, R., \& Heuts, P.H.T.G. (1995b). The role of fear of movement/(re)injury in pain disability. J Occupat Rehab, 5, 235-52.

Vlaeyen, J.W.S., \& Linton, S.J. (2000). Fear-avoidance and its consequences in chronic musculoskeletal pain: a state of the art. Pain, 85(3), 317-332.

Vlaeyen. J.W.S., de Jong, J.R., Geilen, M., Heuts, P.H.T.G., \& van Breukelen, G. (2001) Graded exposure in vivo in the treatment of pain-related fear: a replicated single-case experimental design in four patients with chronic low back pain. Behav Res Ther, 39, 151-166.

Vlaeyen, J.W.S., de Jong, J.R., Geilen, M., Heuts P.H.T.G., \& van Breukelen, G. (2002a). The Treatment of Fear of Movement/(Re)injury in Chronic Low Back Pain: Further Evidence on the Effectiveness of Exposure In Vivo. Clin J Pain, 18, 251-261.

Vlaeyen, J.W.S., de Jong, J.R., Onghena, P., Kerckhoffs-Hanssen, M., \& Kole-Snijders, A.M. (2002b). Can pain-related fear be reduced? The application of cognitive-behavioural exposure in vivo. Pain Res Manag, 7, 144-153.

Vlaeyen, J.W.S., de Jong, J.R., Sieben, J.M., \& Crombez, G. (2002c). Graded exposure in vivo for painrelated fear. In: Turk, D.C., Gatchel, R.J., editors. Psychological Approaches to Pain Management. A practitioner's handbook. Second edition ed. (pp. 210-233). New York: Guilford.

Vlaeyen, J.W.S., de Jong, J.R., Leeuw, M., \& Crombez, G. (2004). Fear reduction in chronic pain: Graded exposure in vivo with behavioral experiments. In: Asmundson, G.J.G., Vlaeyen, J.W.S., Crombez, G., editors. Understanding and treating fear of pain (pp. 313- 346). New York: Oxford University Press.

Vos, C.J., Verhagen, A.P. \& Koes, B.W. (2006). Reliability and responsiveness of the Dutch version of the Neck Disability Index in patients with acute neck pain in general practice. Eur Spine J, 15(11), 1729-1736.

Waddell, G., Newton, M., Henderson, I., Somerville, D., \& Main, C. (1993). A Fear-Avoidance Beliefs Questionnaire $(\mathrm{FABQ})$ and the role of fear-avoidance beliefs in chronic low back pain and disability. Pain, 52, 157-168.

Wampold, B.E., \& Furlong, M.J. (1981). The heuristics of visual inference. Behav Assess, 3, 79- 92.

Welk, G.J., Schaben, J.A., \& Morrow, J.R. jr. (2004). Reliability of accelerometry-based activity monitors: a generalizability study. Med Sci Sports Exerc, 36(9), 1637-1645. 



\section{Chapter 9}

\section{General Discussion}

Karoline Vangronsveld 


\section{INTRODUCTION}

The objective of this thesis was to examine the applicability of the Fear-Avoidance Model to patients with acute whiplash injury and chronic whiplash syndrome. For this purpose, four studies were performed, each addressing some specific research questions, relating to this main objective. This final chapter presents an overview and integration of the main findings of this thesis. First of all the main findings of the various studies are summarized in regards to our main research question. Then, the methodological limitations will be discussed. And finally, clinical recommendations and recommendations for further research are formulated.

\section{MAIN RESULTS}

\section{Do pain catastrophizing and pain-related fear predict the transition from acute whiplash injury to chronic whiplash syndrome?}

Generally, the results of this dissertation provide partial support for the FA-model in predicting the transition from acute whiplash injury to chronic whiplash syndrome. We will summarize the evidence and limitations derived from cross-sectional research, experimental and prospective studies, and finally results derived from a treatment study.

\section{Cross-sectional evidence}

In chapter three, fear of movement and pain catastrophizing were significantly associated with measures of restricted active and passive range of motion (ROM), indicating that fearful patients moved their neck much less when undergoing an assessment of the mobility of the neck. Surprisingly, this relationship was also present during passive ROM, when the physiotherapist took over the assessment, and patients did not have control over their movements. However, the difference scores between active and passive ROM, was not significantly associated with fear of movement or pain catastrophizing except for forward flexion. This was an unexpected result, because we hypothesized that fearful patients would perform submaximally on the range of motion measurement, expressed in a larger difference between active and passive ROM. In addition, we did not find significant differences between the symptomatic group, the asymptomatic group and the controls with regards to the difference scores. The significant difference on passive range of motion between the symptomatic group and the asymptomatic group and controls, indicates that there might be somatic factors involved. However, our method of 
measuring ROM cannot give additional information on possible lesions such as injury to the neck musculature or spine.

\section{Experimental Evidence}

In chapter five we investigated whether the amount of attentional disruption caused by a threatening stimulus was predicted by increased pain catastrophizing and fear of movement. Forty patients with chronic whiplash syndrome performed an attention demanding task while being distracted by a threatening neck movement. Though there was significant interference in the reaction times during the distraction, compared to baseline levels and healthy controls, this effect could not be predicted by higher levels of pain catastrophizing or fear of movement, nor by pain intensity.

\section{Prospective evidence}

The analyses of the diary study, performed in a subgroup of participants within one month after their motor vehicle accident gave evidence for the prospective value of the model. The underlying idea of this study was to investigate the aforementioned hypothesized relationship between the variables of the fear-avoidance model in a within and between subjects experimental design by measuring all variables by means of end-of day diaries. The results showed that pain catastrophizing and fear of movement were associated with higher levels of pain and disability when measured at the same day. When predicting pain and disability the next day, only fear of movement remained a significant predictor, but not pain catastrophizing. We also tested whether the association between fear of movement and pain was bidirectional. The model that tested previous day's pain as a predictor of next day's fear of movement reached significance, but in this analysis the amount of explained variance was close to zero. These results are in favour of a more sequential relationship with fear of movement as a predictor for subsequent pain and disability.

In addition, the analyses with regards to the diary data and self-discrepancies and self-pain enmeshment in chapter 7 showed that fear of movement was associated with a lower concordance between the actual ideal self. Moreover, in the multilevel analyses, pain catastrophizing and fear of movement were both significant predictors for the actual-ideal concordance the next day, even when controlled for levels of pain, disability and a time trend. These results show that in addition to pain and disability, people experiencing acute pain can also already perceive an impact of pain and disability on their identity, and this impact is enhanced by fear of movement and pain catastrophizing.

The analyses on the follow-up data of the cohort study showed that we could extend several results of the baseline measurement to the follow-up data. In contrast to the 
diary study baseline pain catastrophizing and not fear of movement predicted the outcome variables pain, disability and quality of life at 6-months follow-up. However, after entering anger into the model, pain catastrophizing only remained a predictive variable for depression and physical health. Possible common pathways that may explain this relationship between pain catastrophizing and anger need a more thorough investigation.

Another interesting finding in this prospective study was the absence of a significant effect of neuroticism. Neuroticism is the trait-like tendency to experience a broad range of negative feelings, such as distress, worry and anxiety. The result that there was no significant relationship at all between neuroticism and our outcome variables is in contradiction with both the "symptom perception model" (Watson and Pennebaker, 1989) and the "diathesis stress model" (Claridge and Davis, 2001). In the next paragraphs recommendations for research regarding this construct will be made.

\section{Treatment}

In chapter eight, we tested a possible treatment for patients identified as having high levels of pain catastrophizing and pain related fear. These patients have been avoiding several (functional) activities based on the assumption that they might be damaging or painful for their body. The graded exposure in vivo treatment (GEXP) is designed to target catastrophic interpretations and associated pain related fear. GEXP never primarily aims at reducing pain but at the restoration of functional abilities despite pain. Individually tailored practice tasks are developed, based on the graded hierarchy of fear eliciting activities and/or movements. The GEXP takes the form of a series of behavioural experiments in which irrational assumptions are explicitly being challenged.

Using the same replicated single case experimental design, the effectiveness of GEXP has been demonstrated in patients with low back pain (de Jong et al., 2000; Vlaeyen et al., 2002a; Vlaeyen et al., 2002b; Boersma et al., 2004). Similar to experiments in patients with chronic low back pain, the exposure in vivo treatment in patients with chronic neck pain revealed itself as an effective treatment to break the vicious circle of the fear-avoidance model. Patients undergoing the treatment showed significant decreases in levels of pain, disability, pain catastrophizing and fear of movement and an increase in physical activity. This is the first study showing that the effects of GEXP can be generalized to patients with chronic neck pain.

Summarizing, the FA-model is a predictive model for the transition from acute whiplash injury to chronic whiplash syndrome. However, it is not clear whether both fear of movement and pain catastrophizing are strong predictors in the same stages of pain experience. 


\section{Can we generalize the FA-model as a whole to patients with chronic whiplash syndrome?}

Although the results described above seem to suggest that the validity of the FAmodel can be extended to patients with whiplash syndrome, some of the findings warrant a closer look. We will subsequently address the association between fear of movement and pain catastrophizing, the role of hypervigilance, possible mutual maintenance between whiplash and post-traumatic stress, and the putative mechanisms underlying the role of anger in predicting pain and disability.

\section{Association between fear of movement and pain catastrophizing}

First, fear of movement (TSK) was not a significant predictor for disability or pain at 6-months follow-up. This was unexpected since the diary study showed that TSK predicted pain and disability the next day, over and beyond the contribution of pain catastrophizing. One possible explanation is the differential stability of both constructs. There is evidence that pain catastrophizing is a relatively stable characteristic, with few fluctuations over time (Sullivan et al., 1995; Sullivan et al., 2001; Turner et al., 2004). In contrast, fear of movement, as measured with the TSK is likely to be more state-like. This is confirmed by the follow-up data that reveal a significant decrease in levels of fear of movement. Conversely, levels of pain catastrophizing remained more stable. However, this finding seems to depend on the duration of whiplash complaints. For example, the diary study in acute whiplash patients reveals a different pattern. Both pain catastrophizing and fear of movement decrease over the 21-days study period in patients. Similar findings were reported by Sieben et al. (2002) in patients with acute low back pain. She found that the increase in fear of movement in the first two weeks of a new pain episode, rather than baseline levels of fear of movement is predictive of disability (Sieben et al., 2002). In a population of patients with acute low back pain, three subgroups of patients were identified, being (1) one group that remained stable on levels of fear of movement, (2) one group that improved and (3) one group that showed an increase in fear of movement. This latter group had worse outcome at follow-up. Therefore, Sieben et al. (2002) suggested that patients showing an increase in fear of movement in the acute stage of low back pain are at risk for developing chronic complaints.

To our knowledge, our diary study is the first study that has found changes in levels of pain catastrophizing. This is in contradiction to the aforementioned hypothesis that pain catastrophizing is a more trait like concept that remains stable over time (Sullivan et al., 2001). However, data on the stability of this concept has mostly been derived from pain-free individuals or chronic pain patients (Sullivan et al., 1995; Turner et al., 2004). Our data suggest that in patients experiencing acute pain 
catastrophizing does not have the immutable characteristics normally ascribed to personality traits or trait like concepts.

A similar prognosis as made for an increase in fear of movement could be the case for this variable. Not only baseline levels of pain catastrophizing may be important in developing chronic complaints, but patients showing an increase in pain catastrophizing over time may be especially at risk. However, in order to test this hypothesis data collection from the diary study has to be continued for a longer period of time allowing multiple assessments of outcome variables.

Moreover, we found changes in pain catastrophizing and fear of movement, when measuring these variables with respectively three and two items derived from the original questionnaires. Further research could investigate whether these changes can be replicated by using the complete version of the Pain Catastrophizing Scale (PCS) and Tampa Scale of Kinesiophobia (TSK) or similar questionnaires. Swinkels et al. (2003) demonstrated that the test-retest stability of the TSK over a period of 24 hours was more than acceptable in patients with acute low back pain. It is yet unclear if this is also the case for patients experiencing acute whiplash injury. One could question whether the concerns or fears of patients with whiplash injury are identical to those of patients with low back pain patients. Therefore, a more thorough investigation of the psychometric qualities of the TSK in this population is warranted.

The FA-model suggests that the association between pain catastrophizing and disability is mediated by fear of movement, yet empirical support still is lacking. In individuals with chronic low back, Leeuw et al. (in press) found no significant relationship between pain catastrophizing at baseline and disability at follow-up. Our results do not confirm the mediation hypothesis of fear of movement on pain and disability either. In contrast to Leeuw et al. (In Press) we did find a significant relationship between pain catastrophizing at baseline and disability at follow-up. However, the effect of fear of movement, measured at baseline did not reach significance for any of the outcome variables.

\section{Hypervigilance and attention}

The study described in chapter five failed to show a relationship between hypervigilance and pain catastrophizing and fear of movement. Hypervigilance is an overalertness for pain and its cues, resulting in a persistent disruption of attention and behaviour. Hypervigilance is intensified by intense pain, catastrophic thoughts about pain and fear of pain (Goubert et al., 2004; Crombez et al., 2005). Although we found slowed down reaction times in patients with chronic whiplash syndrome when exposed to a threatening stimulus, this slowed down performance could not be predicted by pain intensity, pain catastrophizing or fear of movement. This is in contradiction to earlier studies performed in both healthy subjects and chronic pain 
patients (Crombez et al., 1994; Crombez et al., 1996; 1998; Crombez et al., 1999; Crombez et al., 2002). The highly aversive stimulus in combination with generally low levels of pain catastrophizing may have caused unwanted ceiling effects reducing the power to find the hypothesized relationships. Patients with acute whiplash injury or chronic whiplash syndrome often complain of impairment in cognitive processes, like having difficulties in performing dual tasks (divided attention) (Radanov and Dvorak, 1996). At present it is unknown whether these attentional deficits are the result of physical injuries or the result of interference by pain and threat value of perceived symptoms and disability. Recommendations for further research regarding this specific area will be made in a following paragraph.

\section{The Anger-Pain- Post-Traumatic Stress Disorder Triangle}

The prevalence of acute PTSD in our study, according to the clinical cut-off of the PSS-SR, was $57 \%$ at baseline and $42 \%$ at follow-up. These numbers are far higher than the estimated $34 \%$ after one month in previous research (Ursano et al., 1999).

\section{Anger-PTSD}

Our results on the relationship between anger and PTSD are in line with research on theories suggested by other researchers in different research areas such as PTSD in combat veterans, victims of assault and healthy volunteers (Riggs et al., 1992; Chemtob et al., 1994; Chemtob et al., 1997; Frueh et al., 1997; Andrews et al., 2000; Diong et al., 2005; Orth and Wieland, 2006). Most theories describe anger as an alternative reaction from fear to trauma.

Chemtob et al. (1997) described the "survival mode theory". This model states that patients with Post-traumatic stress have a lower threshold to perceive situations as being dangerous. The experience of danger will activate a biological predisposed survival mode with both fear and flight reactions as well as anger and fight reactions. A similar suggestion was made by Foa et al. (1995) with their "fear avoidance theory", suggesting that people undergoing trauma develop an "anger structure" that is very similar to the "fear structure". Both are easily activated and have similar stimulus elements, valence elements (e.g. danger) and sometimes even similar behavioural responses (e.g. physical arousal). Activating the "anger structure" will inhibit anxiety responses and inhibits the modification of the "fear structure". The same research group also suggested that the victims of trauma are motivated to avoid trauma-related feelings of anxiety by feeling angry. When experiencing an intrusion they will not respond by fear but by anger. Anger is seen as having a more positive valence than anxiety and in this theory has the function of diverting the attention away from anxiety (Riggs et al., 1992; Foa et al., 1995). 
Foa et al. (1989) also suggested that two conditions must be fulfilled to recover from trauma. First, the trauma memory has to be activated and second, the person has to incorporate new information that is incompatible with the information that is already present in the "fear structure". This will change the valence that is given to the structure. The presence of anger will interfere with changing the trauma memory and therefore inhibit recovery. This hypothesis is in line with the results from our follow-up data, showing that anger indeed is a significant risk factor for prolonged post-traumatic stress complaints.

The theory by Foa et al. (1989) thus suggests that exposure treatment may be a beneficial treatment for patients with PTSD, but levels of anger have to be taken into account. Foa et al. (1995) investigated the effect of an exposure therapy on PTSD and found that this was beneficial for all participants. However, patients with low levels of anger showed more improvement during therapy than patients with high levels of anger. Although the primary goal of our treatment study was not to improve post-traumatic stress complaints, the exposure in vivo technique may not only have been beneficial for the patient with regards to pain-related fear and disability levels, but also for other psychological complaints. However, specific complaints such as post-traumatic stress, depression, anger and quality of life were not measured in our treatment study.

Pain - PTSD

We found that neither pain catastrophizing, nor fear of movement was of any significant influence on the maintenance of post-traumatic stress symptoms. This is in contrast to the suggestion by Sharp en Harvey (2001) that the cognitive, affective, and behavioural components of chronic pain may exacerbate and maintain PTSD. At the same time, the physiological, affective and avoidance components of PTSD may exacerbate and maintain problems associated with chronic pain (Sharp and Harvey, 2001).

In support of the idea that the presence of PTSD symptoms affects the symptomatology of whiplash, earlier research has provided preliminary evidence to indicate that the acute posttraumatic stress response is related to bad outcome at follow-up (Drottning et al., 1995; Sterling et al., 2005; Buitenhuis et al., 2006). A re-analyses of our follow-up data revealed that indeed initial symptoms of PTSD were significant predictors for pain and disability at follow-up. Moreover, the effect of anger was non-significant when using PTSD or depression as a predictor instead of pain catastrophizing. Finally, when entering pain catastrophizing, depression, and PTSD jointly as predictors in the model, depression remained a significant predictor for average pain, but none of the variables were significant predictors for disability. The 
significant F-change of the model, but the non-significant beta-values, indicates that these variables may measure the same underlying affect.

A similar suggestion that there is an underlying factor that increases the risk for chronic pain and also PTSD was made by Asmundson et al. $(1995 ; 2000 ; 2002)$ by introducing the concept of Anxiety Sensitivity. Anxiety Sensitivity denotes a dispositional tendency to become fearful and more specifically, refers to the fear of anxiety symptoms based on the belief that they may have harmful consequences. Anxiety sensitivity has been shown to be elevated in patients with PTSD and in patients with chronic pain after a motor vehicle accident (Kuch et al., 1994). When people with high anxiety sensitivity levels encounter a traumatic stressor, painful physical injury, or both, they are believed to respond with a more intense emotional reaction than do those with lower levels. When the traumatic stressor and painprecipitating event are the same or occur in close temporal proximity, anxiety sensitivity may amplify the collective response and may increase vulnerability for development of both PTSD and chronic pain (Asmundson et al., 2002).

\section{Pain - Anger}

Although included for explorative reasons, baseline anger was the strongest predictor for long-term outcomes, in terms of post-traumatic stress symptoms, but also for pain, disability, depression and quality of life.

Several studies have already provided evidence for the association between anger and pain intensity, pain unpleasantness, the affective components of pain and emotional distress in patients with chronic pain and their family (Okifuji et al., 1999). Research on anger has focused on four distinct yet interwoven constructs: anger, hostility, aggression, and anger management style. The term anger is mostly used to refer to an aversive emotion and is conceived as a transitory state that occurs in response to a negative event. By using the Targets of Anger Scale we tried to capture this "state"-like anger in combination with specific targets of anger. This measure does not provide us information on hostility, aggression or anger management style (anger-in and anger-out), although research has shown that these concepts too are related to persistent pain (for a review, see: Greenwood et al., 2003).

It has been suggested that anger has an influence on pain by biological and behavioural mechanisms. Biological mechanisms that have been suggested are endogenous opioid dysfunction (Bruehl et al., 2006) or alterations in the immune system (Kiecolt-Glaser et al., 1993). Several behavioural mechanisms may be important in explaining relationships between anger and pain. First, anger may lead to maladaptive pain behaviours (e.g. avoidance of home or work activities) that may contribute to the maintenance of certain pain conditions. Second, anger may disrupt marital relationships and lead to spousal responses that contribute to pain and maladaptive 
pain behaviours. And third, anger may influence pain by interfering with development of important relationships with health care providers (Greenwood et al., 2003). However, these hypotheses cannot be tested with our data.

\section{Conclusion}

The theories by Chemtob et al. (1994; 1997), Foa et al. (Foa et al., 1989; Foa et al., 1995), and Asmundson et al. (1995; 2000; 2002) suggest possible pathways, but these theories have not yet been applied to different research areas and multiple outcome measures. We will elaborate on this in the next paragraph.

One may wonder whether explicit targets of anger would also be a predictor for the development of other chronic pain complaints. To our knowledge, there are no studies yet to answer this question. It may be the case that although anger is related to pain in different pain populations and healthy controls, it could be a variable of specific influence in patients who's pain complaints are the result of an injury arising from a mishap or accident in which someone may be held answerable (Fernandez and Turk, 1995). This is probably the case in patients suffering from whiplash injury since most patients were not to blame for the motor vehicle accident. Moreover, their anger may be specifically directed towards the person responsible for the accident. This suggestion was already done by Okifuji et al. (1999) who found that up to $60 \%$ of patients with chronic pain still felt angry at the person responsible for their complaints (Okifuyi et al., 1999). However, our first preliminary analyses of specific items of the Targets of Anger Scale (TAS) revealed that this was the case for depression, post-traumatic stress and quality of life, but not for disability and pain. The predictive value of the single item "I am angry towards the person that is responsible for my injury" only reached significance for depression, post-traumatic stress and quality of life.

Furthermore, it will be interesting to investigate whether this anger towards others may also be of influence on the concept of self-discrepancy. Orth et al. (2006) suggest that there is a cognitive component to anger, in the sense that patients have the perception of important goals in their life being blocked by the improper action of an external factor. To either confirm or refute this hypothesis a more thorough investigation of our Targets of Anger Scale is needed. 


\section{SUGGESTIONS FOR FURTHER RESEARCH}

\section{Neuroticism or Negative Affect}

As mentioned before, neuroticism did not have a significant effect on any of the outcome variables. Although the theories described in the pain-anger-PTSD triangle all suggest a predisposed factor, we did not find evidence for neuroticism as a traitlike concept for the prediction of prolonged physical and psychological complaints. Although it has been argued that both concepts measure the same underlying trait vulnerability, the concept of Negative Affectivity may provide us with better tools to identify predisposing trait factors.

Lilienfeld et al. (1993) proposed an interrelated hierarchy to conceptualize the potential interrelationships between pain-relevant constructs. In this model, negative emotionality sits on top of this hierarchy, whereas other more specific constructs such as anxiety sensitivity (second-order factor) and pain catastrophizing (first-order factor) serve as more specific lower-order constructs. Similar to the "diathesis stress" model, it would be interesting to investigate whether this high order concept of negative affectivity is mediated by lower order factors. Although we did not include a specific questionnaire on Negative Affectivity in our research, the predictive value of both pain catastrophizing and anger (and depression in the re-analyses) suggests that this effect may be caused by a more trait-like concept.

\section{Range of motion}

A first striking finding of our study on restricted Range of Motion (ROM) in chapter 3 was the limited passive ROM in patients with acute whiplash injury. Research had shown that patients with acute neck pain after a motor vehicle accident (MVA) show a restricted range of motion compared to controls with no neck pain (Kasch et al., 2001), and that this Active ROM can also discriminate between patients with chronic whiplash syndrome and asymptomatic individual (Dall'Alba et al., 2001), but little was known about passive ROM in patients with acute and chronic whiplash. Our findings on this Passive ROM is of particular interest since it counters the hypothesis by Klein et al. (2001) that a group of patients may perform submaximally because of pain and fear. Our results show that this so-called underperformance in the acute stage of whiplash injury may be more guided by actual limitations.

However, our method of measuring ROM cannot elucidate possible lesions or injuries to the muscles or spine. The adaptation model by Lund et al. (1991) predicts increased activity of the antagonistic muscle and decreased activity of the agonistic muscle during muscle pain. The changes in muscle coordination cause a reduction in 
movement that is considered a useful reflex adaptation, protecting the injured area from further injury and pain. Nederhand et al. (2003) found this altered muscle reactivity in the upper trapezium muscle in patients with acute and chronic neck pain, but muscle activity was not measured specifically related to range of motion. It would be interesting to see whether this muscle reactivity is present when performing a range of motion test.

Second, further research could investigate whether restricted Active ROM and Passive ROM both persist when entering the stage of chronic whiplash syndrome. Our results from the cohort study showed that restricted ROM was not a significant predictor for pain and disability. It would be interesting to investigate the reversed relationship, being whether the persistence of restricted ROM is a result of pain and disability levels, and even in addition a result of fear of movement and pain catastrophizing.

\section{Self-discrepancies and pain-enmeshment}

The second intriguing result of this dissertation was the finding that pain already has an impact on the concept of identity in the early stages of acute whiplash injury. The results show that in the acute stage of whiplash injury self-discrepancies and selfpain enmeshment are related to pain, disability, mood, fear of movement and pain catastrophizing. These results suggest that the impact of acute pain and disability may have been underestimated. When experiencing acute pain, patients already can perceive themselves as being far away from the person they would like to be, close to the person they fear to be and being trapped by pain.

We were also able to relate the concept of self-discrepancies to the Fear-Avoidance model. With regards to the questionnaire data the different discrepancies and selfpain enmeshment were related to specific variables of the FA-model. The AIdiscrepancy was related to depression, whereas the AF-discrepancy was related to pain and disability. Self-pain enmeshment was related to pain catastrophizing.

In the diary measurement we could confirm most relationships with the questionnaires, but there was also a significant correlation between the actual-ideal concordance in the diary and fear of movement. A decrease in fear of movement was associated with an increase in the actual-ideal concordance in the diary. However, this was not the case for pain catastrophizing. The multilevel analyses indicated that both fear of movement and pain catastrophizing are significant predictors for actualideal concordance, when controlled for time trend and disability. Although we found evidence for the causal relationship between variables of the FA-model and the selfdiscrepancy theory, it would be also of interest to investigate the reversed relation- 
ship. Self-discrepancies are present among all people and are not specifically related to pain and disability. It is possible that the presence of a specific type of discrepancy may also be a risk factor for developing chronic pain and disability. This hypothesis is currently the subject of a research project in our research group.

\section{Hypervigilance and attention}

Our study failed to show that interference of a threatening stimulus was associated with pain catastrophizing and fear of movement. As mentioned before, this may be due to lower levels of catastrophizing in our research sample and ceiling effects from our fear manipulation. Recently it has been suggested that hypervigilance may not only be conceptualized as heightened attention towards threatening stimuli, but also with difficulties in disengaging attention from a threatening stimulus. Based on findings in the anxiety literature (Fox et al., 2001; Koster et al., 2004), it has been argued that three components of attention for pain can be distinguished (Van Damme et al., 2002): (1) an initial temporary shift of attention towards the threatening stimulus (attentional shift), (2) a long captivation of attention by the threatening stimulus (engagement) and (3) releasing the attention from the threatening stimulus (disengagement). Recent studies have indicated that the attentional demand of pain is particularly related to difficulties disengaging attention from pain and signals of impending pain (Van Damme et al., 2002; 2004a; Van Damme et al., 2004b). However, this difficulty in disengaging from pain has so far only been demonstrated in healthy controls.

In addition, further investigation is needed on the prevalence and nature of attentional deficits in patients with acute whiplash injury and chronic whiplash injury. Although it is know that patients with chronic whiplash syndrome perform badly on various neuropsychological tests of attentional performance (Kessels and Aleman, 2000), little is known about these complaints in acute whiplash injury. Moreover, it would be interesting to investigate if similar to other complaints these attentional deficits can be enhanced by fear. Although we showed in our study that reactions times slow down when exposing chronic patients to a threatening stimulus, it has yet not been investigated whether the same results can be achieved by using diagnostic tools for attention disorders as outcome measurements. 


\section{METHODOLOGICAL CONSIDERATIONS}

Most methodological limitations have already been described in the previous chapters. Therefore, this section will focus more specifically on the general limitations of the total research project.

\section{Sample bias}

Our patient population was different from other studies because of different inclusion criteria. First of all, in our samples of the diary study and the prospective study, the criterion was that all patients that were involved in a motor vehicle accident could be included. This means that we did not only include patients that reported pain after the motor vehicle accident, but we also included everyone that was involved in a motor vehicle accident but did not report immediate complaints. This last group of participants are mainly represented within the "no disability" groups. It is an interesting question to see why these patients do not develop complaints in the acute stage of whiplash injury, while undergoing the same trauma. Further investigation on our data is warranted to see whether this difference could be due to the type of accident, event factors, and involvement in insurance claims, or being blamed for the motor vehicle accident. A second difference to other populations was that we did not recruit patients through an insurance setting, but through Emergency Care Centres and Police Departments, giving us a wide range of acute complaints (from none to severe).

Finally, due to drop-out we had a small sample in the diary study that makes the generalizability of our results more difficult. We did try to retrieve data on prolonged complaints in participants that dropped out, but the information retrieved was summary.

\section{Methods of measurement}

In the cohort study we used questionnaires that were not yet validated, such as the Targets of Anger Scale. Although the use of this questionnaire provided us with very interesting results, the reliability and validity of this questionnaire in both patients and healthy controls needs to be investigated further. A more thorough investigation of the different items of the Targets of Anger Scale may also shed light on the involvement of anger in possible mechanisms for predicting physical and mental well-being.

Furthermore, no study has investigated the psychometric properties of the TSK in a population of patients with acute whiplash injury or chronic whiplash syndrome. Although the scores on the TSK in patients with chronic whiplash syndrome are 
similar to those in other chronic pain populations (see chapter 6), the TSK measured at baseline was not predictive for prolonged physical and psychological complaints. The evidence for the predictive value of fear of movement in this dissertation has mostly been derived from the diary study where it was assessed by two items. A further investigation of the psychometric properties of the TSK in this population is therefore warranted. It has recently been suggested that the TSK needs to be modified into an 11-item questionnaire. This new version of the TSK would consist of fewer items but still contain the two-subscales and "harm" and "avoidance" (Roelofs et al., In press). Although Swinkels et al. (2006) found that both subscales have similar predictive value in low back pain patients, it would be interesting to see whether this would also be the case for patients with whiplash injury.

We also encountered some problems with the measurement with regards to selfdiscrepancies and self-pain enmeshment. Although we found interesting results, most of the hypotheses could only be confirmed with the data of the diary study. One of the limitations of the study was the use of a non validated questionnaire to measure the self-discrepancies. Research of the data revealed that several patients had difficulties in filling in the questionnaires or that they made mistakes. This could be due to a misinterpretation of the instruction on the questionnaire. The questionnaire could not be validated by the diary or vice versa. Future research could validate these questionnaires or enhance them to make them more user-friendly. It would also be interesting to try to replicate our findings in a larger sample.

\section{IMPLICATIONS FOR CLINICAL PRACTICE}

\section{Acute whiplash injury}

Our results from the diary study suggests that pain related fear may be a target in pain management in acute whiplash injury. In patients with low back pain, an attempt was made by Sieben et al. (Submitted) to generalize the exposure in vivo treatment to patients experiencing acute pain. A randomized controlled trial was conducted to test the effectiveness of exposure in vivo treatment in addition to usual care for acute LBP patients with elevated levels of pain-related fear. Although the study was performed in a small sample size, the results suggest that in a subgroup of very highly and persistently fearful patients exposure in vivo in addition to usual care might be helpful in reducing pain-related fear and improving outcome. Further research is warranted to investigate whether this is also the case for patients with acute whiplash injury. 


\section{Chronic whiplash syndrome}

Our gradual exposure in vivo treatment has shown to be effective for patients with high levels of pain catastrophizing and fear of movement, experiencing chronic pain. However, this was investigated by means of a replicated single case experimental design, and future research should attempt on replicating these finding by use of a randomized controlled trial to establish long-term differential effects.

Our results certainly do suggest that more comprehensive management can be beneficial for patients with acute whiplash injury and chronic whiplash syndrome. In order to obtain this, some additional treatment strategies may be implemented with regards to anger, depression and Post-Traumatic Stress Disorders, since these complaints may be a burden for the individual by reducing subjective well-being and social functioning. It has already been argued in previous paragraphs that the exposure in vivo treatment may also be beneficial for Post-traumatic stress complaints, but may depend on levels of anger. It would be interesting to see if this treatment strategy is also of influence on levels of depression and quality of life. If not, other forms of cognitive-behavioural therapy, such as acceptance based therapy or problem solved therapy could be considered. These forms of therapy have already proven their effectiveness in relation to chronic pain, disability and depression (van den Hout et al., 2003; McCracken et al., 2005). However, the influence of anger on the effectiveness of these therapies has not yet been investigated.

\section{CONCLUSIONS}

As suggested by the systematic review by Scholten-Peeters et al. (2003) we have tried to make a more comprehensive assessment of patients with neck pain after a motor vehicle accident in both the acute and chronic stage of pain. We did this by using different methodological designs, including theory based predictive variables, measuring multiple outcome measures and tried to measure all concepts by using standardized instruments.

Our results revieled that there is an intricate interplay between pain, anger and fear. Although some of our results are in favour of the Fear-Avoidance model, they also highlight the importance of including all variables of the model in research since all of them may be of specific influence in different stages of pain. Finally, the intriguing results on anger and self-discrepancies and self-pain enmeshment should stimulate researchers on being open-minded and innovative in future research. 


\section{REFERENCES}

Andrews B, Brewin CR, Rose S, Kirk M. Predicting PTSD symptoms in victims of violent crime: the role of shame, anger, and childhood abuse. Journal of Abnormal Psychology 2000;109(1):69-73.

Asmundson GJG, Bonin M, Frombach I, Norton GR. Evidence of a disposition toward fearfulness and vulnerability to posttraumatic stress in dysfunctional pain patients. Behaviour Research and Therapy 2000;38:801-812.

Asmundson GJG, Coons MJ, Taylor S, Katz J. PTSD and the Experience of Pain: Research and Clinical Implicatinos of Shared Vulnerability and Mutual Maintenance Models. Canadian Journal of Psychiatry 2002;47(10):930-937.

Asmundson GJG, Norton GR. Anxiety sensitivity in patients with physically unexplaiend chronic back pain: a preliminary report. Behaviour Research and Therapy 1995;33(7):771-777.

Boersma K, Linton SJ, Overmeer T, Jansson M, Vlaeyen J, de Jong J. Lowering fear-avoidance and enhancing function through exposure in vivo. A multiple baseline study across six patients with back pain. Pain 2004;108:8-16.

Bruehl S, Chung OY, Burns JW. Anger Expression and Pain: An Overview of Findings and Possible Mechanisms. Journal of Behavioral Medicine 2006;29(6):593-606.

Buitenhuis J, de Jong PJ, Jaspers JPC, Groothoff JW. Relationship between post-traumatic stress disorder symptoms and the course of whiplash complaints. 2006.

Chemtob CM, Hamada RS, Roitblat HL, Muraoka M. Anger, Impulsivity, and Anger Control in CombatRelated Posttraumatic Stress Disorder. Journal of Consulting and Clinical Psychology 1994;62(4):827-832.

Chemtob CM, Novaco RW, Hamada RS, Gross DM, Smith G. Anger Regulation Deficits in CombatRelated Posttraumatic Stress Disorder. Journal of Traumatic Stress 1997;10(1):17-36.

Claridge G, Davis C. What's the use of neuroticism? Personality and individual differences 2001;31:383400.

Crombez G, Baeyens F, Eelen P. Sensory and temporal information about impending pain: the influence of predictability on pain. Behaviour research and therapy 1994;32(6):611-622.

Crombez G, Eccleston C, Baeyens F, Eelen P. The disruptive nature of pain: an experimental investigation. Behaviour research and therapy 1996;34(11-12):911-918.

Crombez G, Eccleston C, Baeyens F, Eelen P. attentional disruption is enhanced by the threat of pain. Behaviour research and therapy 1998;36:195-204.

Crombez G, Eccleston C, Baeyens F, Van Houdenhove B, van den Broeck A. Attention to chronic pain is dependent upon pain-related fear. Journal of Psychosomatic Research 1999;47(5):403-410.

Crombez G, Eccleston C, van den Broeck A, Van Houdenhove B, Goubert L. The effects of catastrophic thinking about pain on attentional interference by pain: no mediation of negative affectivity in healthy volunteers and in patients with low back pain. Pain research and management 2002;7(1):3139.

Crombez G, Van Damme S, Eccleston C. Hypervigilance to pain: an experimental and clinical analysis. Pain 2005;116:4-7.

Dall'Alba PT, Sterling MM, Treleaven JM, Edwards SL, Jull GA. Cervical range of motion discriminates between asymptomatic persons and those whit whiplash. Spine 2001;26(19):2090-2094.

de Jong J, Vlaeyen J, Geilen M, Heuts P. De angst voor bewegen: geleidelijke exposure in vivo bij chronische lagerugpijn. Directieve Therapie 2000;20:143-161.

Diong SM, Bishop GD, Enkelmann HC, Tong EMW, Why YP, Ang JCH, Khader M. Anger, stress, coping, social support and health: modelling the relationships. Psychology and Health 2005;20(4):467-495. 
Drottning M, Staff PH, Levin L, Malt UF. Acute emotional response to common whiplash predicts subsequent pain complaints. Nordic Journal of Psychiatry 1995;49:293-299.

Fernandez E, Turk DC. The scope and significance of anger in the experience of chronic pain. Pain 1995;61(165-175):165-175.

Foa EB, Riggs DS, Dancu CV, Rothbaum BO. The impact of fear activation and anger on the efficacy of exposure treatment for posttraumatic stress disorder. Journal of Traumatic Stress 1995;6:459-473.

Foa EB, Steketee G, Rothbaum BO. Behavioral/Cognitive conceptualization of post-traumatic stress disorder. Behavior Therapy 1989;20:155-176.

Fox E, Russo R, Bowles R, Dutton K. Do threatening stimuli draw or hold attention in subclinical anxiety? Journal of Experimental Psychology 2001;130:681-700.

Frueh BC, Henning KR, Pellegrin KL, Chobot K. Relationship between scores on anger measures and PTSD symptomatology, employment, and compensation-seeking status in combat veterans. Journal of Clinical Psychology 1997;53:871-878.

Goubert L, Crombez G, Eccleston C, Devulder J. Distraction from chronic pain during a pain-inducing activity is associated with greater post-activity pain. Pain 2004;110:220-227.

Greenwood KA, Thurston R, Rumble M, Waters SJ, Keefe FJ. Anger and persistent pain: current status and future directions. Pain 2003;103:1-5.

Kasch H, Stengaard-Pedersen K, Arendt-Nielsen L, Jensen TS. Headache, neck pain and neck mobility after acute whiplash injury. A prospective study. Spine 2001;26(11):1246-1251.

Kessels RPC, Aleman A. Cognitieve stoornissen bij patiënten met het whiplashsyndroom. Een metaanalyse. Gedrag \& Gezondheid 2000;28(4):229-234.

Kiecolt-Glaser JK, Marlarkey W, Chee M, T. N, Cacioppo J, Mao H, Glaser R. Negative behavior during martial confict is associated with immunological down-regulation. Psychosomatic Medicine 1993;55:395-409.

Klein GN, Mannion AF, Panjabi MM, Dvorak J. Trapped in the neutral zone: another symptom of whiplash-associated disorder? European Spine Journal 2001;10:141-148.

Koster EHW, Crombez G, Verschuere B, De Houwer J. Selective attention to threat in te dot probe paradigm: differentiating vigilance and difficulty to disengage. Behaviour research and therapy 2004;42(10):1183-1192.

Kuch K, Cox BJ, Evans R, Shulman I. Phobias, Panic and Pain in 55 Survivors of Road Vehicle Accidents. Journal of Anxiety Disorders 1994;8(2):181-187.

Leeuw M, Goossens MEJB, Linton SJ, Crombez G, Boersma K, Vlaeyen JWS. The Fear-Avoidance Model of Musculoskeletal Pain: Current State of Scientific Evidence. journal of Behavioral Medicine In Press.

Lilienfeld SO, Turner SM, Jacob RG. Anxiety sensitivity: an examination of theoretical and methodological issues. Advances in Behaviour Research and Therapy 1993;15:147-183.

Lund JP, Donga R, Widmer CG, Stohler CS. The pain-adaptation model: a discussion of the relationship between chronic musculoskeletal pain and motor activity. Canadian Journal of Physiology and Pharmacology 1991;69:683-694.

McCracken LM, Vowles KE, Eccleston C. Acceptance-based treatment for persons with complex, long standing chronic pain: a preliminary analysis of treatment outcome in comparison to a waiting phase. Behaviour Research and Therapy 2005;43(10):1335-1346.

Nederhand MJ. Muscle activation patterns in post traumatic neck pain. Enschede: Roessingh Research and Development, 2003.

Okifuji A, Turk DC, Curran SL. Anger in chronic pain: investigations of anger targets and intensity. Journal of Psychosomatic Research 1999;47(1):1-12.

Okifuyi A, Turk DC, Curran SL. Anger in chronic pain: investigations of anger targets and intensity. Journal of Psychosomatic Research 1999;47(1):1-12. 
Orth U, Wieland E. Anger, Hostility, and Posttraumatic Stress Disorder in Trauma-Exposed Adults: A Meta-Analysis. Journal of Consulting and Clinical Psychology 2006;74(4):698-706.

Radanov BP, Dvorak J. Impaired cognitive functioning after whiplash injury of the cervical spine. Spine 1996;21(3):392-397.

Riggs DS, Dancu CV, Gershuny BS, Greenberg D, Foa EB. Anger and Post-Traumatic Stress Disorder in Female Crime Victims. Journal of Traumatic Stress 1992;5(4):613-625.

Roelofs J, Sluiter J, Frings-Dresen MHW, Goossens M, Thibault P, Boersma K, Vlaeyen JWS. Fear of movement and (re)injury in chronic musculoskeletal pain: evidence fo an invariant two-factor model of the Tampa Scale for Kinesiophobia across pain diagnoses and Dutch, Swedish, and Canadian samples. Pain In press.

Scholten-Peeters GGM, Verhagen AP, Bekkering GE, van der Wint DAWM, Barnsley L, Oostendorp RAB, Hendriks EJM. Prognostic factors of whiplash-associated disorders: a systematic review of prospective cohort studies. Pain 2003;104:303-322.

Sharp TJ, Harvey AG. Chronic pain and posttraumatic stress disorder: mutual maintenance? Clinical Psychology Review 2001;21(6):857-877.

Sieben JM, Portegijs PJM, Vlaeyen JWS, Knipschild P, Kester ADM, Knottnerus A, Arntz A. Exposure in vivo treatment in acute low back pain patients with elevated levels of pain-related fear: a randomised controlled trial. Submitted.

Sieben JM, Vlaeyen JWS, Tuerlinckx S, Portegijs PJM. Pain-related fear in acute low back pain: the first two weeks of a new episode. European Journal of Pain 2002;6:229-237.

Sterling M, Jull G, Vicenzino B, Kenardy J, Darnell R. Physical and psychological factors predict outcome following whiplash injury. Pain 2005;114:141-148.

Sullivan MJL, Bishop SR, Pivik J. The Pain Catastrophizing Scale: Development and validation. Psychological Assessment 1995;7(4):524-532.

Sullivan MJL, Thorn B, Haythornthwaite JA, Keefe F, Martin M, Bradley LA, Lefebvre JC. Theoretical perspectives on the relation between catastrophizing and pain. The Clinical Journal of Pain 2001;17:52-64.

Swinkels-Meewisse EJ, Roelofs J, Schouten EGW, Verbeek ALM, Oostendorp RAB, Vlaeyen JWS. Fear of movement/(re)injury predicting chronic disabling low back pain: a prospective inception cohort study. Spine 2006;31(6):658-664.

Swinkels-Meewisse EJCM, Swinkels RAHM, Verbeek ALM, Vlaeyen JWS, Oostendorp RAB. Psychometric properties of the Tampa Scale for Kinesiophobia and the fear-avoidance beliefs questionnaire in acute low back pain. Manual Therapy 2003;8(1):29-36.

Turner JA, Mancl L, Aaron LA. Pain-related catastrophizing: a daily process study. Pain 2004;110(12):103-111.

Ursano RJ, Fullerton CS, Epstein RS, Crowley B, Kao T-C, Vance K, Craig KJ, Dougall AL, Baum A. Acute and chronic posttraumatic stress disorder in Motor Vehicle Accident Victims. The American Journal of Psychiatry 1999;156:589-595.

Van Damme S, Crombez G, Eccleston C. Retarded disengagement from pain cues: the effects of pain catastrophizing and pain expectancy. Pain 2002;100:111-118.

Van Damme S, Crombez G, Eccleston C. Disengagement from pain: the role of catastrophic thinking about pain. Pain 2004a;107:70-76.

Van Damme S, Lorenz J, Eccleston C, Koster EHW, De Clercq A, Crombez G. Fear-conditioned cues of impending pain facilitate attentional engagement. Clinical Neurophysiology 2004b; In Press.

van den Hout JHC, Vlaeyen JWS, Heuts PHTG, Zijlema JHL, Wijnen JAG. Secondary prevention of work-related disability in nonspecific low back pain: Does problem-solving therapy help? A randomized clinical trial. Clinical Journal of Pain 2003;19(2):87-96. 
Vlaeyen JWS, de Jong J, Geilen M, Heuts PHTG, van Breukelen G. The treatment of fear of movement/(re)injury in chronic low back pain - Further evidence on the effectiveness of exposure in vivo. The Clinical Journal of Pain 2002a;18(4):251-261.

Vlaeyen JWS, de Jong JR, Onghena P, Kerckhoffs-Hanssen M, Kole-Snijders AMJ. Can pain-related fear be reduced? the application of cognitive-behavioural exposure in vivo. Pain research and management 2002b;7(3):144-153.

Watson D, Pennebaker JW. Health Complaints, Stress and Distress: Exploring the Central Role of Negative Affectivity. Psychological review 1989;96(2):234-254. 
Summary 
SUMMARY 
Chronic neck pain is often the result of motor vehicle accidents, and rear-end collisions in particular. A striking pattern of complaints often occurs after the accident. The most striking complaints are neck pain, headache, visual disturbances, dizziness, muscle weakness, parasthesias, concentration difficulties, amnesia, fear, anxiety, and mood disorders. It is estimated that after one year, ca. $20 \%$ of patients with an acute neck pain episode have developed a chronic neck pain, also called "chronic whiplash syndrome". So far, studies focussing on medical predictors for chronic whiplash syndrome have not found conclusive evidence that biomedical factors contribute to the development and persistence of complaints. In this dissertation we focus on the predictive value of psychological variables in the transition from acute whiplash injury to chronic whiplash syndrome. More in particular we investigated the applicability of the Fear-Avoidance model to this specific population. The Fear-Avoidance model is a promising model since it incorporates several risk factors known to be associated with pain and based on experimental evidence and presents possible pathways by which injured patients get caught in a downward spiral of increasing avoidance, disability and pain. Two opposing behavioural responses are predicted, based on the interpretation of the pain: confrontation and avoidance. This downward spiral takes place if a person has negative expectancies about the harmfulness of pain (pain catastrophizing), and subsequently becomes fearful of pain. This fear of pain leads to hypervigilance and avoidance behaviour that, over a longer period of time, contributes to deconditioning, and in turn, reinforces further pain experiences, negative expectancies and avoidance. The studies in this dissertation seek to find evidence that these mechanisms occur in patients with neck pain after a motor vehicle accident. In addition, we investigated the role of other psychological factors (anger, self-discrepancies and self-pain enmeshment) that potentially can influence the course of pain disability after a motor vehicle accident.

It is possible that pain has a larger impact on patients then assumed so far. Due to pain-related fear, the emerging avoidance behaviour and disability may in fact increase the discrepancy between the major life goals of the individual and the actual situation. These kinds of self-discrepancies are known to affect a person's experience of self and identity. The self-discrepancy and self-pain enmeshment theory both elaborate on the effects of actual-ideal discrepancies on mood, pain and disability.

To test the association between the variables of the Fear-Avoidance model and acute and persistent neck pain after a motor vehicle accident, we performed a longitudinal cohort study, a diary study and an experimental study. Moreover, the effects of an intervention targeting specific elements of the fear-avoidance model were investigated. The theoretical background and the results of the studies are described in the nine chapters of the dissertation. 
Chapter 1 provides a theoretical introduction to the subject of the thesis. An overview of possible predictors is presented. The assumptions of the fear-avoidance model and theories on self-discrepancies and self-pain enmeshment are discussed. The introductory chapter concludes with an outline of the dissertation.

Chapter 2 reviews the existing evidence in favour of the FA-model in patients with chronic whiplash syndrome. Although the first results on pain catastrophizing and fear of movement are inconclusive, it is argued that the FA-model provides a sound theoretical framework to guide further research in the field of chronic whiplash syndrome. The model could be expanded by other variables such as post-traumatic stress complaints to capture specific features of this pain population.

Chapter 3 describes the cross-sectional analyses of the data of our cohort study. We tested whether restricted Range of Motion (ROM) is associated with fear of movement. The results show that symptomatic participants not only differ on Active ROM when compared to asymptomatic and control participants, but also on Passive ROM, suggesting that somatic factors may be of influence. Relationships for fear of movement and pain catastrophizing were found for both Active ROM and Passive ROM. The suggested hypothesis that the difference score (Passive ROM - Active ROM) would also be related to elevated levels of fear of movement and pain catastrophizing cannot be confirmed. The difference score shows no significant relations with fear of movement, except for the forward flexion movement.

Chapter 4 describes the results from a diary study in 60 participants, assessed within one month after their motor vehicle accident. The hypothesized relationship between the variables of the fear-avoidance model were tested using both a within and between subjects experimental design. Multilevel analyses show that both between and within persons, high levels of pain catastrophizing and fear of movement are associated with more pain and disability when measured at the same day. Moreover, fear of movement is also predictive of pain and disability on the following day. We also examined the reverse association, i.e. whether changes in pain predict changes in next day's fear of movement and pain catastrophizing. Although for fear of movement the model reaches significance, the amount of explained variance is negligible. This study yields evidence for the predictive value of the FA-model in the acute stage of whiplash injury.

Chapter 5 presents the analyses of the follow-up data of the prospective cohort study and addresses the question whether the variables derived from the FA-model are significant predictors for the transition from acute whiplash injury to chronic whiplash syndrome. By means of multiple regression analyses, the predictive value of various concepts of the FA-model (pain catastrophizing and pain related fear) are investigated together with more explorative analyses with anger as the independent variable. We also examined whether these variables are not only predictive for the 
development of chronic disability and pain but also for the development of depression and post - traumatic stress disorder. As expected, baseline levels of the dependent variables are found to be the strongest predictors for persistent complaints. In addition, pain catastrophizing is a significant predictor for disability, depression and quality of life. However, with regards to disability and mental health, the significant effect of pain catastrophizing diminishes when anger is entered into the model. Unexpectedly, Fear of movement does not reach significance for any of the outcome variables, but in contrast, anger turns out to be a significant predictor for all the outcome variables included in our study. It is concluded that in addition to baseline levels of complaints, pain catastrophizing and anger are predictors for prolonged physical and psychological complaints and that both factors may provide us with tools for screening and early interventions.

In chapter 6 we investigated by means of a laboratory experiment whether hypervigilance is an important factor in the maintenance of chronic whiplash syndrome. Forty patients with chronic whiplash syndrome were requested to perform an attention-demanding task while being distracted by a threatening neck movement. Patients show a more pronounced deterioration of performance compared to controls when exposed to a threatening stimulus. However, we did not find the hypothesized relation between attentional interference and pain intensity, pain catastrophizing or fear of movement.

Chapter 7 focuses on the relationship between pain-related fear, self-discrepancies and self-pain enmeshment. A secondary analysis was performed on the data of the diary study reported in chapter 4 to investigate whether other mechanisms can take place in addition to the fear-avoidance model in acute whiplash injury. We measured self-pain enmeshment (SPE) and two types of self-discrepancies; Actual-Ideal self (AI) and Actual-feared self (AF) with a questionnaire on day 1 of the study, in addition to a set of baseline questionnaires on pain, disability, depression, fear of movement and pain catastrophizing. Participants kept a diary for 21 consecutive days in which the AI discrepancy, pain, disability, mood, fear of movement and pain catastrophizing were assessed. We found significant correlations between the AIdiscrepancy and depression, the AF-discrepancy, pain and disability, and between SPE and pain catastrophizing. An increase in the actual-ideal (AI) concordance is significantly related with an increase in positive mood and a decrease in levels of pain, disability and fear of movement. Multilevel analyses on the diary data show that in the acute stage of whiplash injury self-discrepancies are present and that they are related to mood, pain, and disability, fear of movement and pain catastrophizing. It is concluded that patients can perceive an impact of pain and disability on their identity, and that this impact is enhanced by fear of movement and pain catastrophizing. 
Chapter 8 reports the results on an intervention study targeting pain catastrophizing and fear of movement in high fearful patients with chronic neck pain after a motor vehicle accident. Eight patients underwent both Graded Activity treatment and Graded Exposure in vivo treatment in counter balanced order. The results show that the Graded Exposure in vivo treatment is superior to the Graded Activity Treatment. Graded Exposure in Vivo treatment leads to significant decreasing levels of selfreported pain-related fear, pain intensity and disability and to an increase in physical activity. These results provide indirect evidence for the role of pain-related fear in predicting avoidance behaviour and disability.

Chapter 9 is the final chapter of this dissertation, and provides a summary of the main results followed by a general discussion of the findings. We conclude that we found partial evidence for the FA-model as a predictive model for the transition from acute whiplash injury to chronic whiplash syndrome. Our results also highlight the importance of including additional variables such as anger, self-discrepancies, and self-pain enmeshment. Moreover, the FA-model not only predicts pain and disability, but is also of influence on other outcome variables such as depression, post-traumatic stress, quality of life and self-discrepancies. Next, the limitations of the dissertation are discussed and recommendations for further research are made. Finally, clinical recommendations and a final conclusion are given. 
Samenvatting 
SAMENVATTING 
Chronische nek pijn is vaak het gevolg van een verkeersongeval, en dan met name van een kop-staart aanrijding. Na zo een ongeval ontwikkelen mensen vaak een zeer specifiek klachtenpatroon. Patiënten klagen meestal van nekpijn, hoofdpijn, stoornissen in het gezichtsvermogen, duizeligheid, spierzwakheid, verlammingsverschijnselen, moeilijkheden met concentratie, geheugenverlies, angst en een verlaagde stemming. Naar schatting ontwikkelt ongeveer $20 \%$ van de patiënten met acute nek pijn ook chronische nekpijn, of het zogenoemde "Chronische Whiplash Syndroom". Onderzoek dat zich voornamelijk op medische voorspellers voor dit syndroom heeft gericht, heeft nog geen sluitend bewijs gevonden dat biomedische factoren zouden bijdragen aan het ontstaan en ontwikkelen van de chronische klachten.

In dit proefschrift wordt onderzocht of psychologische variabelen voorspellend zijn voor de overgang van acute whiplash kwetsuur naar chronisch whiplash syndroom. Meer specifiek werd er onderzocht of het Vrees-Vermijdings model (FearAvoidance model) kan toegepast worden op deze specifieke populatie. Het VreesVermijdings-model is een veelbelovend model omdat het diverse, reeds bekende risicofactoren voor chronische pijn omvat en het is gebaseerd op empirie. Het VreesVermijdings-model veronderstelt twee tegengestelde gedragsresponsen: confrontatie en vermijding. Het geeft een mogelijke vicieuze cirkel weer waarin patiënten gevangen kunnen raken in een neerwaartse spiraal van toenemend vermijdingsgedrag, beperkingen en pijn. Deze neerwaartse spiraal kan plaatsvinden wanneer de patiënt negatieve verwachtingen heeft over de schade die pijn kan toebrengen (pijn catastroferen) en daardoor angstig wordt voor pijn. Deze angst voor pijn leidt tot verhoogde aandacht voor pijn en vermijdingsgedrag, dat over een langere periode heen bijdraagt tot een slechtere conditie. Dit versterkt weer nieuwe pijnervaringen, negatieve verwachtingen en vermijdingsgedrag. De studies beschreven in dit proefschrift onderzochten of deze mechanismen ook plaats vinden bij patiënte met nekpijn na een auto-ongeval. Daarenboven werd ook de rol van andere psychologische variabelen onderzocht, zoals boosheid, zelf-discrepanties en zelf-pijn-verweving, die mogelijk van invloed kunnen zijn op het verloop van pijn en beperkingen a een autoongeval.

Het is echter mogelijk dat pijn een grotere impact heeft op de patiënt dan tot nu toe werd verondersteld. Door vrees voor pijn, vermijdingsgedrag en beperkingen kan er een groot verschil (discrepantie) tot stand komen tussen de belangrijke doelen die men in het leven wenste te bereiken en de actuele situatie. Dit soort discrepanties zijn van invloed op de ervaring van iemands identiteit. De zelf-discrepantie theorie (Self-Discrepancy theory) en de zelf-pijn-ververwevingstheorie (Self-PainEnmeshment) gaan in op de effecten van zelf-discrepanties, stemming en pijn op de identiteit.

Om de verbanden tussen de variabelen van het Vrees-Vermijdings-model en aan houdende nekpijn na een auto-ongeval te onderzoeken, werd er een longitudinale 
cohort studie uitgevoerd met daarnaast ook een dagboekstudie en een experimentele studie. Daarenboven werd de effectiviteit onderzocht van een behandeling die zich specifiek richt op elementen uit het Vrees-Vermijdings-model.

Hoofdstuk 1 geeft een theoretische inleiding over het onderwerp van dit proefschrift. Er wordt een overzicht gegeven van mogelijke voorspellende variabelen. Daarna volgt een beschrijving van het Vrees-Vermijdingsmodel, de zelf-discrepantie theorie en de zelf-pijn-verwevingstheorie. Het inleidend hoofdstuk eindigt met een beschrijving van de verschillende hoofdstukken in dit proefschrift.

Hoofdstuk 2 bespreekt de bestaande literatuur met betrekking tot het VreesVermijdings-model en patiënten met het chronisch whiplash syndroom. Alhoewel de eerste resultaten voor pijn catastroferen en bewegingsvrees geen sluitend bewijs leveren, wordt beargumenteerd waarom het Vrees-Vermijdings-model een veelbelovend theoretisch raamwerk kan zijn om verder onderzoek naar chronisch whiplash syndroom te sturen. Het model kan eventueel aangepast worden met andere factoren zoals Posttraumatische Stress klachten om zo specifieke kenmerken van deze populatie te ontdekken.

Hoofdstuk 3 beschrijft de cross-sectionele analyses van de data van onze cohortstudie. We onderzochten of beperkte bewegingsmogelijkheden van de nek (ROM: Range of Motion) geassocieerd zijn met vrees voor bewegen. De resultaten laten zien dat personen met klachten na een auto-ongeval niet alleen verschillen voor Actieve ROM van de personen zonder klachten en de gezonde controle groep, maar dat zij ook verschillen met betrekking tot Passieve ROM. Dit suggereert dat somatische factoren van invloed kunnen zijn. De relaties met vrees voor bewegen en pijn catastroferen werden zowel voor Actieve als voor Passieve ROM gevonden. De hypothese dat de verschilscore (Actieve ROM - Passieve ROM) gerelateerd is aan vrees voor bewegen en pijn catastroferen kon niet worden bevestigd. De verschilscores tussen Actieve ROM en Passieve ROM waren niet significant gerelateerd aan vrees voor beweging of pijn catastroferen, behalve voor de voorwaartse flexie beweging.

Hoofdstuk 4 beschrijft de eerste resultaten van de dagboekstudie waarin 60 deelnemers getest werden binnen één maand na hun auto-ongeval. De veronderstelde relaties tussen de variabelen van het Vrees-Vermijdings-model werden getest door middel van een 'tussen subject' en 'binnen subject' design. Multilevel analyses lieten zien dat zowel tussen personen als binnen éénzelfde persoon hogere scores van pijn catastroferen en vrees voor bewegen gerelateerd waren aan meer pijn en meer beperkingen, wanneer alle variabelen gemeten werden op dezelfde dag. Daarenboven was vrees voor bewegen ook een significante voorspeller voor pijn en beperkingen de volgende dag. We onderzochten ook de omgekeerde relatie, namelijk of pijn ook veranderingen kon voorspellen de volgende dag in vrees voro bewe- 
gen en pijn catastroferen. Alhoewel we voor bewegingsvrees hierin een significante relatie vonden, was het percentage verklaarde variantie verwaarloosbaar.

Hoofdstuk 5 geeft de resultaten weer van de analyses van de follow-up data van de cohort studie en gaat in op de vraag of de variabelen in het Vrees-Vermijdingsmodel significante voorspellers zijn voor de overgang van acute whiplash kwetsuur naar het chronisch whiplash syndroom. Door middel van multipele regressie analyses werd de voorspellende waarde van verschillende concepten uit het VreesVermijdingsmodel (pijn catastroferen, vrees voor bewegen) onderzocht samen met een exploratieve analyse voor de variabele boosheid. Er werd ook onderzocht of deze variabelen niet alleen goede voorspellers waren voor aanhoudende pijn en beperkingen, maar ook voor het ontwikkelen van depressie en posttraumatische stress stoornis en kwaliteit van leven. De baseline scores van alle afhankelijke variabelen waren de sterkste voorspellers voor aanhoudende klachten. Pijn catastroferen was een significante voorspeller voor zowel beperkingen, depressie en kwaliteit van leven. Echter, wanneer boosheid werd toegevoegd als voorspeller, verdween het effect van pijn catastroferen als voorspeller van beperkingen en fysieke gezondheid. Vrees voor bewegen, was geen significante voorspeller, maar boosheid was een significante voorspeller voor alle uitkomstvariabelen. Als conclusie kunnen we stellen dat baseline scores van de afhankelijke variabelen de belangrijkste voorspellers zijn van aanhoudende klachten, maar dat daarbovenop ook pijn catastroferen en boosheid van invloed zijn. Zowel pijn catastroferen als boosheid geven ons dus nieuwe aangrijpingspunten voor het screenen van patiënten en het uitvoeren van behandelingen in het acute stadium.

Hoofdstuk 6 gaat in op het experiment in het gedragslaboratorium waar we onderzochten of hypervigilantie een belangrijke factor is in het instandhouden van het chronisch whiplash syndroom. Veertig patiënten met chronisch whiplash syndroom werd gevraagd om een aandachtsopeisende taak uit te voeren (het herkennen van tonen) terwijl ze afgeleid werden door een angstaanjagende nekbeweging. Alhoewel werd gevonden dat patiënten een grote vertraging in hun reactietijden lieten zien vergeleken met controles, konden we deze vertraging niet toewijzen aan een toename van pijn, pijn catastroferen of bewegingsvrees.

Hoofdstuk 7 focust op de relatie tussen pijn gerelateerde vrees, zelf-discrepanties en zelf-pijn-verweving. Er werd een tweede analyse gedaan op de data verkregen uit de dagboekstudie uit hoofdstuk 4 om te onderzoeken welke andere mechanismen konden plaatsvinden naast het mechanisme van het Vrees-Vermijdings-model bij mensen met een acute whiplash kwetsuur. Zelf-pijn-verweving en twee types van zelf-discrepanties (Acuteel-Ideaal en Actueel-Vrees) werden gemeten met vragenlijsten op dag 1 samen met andere vragenlijsten over pijn, beperkingen, depressie, vrees voor bewegen en pijn catastroferen. Proefpersonen hielden ook 21 dagen lang een dagboek bij waarin iedere dag de overeenstemming tussen het Ideale zelf en het 
Actuele zelf werd gemeten alsook pijn, beperkingen, stemming, vrees voor bewegen en pijn catastroferen. Bij de vragenlijsten vonden we significante associaties tussen de Acuele- Ideale (AI) discrepantie en depressie, tussen Actuele- Vrees (AV) discrepantie en pijn en beperkingen en tussen Zelf-Pijn-Verweving (ZPV) en pijn catastroferen. In het dagboek vonden we dezelfde significante relaties tussen het verbeteren in het overeenstemmen tussen het Actuele Zelf en het Ideale Zelf en toenames in positieve stemming en afname in negatieve stemming. Daarenboven vonden we ook een relatie met de afname van pijn, beperkingen en vrees voor bewegen. De multilevel analyse liet zien dat in de acute periode van de whiplash kwetsuur zelf-discrepanties reeds aanwezig zijn en dat zij gerelateerd zijn aan stemming, pijn, en beperkingen, vrees voor bewegen en pijn catastroferen. De resultaten laten zien dat patiënten een impact kunnen ervaren van pijn en beperkingen op hun identiteit en dat deze impact vergroot wordt door vrees voor bewegen en pijn catastroferen.

Hoofdstuk 8 rapporteert de resultaten van een behandel studie waarbij specifiek werd ingegrepen op vrees voor bewegen en pijn catastroferen in patiënten met hoge niveaus van vrees. Acht patiënten namen deel aan een behandeling bestaande uit zowel Graded Activity (GA, graduele opbouw van acitiviteiten) en Graded Exposure in vivo (GEXP, geleidelijke blootstelling aan gevreesde activiteiten). De resultaten laten zien dat de GEXP behandeling beter was dan de GA behandeling. GEXP leidde tot significante afname van zelf gerapporteerde pijngerelateerde vrees, pijn intensiteit en beperkingen en tot een toename van het activiteiten niveau. De resultaten leveren indirect bewijs voor de rol van pijngerelateerde vrees in het voorspellen van vermijdingsgedrag en beperkingen.

Hoofdstuk 9 is het laatste hoofdstuk van dit proefschrift en geeft eerst een overzicht van de belangrijkste resultaten van dit proefschrift en een algemene discussie van de bevindingen. We kunnen concluderen dat we gedeeltelijk bewijs vonden voor het Vrees-Vermijdings-model als een voorspellend model voor de overgang van acute whiplash kwetsuur naar chronisch whiplash syndroom. Onze resultaten benadrukken het belang voor het includeren van bijkomende factoren zoals boosheid, zelfdiscrepanties en zelf-pijn-verweving. Daarenboven blijkt het Vrees-Vermijdingsmodel niet alleen voorspellend te zijn voor pijn en beperkingen, maar ook voor depressie, post-traumatische stress en kwaliteit van leven. $\mathrm{Na}$ de resultaten en discussie worden de beperkingen van het proefschrift besproken en worden er aanbevelingen gemaakt voor toekomstig onderzoek. Tenslotte worden de klinische implicaties besproken en wordt en een slotconclusie gegeven. 
Dankwoord 
Dit is het allerlaatste hoofdstuk van dit proefschrift en het meest belangrijke. In dit stukje krijg ik namelijk de kans om iedereen te bedanken die in welke mate dan ook heeft bijgedragen tot dit proefschrift. De lijst is lang en ik ben er zeker van dat me tijdens het schrijven wat namen ontglippen, maar ik zal proberen volledig te zijn.

Allereerst wil ik mijn promotoren Madelon en Johan en co-promotor Mariëlle bedanken. Zonder jullie was dit proefschrift er waarschijnlijk nooit gekomen. Jullie enthousiasme, kennis, creativiteit en gedrevenheid is de stille motor geweest die dit project heeft voortgeduwd. Dank jullie wel voor al het vertrouwen dat jullie in mij hadden en de kansen die jullie mij geboden hebben. Madelon, aan jou een extra woordje van dank. Als dagelijks begeleider was je meer betrokken bij al mijn onderzoeksavonturen. Je hebt me de basis geleerd waarop ik nu verder kan werden, maar nog belangrijker heb je de passie voor het onderzoek altijd aangewakkerd en laten zien dat degelijkheid, integriteit, bescheidenheid en gedrevenheid iemand tot een goede onderzoeker kunnen laten uitgroeien.Verder nog een bedankje aan al die andere "begeleiders" die op welke manier dan ook mij ondersteund hebben, dr. Jaap Patijn, Prof. Stephen Morley, Prof. Geert Crombez, dr. Stefaan Van Damme en Prof. Steven Linton.

Naast mijn begeleiders zijn er op de werkvloer nog heel veel mensen die ik zou willen bedanken, teveel om op te noemen dus ik probeer ze wat te groeperen. De collega's van CPS voor alle koffie-breaks, lunches, snoepjes, grapjes filmavonden, etentjes en tafeltennis, de buurvrouwen van mijn kantoor, de studenten die data hebben verzameld (met name Ingrid, Marja en Elke), het ondersteunend personeel dat betrokken was bij de onderzoeken, de collega's binnen het SOMATO-overleg en de collega's binnen het PijnKennisCentrum. Ik ga slechts twee collega's speciaal vernoemen. Ivan, ik ben heel blij dat jij mijn paranimf wilt zijn. Je bent begonnen als mijn onderzoeksassistent, maar je werd al snel een volwaardig collega en vriend. Ik ben heel blij dat ik al die tijd met je heb samen kunnen werken en dat je tijdens de ceremonie naast me wilt staan. Lieve Esther, als kamergenootje heb je het niet altijd even makkelijk met me gehad tijdens de laatste eindspurt. Toch wist je me altijd op te vrolijken, kon je alles relativeren en had je voor ieder endnote-probleem een oplossing. Ik hoop dat we samen nog een tijdje die kamer mogen delen en nog veel ijsjes en koffie kunnen halen en veel chocotofs eten !

Mijn dank gaat ook uit naar alle patiënten en vrijwilliger die hebben deelgenomen aan de onderzoeken die in dit proefschrift zijn beschreven. Ook wil ik de volgende ziekenhuizen, huisartsenposten, verkeersongevallendiensten en patiëntenverenigingen bedanken die meegewerkt hebben aan de werving van de patiënten: Academisch Ziekenhuis Maastricht, Atrium Ziekenhuis Heerlen, Maaslandzieken- 
huis Sittard, Ziekenhuis Oost-Limburg Genk, Salvator Ziekenhuis Hasselt, Huisartsenpost Heerlen, Huisartsenpost Maastricht, Verkeerongevallendienst ZuidLimburg, Whiplashstichting Nederland, en Whiplashvereniging België.

Ook heel veel dank aan alle vrienden die de schaarse vrije tijd tot echte ontspanning hebben gemaakt, Elke, Ilse en Kris, bedankt voor die jarenlange vriendschap en alle etentjes. Elke, bedankt voor al die anti-RSI massages ! Mijn "groepje" van Maastricht, Jolanda, Natascha, Angelique, Wendy, Suzanne en natuurlijk Claire, mijn allerliefst paranimf. Dank voor alle weekendjes, sauna's, blitz-spelletjes en jullie niet aflatende interese voor alles wat er tijdens het schrijven van dit proefschrift gebeurde. Nog een dankjewel aan alle andere vrienden, de Ferme Wijven (Leentje, Wendy en Mich), de vrijwilligers en stafleden van het Rode Kruis Limburg, Dringende Sociale Interventie, de meisjes en Samina van de flamencoles, het bestuur en de leden van de vereniging "Alles op Wieltjes". Dank je wel ook aan alle tantes, ooms, neven, nichten en aangetrouwden van de families Vangronsveld-Nassen. Eindelijk komt er dat lang beloofde feest !

En ik eindig met wat voor mij het belangrijkste is. Lieve mama, papa en Hilde. Dit boekje is eigenlijk voor jullie. Mama en papa, ik ben wie ik ben door al de dingen die jullie me geleerd hebben. Jullie zijn nu trots op wat ik nu bereikt heb, maar ik ben trots op mijn mama en papa. Jullie zijn mijn steun en toeverlaat, de warmte die ik zo vaak nodig heb, de motivatie om altijd mijn best te doen, maar vooral gewoon de liefste mama en papa van de wereld. Hildeke, er is niemand meer trots op mij dan jij. Je bent mijn grootste supporter en de allerliefste zus.

Dank je wel aan jullie allemaal,

Karoline 

About the author 
ABOUT THE AUTHOR 
Karoline Vangronsveld was born in Bilzen (Belgium) on octobre the 22nd, 1976. She obtained her diploma of secondary education (Latin - Mathematics - Sciences) in 1994 at the Provinciaal Hoger Handelsinstituut in Hasselt. She graduated in 1999 as a Social and Pedagogical Worker at the Hogeschool Maastricht. She continued her studies at the University of Maastricht, Faculty of Health Sciences while working as a social worker in the field of special youth care and youth justice. She obtained her diploma of Master of Sciences, specialized in Mental Health Sciences in 2002. From 2003 until 2007 she was a Phd-student at Maastricht University, Department of Medical, Clinical and Experimental Psychology and carried out the studies included in this dissertation. She is now currently working as a Post-Doc researcher and university teacher at Maastricht University, Department of Clinical Psychological Science. 



\section{Publications}


PUBLICATIONS 
Vangronsveld K., Van Damme S., Peters S., Vlaeyen J., Goossens M., Crombez G. (2007) An experimental investigation on attentional interference by threatening fixations of the neck in patients with chronic whiplash syndrome. Pain, 127, 121128

Vangronsveld K, van den Hout A., Vlaeyen J. (2007) The influence of distraction on pain and anxiety during venipuncture in children between 8 and 11 years old. The Netherlands Journal of Psychology, 63 (1), 21-28.

Vangronsveld K. (2004). Whiplash: anatomisch/fysiologisch of meer psychologisch gebeuren? Stimulus, 4, p. 433-444.

Vangronsveld K., Peters M., Goossens M., Linton S., Vlaeyen J. Applying the FearAvoidance model to chronic whiplash syndrome. Pain, In Press.

Vangronsveld K., Peters M., Goosses M., Vlaeyen J. The influence of fear of movement and pain catastrophizing on daily pain and disability in individuals with acute whiplash complaints: a daily diary study. Submitted.

De Jong J., Vangronsveld K., Peters M., Goossens M., Vlaeyen J. Reduction of pain-related fear and disablity in posttraumatic neck pain: a replicated single case experimental study of exposure in vivo. Submitted. 
